Cícero Ribeiro de Lima

\title{
Estudo da Obtenção de Imagens de Tomografia de Impedância Elétrica do Pulmão pelo Método de Otimização Topológica
}

Tese apresentada à Escola Politécnica da Universidade de São Paulo para obtenção do Título de Doutor em Engenharia Mecânica. 
Cícero Ribeiro de Lima

\section{Estudo da Obtenção de Imagens de Tomografia de Impedância Elétrica do Pulmão pelo Método de Otimização Topológica}

Tese apresentada à Escola Politécnica da Universidade de São Paulo para obtenção do Título de Doutor em Engenharia Mecânica.

Área de concentração:

Engenharia Mecânica/Mecatrônica

Orientador:

Prof Dr Emílio Carlos Nelli Silva 


\section{Ficha Catalográfica}

Lima, Cícero Ribeiro de

Estudo da Obtenção de Imagens de Tomografia de Impedância Elétrica do Pulmão pelo Método de Otimização Topológica/C. R. de Lima - ed. rev. - São Paulo, 2006. 188 p.

Tese (Doutorado) - Escola Politécnica da Universidade de São Paulo. Departamento de Engenharia Mecatrônica e de Sistemas Mecânicos.

1.Tomografia 2.Topologia (Otimização) 3.Método dos Elementos Finitos I. Universidade de São Paulo. Escola Politécnica. Departamento de Engenharia Mecatrônica e de Sistemas Mecânicos. II. t. 
À minha família. 


\section{Agradecimentos}

Primeiramente agradeço a Deus.

Em seguida, agradeço ao meu orientador, Prof. Dr. Emílio Carlos Nelli Silva, pelo apoio, paciência, orientação segura e principalmente pelo incentivo ao desenvolvimento da minha carreira acadêmica. Expresso com satisfação o meu reconhecimento e respeito pelo seu exemplo de dedicação acadêmica.

À FAPESP (Fundação de Amparo à Pesquisa do Estado de São Paulo) pelo apoio financeiro deste trabalho, através de bolsa de doutorado (processo $\left.n^{\circ} 2002 / 01625-0\right)$.

Ao Prof. Dr. Raul Gonzalez Lima e seu grupo de pesquisa, pela atenção preciosa e esclarecimentos às dúvidas referentes a alguns tópicos específicos de seus trabalhos de pesquisa.

Aos meus amigos e familiares, pelo apoio e carinho.

E por fim, a todos que direta ou indiretamente contribuíram para a realização deste trabalho. 


\section{Resumo}

A Tomografia por Impedância Elétrica (TIE) é uma técnica recente de obtenção de imagens médicas para monitoração de tecidos biológicos. A TIE nos permite obter imagens que representam um plano transverso de qualquer seção do corpo humano (cabeça, tórax, coxa, etc.), onde cada "pixel" na imagem representa a sua impedância ou resistividade elétrica. As imagens são geradas através de valores de voltagens medidos em eletrodos posicionados em torno da seção do corpo humano. Estas voltagens são obtidas aplicando-se uma seqüência de corrente elétrica de baixa amplitude nos eletrodos, de acordo com um padrão da excitação elétrica (adjacente ou diametral). A TIE é baseada na solução de um problema inverso, onde dadas as voltagens medidas no exterior do corpo, essa técnica tenta encontrar a distribuição de condutividades no interior do corpo. O objetivo principal deste trabalho é aplicar o Método de Otimização Topológica (MOT) para obtenção de imagens da seção de um corpo na TIE. A Otimização Topológica (OT) busca a distribuição de material no interior de um domínio de projeto, retirando e adicionado material em cada ponto desse domínio de maneira a minimizar (ou maximizar) uma função objetivo especificada, satisfazendo dadas restrições impostas ao problema de otimização. Neste trabalho, o MOT é um método iterativo, cujo algoritmo computacional (implementado em linguagem C) combina o Método dos Elementos Finitos (MEF) e um algoritmo de otimização conhecido por Programação Linear Sequencial (PLS). O problema de obtenção da imagem usando MOT consiste em se obter a distribuição de material (ou de condutividade) na seção do corpo que minimize a diferença entre os potenciais elétricos medidos nos eletrodos e os potenciais calculados num modelo computacional. A principal vantagem do MOT, aplicado à obtenção de imagens na TIE, é permitir a inclusão de várias restrições no problema de otimização, reduzindo o espaço de solução e evitando imagens sem significado clínico. Neste trabalho, o MOT utiliza o modelo de material SIMP para relaxar o problema de OT e vários esquemas são implementados com o intuito de regularizar o problema inverso da TIE (resolvido pelo MOT), tais como parâmetro de sintonia da imagem ("tuning"), restrição baseada na condutividade média do domínio da imagem, filtro espacial de controle de gradientes, aumento gradual do fator de penalidade do modelo de material durante o processo de otimização (método de continuação) e aproximação contínua da distribuição de material ("CAMD"). Este trabalho está inserido num projeto temático cujo objetivo é estudar técnicas de reconstrução de imagem aplicadas a um tomógrafo por impedância elétrica para monitorar de forma precisa a ventilação forçada do pulmão e diagnosticar quando alguma parte do pulmão estiver danificada (obstruída ou colapsada) durante o processo de ventilação forçada. Para ilustração, são apresentadas imagens obtidas utilizando-se dados numéricos e experimentais de voltagem de domínios 2D bem conhecidos. 


\section{Abstract}

The Electrical Impedance Tomography (EIT) is a recent monitoring technique on biological tissues. The EIT allows us to obtain images representing a transversal plane of any section of human body (head, thorax, thigh, etc). Each image pixel is related to its corresponding value of electrical impedance (or resistivity). The images are generated based on voltage values measured on electrodes positioned around the section of human body. These voltages are obtained by applying to the electrodes an alternated sequence of low intensity electrical currents in according to an excitation pattern (adjacent or diametral). The EIT is based on an inverse problem, where given the voltages measured outside of body, this technique tries to find the conductivity distribution inside of the body. In this work, the main objective is to apply Topology Optimization Method (TOM) to obtain images of body section in EIT. Topology Optimization seeks a material distribution inside of a design domain, determining which points of space should be material "A" and which points should be material "B", to minimize (or maximize) an objective function requirement, satisfying specified constraints. In this work, the MOT is an iterative method whose computational algorithm (implemented in C language) combines Finite Element Method (FEM) and an optimization algorithm called Sequential Linear Programming (SLP). The topology optimization problem applied to obtain images consists of finding the material (or conductivity) distribution in the body section that minimizes the difference between electric potential measured on electrodes and electric potential calculated by using a computational model. The main advantage of TOM applied to image reconstruction in EIT is to allow us to include several constraints in optimization problem, which reduces the solution space and avoids images without clinical meaning. In this work, the MOT uses a material model based on SIMP to make relaxation of topology optimization problem and several regularization schemes are implemented to solve inverse problem of EIT, such as image tuning control, weighted distance interpolation based on average conductivity of domain, spatial filtering technique for gradient control, graduated changing in penalty factor of material model during the optimization process (continuation method), and continuous approximation of material distribution (CAMD). This work is part of a thematic project whose aim is to study reconstruction image algorithms that could be used in an EIT device to monitor accurately mechanical ventilation of lung and to diagnose when any portion of lung is damaged (obstructed or collapsed) during mechanical ventilation process. To illustrate the implementation of the method, image reconstruction results obtained by using voltage numerical and experimental data of well-know 2D domains are shown. 


\title{
Sumário
}

\section{Lista de Figuras}

\author{
Lista de Tabelas
}

\section{Lista de Abreviaturas e Siglas}

\section{Lista de Símbolos}

1 Introdução 1

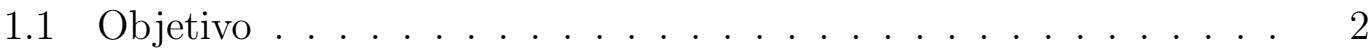

1.2 Justificativa . . . . . . . . . . . . . . . . . . 3

1.3 Contribuição . . . . . . . . . . . . . . . . . . . . . . 4

2 Tomografia por Impedância Elétrica 5

2.1 Introdução . . . . . . . . . . . . . . . . . . . 5

2.2 Reconstrução de Imagens para Tomografia . . . . . . . . . . . . . 7

2.3 Algoritmos de Reconstrução na TIE . . . . . . . . . . . . . . . . . 9

2.4 Conceito Básico e Aplicações da TIE . . . . . . . . . . . . . . . . 11

2.5 Aplicações Médicas da TIE . . . . . . . . . . . . . . . . . . . . . 13

2.5.1 Histórico . . . . . . . . . . . . . . . . . . . . 13

2.5.2 Aplicações Clínicas . . . . . . . . . . . . . . . . . . 15

2.6 Aplicações da TIE para o Monitoramento dos Pulmões . . . . . . 15

2.7 Considerações Finais . . . . . . . . . . . . . . . . . . . . . . . . . 17

2.7.1 Imagem Absoluta e Imagem Relativa . . . . . . . . . . . . 17

2.7.2 Demais Considerações . . . . . . . . . . . . . . . . 18 
3.1 Introdução . . . . . . . . . . . . . . . . . . . . . . . 20

3.2 Breve Histórico do MOT . . . . . . . . . . . . . . . . . . . 21

3.3 Aplicações do MOT para Meios Condutivos . . . . . . . . . . . 23

3.4 Conceitos Fundamentais do MOT . . . . . . . . . . . . . . 24

3.4.1 Domínio Fixo de Projeto . . . . . . . . . . . 25

3.4.2 Modelo de Material . . . . . . . . . . . . . . 25

4 Modelo de MEF da Seção Submetida a Tomografia 29

4.1 Introdução . . . . . . . . . . . . . . . . . . . . . 29

4.2 Equações Constitutivas do Meio Condutivo . . . . . . . . . . . . . 29

4.3 Modelagem do Meio Condutivo . . . . . . . . . . . . . . . . 30

4.4 Matriz de Condutividade do Elemento . . . . . . . . . . . . 32

4.4.1 Matriz de Condutividade do Elemento Quadrilátero . . . . 33

4.4.2 Matriz de Condutividade do Elemento Triangular . . . . . 36

4.5 Determinação dos Potenciais Elétricos Nodais . . . . . . . . . . . 37

4.6 Modelo de Eletrodos . . . . . . . . . . . . . . . . . . . . . . 38

5 Formulação do Problema de OT aplicado a TIE 40

5.1 Estrutura Básica do Problema . . . . . . . . . . . . . . . 40

5.2 Parâmetro de Sintonia da Imagem ("tuning") . . . . . . . . . . . 41

5.3 Restrição de Condutividade Média . . . . . . . . . . . . . . . . 42

5.4 Análise de Sensibilidade . . . . . . . . . . . . . . . . . . 44

6 Solução e Implementação Numérica do Problema 50

6.1 Solução do Problema de Otimização Topológica Aplicado a TIE . 50

6.1.1 Programação Linear Seqüencial (PLS) . . . . . . . . . . 50

6.1 .2 Limites Móveis . . . . . . . . . . . . . . . . 51

6.2 Implementação Numérica da Solução do Problema . . . . . . . . . 53 
6.3 Estratégias para Otimização das Variáveis do Problema . . . . . . 54

6.3.1 Abordagem 1: otimização das variáveis separadamente . . 56

6.3.2 Abordagem 2: otimização das variáveis com alternância . . 57

6.4 Filtro Espacial . . . . . . . . . . . . . . . . . . . . . 59

6.5 Método da Continuação . . . . . . . . . . . . . . . . . . . 61

6.6 Aproximação Contínua de Distribuição de Material ("CAMD") . . 62

7 Resultados

7.1 Introdução . . . . . . . . . . . . . . . . . . . . . . 64

7.2 Padrões de Excitação Elétrica . . . . . . . . . . . . . . . . 65

7.3 Resultados Obtidos com Dados Numéricos . . . . . . . . . . . . 66

7.3.1 Reprodução da Imagem num Domínio Elíptico . . . . . . . 66

7.3.2 Resultados Obtidos com Parâmetro de Sintonia ("tuning") 74

7.3.3 Inclusão de Ruído nos Valores de Voltagens . . . . . . . . 79

7.3.4 Obtenção de Imagem no Domínio com Elementos Quadriláteros e Triangulares . . . . . . . . . . . . 81

7.3.5 Imagem de um Objeto em Diferentes Posições no Domínio 88

7.3.6 Resultados Obtidos com a Aplicação da Restrição de Condutividade Média . . . . . . . . . . . . . . . . . . . . . 90

7.3.7 Resultados Obtidos Utilizando o Filtro Espacial . . . . . . 114

7.3.8 Utilizando o Método da Continuação . . . . . . . . . . . . 135

7.3.9 Aplicação da Aproximação Contínua de Distribuição de Material ("CAMD") . . . . . . . . . . . . . . . 139

7.4 Resultados Obtidos a Partir de Dados Experimentais . . . . . . . 142

7.4.1 Utilizando o Fantoma com 32 Eletrodos . . . . . . . . . . 143

7.4.2 Utilizando o Fantoma com 30 Eletrodos . . . . . . . . . . 149

8 Conclusões

8.1 Trabalhos Futuros . . . . . . . . . . . . . . . . . 160

8.2 Considerações Finais . . . . . . . . . . . . . . . . . . . . . . 162 
Anexo A - Reformulação dos gradientes da função objetivo para dados com $\Delta \phi$

Anexo B - Estrutura do software de MOT aplicado à TIE

Referências

Apêndice A - Princípio dos Potenciais Virtuais 


\section{Lista de Figuras}

1.1 Ilustração dos eletrodos em torno do tórax na TIE. . . . . . . . . 1

2.1 Tomografia Computadorizada do toráx humano. . . . . . . . . . . 6

2.2 Geometria básica para a tomografia bidimensional. . . . . . . . . 8

3.1 Exemplo de aplicação da otimização topológica. . . . . . . . . . . 20

3.2 Comportamento da curva do modelo de material conforme o valor do expoente $p$ é aumentado. . . . . . . . . . . . . . . . 28

4.1 Domínio de projeto dividido em elementos finitos. . . . . . . . . . 31

4.2 Exemplo de domínio de projeto para obtenção da imagem. . . . . 32

4.3 Elementos finitos dos modelos de MEF do domínio de obtenção de imagem. . . . . . . . . . . . . . . . . . 33

4.4 Elemento do modelo de eletrodo. . . . . . . . . . . . . . . . 38

5.1 Seção do corpo submetido a dois casos diferentes de excitação. . . 45

5.2 Aplicação da primeira medição de potenciais (i=1) . . . . . . . . 47

5.3 Aplicação da segunda medição de potenciais (i=2) . . . . . . . . . 48

5.4 Considerando todos os $n p$ casos de medição. . . . . . . . . . . . . 49

6.1 Limites móveis. . . . . . . . . . . . . . . . . . . . . . . 52

6.2 Fluxograma do algoritmo de MOT. . . . . . . . . . . . . . . 54

6.3 Procedimento para desenvolver as otimizações das variáveis $\rho t_{j}$ e $\rho_{k}($ Abordagem 1). . . . . . . . . . . . . . 56

6.4 Procedimento para alternar as otimizações das variáveis $\rho t_{j}$ e $\rho_{k}$ (Abordagem 2). . . . . . . . . . . . . . . . 57

6.5 Raio de abrangência do filtro espacial. . . . . . . . . . . . . . 60

7.1 Padrões de excitação elétrica. . . . . . . . . . . . . . . . 66

7.2 Malha com 1120 elementos, utilizada para obtenção da imagem. . 67 
7.3 Fantomas numéricos com 3072 elementos quadriláteros e imagens a serem reconstruídas no domínio elíptico da figura 7.2. . . . . 68

7.4 Resultado obtido no domínio elíptico (uma região), aplicando-se o padrão adjacente. . . . . . . . . . . . . . . . 70

7.5 Resultado obtido no domínio elíptico (duas regiões), aplicando-se o padrão adjacente. . . . . . . . . . . . . . . . . 71

7.6 Resultado obtido no domínio elíptico (uma região), aplicando-se o padrão diametral. . . . . . . . . . . . . . . . . . . . 71

7.7 Resultado obtido no domínio elíptico (duas regiões), aplicando-se o padrão diametral. . . . . . . . . . . . . . . . . . . 71

7.8 Valores absolutos de condutividade elétrica das regiões escuras das figuras 7.4 e $7.6 \ldots \ldots \ldots \ldots$. . . . . . . . . . . . . . 73

7.9 Valores absolutos de resistividade elétrica das regiões escuras das figuras 7.4 e $7.6 \ldots \ldots \ldots \ldots$. . . . . . . . . . . . . . 73

7.10 Valores absolutos de condutividade elétrica das regiões escuras das figuras 7.5 e $7.7 \ldots \ldots \ldots . \ldots \ldots . \ldots . \ldots . \ldots 73$

7.11 Valores absolutos de resistividade elétrica das regiões escuras das figuras 7.5 e $7.7 \ldots \ldots \ldots \ldots$. . . . . . . . . . . . . . 74

7.12 Imagem obtida (uma região), usando o padrão adjacente e $V^{*}=5 \% .75$

7.13 Imagem obtida (uma região), usando o padrão diametral e $V^{*}=5 \% .75$

7.14 Imagem obtida (duas regiões), usando o padrão adjacente e $V^{*}=18 \% .75$

7.15 Imagem obtida (duas regiões), usando o padrão diametral e $V^{*}=18 \% .76$

7.16 Valores absolutos de condutividade elétrica das regiões escuras das figuras 7.12 e $7.13 . \ldots \ldots$. . . . . . . . . . . . . . 77

7.17 Valores absolutos de resistividade elétrica das regiões escuras das figuras 7.12 e $7.13 . \ldots \ldots$. . . . . . . . . . . . . . 77

7.18 Valores absolutos de condutividade elétrica das regiões escuras das figuras 7.14 e $7.15 . \ldots \ldots \ldots$. . . . . . . . . . . 77

7.19 Valores absolutos de resistividade elétrica das regiões escuras das figuras 7.14 e $7.15 . \ldots \ldots \ldots 7 . \ldots \ldots$

7.20 Introdução do ruído artificial no padrão adjacente. . . . . . . . . . 79 
7.21 Introdução do ruído artificial no padrão diametral. . . . . . . . . .

7.22 Valores absolutos de condutividade elétrica das regiões escuras das figuras 7.20 e $7.21 \ldots \ldots \ldots$. . . . . . . . . . . . 80

7.23 Valores absolutos de resistividade elétrica das regiões escuras das figuras 7.20 e $7.21 . \ldots \ldots \ldots$. . . . . . . . . . . . . 80

7.24 a) imagem a ser obtida; b) fantoma numérico utilizado. . . . . . . 82

7.25 Domínio de obtenção da imagem com 576 elementos quadriláteros e 32 elementos de eletrodos. . . . . . . . . . . . . . . . 82

7.26 Domínio de obtenção da imagem com 1248 elementos triangulares e 32 elementos de eletrodos. . . . . . . . . . . . . . . 83

7.27 Resultado obtido no domínio discretizado em elementos triangulares, aplicando-se padrão adjacente. . . . . . . . . . 84

7.28 Resultado obtido no domínio discretizado em elementos triangulares, aplicando-se padrão diametral. . . . . . . . . . . 84

7.29 Valores absolutos de condutividade elétrica das imagens mostradas nas figuras 7.27 e $7.28 \ldots \ldots \ldots$. . . . . . . . . . . . 85

7.30 Valores absolutos de resistividade elétrica das imagens mostradas nas figuras 7.27 e $7.28 \ldots \ldots \ldots$. . . . . . . . . . . . 85

7.31 Resultado obtido no domínio discretizado em elementos quadriláteros, aplicando-se padrão adjacente. . . . . . . . . 87

7.32 Resultado obtido no domínio discretizado em elementos quadriláteros, aplicando-se padrão diametral. . . . . . . . . . 87

7.33 Imagens a serem obtidas no domínio circular $\left(V^{*}=3,8 \%\right) \ldots$. . . . 89

7.34 Fantomas numéricos do domínio circular: a) objeto na borda; b) objeto entre a borda e o centro; c) objeto no centro. . . . . . . . . 90

7.35 Imagens obtidas com $p=2, \rho_{k}^{0}=0,15$ e elementos quadriláteros. . . 91

7.36 Imagens obtidas com $p=2, \rho_{k}^{0}=0,50$ e elementos quadriláteros. . . 91

7.37 Imagens obtidas com $p=2, \rho_{k}^{0}=0,85$ e elementos quadriláteros. . . 91

7.38 Gráficos de convergência e resistividades da imagem obtida com $p=2$ e $\rho_{k}^{0}=0,15$, mostrada na figura $7.35($ a) . . . . . . . . . 94 
7.39 Gráficos de convergência e resistividades da imagem obtida com $p=2$ e $\rho_{k}^{0}=0,15$, mostrada na figura $7.35(\mathrm{~b}) \ldots \ldots \ldots$. . . . . 94

7.40 Gráficos de convergência e resistividades da imagem obtida com $p=2, \rho_{k}^{0}=0,15$, mostrada na figura $7.35($ c). . . . . . . . . . 94

7.41 Gráficos de convergência e resistividades da imagem obtida com $p=2$ e $\rho_{k}^{0}=0,50$, mostrada na figura $7.36($ a) . . . . . . . . . . 95

7.42 Gráficos de convergência e resistividades da imagem obtida com $p=2$ e $\rho_{k}^{0}=0,50$, mostrada na figura $7.36(\mathrm{~b}) \ldots \ldots \ldots$. . . . . 95

7.43 Gráficos de convergência e resistividades da imagem obtida com $p=2$ e $\rho_{k}^{0}=0,50$, mostrada na figura $7.36($ c) . . . . . . . . . . 95

7.44 Gráficos de convergência e resistividades da imagem obtida com $p=2$ e $\rho_{k}^{0}=0,85$, mostrada na figura $7.37($ a) . . . . . . . . . . 96

7.45 Gráficos de convergência e resistividades da imagem obtida com $p=2$ e $\rho_{k}^{0}=0,85$, mostrada na figura $7.37(\mathrm{~b}) \ldots \ldots \ldots$. . . . . 96

7.46 Gráficos de convergência e resistividades da imagem obtida com $p=2$ e $\rho_{k}^{0}=0,85$, mostrada na figura $7.37($ c) . . . . . . . . . . 96

7.47 Imagens obtidas com $p=4, \rho_{k}^{0}=0,15$ e elementos quadriláteros. . . 98

7.48 Imagens obtidas com $p=4, \rho_{k}^{0}=0,50$ e elementos quadriláteros. . . 98

7.49 Imagens obtidas com $p=4, \rho_{k}^{0}=0,85$ e elementos quadriláteros. . . 98

7.50 Gráficos de convergência e resistividades da imagem obtida com $p=4$ e $\rho_{k}^{0}=0,15$, mostrada na figura $7.47($ a) . . . . . . . . . . . . 99

7.51 Gráficos de convergência e resistividades da imagem obtida com $p=4$ e $\rho_{k}^{0}=0,15$, mostrada na figura $7.47(\mathrm{~b}) \ldots \ldots$. . . . . . . . 99

7.52 Gráficos de convergência e resistividades da imagem obtida com $p=4$ e $\rho_{k}^{0}=0,15$, mostrada na figura $7.47($ c) . . . . . . . . . . . . 99

7.53 Gráficos de convergência e resistividades da imagem obtida com $p=4$ e $\rho_{k}^{0}=0,50$, mostrada na figura $7.48($ a) . . . . . . . . . . . 100

7.54 Gráficos de convergência e resistividades da imagem obtida com $p=4$ e $\rho_{k}^{0}=0,50$, mostrada na figura $7.48(\mathrm{~b}) \ldots \ldots \ldots$. . . . . . 100

7.55 Gráficos de convergência e resistividades da imagem obtida com $p=4$ e $\rho_{k}^{0}=0,50$, mostrada na figura $7.48($ c) . . . . . . . . . . . 100 
7.56 Gráficos de convergência e resistividades da imagem obtida com $p=4$ e $\rho_{k}^{0}=0,85$, mostrada na figura 7.49 (a) . . . . . . . . . . 101

7.57 Gráficos de convergência e resistividades da imagem obtida com $p=4$ e $\rho_{k}^{0}=0,85$, mostrada na figura $7.49(\mathrm{~b}) \ldots \ldots \ldots$. . . . . . 101

7.58 Gráficos de convergência e resistividades da imagem obtida com $p=4$ e $\rho_{k}^{0}=0,85$, mostrada na figura $7.49(\mathrm{c}) \ldots \ldots$. . . . . . . 101

7.59 Imagens obtidas com $p=2, \rho_{k}^{0}=0,15$ e elementos triangulares. . . . 104

7.60 Imagens obtidas com $p=2, \rho_{k}^{0}=0,50$ e elementos triangulares. . . . 104

7.61 Imagens obtidas com $p=2, \rho_{k}^{0}=0,85$ e elementos triangulares. . . . 104

7.62 Gráficos de convergência e resistividades da imagem obtida com $p=2$ e $\rho_{k}^{0}=0,15$, mostrada na figura $7.59(\mathrm{a}) \ldots \ldots$. . . . . . . 104

7.63 Gráficos de convergência e resistividades da imagem obtida com $p=2$ e $\rho_{k}^{0}=0,15$, mostrada na figura $7.59(\mathrm{~b}) \ldots \ldots \ldots$. . . . . 105

7.64 Gráficos de convergência e resistividades da imagem obtida com $p=2$ e $\rho_{k}^{0}=0,15$, mostrada na figura $7.59($ c) . . . . . . . . . 105

7.65 Gráficos de convergência e resistividades da imagem obtida com $p=2$ e $\rho_{k}^{0}=0,50$, mostrada na figura $7.60($ a) . . . . . . . . . 105

7.66 Gráficos de convergência e resistividades da imagem obtida com $p=2$ e $\rho_{k}^{0}=0,50$, mostrada na figura $7.60(\mathrm{~b}) \ldots \ldots \ldots$. . . . 106

7.67 Gráficos de convergência e resistividades da imagem obtida com $p=2$ e $\rho_{k}^{0}=0,50$, mostrada na figura $7.60(\mathrm{c}) \ldots \ldots \ldots$. . . . . 106

7.68 Gráficos de convergência e resistividades da imagem obtida com $p=2$ e $\rho_{k}^{0}=0,85$, mostrada na figura $7.61(\mathrm{a}) \ldots \ldots \ldots$. . . . . 106

7.69 Gráficos de convergência e resistividades da imagem obtida com $p=2$ e $\rho_{k}^{0}=0,85$, mostrada na figura $7.61(\mathrm{~b}) \ldots \ldots \ldots$. . . . . 107

7.70 Gráficos de convergência e resistividades da imagem obtida com $p=2$ e $\rho_{k}^{0}=0,85$, mostrada na figura $7.61(\mathrm{c}) \ldots \ldots \ldots$. . . . . 107

7.71 Imagens obtidas com $p=4, \rho_{k}^{0}=0,15$ e elementos triangulares. . . . 109

7.72 Imagens obtidas com $p=4, \rho_{k}^{0}=0,50$ e elementos triangulares. . . . 109

7.73 Imagens obtidas com $p=4, \rho_{k}^{0}=0,85$ e elementos triangulares. . . . 110 
7.74 Gráficos de convergência e resistividades da imagem obtida com $p=4$ e $\rho_{k}^{0}=0,15$, mostrada na figura $7.71(\mathrm{a}) \ldots \ldots \ldots$

7.75 Gráficos de convergência e resistividades da imagem obtida com $p=4$ e $\rho_{k}^{0}=0,15$, mostrada na figura $7.71(\mathrm{~b}) \ldots \ldots$. . . . . . . 110

7.76 Gráficos de convergência e resistividades da imagem obtida com $p=4$ e $\rho_{k}^{0}=0,15$, mostrada na figura $7.71(\mathrm{c}) \ldots \ldots \ldots$. . . . . . 111

7.77 Gráficos de convergência e resistividades da imagem obtida com

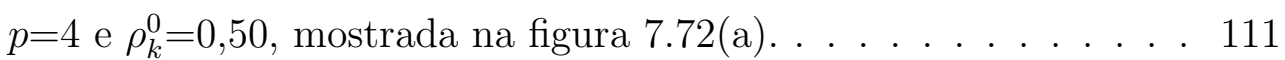

7.78 Gráficos de convergência e resistividades da imagem obtida com $p=4$ e $\rho_{k}^{0}=0,50$, mostrada na figura $7.72(\mathrm{~b}) \ldots \ldots \ldots$. . . . . . 111

7.79 Gráficos de convergência e resistividades da imagem obtida com $p=4$ e $\rho_{k}^{0}=0,50$, mostrada na figura $7.72(\mathrm{c}) \ldots \ldots$. . . . . . . . 112

7.80 Gráficos de convergência e resistividades da imagem obtida com $p=4$ e $\rho_{k}^{0}=0,85$, mostrada na figura $7.73($ a) . . . . . . . . . . . 112

7.81 Gráficos de convergência e resistividades da imagem obtida com $p=4$ e $\rho_{k}^{0}=0,85$, mostrada na figura $7.73(\mathrm{~b}) \ldots \ldots$. . . . . . . . 112

7.82 Gráficos de convergência e resistividades da imagem obtida com $p=4$ e $\rho_{k}^{0}=0,85$, mostrada na figura $7.73(\mathrm{c}) \ldots \ldots \ldots$. . . . . . 113

7.83 Imagens obtidas com $p=2, \rho_{k}^{0}=0,15$ e elementos quadriláteros. . . 116

7.84 Imagens obtidas com $p=2, \rho_{k}^{0}=0,50$ e elementos quadriláteros. . . 116

7.85 Imagens obtidas com $p=2, \rho_{k}^{0}=0,85$ e elementos quadriláteros. . . 116

7.86 Gráficos de convergência e resistividades da imagem obtida com $p=2$ e $\rho_{k}^{0}=0,15$, mostrada na figura $7.83(\mathrm{a}) \ldots \ldots \ldots$. . . . . 117

7.87 Gráficos de convergência e resistividades da imagem obtida com $p=2$ e $\rho_{k}^{0}=0,15$, mostrada na figura $7.83(\mathrm{~b}) \ldots \ldots$. . . . . . . 117

7.88 Gráficos de convergência e resistividades da imagem obtida com $p=2$ e $\rho_{k}^{0}=0,15$, mostrada na figura $7.83(\mathrm{c}) \ldots \ldots$. . . . . . . 117

7.89 Gráficos de convergência e resistividades da imagem obtida com $p=2$ e $\rho_{k}^{0}=0,50$, mostrada na figura $7.84(\mathrm{a}) \ldots \ldots \ldots \ldots$

7.90 Gráficos de convergência e resistividades da imagem obtida com $p=2$ e $\rho_{k}^{0}=0,50$, mostrada na figura $7.84(\mathrm{~b}) \ldots \ldots \ldots \ldots$ 
7.91 Gráficos de convergência e resistividades da imagem obtida com $p=2$ e $\rho_{k}^{0}=0,50$, mostrada na figura $7.84(\mathrm{c}) \ldots \ldots \ldots$. . . . . 118

7.92 Gráficos de convergência e resistividades da imagem obtida com $p=2$ e $\rho_{k}^{0}=0,85$, mostrada na figura $7.85($ a) . . . . . . . . . . 119

7.93 Gráficos de convergência e resistividades da imagem obtida com $p=2$ e $\rho_{k}^{0}=0,85$, mostrada na figura $7.85(\mathrm{~b}) \ldots \ldots \ldots$. . . . . . 119

7.94 Gráficos de convergência e resistividades da imagem obtida com $p=2$ e $\rho_{k}^{0}=0,85$, mostrada na figura $7.85($ c) . . . . . . . . . . . 119

7.95 Imagens obtidas com $p=4, \rho_{k}^{0}=0,15$ e elementos quadriláteros. . . 120

7.96 Imagens obtidas com $p=4, \rho_{k}^{0}=0,50$ e elementos quadriláteros. . . 120

7.97 Imagens obtidas com $p=4, \rho_{k}^{0}=0,85$ e elementos quadriláteros. . . 121

7.98 Gráficos de convergência e resistividades da imagem obtida com

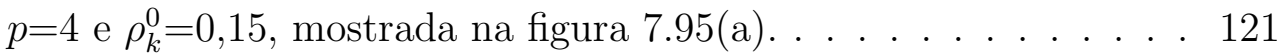

7.99 Gráficos de convergência e resistividades da imagem obtida com $p=4$ e $\rho_{k}^{0}=0,15$, mostrada na figura $7.95(\mathrm{~b}) \ldots \ldots \ldots$. . . . . . 121

7.100Gráficos de convergência e resistividades da imagem obtida com $p=4$ e $\rho_{k}^{0}=0,15$, mostrada na figura $7.95(\mathrm{c}) \ldots \ldots$. . . . . . . . 122

7.101Gráficos de convergência e resistividades da imagem obtida com $p=4$ e $\rho_{k}^{0}=0,50$, mostrada na figura $7.96($ a) . . . . . . . . . . . 122

7.102Gráficos de convergência e resistividades da imagem obtida com $p=4$ e $\rho_{k}^{0}=0,50$, mostrada na figura $7.96(\mathrm{~b}) \ldots \ldots \ldots$. . . . . . 122

7.103Gráficos de convergência e resistividades da imagem obtida com $p=4$ e $\rho_{k}^{0}=0,50$, mostrada na figura $7.96(\mathrm{c}) \ldots \ldots$. . . . . . . . 123

7.104Gráficos de convergência e resistividades da imagem obtida com $p=4$ e $\rho_{k}^{0}=0,85$, mostrada na figura $7.97(\mathrm{a}) \ldots \ldots$. . . . . . . . 123

7.105Gráficos de convergência e resistividades da imagem obtida com

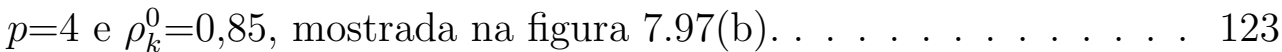

7.106Gráficos de convergência e resistividades da imagem obtida com $p=4$ e $\rho_{k}^{0}=0,85$, mostrada na figura $7.97(\mathrm{c}) \ldots \ldots \ldots$. . . . . . 124

7.107Imagens obtidas com $p=2, \rho_{k}^{0}=0,15$ e elementos triangulares. . . . 125

7.108Imagens obtidas com $p=2, \rho_{k}^{0}=0,50$ e elementos triangulares. . . . 125 
7.109Imagens obtidas com $p=2, \rho_{k}^{0}=0,85$ e elementos triangulares. . . . 125

7.110Gráficos de convergência e resistividades da imagem obtida com $p=2$ e $\rho_{k}^{0}=0,15$, mostrada na figura $7.107($ a) . . . . . . . . . 126

7.111Gráficos de convergência e resistividades da imagem obtida com $p=2$ e $\rho_{k}^{0}=0,15$, mostrada na figura $7.107(\mathrm{~b}) \ldots \ldots \ldots$

7.112Gráficos de convergência e resistividades da imagem obtida com $p=2$ e $\rho_{k}^{0}=0,15$, mostrada na figura $7.107(\mathrm{c}) \ldots \ldots \ldots$

7.113Gráficos de convergência e resistividades da imagem obtida com $p=2$ e $\rho_{k}^{0}=0,50$, mostrada na figura $7.108($ a) . . . . . . . . . . 127

7.114Gráficos de convergência e resistividades da imagem obtida com $p=2$ e $\rho_{k}^{0}=0,50$, mostrada na figura $7.108(\mathrm{~b}) \ldots \ldots$. . . . . . . 127

7.115Gráficos de convergência e resistividades da imagem obtida com $p=2$ e $\rho_{k}^{0}=0,50$, mostrada na figura $7.108($ c) . . . . . . . . . . . 127

7.116Gráficos de convergência e resistividades da imagem obtida com $p=2$ e $\rho_{k}^{0}=0,85$, mostrada na figura $7.109($ a) . . . . . . . . . . . 128

7.117Gráficos de convergência e resistividades da imagem obtida com $p=2$ e $\rho_{k}^{0}=0,85$, mostrada na figura $7.109(\mathrm{~b}) \ldots \ldots \ldots$

7.118Gráficos de convergência e resistividades da imagem obtida com $p=2$ e $\rho_{k}^{0}=0,85$, mostrada na figura $7.109($ c) . . . . . . . . . . 128

7.119Imagens obtidas com $p=4, \rho_{k}^{0}=0,15$ e elementos triangulares. . . . 129

7.120Imagens obtidas com $p=4, \rho_{k}^{0}=0,50$ e elementos triangulares. . . . 129

7.121Imagens obtidas com $p=4, \rho_{k}^{0}=0,85$ e elementos triangulares. . . . 130

7.122Gráficos de convergência e resistividades da imagem obtida com $p=4$ e $\rho_{k}^{0}=0,15$, mostrada na figura $7.119($ a) . . . . . . . . . 130

7.123Gráficos de convergência e resistividades da imagem obtida com $p=4$ e $\rho_{k}^{0}=0,15$, mostrada na figura $7.119(\mathrm{~b}) \ldots \ldots$. . . . . . 130

7.124Gráficos de convergência e resistividades da imagem obtida com $p=4$ e $\rho_{k}^{0}=0,15$, mostrada na figura $7.119(\mathrm{c}) \ldots \ldots \ldots$. . . . . . 131

7.125Gráficos de convergência e resistividades da imagem obtida com $p=4$ e $\rho_{k}^{0}=0,50$, mostrada na figura $7.120($ a) . . . . . . . . . . 131

7.126Gráficos de convergência e resistividades da imagem obtida com $p=4$ e $\rho_{k}^{0}=0,50$, mostrada na figura $7.120(\mathrm{~b}) \ldots \ldots \ldots$. . . . . 131 
7.127Gráficos de convergência e resistividades da imagem obtida com $p=4$ e $\rho_{k}^{0}=0,50$, mostrada na figura $7.120($ c) . . . . . . . . . . 132

7.128Gráficos de convergência e resistividades da imagem obtida com $p=4$ e $\rho_{k}^{0}=0,85$, mostrada na figura $7.121($ a) . . . . . . . . . . 132

7.129Gráficos de convergência e resistividades da imagem obtida com $p=4$ e $\rho_{k}^{0}=0,85$, mostrada na figura $7.121(\mathrm{~b}) \ldots \ldots$. . . . . . . 132

7.130Gráficos de convergência e resistividades da imagem obtida com

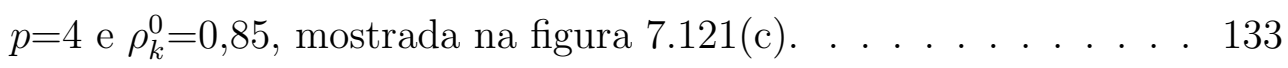

7.131Imagens obtidas com o método da continuação $(p=1,2,3,4,5$ e 6), RCM, filtro e $\rho_{k}^{0}=0,85 \ldots \ldots \ldots \ldots$

7.132Gráfico de convergência e gráfico de resistividades da imagem mostrada na figura $7.131(\mathrm{a}) \ldots \ldots \ldots \ldots$

7.133Gráfico de convergência e gráfico de resistividades da imagem mostrada na figura $7.131(\mathrm{~b}) \ldots \ldots \ldots \ldots$

7.134Gráfico de convergência e gráfico de resistividades da imagem mostrada na figura $7.131(\mathrm{c}) . \ldots \ldots$. . . . . . . . . 136

7.135Imagens obtidas com a aplicação do CAMD (condutividades em $\left.(\Omega m)^{-1}\right) \ldots \ldots \ldots \ldots \ldots \ldots \ldots$

7.136Gráfico de convergência e gráfico de resistividades da imagem

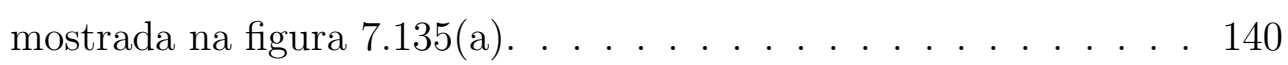

7.137Gráfico de convergência e gráfico de resistividades da imagem mostrada na figura $7.135($ b) . . . . . . . . . . . . . . . . 140

7.138Gráfico de convergência e gráfico de resistividades da imagem mostrada na figura $7.135(\mathrm{c})$. . . . . . . . . . . . . . 140

7.139Fantoma experimental com solução salina, 32 eletrodos e um copo de vidro inserido (cortesia do Prof. Raul Gonzalez Lima). . . . . . 144

7.140Resultado obtido com dados experimentais, elementos quadriláteros e considerando o padrão adjacente. . . . . . . . . . 145

7.141Gráfico de resistividades da imagem mostrada na figura 7.140(a). 145

7.142Ilustração da posição do copo de vidro na cuba com 32 eletrodos. 146

7.143Resultado obtido com dados experimentais, elementos quadriláteros e desligando o filtro nas cinco últimas iterações. . . . 147 
7.144Resultado obtido com dados experimentais, elementos triangulares e desligando o filtro nas últimas iterações. . . . . . . . . . . . . . 148

7.145Resultado obtido com dados experimentais, utilizando o CAMD e malha de obtenção de imagem com 576 elementos quadriláteros. . 148

7.146Resultado obtido com dados experimentais, utilizando o CAMD e malha de obtenção de imagem com 1248 elementos triangulares. . 149

7.147Fantoma experimental com solução salina, 30 eletrodos e um objeto cilíndrico de acrílico inserido (cortesia do Prof. Raul Gonzalez Lima).150

7.148Esquema para medição dos potenciais elétricos na forma "diferencial". . . . . . . . . . . . . . . . . . . . . 151

7.149Domínio de obtenção da imagem com 934 elementos triangulares e 30 elementos de eletrodos. . . . . . . . . . . . . . . . . . 152

7.150Imagens obtidas (distribuição de condutividades) com medidas de potenciais elétricos "diferenciais". . . . . . . . . . . . . . . 153

7.151Gráfico de convergência e gráfico de resistividades da imagem mostrada na figura $7.150($ a) . . . . . . . . . . . . . . 153

7.152Gráficos da distribuição de resistividades das imagem mostradas nas figuras 7.150 (b) e 7.150 (c), respectivamente. . . . . . . . . 153

7.153Resultado obtido com medidas de potenciais elétricos "diferenciais", utilizando o CAMD e objeto posicionado na borda da cuba. . . . . . . . . . . . . . . . . 155

7.154Resultado obtido com medidas de potenciais elétricos "diferenciais", utilizando o CAMD e objeto posicionado entre a borda e o centro da cuba. . . . . . . . . . . . . . . 155

7.155Resultado obtido com medidas de potenciais elétricos "diferenciais", utilizando o CAMD e objeto posicionado no centro da cuba. . . . . . . . . . . . . . . . . . . . . 155

A.1 Aplicação da primeira medição de potenciais (i=1). . . . . . . . . 164

B.1 Fluxograma básico do pré-processamento. . . . . . . . . . . . 167

B.2 Fluxograma da estrutura do TOMOGOT - Parte I. . . . . . . . 168

B.3 Fluxograma da estrutura do TOMOGOT - Parte II. . . . . . . . . 169

B.4 Fluxograma da rotina de MEF. . . . . . . . . . . . . . . . . 171 


\section{Lista de Tabelas}

7.1 Valores dos parâmetros de eletrodos para o padrão adjacente . . 69

7.2 Valores dos parâmetros de eletrodos para o padrão diametral . . .

7.3 Erro de $V^{*}$ e da coordenada $(x, y)$ do centróide da imagem do objeto e valor máximo de $\rho_{k}$, com $p=2, \mathrm{RCM}$ e elementos

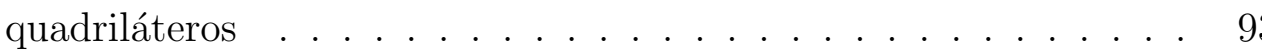

7.4 Erro de $V^{*}$ e da coordenada $(x, y)$ do centróide da imagem do objeto e valor máximo de $\rho_{k}$, com $p=4, \mathrm{RCM}$ e elementos

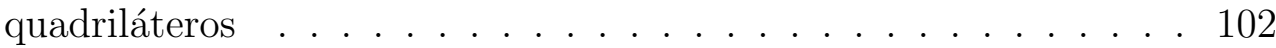

7.5 Erro de $V^{*}$ e da coordenada $(x, y)$ do centróide da imagem do objeto e valor máximo de $\rho_{k}, \operatorname{com} p=2, \mathrm{RCM}$ e elementos triangulares 108

7.6 Erro de $V^{*}$ e da coordenada $(x, y)$ do centróide da imagem do objeto e valor máximo de $\rho_{k}, \operatorname{com} p=4, \mathrm{RCM}$ e elementos triangulares 113

7.7 Erro de $V^{*}$ e da coordenada $(x, y)$ do centróide da imagem do objeto e valor máximo de $\rho_{k}$, com $p=2, \mathrm{RCM}$, filtro e elementos

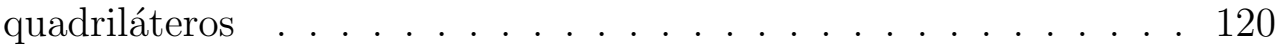

7.8 Erro de $V^{*}$ e da coordenada $(x, y)$ do centróide da imagem do objeto e valor máximo de $\rho_{k}$, com $p=4, \mathrm{RCM}$, filtro e elementos quadriláteros . . . . . . . . . . . . . . . . 12

7.9 Erro de $V^{*}$ e da coordenada $(x, y)$ do centróide da imagem do objeto e valor máximo de $\rho_{k}$, com $p=2, \mathrm{RCM}$, filtro e elementos triangulares . . . . . . . . . . . . . . . . . . 129

7.10 Erro de $V^{*}$ e da coordenada $(x, y)$ do centróide da imagem do objeto e valor máximo de $\rho_{k}$, com $p=4, \mathrm{RCM}$, filtro e elementos

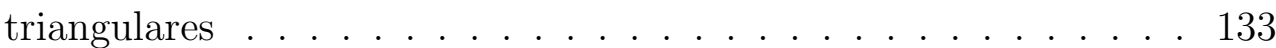

7.11 Comparação entre resultados obtidos para $V^{*}$ e para a coordenada $(x, y)$ (dadas em milímetros), sem e com aplicação do CAMD . . . 142 


\section{Lista de Abreviaturas e Siglas}

ANSYS Software comercial de elementos finitos

ASCII American Standard Code for Information Interchange

CAMD Continuous Approximation of Material Distribution

DSPLP Rotina de programação linear que usa o método Simplex

FDTD Finite-Difference Time Domain

MEF Método dos Elementos Finitos

MOT Método de Otimização Topológica

OT Otimização Topológica

PL Programação Linear

PLS Programação Linear Sequencial

RCM Restrição da Condutividade Média

RM Ressonância Magnética

SIMP Simple Isotropic Material with Penalization

TC Tomografia Computadorizada

TIE Tomografia por Impedância Elétrica

TOMOGOT Software implementado neste trabalho, que aplica o MOT à TIE

UTI Unidade de Terapia Intensiva

2D Bidimensional

3D Tridimensional 


\section{Lista de Símbolos}

\begin{tabular}{|c|c|}
\hline símbolo & descrição \\
\hline$f$ & função contínua qualquer \\
\hline$\Omega m$ & ohms-metro \\
\hline $\mathbf{E}$ & campo elétrico \\
\hline$\hat{\rho}$ & densidade de carga \\
\hline$\varepsilon_{r}$ & permissividade relativa \\
\hline$\varepsilon_{o}$ & permissividade específica \\
\hline$\phi$ & potencial elétrico \\
\hline $\mathbf{J}$ & densidade de corrente \\
\hline$\sigma$ & condutividade do domínio \\
\hline$\phi$ & vetor dos potenciais elétricos \\
\hline$\psi$ & vetor dos potenciais elétricos nodais \\
\hline $\mathbf{N}$ & matriz das funções de forma do elemento \\
\hline$\nabla$ & operador gradiente \\
\hline$\xi$ & abscissa do sistema de coordenadas local do elemento \\
\hline$\eta$ & ordenada do sistema de coordenadas local do elemento \\
\hline$V_{e}$ & volume do elemento \\
\hline $\bar{\phi}$ & distribuição virtual de potenciais elétricos \\
\hline$\Gamma_{q}$ & fronteira do domínio que contém a condição de contorno \\
\hline $\bar{\phi}_{q}$ & distribuição virtual de potenciais elétricos em $\Gamma_{q}$ \\
\hline $\mathbf{n}$ & vetor normal à superfície do domínio \\
\hline$I_{n}$ & componente da corrente elétrica na direção de $\mathbf{n}$ \\
\hline$\sigma$ & tensor de condutividade elétrica \\
\hline$\sigma_{x}$ & condutividade elétrica do elemento na direção $x$ \\
\hline$\sigma_{y}$ & condutividade elétrica do elemento na direção $y$ \\
\hline $\mathbf{B}_{(e)}$ & matriz de operadores diferenciais das funções de forma \\
\hline $\mathbf{k}_{(e)}$ & matriz de condutividade elétrica do elemento \\
\hline$\partial$ & operador gradiente \\
\hline$A_{e}$ & área do elemento \\
\hline$h_{e}$ & espessura do elemento \\
\hline $\mathbf{J}_{(e)}$ & matriz Jacobiana \\
\hline
\end{tabular}




\begin{tabular}{|c|c|}
\hline símbolo & descrição \\
\hline $\operatorname{det} \mathbf{J}_{(e)}$ & determinante da matriz Jacobiana \\
\hline$x$ & abscissa do sistema de coordenadas global \\
\hline$y$ & ordenada do sistema de coordenadas global \\
\hline $\mathbf{K}$ & matriz de condutividade global \\
\hline I & vetor de carregamento elétrico nodal \\
\hline $\mathbf{k}_{e l}$ & matriz de condutividade elétrica do elemento de eletrodo \\
\hline$\rho t$ & impedância de contato do eletrodo \\
\hline$M$ & número total de elementos \\
\hline$\Omega$ & domínio fixo de projeto \\
\hline$F$ & função objetivo \\
\hline$\phi_{\mathrm{ij} 0}$ & potenciais elétricos medidos nos eletrodos \\
\hline$\phi_{\mathrm{ij}}$ & potenciais elétricos calculados \\
\hline ne & número de casos de carga de corrente aplicados \\
\hline$n p$ & número de pontos de medição \\
\hline$\rho_{k}$ & variável de projeto \\
\hline$\chi(x)$ & função discreta de distribuição de densidades \\
\hline$\Omega_{D}$ & região inserida no domínio $\Omega$ \\
\hline$C_{0}$ & tensor constitutivo do material base \\
\hline $\mathrm{C}_{k}$ & propriedade efetiva de condutividade do elemento \\
\hline$p$ & fator de penalidade das densidades intermediárias \\
\hline$\rho(x)$ & função contínua de distribuição de densidades \\
\hline$C(x)$ & propriedade efetiva do material \\
\hline $\mathbf{C}_{A}$ & propriedade de condutividade do material "A" \\
\hline $\mathbf{C}_{B}$ & propriedade de condutividade do material "B" \\
\hline$F_{\text {linear }}$ & função linear a ser minimizada na PL \\
\hline$\rho^{i}$ & valor da variável de projeto na iteração $i$ \\
\hline$F(\rho)$ & função não-linear em $\rho$ \\
\hline$f(\rho)$ & aproximação linear da função não-linear $F(\rho)$ \\
\hline$\rho_{\min }^{i}$ & limite móvel inferior de $\rho^{i}$ \\
\hline$\rho_{\max }^{i}$ & limite móvel superior de $\rho^{i}$ \\
\hline$\rho_{\min }$ & valor extremo mínimo da variável de projeto \\
\hline$\rho_{\max }$ & valor extremo máximo da variável de projeto \\
\hline$\Delta \rho_{k}^{i}$ & variação de sinal de $\rho_{k}$ na iteração corrente \\
\hline$\Delta \rho_{k}^{i-1}$ & variação de sinal de $\rho_{k}$ numa iteração anterior \\
\hline$\Delta \rho_{k}^{i-2}$ & variação de sinal de $\rho_{k}$ nas duas últimas iterações \\
\hline
\end{tabular}




\begin{tabular}{|c|c|}
\hline símbolo & descrição \\
\hline $\bar{\rho}_{k}^{i}$ & valor associado a cada variável de projeto na iteração $i$ \\
\hline $\bar{\rho}_{\min }$ & valor mínimo de $\bar{\rho}_{k}^{i}$ \\
\hline $\bar{\rho}_{\max }$ & valor máximo de $\bar{\rho}_{k}^{i}$ \\
\hline$I_{i}$ & corrente elétrica \\
\hline$\Gamma_{i}$ & superfície onde é aplicado a corrente elétrica \\
\hline $\mathbf{I}_{i}$ & forma vetorial de $I_{i}$ \\
\hline$\Phi_{i}$ & forma vetorial de $\phi_{i}$ \\
\hline$\rho_{k}^{0}$ & valor inicial da variável de projeto \\
\hline$V_{k}$ & volume de cada elemento do domínio discretizado \\
\hline$V^{*}$ & restrição de material no domínio \\
\hline$d_{k}$ & distância do centro do elemento ao centro do domínio \\
\hline $\bar{\rho}^{*}$ & pseudo-densidade média \\
\hline $\bar{\rho}$ & resistividade média do meio \\
\hline$q$ & expoente utilizado para intensificar o grau da restrição \\
\hline$R_{\Omega}$ & resistência elétrica média no domínio \\
\hline $\bar{U}$ & potencial elétrico médio no domínio \\
\hline $\bar{C}$ & condutividade média no domínio \\
\hline$w$ & peso atribuído heuristicamente no filtro \\
\hline$R_{i j}$ & distância entre centróides dos elementos \\
\hline$R_{\max }$ & raio de abrangência do filtro \\
\hline$n v$ & número de vizinhos do elemento central \\
\hline$e\left(V^{*}\right)$ & erro no valor da restrição de material no domínio \\
\hline$e(x)$ & erro no valor da abscissa $x$ \\
\hline$e(y)$ & erro no valor da ordenada $y$ \\
\hline$\rho_{k}^{\max }$ & valor máximo encontrado para a variável de projeto \\
\hline$\rho_{i}$ & variável de projeto definida em cada nó do elemento \\
\hline$\sigma_{(e)}$ & condutividade específica do material do elemento \\
\hline$\Delta \phi$ & diferença entre valores de potenciais elétricos \\
\hline$V$ & volume total do domínio \\
\hline$n_{x}$ & componente horizontal do vetor unitário $\mathbf{n}$ \\
\hline$n_{y}$ & componente vertical do vetor unitário $\mathbf{n}$ \\
\hline$L_{1}\left(\phi_{2}\right)$ & energia mútua do sistema \\
\hline
\end{tabular}




\section{Introdução}

A Tomografia por Impedância Elétrica (TIE) é uma técnica de monitoração, em desenvolvimento desde a década de 80, que permite obter imagens que representam um plano transverso de qualquer seção de um corpo, onde cada "pixel" na imagem representa a sua impedância ou resistividade elétrica estimada. As imagens são geradas mediante valores de voltagem obtidos com a aplicação de uma seqüência alternada, segundo um certo padrão de excitação (diametral, adjacente, etc), de correntes elétricas de baixa amplitude através de eletrodos posicionados ao redor do corpo e alinhados num plano correspondente a uma seção transversal. A figura 1.1 ilustra os eletrodos posicionados num corpo humano para obtenção de imagem do pulmão através da TIE (CHENEY; ISAACSON; NEWELL, 1999).

Na TIE procede-se a solução de um problema inverso, ou seja, dadas as medidas de voltagem obtidas nos eletrodos, estima-se a distribuição de condutividades da seção do corpo cuja imagem se quer reproduzir. Esse problema é não-linear, pois a função que representa a voltagem obtida no contorno do corpo depende de forma não-linear tanto da corrente elétrica aplicada nos eletrodos como da distribuição de condutividades estimada para a região do corpo cuja imagem é desejada. Além disso, o problema é também mal-posto, ou seja, a sua solução é descontínua com relação as voltagens medidas, fazendo com que pequenas variações nessas voltagens (ruídos) causem grandes oscilações na
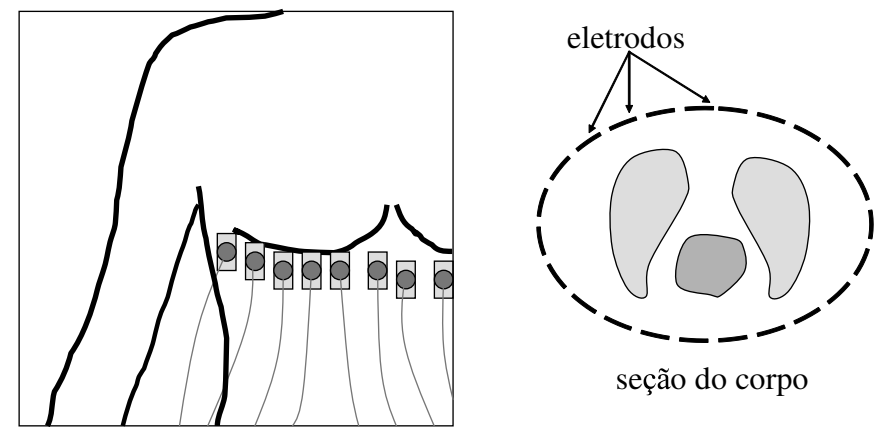

Figura 1.1: Ilustração dos eletrodos em torno do tórax na TIE. 
imagem obtida (OOSTEROM, 1991). Essas características fazem com que a TIE seja bastante dependente do algoritmo de reconstrução utilizado para a solução do problema inverso. Assim, vários algoritmos vem sendo aplicados por pesquisadores do mundo inteiro para resolver o problema da TIE (BORCEA, 2002). Maiores detalhes sobre a TIE são descritos no capítulo 2 deste trabalho.

\section{$1.1 \quad$ Objetivo}

O objetivo principal deste trabalho é o estudo da aplicação do Método de Otimização Topológica (MOT) para obtenção de imagens do pulmão utilizando-se a TIE. O MOT é uma metodologia que visa distribuir o material no interior de um domínio fixo discretizado em elementos finitos de maneira a atender uma função objetivo especificada (BENDSøE; KIKUCHI, 1988). O problema de obtenção da imagem usando MOT consiste em se obter a distribuição de material, conseqüentemente a distribuição de condutividade (ou resistividade), no domínio da seção do corpo (cuja imagem é desejada) que minimize a diferença entre os potenciais elétricos medidos nos eletrodos e os potenciais calculados no modelo computacional da seção. A solução deste problema de otimização no MOT é obtida combinando-se um método de análise, em geral o Método dos Elementos Finitos (MEF) (BATHE, 1996), e um algoritmo de otimização como a Programação Linear Sequencial (PLS) (HAFTKA; GüRDAL; KAMAT, 1996). O capítulo 3 mostra uma descrição mais detalhada sobre o MOT. Este trabalho está inserido num projeto temático (AMATO, 2001) cujo objetivo é estudar técnicas de reconstrução de imagem aplicadas a um tomógrafo por impedância elétrica para monitorar de forma precisa a ventilação forçada do pulmão. Nesse caso, a TIE é utilizada para a detecção de danos no pulmão durante o processo de ventilação artificial em leitos de Unidade de Terapia Intensiva (UTI) de forma que o ajuste no ventilador artificial do pulmão possa ser realizado para causar o mínimo dano ao paciente. O projeto temático envolve a construção de um protótipo do hardware e o desenvolvimento de software para a obtenção da imagem, se limitando apenas a explorar o tema, desenvolvendo as bases teóricas, modelos e algoritmos que possibilitem a implementação clínica da TIE. A metodologia adotada no projeto temático para investigar os problemas teóricos da TIE tem a estrutura de uma competição de métodos, na qual o MOT, empregado neste trabalho, participa. O método adotado neste trabalho para reconstrução de imagem na TIE deverá ser capaz de estimar distribuições absolutas de condutividade ou resistividade, de forma que seja possível diagnosticar quando alguma parte do pulmão está com 
líquido, ou colapsada, ou cheia de ar com obstrução. O pulmão parece ser um órgão privilegiado para o uso desta técnica, uma vez que a presença de mais ou menos ar altera drasticamente a condutividade do tecido pulmonar (NOPP et al., 1993).

\subsection{Justificativa}

Uma das justificativas para a realização deste trabalho é o fato que na literatura a maior parte dos estudos para reconstrução de imagem por impedância elétrica se concentram no desenvolvimento de métodos relativos e poucas técnicas se encontram disponíveis para métodos absolutos. Os métodos relativos (imagens relativas) são aqueles que fornecem a imagem de variações de condutividade no interior do domínio quase em tempo real, enquanto que os métodos absolutos (imagens estáticas) fornecem uma imagem de valores absolutos de condutividade (ou resistividade), porém num tempo maior. O algoritmo de MOT, em estudo neste trabalho para a obtenção de imagens do pulmão através da TIE, está classificado como um método absoluto.

Em vista que, a obtenção da imagem do tomógrafo usando otimização topológica consiste num subtema do projeto temático, justifica-se também a realização deste trabalho sabendo-se que um tomógrafo de TIE (em estudo no projeto temático) consistirá num importante instrumento a ser usado pelo médico intensivista que atualmente não dispõe de recursos precisos para detectar a presença de danos pulmonares em tempo real, sendo obrigado a lidar com o pulmão como uma "caixa preta" lacrada. Exames radiológicos comuns são obtidos quando já é tarde, além de não apresentarem sensibilidade suficiente (AMATO et al., 1998). Embora mais simples que os tomógrafos de raios-X e ressonância magnética, é um aparelho menor, sendo portátil, o que permite a sua instalação no leito de um paciente da UTI o que é extremamente importante, pois há um risco de óbito ao se levar o paciente do leito de UTI para a sala de tomografia. O tomógrafo de impedância elétrica é simples de usar e muito mais barato que os tomógrafos já citados, tornando-o mais acessível aos hospitais brasileiros. Além disso, não expõe o paciente a qualquer tipo de radiação, somente à aplicação de uma corrente de baixa intensidade, que não causa lesão aos tecidos, e que pode ser aplicada por dias seguidos na mesma região. De acordo com Amato (2001) aproximadamente 250.000 pacientes/ano são submetidos à ventilação artificial prolongada, em UTIs no Brasil e apesar dos avanços tecnológicos nos dias atuais, o médico ainda não dispõe de ferramentas para lidar com uma das principais causas de mortalidade 
nestes pacientes: as complicações pulmonares decorrentes do trauma mecânico imposto pela própria ventilação artificial e do colapso pulmonar freqüentemente associado. Uma nova técnica de ventilação pulmonar proposta por ele reduziu em $50 \%$ a mortalidade geral de pacientes sob ventilação artificial. Dessa forma estima-se que é possível se evitar, no mínimo, em torno de 15.000 mortes/ano no Brasil. No entanto, o sucesso da aplicação dessa técnica depende da monitoração pulmonar precisa da ventilação forçada do pulmão.

\subsection{Contribuição}

O MOT tem como principal vantagem a facilidade de inclusão de várias restrições no problema de reconstrução de imagem, através de seu algoritmo de busca (a PLS), limitando facilmente o espaço de solução àquele esperado e evitando-se assim imagens sem significado clínico. Além disso, na literatura verifica-se que os outros algoritmos utilizados para obtenção de imagem na TIE não exploram a aplicação de métodos de programação linear, como a PLS utilizada no MOT. Com a utilização do MOT pode-se, por exemplo, limitar no domínio de projeto a região em que a presença de ar no pulmão pode ocorrer, além de permitir lidar com a presença de regiões conhecidas no interior do domínio (por exemplo, osso, coração, etc). Ao final deste trabalho, espera-se ter contribuído com o desenvolvimento de uma técnica de tomografia útil para aplicações médicas no trato de pulmões.

Nos capítulos seguintes, será apresentada a aplicação do MOT para obtenção de imagens do pulmão através da TIE. Assim, nos capítulos 2 e 3 são feitas revisões bibliográficas sobre os aspectos mais relevantes da técnica de Tomografia por Impedância Elétrica e sobre o Método de Otimização Topológica. Em seguida, no capítulo 4, é descrita a modelagem de MEF da seção do corpo submetido a TIE. Nos capítulos 5 e 6 são descritas a formulação teórica e a implementação numérica do problema de otimização topológica aplicado na obtenção de imagem na TIE. No capítulo 7, são apresentados os resultados obtidos através do algoritmo implementado, utilizando dados numéricos e experimentais. Finalmente, no capítulo 8 são mostradas as conclusões, observações e trabalhos futuros. 


\section{Tomografia por Impedância Elétrica}

\subsection{Introdução}

Durante a segunda metade do século XX, novas e melhores técnicas foram desenvolvidas para se observar o interior do corpo humano. Desde então, as técnicas de tomografia vêm se consolidando como as mais importantes para a obtenção de imagens médicas (BATES; GARDEN; PETERS, 1983). As técnicas de tomografia são capazes de obter a imagem da seção de um corpo sólido mediante a informação obtida de uma série de medidas em várias direções no plano da seção. Tecnologias de informática são utilizadas para auxiliarem no processo de obtenção da imagem, de tal forma que um tomógrafo é composto por um instrumental que inclui um computador acoplado que reconstrói a imagem topográfica com base em dados obtidos externamente ao corpo (submetido à tomografia), e segundo um algoritmo matemático de reconstrução de imagem previamente estabelecido (BATES; GARDEN; PETERS, 1983).

O primeiro tomógrafo computadorizado surgiu na década de 70 e baseia-se na técnica de radiografia, descoberta por Wilhelm Conrad Röntgen (1895), na qual as imagens são obtidas expondo a região do corpo, que se quer analisar, a uma radiação ionizante (raios-X) que atravessa o corpo e atinge uma placa fotográfica, que revelada mostra as sombras das regiões do corpo que atenuam a incidência dos raios-X (JAUNCEY, 1945). Na Tomografia Computadorizada (TC) a imagem é obtida por meio de um algoritmo de reconstrução de imagem que utiliza a informação de radiografias de diferentes ângulos em torno da seção do corpo a ser tomografada (HERMAN, 1980). A figura 2.1 ilustra uma TC da seção transversal do toráx humano. Subseqüentemente outros fenômenos físicos, tais como radiação gama, ultra-som, corrente elétrica, campos magnéticos, radio-freqüência e microondas, foram sendo testados e empregados em várias aplicações de tomografia, tais como em diagnósticos radiológicos, testes não-destrutivos, medicina nuclear, cristalografia, prospecção geológica, 


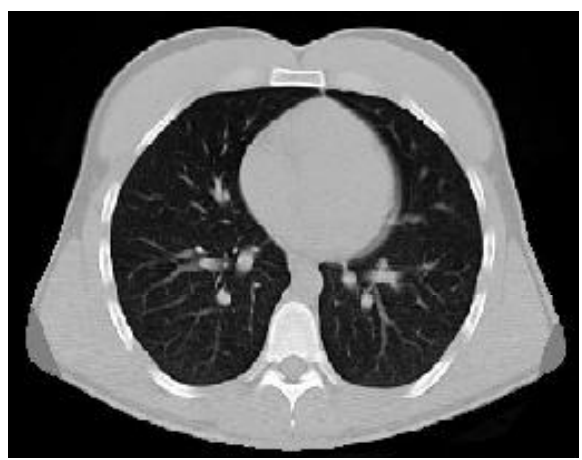

Figura 2.1: Tomografia Computadorizada do toráx humano.

mapeamento da distribuição de condutividades e de temperaturas interna ao corpo humano, etc (BATES; GARDEN; PETERS, 1983).

Outra técnica de tomografia muito conhecida é a Ressonância Magnética (RM), que utiliza os princípios da ressonância magnética nuclear, em que o paciente é submetido a ondas de rádio e um campo magnético intenso. Esta técnica baseia-se no princípio de que diferentes átomos do corpo humano absorvem diferentes freqüências de ondas de rádio quando submetidos a um campo magnético. Um algoritmo de reconstrução é usado para obter as imagens a partir da informação da intensidade de absorção das ondas de rádios pelo corpo (HINSHAW; LENT, 1983). A RM é considerada a modalidade de diagnóstico por imagem mais versátil, poderosa e sensível disponível atualmente. Por exemplo, na aplicação médica sua importância pode ser resumida como a capacidade de gerar imagens funcionais, de cortes finos, de modo não invasivo, de qualquer parte do organismo, a partir de qualquer ângulo e direção, em um período relativamente curto (MANSFIELD; MORRIS, 1982). As imagens obtidas pela RM oferecem uma resolução equivalente ou superior aos raios-X e às outras técnicas de tomografia. $\mathrm{O}$ tomógrafo de RM é uma ferramenta de diagnóstico especialmente útil para obter imagens do cérebro, da cabeça e do pescoço. Porém, a RM é contra-indicada em pacientes portadores de marcapassos e àqueles que necessitam ter algum tipo de instrumento metálico próximo ao corpo. Cada técnica tem suas particularidades. Assim, em cada situação clínica haverá uma técnica de obtenção de imagens eficaz na visualização do processo patológico que afeta a região corporal a ser analisada.

Uma técnica bastante explorada desde o início da década de 80 e que vem se tornando uma alternativa em potencial às técnicas tradicionais é a Tomografia por Impedância Elétrica (TIE), que permite obter imagens de uma seção do corpo mediante valores de voltagem medidos em eletrodos posicionados ao redor do corpo (HENDERSON; WEBSTER, 1978; PRICE, 1979; BARBER; BROWN, 1984). A 
resolução das imagens geradas pela TIE é baixa, se comparada às outras técnicas de tomografia. Apesar disso, a TIE apresenta vantagens que a tornam viável para aplicação clínica. Por exemplo, esta técnica não expõe a região do corpo que se quer observar a qualquer tipo de radiação, tem baixo custo em relação às outras técnicas de tomografia e, além disso, um tomógrafo de TIE é portátil e pode ser utilizado junto ao leito do paciente (CHENEY; ISAACSON; NEWELL, 1999; BROWN, 2001). A TIE pode ser empregada tanto em aplicações médicas como industriais (BROWN, 2001), conforme descrito mais adiante na seção 2.4. Este trabalho se concentra no estudo da TIE direcionada para aplicação na área médica, especificamente para o monitoramento preciso do processo de ventilação forçada do pulmão (AMATO et al., 1998).

A seguir, na seção 2.2, é descrito o princípio fundamental de reconstrução de imagem aplicado às técnicas de tomografia. Como a TIE é alvo de estudo deste trabalho, as demais seções tratam especificamente do conceito básico, aplicações e algoritmos da TIE.

\subsection{Reconstrução de Imagens para Tomografia}

De maneira geral, neste item, são mostradas as abordagens utilizadas para a reconstrução da distribuição de propriedades materiais numa seção transversal (bidimensional) do corpo que se quer observar na tomografia. Conforme o grau de controle exigido nas técnicas de tomografia as fontes de fenômenos físicos (radiação, propagação de onda, campos estáticos, campos elétricos, etc), utilizadas para se obter a imagem da seção do corpo, são emitidas do interior ou do exterior do corpo. Isso produz dois esquemas de medição distintos para a reconstrução de imagens por tomografia. Num deles, transdutores (externos ao corpo) detectam os fenômenos físicos (fótons, pósitrons, radiação térmica, etc) emitidos por substâncias introduzidas ou provenientes do interior do corpo. Técnicas de tomografia como, a emissão de fótons, a emissão de pósitrons e a radiometria, são exemplos que utilizam esse tipo de esquema. No outro, as fontes dos fenômenos físicos estão localizadas no exterior do corpo submetido à tomografia. Técnicas de tomografia como a emissão de raios-X, ultra-som, TIE e outros utilizam essa abordagem. Mais detalhes sobre essas abordagens na tomografia apresentadas acima podem ser encontrados em Bates, Garden e Peters (1983), Lewitt (1983) e Censor (1983).

Para melhor entendimento do processo de tomografia, considere o círculo circunscrito, representado por $\Gamma_{\mathrm{C}}$ na figura 2.2 , que limita a seção transversal 


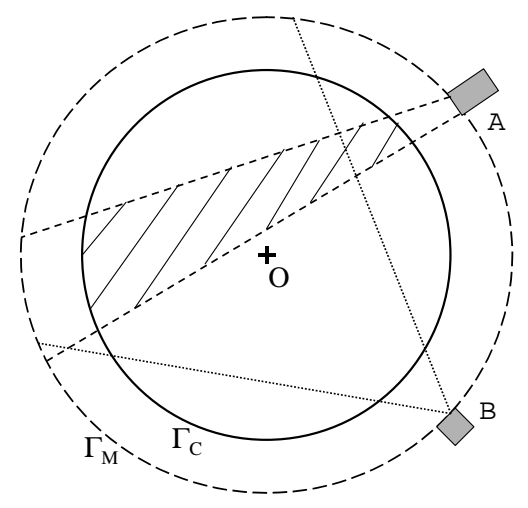

Figura 2.2: Geometria básica para a tomografia bidimensional.

que se quer observar. Os fenômenos físicos são medidos no exterior do círculo circunscrito $\Gamma_{\mathrm{C}}$, ou seja, todas as medidas são obtidas externamente à seção do corpo que se quer observar. Na prática, existem ruídos que prejudicam a precisão do sistema de medição dos fenômenos físicos. Escolhe-se a fronteira de medição, representada pelo círculo $\Gamma_{\mathrm{M}}$ na figura 2.2 , a qual é concêntrica com o círculo circunscrito $\Gamma_{\mathrm{C}}$. A região limitada pelo círculos $\Gamma_{\mathrm{C}}$ e $\Gamma_{\mathrm{M}}$ é considerada tênue, ou seja, essa região não contém distribuição de propriedades materiais da seção do corpo que se quer observar.

A resolução da imagem reconstruída é o principal indicador para afirmar se uma técnica de tomografia é provavelmente útil para uma determinada aplicação. Um fator que limita essa resolução é o tamanho dos transdutores utilizados (fontes de recepção e emissão dos fenômenos físicos), pois isso limita o número de transdutores vizinhos que poderão ser utilizados, conseqüentemente o número de observações que podem ser realizadas. Um parâmetro importante de um transdutor é a abrangência do seu feixe de fenômenos físicos emitido (ou recebido), que é classificada em banda-estreita ("narrow-beam") e banda-larga ("wide-beam") (BATES; GARDEN; PETERS, 1983). A figura 2.2 também ilustra, esquematicamente, a abrangência do feixe emitido por um transdutor de banda-estreita (transdutor A, representado na figura 2.2 por um retângulo) e por um transdutor de banda-larga (transdutor B, representado na figura 2.2 por um quadrado). A utilização de transdutores de banda-larga exige algoritmos complexos de reconstrução de imagem, inclusive devido ao fato do problema de obtenção da imagem ser um problema mal-posto, o qual encontra mais de uma distribuição de propriedades materiais em $\Gamma_{\mathrm{C}}$ para o mesmo sinal emitido em $\Gamma_{\mathrm{M}}$ (TIKHONOV; ARSENIN, 1977; TIKHONOV, 1991). Uma aplicação típica desses transdutores é encontrada na TIE, onde a corrente elétrica de baixa freqüência, aplicada em eletrodos (transdutores) posicionados ao redor do corpo, se espalha 
pelo corpo submetido à tomografia (ISAACSON; CHENEY; NEWELL, 1992). Os algoritmos de reconstrução de imagem com esquemas que utilizam transdutores de banda-estreita, como os utilizados em tomografias por radiação, são mais estáveis e matematicamente mais simples, pois cada medida é sensível somente à região interceptada pelo feixe emitido (BATES; GARDEN; PETERS, 1983).

Os algoritmos de reconstrução na tomografia devem solucionar classes de problemas para a obtenção de imagens de tomografia: o problema direto e o problema inverso (LEWITT, 1983; CENSOR, 1983). No problema direto, dado as fontes de fenômenos físicos e a distribuição de propriedades materiais da seção do corpo (cuja imagem é desejada), calcula-se o sinal de resposta correspondente às fontes. Por exemplo, na TIE o problema direto determina a distribuição de potenciais elétricos produzido, dado um carregamento elétrico aplicado e as propriedades de condutividade do material da seção do corpo (YORKEY; WEBSTER; TOMPKINS, 1987). Já no problema inverso, dado o sinal de resposta e as fontes de fenômenos físicos, reconstrói-se a distribuição de propriedades materiais da seção do corpo. Em técnicas de tomografia que utilizam radiação, é possível obter formulações inversas bem "comportadas" (LEWITT, 1983). Porém, o algoritmo de reconstrução opera com a hipótese de que a direção percorrida pela radiação ("raio"), no interior de $\Gamma_{\mathrm{C}}$, é uma linha reta.

Na TIE a solução do problema inverso corresponde a se obter uma estimativa da condutividade (ou resistividade) da seção do corpo, a partir das voltagens medidas no contorno dessa seção. Sabe-se que o problema inverso da TIE é mal-posto (SYLVESTER; UHLMANN, 1987; GISSER; ISAACSON; NEWELL, 1990) e essa característica faz com que a TIE seja bastante dependente do algoritmo de reconstrução utilizado, cujo mesmo deve possuir uma regularização para conseguir condicionar melhor a solução do problema (TIKHONOV, 1991; ADLER; GUARDO, 1996; WEST et al., 2001; SCHMITT et al., 2002). Assim, vários algoritmos vem sendo testados por vários pesquisadores nacionais e internacionais com o objetivo de identificar a melhor maneira para a solução do problema inverso da TIE (BORCEA, 2002).

\subsection{Algoritmos de Reconstrução na TIE}

Desde o advento da TIE, vários diferentes algoritmos de reconstrução de imagem são aplicados para resolver o problema inverso e não-linear da TIE, sendo que um comparativo entre alguns deles pode ser visto em (YORKEY; WEBSTER; TOMPKINS, 1987). Os algoritmos de reconstrução para a TIE podem ser divididos 
em duas classes: algoritmos não-iterativos e algoritmos iterativos (LEWITT, 1983; CENSOR, 1983; BARBER, 1989).

Os algoritmos não-iterativos baseiam-se em aproximações lineares do problema inverso da TIE e na hipótese de distribuição homogênea de condutividades (LEWITT, 1983; BORCEA, 2002). Embora desprezem o efeito da não-linearidade do problema de obtenção de imagem na TIE, esses algoritmos são bastante atrativos, pois lidam com formulações matemáticas não muito complexas e são muito rápidos computacionalmente, obtendo dezenas de imagens por segundo, por exemplo (CHENEY; ISAACSON; NEWELL, 1999). Entre os algoritmos de reconstrução de imagem classificados como não-iterativos está o método de "backprojection" e variantes do método (BARBER; BROWN; FREESTON, 1983). A estimativa da distribuição de condutividades através dos algoritmos baseados no "backprojection" segue um princípio similar ao do algoritmo de reconstrução utilizado na tomografia por raios-X, onde a imagem reproduzida é uma soma de imagens obtidas na região de equipotenciais relevantes (LEWITT, 1983). Os algoritmos baseados no "backprojection" constituem um grupo, dentro da classe de métodos não-iterativos, muito utilizado por vários pesquisadores (SANTOSA; VOGELIUS, 1990; AVIS; BARBER, 1995; BAYFORD et al., 1995; KOTRE, 1994). Um outro grupo comum é o constituído por algoritmos baseados na obtenção da matriz de sensibilidades, que multiplicada pelos valores de condutividades estimados produz os valores de voltagens medidos nos eletrodos (MORUCCI et al., 1994). Desta forma, para se obter uma imagem, associada a distribuição de condutividades, basta inverter a matriz de sensibilidades (GADD; RECORD; ROLFE, 1992).

Já, os algoritmos iterativos convertem o problema não-linear da TIE (maior) numa série de problemas lineares menores e por meio da solução sucessiva desses problemas menores buscam a solução do problema maior (CENSOR, 1983). No processo iterativo, inicialmente assume-se uma distribuição de condutividades e para um valor de corrente elétrica conhecida resolve-se as equações de Poisson do domínio condutivo em questão, determinando assim a distribuição de potenciais elétricos desse domínio. Os valores de potenciais encontrados no contorno do domínio são comparados com valores de potenciais elétricos medidos previamente. A diferença entre esses potenciais (medidos e calculados) é utilizada para orientar o algoritmo a buscar a cada iteração, sucessivamente, a distribuição de potenciais elétricos calculada que mais se aproxima da distribuição de potenciais real do domínio. Cada algoritmo iterativo se diferencia um do outro pela maneira de ajustar os valores de condutividades estimados a cada iteração (BARBER, 
1989). Entre os algoritmos de reconstrução classificados como iterativos está o método proposto por Kim, Webster e Tompkins (1983), que propõe uma forma de perturbar a matriz de sensibilidades de tal forma a corrigir em cada iteração a distribuição de condutividades estimada. Outros algoritmos iterativos bem conhecidos são os baseados no método de Newton-Raphson (PRESS et al., 1999), tais como o "Modified Newton-Raphson" (YORKEY; WEBSTER; TOMPKINS, 1987), o algoritmo NOSER - "Newton's One Step Error Reconstruction” (CHENEY et al., 1990), que obtém a imagem na TIE em apenas uma iteração, e outros (WOO et al., 1993; EDIC et al., 1995, 1998).

Um crescente número de trabalhos vem explorando diversos algoritmos de reconstrução de imagens aplicáveis à TIE (BARBER, 1989; CHENEY; ISAACSON; NEWELL, 1999; BORCEA, 2002), tendo em vista um objetivo comum: melhorar a qualidade de imagem da TIE e aumentar a velocidade de obtenção da imagem. Os algoritmos não-iterativos levam vantagem no que diz respeito a velocidade de obtenção de imagem, porém ignoram o efeito da não-linearidade do problema de obtenção de imagem na TIE, levando a imprecisão da estimação obtida. Os algoritmos iterativos são mais sensíveis a ruídos nos dados fornecidos ao algoritmo e a imagem é obtida num tempo maior, contudo permitem estimar valores absolutos de condutividades com uma precisão maior. Neste trabalho, o algoritmo aplicado para a obtenção de imagens na TIE é baseado no processo iterativo do Método de Otimização Topológica (BENDSøE; KIKUCHI, 1988), que por ser objeto de estudo deste trabalho, é descrito com mais detalhes no capítulo 3.

\subsection{Conceito Básico e Aplicações da TIE}

A TIE é uma técnica para estimação da distribuição de condutividades no interior de um corpo mediante informação de voltagens medidas na parte externa do corpo. Uma revisão sobre sobre a teoria desta técnica de tomografia pode se encontrada em Borcea (2002). Uma cinta de eletrodos é colocada na superfície do corpo, em torno da seção transversal que deseja observar. Aplica-se corrente elétrica num par de eletrodos e os potenciais elétricos que surgem nos demais eletrodos são medidos e registrados por um sistema de aquisição de dados (BOONE et al., 1997).

A corrente elétrica é aplicada nos eletrodos seguindo um certo padrão de excitação, que pode ser adjacente ou diametral. No padrão adjacente, a corrente elétrica entra por um eletrodo e sai por outro eletrodo vizinho (BARBER, 1989; ISAACSON; CHENEY; NEWELL, 1992). Já, no padrão diametral a corrente 
elétrica entra por um eletrodo e sai por outro diametralmente oposto (CHENEY; ISAACSON, 1992; AVIS; BARBER, 1994). Em ambos os padrões o par de eletrodos excitado é alternado sucessivamente em torno da seção transversal do corpo até se obter um conjunto de observações linearmente independentes, determinado pelo número de eletrodos utilizados (SEAGAR; BABER; BROWN, 1987; TANG et al., 2002). Assim, o aumento da resolução da imagem na TIE está relacionado com a quantidade de informação de potenciais elétricos obtidos no contorno do domínio submetido à tomografia, portanto para aumentar a resolução é conveniente aumentar o número de eletrodos posicionados ao redor do corpo (FUKS, 1991; TANG et al., 2002).

Geralmente na TIE, aplica-se corrente elétrica alternada (AC) (LAWRENCE, 1996). Em aplicações médicas, a corrente contínua (DC) provoca corrosão no eletrodo devido uma ação eletrolítica no contato do eletrodo com a pele do paciente, podendo causar a formação de úlceras na pele na região do contato (BROWN, 1983). A faixa de intensidade e freqüência de corrente alternada aplicada na TIE varia conforme a aplicação da TIE. Por exemplo, nas aplicações para a área médica a intensidade e freqüência variam de 1 a $10 \mathrm{~mA}$ (miliampère) e $10 \mathrm{kHz}$ a $1 \mathrm{MHz}$, respectivamente (NEWELL; GISSER; ISAACSON, 1988).

Conhecendo-se os valores de potenciais elétricos (voltagem), medidos nos eletrodos, um computador acoplado ao hardware da TIE recebe os valores de voltagem lidos pelo sistema de aquisição de dados e através de um algoritmo de reconstrução procede a estimação da distribuição de condutividades no interior da seção do corpo, associando a uma imagem gráfica (GISSER et al., 1988; RIGAUD et al., 1993). Pode-se dizer que a imagem obtida é uma distribuição de condutividades (ou resistividades) que minimiza uma particular "função-erro" definida por um algoritmo de reconstrução (COOK et al., 1994; RIGAUD; MORUCCI, 1996; CHENEY; ISAACSON, 1991).

Aspectos teóricos da obtenção de imagem através da TIE mostram que é possível estimar uma distribuição uniforme de condutividades oriundas de materiais isotrópicos a partir de medidas de voltagens, desde que essas medidas sejam infinitamente precisas e tomadas em todos os pontos do contorno da seção do corpo (KOHN; VOGELIUS, 1984, 1985; SYLVESTER; UHLMANN, 1986, 1987). Porém, na prática essas condições não são atingíveis devido as limitações em se medir de forma precisa os valores de voltagens através do aparato eletrônico utilizado na TIE (METHERALL, 1998; BERTEMES-FILHO, 2002), de onde se extrai um número finito de medições de voltagens através de um número determinado de eletrodos em torno da seção do corpo (TANG et al., 2002). Na literatura 
encontram-se diversos algoritmos de reconstrução, com diferentes estratégias adotadas para lidar com essas limitações da TIE (YORKEY; WEBSTER; TOMPKINS, 1987). Mais detalhes sobre algoritmos de reconstrução utilizados para obtenção de imagem na TIE podem ser vistos nas seções 2.3 e 2.5 deste capítulo.

Devido a sua natureza, a TIE tem potencial aplicação na geofísica (DINES; LYTLE, 1981), em ensaios com testes não-destrutivos (EGGLESTON et al., 1989), em processos industriais (DICKIN et al., 1992; YORK, 2001) e recentemente em aplicações médicas (HOLDER, 1993), sendo esta última descrita com mais detalhes na seção 2.5 deste capítulo. Na geofísica a TIE pode ser aplicada para localizar depósitos de minerais subterrâneos (PARKER, 1984), monitorar o fluxo de fluidos subterrâneos para fins de extração de petróleo (RAMIREZ et al., 1993) e detectar contaminantes químicos dissolvidos em águas subterrâneas (D'ANTONA; ROCCA, 2002; D'AnTONA et al., 2002). Em ensaios com testes não-destrutivos, a TIE pode ser usada para detecção de fissuras internas, bolhas e corrosão em peças mecânicas (LAZAROVITCH; RITTEL; BUCHER, 2002; SANTOSA; VOGELIUS, 1991; SANTOSA; KAUP; VOGELIUS, 1996). Visualização de bolhas em escoamento de fluidos bifásicos (XIE et al., 1992; CHO; KIM; LEE, 1999; JEON et al., 2004; GEORGE et al., 2000; KIM et al., 2001), monitoramento contínuo da operação de separação de misturas líquido-líquido ou sólido-líquido em hidrociclones (WILLIAMS et al., 1999; GUTIERREZ et al., 2000; BENNETT; WILLIAMS, 2004) e acompanhamento do processo de queima de combustível de máquinas de combustão interna (WATERFALL; HE; BECK, 1997) são exemplos de aplicações industriais da TIE.

\subsection{Aplicações Médicas da TIE}

Aplicada a área médica, a TIE é uma técnica de monitoração em tecidos biológicos que, basicamente, consiste na obtenção da imagem de uma seção transversal do corpo do paciente, onde cada ponto ("pixel") na imagem representa a sua resistividade elétrica estimada, a partir de injeção de corrente elétrica em eletrodos posicionados ao redor dessa seção (CHENEY; ISAACSON; NEWELL, 1999). Nesta seção, é mostrado o histórico da TIE aplicada a área médica, bem como suas possíveis aplicações clínicas.

\subsubsection{Histórico}

Os primeiros estudos e formulações teóricas para implementação de algoritmos (softwares) e hardwares de reconstrução de imagem que fundamentaram a TIE 
em aplicações clínicas surgiram na década de 80 na Universidade de Sheffield (Inglaterra). Pesquisadores desta universidade estudaram a técnica de TIE, e descreveram as razões do interesse para aplicação clínica da TIE como, por exemplo, no monitoramento de funções pulmonares, cardíacas e gástricas, e chamaram a atenção para futuros desenvolvimentos desta técnica de tomografia (BARBER; BROWN, 1984). Eles são praticamente os pioneiros na formulação de teorias e obtenção de dados que baseiam a TIE até o presente momento na área médica. É deles o desenvolvimento e a patente do primeiro aparelho comercial de TIE. Este aparelho é baseado no método de "backprojection" e possui um sistema denominado de APT ("Applied Potencial Tomography") (BARBER; BROWN, 1984), que é composto por uma fonte simples de corrente elétrica, 16 eletrodos e utiliza o padrão adjacente para aplicação da corrente elétrica. Embora este sistema APT permita apenas obter imagens de baixa resolução, ele tem sido utilizado em estudos de vários procedimentos médicos como o monitoramento do fluxo de sangue no tórax e problemas de colapso no pulmão (HOLDER, 1993), por exemplo.

Na década de 90, diversos pesquisadores desenvolveram outros projetos e instrumentações experimentais que avaliam o método de "backprojection" para a TIE (SANTOSA; VOGELIUS, 1990; GUARDO et al., 1991) e descreveram a importância da obtenção dos resultados experimentais nos denominados fantomas ("phantons") (PAULSON; BRECKON; PIDCOCK, 1992; KERNER et al., 2000). Por exemplo, pesquisadores do Rensselear Polytechnic Institute (EUA) projetaram e construíram um outro aparelho de TIE com um sistema denominado de ACT ("Adaptive Current Tomography") (CHENEY; ISAACSON; NEWELL, 1999), que é capaz de obter 20 imagens estáticas por segundo e utiliza 32 eletrodos. Este aparelho utiliza um método "rápido" (relativo) de reconstrução de imagem baseado no algoritmo de Newton de Uma Iteração ("NOSER") (CHENEY et al., 1990; HYARIC A.L., 2000).

No Brasil, o desenvolvimento de algoritmos e hardwares para a TIE vem sendo feito por pesquisadores da Universidade de São Paulo num projeto temático que visa estudar as técnicas de reconstrução de imagem aplicadas a um aparelho de TIE para monitorar de forma precisa a ventilação artificial do pulmão (AMATO, 2001). Nesse projeto, alguns trabalhos já foram realizados, como as publicações de Trigo, Gonzalez-Lima e Amato (2004) que propõem a aplicação de um algoritmo de reconstrução que utiliza o Filtro de Kalman Estendido (SORENSON, 1985; TRIGO, 2005) para a estimação da distribuição de condutividades absolutas na TIE, a dissertação de Molina (2002) que estuda o refinamento iterativo da malha 
de elementos finitos do domínio discreto para reduzir os erros numéricos no Filtro de Kalman Estendido e a dissertação de Miranda (2003) que utiliza o método iterativo de Newton-Raphson para estimar a distribuição de condutividades.

\subsubsection{Aplicações Clínicas}

Nas últimas duas décadas a TIE vem se tornando uma alternativa real para obtenção de imagens médicas em diversas aplicações clínicas, tais como detecção de hemorragias intraventricular em bebês prematuros (MURPHY et al., 1987), monitoramento do funcionamento gástrico e do processo de lavagem estomacal (MANGNALL et al., 1987), deteç̧ão de embolia pulmonar (HARRIS et al., 1988), monitoramento da apnéia (WOO et al., 1992), detecção de câncer de mama (MURUGAN, 1999; ZOU; GUO, 2003), monitoramento do fluxo sanguíneo e das funções cardíacas (EYüBOGLU et al., 1987).

Alguns tipos de tumores podem ser tratados com a aplicação de temperatura na região afetada e como a condutividade do tecido humano varia com a temperatura (GRIFFITHS, 1987), a TIE pode ser aplicada neste caso para monitorar o procedimento de terapia com hipertermia (CONWAY, 1987). A variação de volume de sangue nos vasos sanguíneos da cabeça pode provocar variações significativas na condutividade elétrica do cérebro. Assim, recentemente, a TIE também vem sendo testada para a obtenção do mapeamento da distribuição de condutividades do cérebro humano para fins de estudo da epilepsia (HOLDER, 1998).

O presente trabalho se concentra no estudo da aplicação da TIE para o monitoramento preciso da ventilação forçada do pulmão (AMATO et al., 1998; FRERICHS et al., 1998). Assim, uma descrição mais detalhada sobre o assunto pode ser vista a seguir.

\subsection{Aplicações da TIE para o Monitoramento dos Pulmões}

A técnica da TIE é particularmente adequada para o estudo da função pulmonar devido as grandes variações de resistividade no pulmão induzidas pelo movimento do ar, sangue ou fluido extravascular no tórax (HARRIS et al., 1987). Por exemplo, o pulmão é um órgão cujo valor da resistividade está em torno de 7,2 $\Omega m$ quando o ar é expirado, porém esse valor varia bastante conforme o ar é inspirado, alcançando 23,6 $\Omega m$ (BARBER, 1989, 1990). Esta característica possibilita a 
aplicação da TIE para estimar a variação na distribuição de resistividades (ou condutividades) do pulmão durante o seu funcionamento e conseqüentemente diagnosticar se alguma região dele está com acúmulo de líquido ou colapsada (NEWELL et al., 1996). A ventilação forçada dos pulmões (AMATO et al., 1998; FRERICHS et al., 1998) é uma aplicação bastante típica da TIE nesta área. A idéia de se observar a variação da impedância do toráx por meio da ventilação artificial é antiga (WITSOE; KINNEN, 1967). Porém, o uso da técnica da TIE para este fim teve início na década de 80, quando Harris et al. (1987) mostrou que a variação de condutividade de uma respiração prolongada pode ser observada através de imagens de TIE, conseguindo a monitoração da ventilação forçada do pulmão com mais ou menos $10 \%$ de precisão (HARRIS et al., 1988).

O comportamento da variação da condutividade dos pulmões com relação ao seu peso próprio (efeitos gravitacionais) também pode ser investigado com auxílio da TIE (HARRIS et al., 1988), sendo que neste caso nota-se que a impedância do pulmão é bastante dependente da postura do corpo (FRERICHS; HAHN; HELLIGE, 1996). As primeiras imagens de TIE que mostram o movimento do fluxo sanguíneo do coração para os pulmões e vice-versa e a relação entre os volumes envolvidos, durante o ciclo cardíaco foram demonstradas ainda na década de 80 (EYüBOGLU et al., 1987; MCARDLE, 1992), o que significou um avanço na aplicação da TIE também para monitoramento do sincronismo cardio-pulmonar. Desta maneira, comparando as imagens da ventilação forçada do pulmão e as do sincronismo cardio-pulmonar, os pesquisadores da época notaram que a TIE também pode ser utilizada para detecção de defeitos na irrigação de sangue para o pulmão (EYüBOGLU, 1988). Além disso, observaram também que através desta técnica é possível identificar a presença da artéria pulmonar e a parte venosa, permitindo constatar que nas regiões afetadas por embolia pulmonar a parte venosa se torna dominante (LEATHARD et al., 1994).

Após estes primeiros estudos, outros trabalhos surgiram durante as duas últimas décadas para consolidar a TIE na aplicação do monitoramento da função pulmonar. Por exemplo, Smulders e Oosterom (1992) propuseram uma aplicação da TIE para determinação do volume do pulmão para fins de pletismografia (registro das modificações de tamanho do pulmão, devido aos fenômenos circulatórios que ocorrem nele). Woo et al. (1992) propuseram outra aplicação onde a TIE é utilizada para monitoramento da apnéia e detecção de edema pulmonar. Adler et al. (1997) realizaram experiências em tórax caninos para investigar a capacidade da TIE em obter de forma precisa os valores de resistividade de volumes de gás e de líquido induzidos nos pulmões e concluiu 
que a técnica é perfeitamente capaz para este fim. Além disso, Frerichs et al. (1998) verificaram e atestaram a capacidade da TIE para acompanhar o desenvolvimento de lesões e conseqüente agravamento do pulmão na ventilação forçada. Várias aplicações recentes da TIE propostas para o monitoramento da ventilação forçada do pulmão podem ser encontradas em Noble et al. (1999), Frerichs (2000), Genderingen, Vught e Jansen (2003) e Hinz et al. (2003).

Porém, neste tipo de aplicação da TIE os pesquisadores lidam com um grande problema: a mudança de posicionamento dos eletrodos devido a expansão do toráx durante a respiração. Isto modifica a resistência do contato entre pele e eletrodo, bem como pode induzir erros no algoritmo de reconstrução e prejudicar a qualidade da imagem obtida. Maiores detalhes sobre esse efeito da expansão do tórax nas voltagens medidas nos eletrodos e na distribuição de condutividades estimadas pela TIE são descritos em Adler, Guardo e Berthiaume (1996).

\subsection{Considerações Finais}

\subsubsection{Imagem Absoluta e Imagem Relativa}

Na TIE, uma imagem absoluta (ou estática) se refere a obter na tomografia uma distribuição de propriedades (condutividade ou resistividade) "congelada" num dado instante de tempo. Desta forma, é possível quantificar, através da imagem obtida, os valores absolutos de condutividades na seção do corpo, por exemplo. Neste caso, a precisão nos valores das voltagens medidas e calculadas na TIE é de fundamental importância para garantir uma imagem confiável. Obter os valores absolutos de resistividade na TIE pode ser útil em aplicações médicas, tais como o monitoramento do pulmão. A variação da resistividade no pulmão é bastante significativa durante a respiração, portanto conhecendo os valores absolutos dessa propriedade em cada ponto da imagem obtida, o médico pode identificar qual região do pulmão contém mais ou menos ar e se existe alguma região com líquido em excesso, por exemplo.

A obtenção de imagens relativas na TIE está relacionada com distribuição de condutividades estimadas a partir de dois instantes diferentes de tempo, tomando um deles como referencial. Essas imagens são úteis para monitorar o fluxo de um processo no tempo. Por exemplo, o monitoramento da função pulmonar durante a respiração. Neste caso, o médico pode usar as imagens relativas para acompanhar o crescimento ou não de alguma anomalia que ocorra no pulmão. Como esse monitoramento ocorre praticamente em tempo real, o algoritmo utilizado para 
gerar a imagem deve ser "rápido", portanto o uso de métodos não-iterativos, neste caso, é a melhor opção.

$\mathrm{Na}$ literatura, uma parte dos estudos em TIE concentram-se no desenvolvimento de métodos para obtenção de imagens relativas, e outra para obtenção de imagens absolutas, as quais vêm sendo investigadas utilizando-se aplicação inédita de diversos métodos originais, tais como os algoritmos baseados no método de Newton-Raphson (YORKEY; WEBSTER; TOMPKINS, 1987; CHENEY et al., 1990; EDIC et al., 1995), no Filtro de Kalman (VAUHKOnEN; KARJALAINEN; KAIPIO, 1998; TRIGO; GONZALEZ-LIMA; AMATO, 2004) e nos Algoritmos Genéticos (OLMI; BINI; PRIORI, 2000). O algoritmo de otimização topológica aplicado a TIE, em estudo neste trabalho, é projetado para fornecer imagens absolutas.

\subsubsection{Demais Considerações}

Do ponto de vista da Engenharia, a TIE vem sendo tratada pela maioria dos autores como um problema de estimação de parâmetros de um modelo não-linear que representa a distribuição de condutividades ou resistividades de um domínio. Supõe-se conhecidos os padrões de excitação do sistema e a estrutura do modelo e são medidos os potenciais elétricos no contorno da região. De acordo com resultados preliminares coletados na UTI-Respiratória do Hospital das Clínicas, embora as imagens geradas pelos algoritmos e dispositivos de tomografia atuais serem adequadas para alguns tipos de diagnóstico em Pneumologia (AMATO, 2001), elas devem ser bastante melhoradas para o monitoramento preciso do pulmão nestes diagnósticos. Em particular, o método tradicional de "backprojection" aplicado a TIE (SANTOSA; VOGELIUS, 1990) deforma a imagem consideravelmente, forçando a distribuição de condutividades a se projetar sobre um círculo. Como conseqüência, além de uma imagem pulmonar anatomicamente distorcida, o cálculo das variações da ventilação regional e da aeração pulmonar é distorcido nas regiões mais anteriores e mais posteriores do pulmão, prejudicando uma aplicação clínica apropriada. Além disso, a grande maioria dos algoritmos (incluindo os baseados no "backprojection") não estima a condutividade absoluta do meio, mas variações de condutividade entre dois instantes (imagem relativa). Como mencionado anteriormente, a obtenção da imagem na TIE (solução do problema inverso) está sendo estudada utilizando-se a aplicação inédita de diversos tipos de métodos originais, os quais vêm sendo comparados com métodos já estabelecidos, para verificar os diferentes desempenhos, os efeitos sobre as 
propagações de erros numéricos, e a estabilidade frente a situações limites, e finalmente para identificar as modificações que devem tornar estes métodos de estimação mais efetivos. 


\section{Método de Otimização Topológica}

\subsection{Introdução}

Essencialmente, a Otimização Topológica (OT) busca a distribuição de material no interior de um domínio de projeto, retirando e adicionado material em cada ponto desse domínio de maneira a minimizar (ou maximizar) uma função objetivo especificada, satisfazendo dadas restrições impostas ao problema de otimização. A figura 3.1 ilustra o processo da otimização topológica em um exemplo clássico de maximização de rigidez de uma estrutura com restrição de peso. No caso, por questões de economia de tempo computacional, somente metade da viga é modelada.

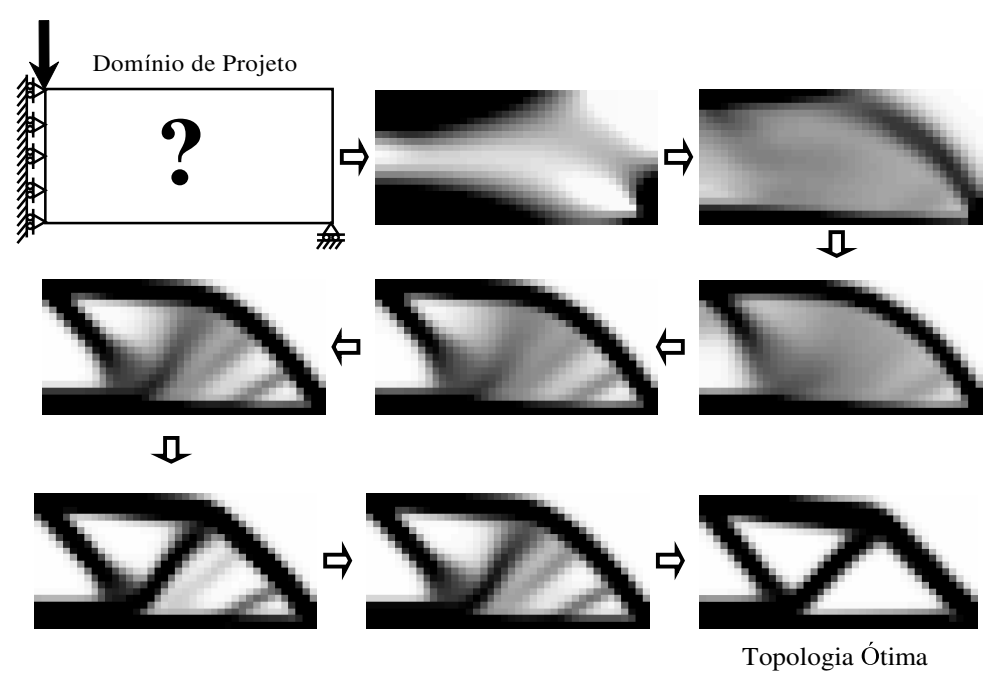

Figura 3.1: Exemplo de aplicação da otimização topológica.

Diferente de outros métodos, tais como a Otimização de Forma e Otimização Paramétrica (HAFTKA; GANDHI, 1986), a OT não requer nenhum conhecimento prévio da topologia, que é obtida iterativamente a partir de um valor inicial qualquer de distribuição de material. Neste trabalho, um algoritmo de otimização topológica poderoso, conhecido por Método de Otimização Topológica (MOT) (BENDSøE; KIKUCHI, 1988), é utilizado para encontrar de forma iterativa a 
distribuição ótima de material. Este algoritmo combina essencialmente métodos de otimização (VANDERPLAATZ, 1984) com um método numérico de análise, como por exemplo o Método dos Elementos Finitos (MEF) (BATHE, 1996). Outros métodos numéricos de análise podem ser utilizados, no entanto devem ser genéricos o suficiente de forma a lidar com geometrias complexas, como é o caso da seção de um tórax humano.

Desde sua introdução nos EUA e Europa, no final da década de 80, o MOT tem ganhado destaque no meio acadêmico e na indústria (BENDSØE; SIGMUND, 2003). A seguir, são descritos uma introdução da história do MOT, a sua aplicação a projetos que lidam com meios condutivos e os principais conceitos que baseiam o método.

\subsection{Breve Histórico do MOT}

A otimização topológica surgiu da necessidade de se aprimorar as técnicas de otimização existentes (VANDERPLAATZ, 1984; HAFTKA; GüRDAL; KAMAT, 1996) para permitir a viabilidade de uma distribuição de material mais acentuada no interior do domínio da estrutura e de forma sistemática. No final da década de 80, Bendsøe e Kikuchi (1988) introduziram uma metodologia alternativa para a otimização, baseada no princípio em se fixar o domínio inicial da estrutura e portanto manter inalterado o modelo de elementos finitos utilizado no processo de otimização. Desta maneira, surge a metodologia para otimização topológica de estruturas mecânicas, baseada no conceito de domínio fixo estendido de projeto e, inicialmente, no método da homogeneização (ALLAIRE, 2002). O MOT é um tema recente no campo da otimização, porém os conceitos básicos que dão suporte teórico ao método foram estabelecidos a mais de um século. Rozvany, Bendsøe e Kirsch (1995) e Bendsøe (1995) faz uma boa revisão desses conceitos. A metodologia criada por Bendsøe e Kikuchi (1988) para a OT, foi fortemente inspirada nas conclusões obtidas por Cheng e Olhoff (1981), cujos trabalhos lidam com otimização da distribuição de espessuras em placas e chapas. Eles investigaram a formulação matemática para o problema de maximização de rigidez (com restrição de volume) de placas delgadas, onde a variável de projeto é a espessura da placa, e concluíram que para este problema de otimização existem várias soluções ótimas locais. Ou seja, os resultados encontrados por eles indicam que a solução ótima é uma placa que, ao longo da espessura, é composta por regiões com infinitos reforços infinitesimais (nervuras), cujo comportamento é similar a de um material composto por infinitas microestruturas (HASSANI; 
HILTON, 1998). Em termos matemáticos a introdução de uma microestrutura na formulação de um problema de otimização requer a relaxação do variacional do problema para permitir a otimização (KOHN; STRANG, 1986). Bendsøe (1989) descreve várias maneiras de se conseguir a relaxação mencionada acima através da introdução de um modelo de material baseado na distribuição de densidades na microestrutura.

Originalmente o MOT foi desenvolvido para projetos de maximização de rigidez de estruturas mecânicas (SUZUKI; KIKUCHI, 1991) e recentemente tem sido expandido com sucesso para várias outras aplicações. Díaz e Bendsøe (1992) apresentaram uma formulação para o problema de maximização de rigidez de estruturas elásticas submetida a várias cargas não simultâneas. Thomsen (1992) trataram numericamente uma extensão do método aplicada a otimização de estruturas compostas por mais de um material. Problemas de otimização topológica considerando freqüência de ressonância em estruturas contínuas são descritos em Díaz e Kikuchi (1992). Enquanto isso, problemas de flambagem usando o MOT foram resolvidos por Neves, Rodrigues e Guedes (1995). Rodrigues e Fernandes (1995) descreveram a OT de estruturas termoelásticas submetidas a cargas térmicas. Além das aplicações na área estrutural clássica, a utilização do MOT expandiu-se para outras áreas de projeto. Por exemplo, a aplicação do método por Anathasuresh, Kota e Gianchandani (1994) em projetos de mecanismos flexíveis motivou o surgimento de vários trabalhos nesta área (NISHIWAKI et al., 1998; SIGMUND, 1997). A dissertação de mestrado de Lima (2002) traz uma boa revisão sobre projeto de mecanismos flexíveis usando o MOT. Problemas de maximização da condutividade térmica na transferência de calor são resolvidos em Park (1995). Atualmente a metodologia da OT está bem estabelecida, tornando-se evidente em várias linhas de projetos. Dentre eles, os projetos de atuadores piezelétricos (SILVA; FONSECA; KIKUCHI, 1997; SILVA; NISHIWAKI; KIKUCHI, 2000), projetos de micromecanismos flexíveis com atuação térmica (JONSMANN; SIGMUND; BOUWSTRA, 1999), projetos de estruturas sob atuação de campos magnéticos (YOO; KIKUCHI, 2000), entre outros. Recentemente, Byun, Park e Hahn (2002) também aplica o MOT ao projeto de micro-atuadores eletrostáticos, onde distribuem um material dielétrico no domínio de um rotor com o objetivo de obter o máximo torque, maximizando a diferença de energia do sistema em duas posições distintas do rotor (BYUN; PARK; HAHN, 2002; BYUN; LEE; PARK, 2004). 


\subsection{Aplicações do MOT para Meios Condutivos}

Park (1995) mostra em seu trabalho uma extensão da aplicação do MOT para obtenção da melhor distribuição de materiais altamente condutivos num domínio aplicada a problemas de transferência de calor em estado estacionário ("steady state"). Neste caso, a formulação do problema de otimização topológica é baseada no conceito de analogia entre as formulações matemáticas da elasticidade linear e da transferência de calor no estado estacionário, onde observa-se que embora sendo os tensores de condutividade térmica $\left(K_{i j}\right)$ e de elasticidade $\left(E_{i j k l}\right)$ de ordens diferentes (segunda e quarta ordem, respectivamente) podemos estabelecer uma analogia entre as variáveis envolvidas nos dois problemas distintos de otimização (temperatura e deslocamento, fluxo de calor e tensão, gradiente de temperatura e deformação, etc). Assim, desde que estabelecida esta analogia, o problema de encontrar a ótima distribuição de material altamente condutivo num domínio corresponde a encontrar a melhor topologia possível para um determinado caso onde deva-se distribuir no interior do domínio de projeto material de alta rigidez. Conforme mostra Park (1995), para obtermos uma estrutura altamente rígida no problema de elasticidade linear a energia total de deformação deve ser minimizada, de forma análoga para obtemos um domínio com alta condutividade no problema de transferência de calor a energia potencial total é minimizada.

Devido à natureza, o MOT também pode ser aplicado para a solução de problemas inversos para mapeamento da distribuição de propriedades físicas (condutividade, resistividade e permissividade) no interior de um domínio qualquer. Porém, na literatura encontram-se poucas aplicações deste tipo.

Byun et al. (2000) utiliza o MOT para mapear dois materiais inseridos num domínio quadrilátero, cuja relação entre suas permissividades relativas $\left(\varepsilon_{r}\right)$ é de 1 para 10. Eles utilizam os conceitos de energia mútua (COOK; YOUNG, 1985) para computar rapidamente o cálculo dos gradientes da função objetivo, dada pela minimização da diferença quadrática entre voltagens medidas e calculadas, e um algoritmo de otimização baseado em análise de sensibilidade (cálculo de gradientes) para atualizar as variáveis de projeto a cada iteração do MOT. Kang et al. (2002) apresentaram um algoritmo para reconstrução de um objeto dielétrico 2D imerso num meio de alta permissividade. O algoritmo baseia-se no MOT e na técnica FDTD ("Finite-Difference Time Domain"), que é uma técnica comum para modelagem e simulação de campos eletromagnéticos (CHUNG; CHEON; HAHN, 2000). Eles utilizam as microondas como fonte de 
excitação para estimar a distribuição de permissividade do meio e do objeto dielétrico inserido.

Neste presente trabalho, o mapeamento da distribuição de condutividades (ou resistividades) de um material dielétrico inserido num meio condutivo, aplicado a TIE, é feito através de um algoritmo de reconstrução baseado no MOT, com aplicação do SIMP, do MEF e da Programação Linear Sequencial (PLS).

\subsection{Conceitos Fundamentais do MOT}

Do ponto de vista do MOT, a topologia a ser otimizada pode ser representada por uma função discreta $\chi(x)$, definida em cada ponto $(x)$ do domínio $(\Omega)$, da seguinte maneira:

$$
\chi(x)=\left\{\begin{array}{l}
1 \text { se } x \in \Omega \\
0 \text { se } x \in \Omega / \Omega_{D}
\end{array}\right.
$$

onde $\Omega_{D}$ é a região onde há presença de material, inserida no domínio $(\Omega)$. Sendo o material isotrópico, podemos escrever:

$$
C(x)=\chi(x) C_{0}
$$

onde $C_{0}$ é o tensor constitutivo do material base.

Fisicamente, a função discreta $\chi(x)$ define se o ponto $(x)$ do domínio é preenchido totalmente com material ou é um vazio, não havendo estágios intermediários. Porém, a parametrização discreta, ou seja, a condição em que cada ponto do domínio assume somente material tipo "A" ou somente material tipo "B", não apresenta solução para o problema devido sua dependência a discretização, a menos que seja introduzida uma restrição de complexidade, como a restrição de perímetro (HABER; JOG; BENDSOE, 1996). Uma outra maneira de obter a solução é relaxar o problema, ou seja, permitir que as variáveis de projeto assumam valores intermediários entre "A" e "B", através de um modelo de material que substitua a função discreta da equação (3.2) por uma contínua (CHEnG; OLHOFF, 1982; BEndsøe, 1989). Segundo Kohn e Strang (1986), um modelo de material que fornece uma função contínua e consistente das propriedades do material em cada ponto do domínio, garante a existência da solução do problema de otimização topológica. A aproximação contínua para o problema discreto da OT é amplamente utilizado em diversas aplicações do MOT, porém também são encontrados na literatura propostas de algoritmos de OT que lidam diretamente com o problema discreto (BECKERS, 1999; SVANBERG; 
WERME, 2005).

A formulação do MOT utilizada neste trabalho é baseada em dois conceitos fundamentais: domínio fixo de projeto e modelo de material (BENDSØE, 1995). A seguir, esses dois conceitos são detalhados, para maiores esclarecimentos.

\subsubsection{Domínio Fixo de Projeto}

O domínio fixo de projeto $(\Omega)$ consiste num domínio com geometria fixa, limitado pelas condições de contorno do problema e onde ocorre a distribuição de material. O objetivo da otimização topológica é determinar a distribuição ótima de propriedades de materiais no interior do domínio fixo de projeto. $\mathrm{Na}$ implementação numérica, o domínio fixo de projeto é discretizado em elementos finitos e sua malha de elementos finitos não é alterada durante o processo de otimização, sendo alterada somente a distribuição de material nos elementos. Como o domínio é fixo, o processo de otimização se torna bastante vantajoso, pois as derivadas de uma função contínua qualquer $(f)$, definida no domínio, são facilmente calculadas usando a seguinte expressão:

$$
\frac{\partial}{\partial \rho} \int_{\Omega} f d \Omega=\int_{\Omega} \frac{\partial f}{\partial \rho} d \Omega
$$

onde $\rho$ é uma variável de projeto.

\subsubsection{Modelo de Material}

No algoritmo de OT adotado neste trabalho, o material em cada ponto do domínio pode variar de um material "A" a um material "B" assumindo materiais intermediários entre "A" e "B" de acordo com uma equação matemática que define a mistura de dois ou mais materiais. Por exemplo, numa aplicação à TIE, o material "A" poderia representar o tecido dos pulmões e o material "B" a presença de ar nos pulmões. Assim, as variáveis de projeto do problema de otimização topológica são as variáveis que definem a mistura de material em cada ponto do domínio de projeto.

Existem vários modelos de material que podem ser utilizados, dentre eles o chamado método de densidades ou SIMP ("Simple Isotropic Material with Penalization") (ZHOU; ROZVANY, 1991; MLEJNEK, 1992) e o método da homogeneização (BENDSøE; KIKUCHI, 1988; ALLAIRE, 2002). O método da homogeneização é baseado em microestruturas formadas pela mistura de materiais. Uma revisão sobre esse método pode ser encontrada em Hassani e 
Hilton (1998). Esse método se constitui num modelo de material complexo e robusto para a definição das propriedades efetivas de um material composto, conhecida a geometria e composição de sua microestrutura, porém isso tem um custo - a introdução de muitas variáveis de projeto no problema de otimização topológica, o que torna o MOT desvantajoso devido à complexidade da implementação numérica e ao alto custo computacional.

Neste trabalho, o modelo de material adotado é baseado no SIMP ("Simple Isotropic Material with Penalization"), que permite que as variáveis de projeto do problema (normalizadas entre 0 e 1) variem de uma maneira contínua. Portanto, na seção seguinte é feita a descrição da equação matemática que define o modelo de material adotado para a obtenção de imagem na TIE.

\subsubsection{Modelo Baseado no SIMP}

Por ser um modelo mais simples de implementar e por utilizar somente uma variável de projeto - a densidade relativa do material em cada ponto domínio fixo de projeto, o SIMP vem conquistando a preferência dos pesquisadores em OT. Além disso, esse modelo permite obter um resultado muito semelhante ao obtido usando o método da homogeneização (SIGMUND, 1997; JONSMANN; SIGMUND; BOUWSTRA, 1999).

A equação matemática que define o valor da densidade em cada ponto do domínio $(\Omega)$ no problema relaxado com o SIMP, é dada por:

$$
C(x)=\rho(x) C_{0}
$$

onde $\rho(x)$ é interpretada como uma função (contínua) de distribuição de pseudo-densidades (variável de projeto), com $0 \leq \rho(x) \leq 1$ e $x \in \Omega$. A relação linear produzida pela equação (3.4) nos faz acreditar que, matematicamente, qualquer valor de propriedade efetiva do material, $C(x)$, variando de "zero" (ou um valor bem próximo de zero para evitar o problema de condicionamento numérico) até o valor da propriedade efetiva do material base $\left(C_{0}\right)$ pode ser obtido e é viável. Porém, fisicamente isso não é verdade, pois como o valor da propriedade efetiva do material é definido pela composição dos grãos obtida no processo de fabricação do material, nem todos os valores neste intervalo são atingíveis. No entanto, do ponto de vista prático o interessante é que, através de uma função contínua, se possa alcançar uma solução para o problema de otimização em que a topologia ótima obtida seja composta por materiais cujas propriedades efetivas sejam factíveis. A ocorrência de valores intermediários para a variável de projeto 
estabelece a relaxação do problema de otimização topológica e permite a obtenção de uma solução (KOHN; STRANG, 1986; BENDSøE, 1995), embora implique em obter uma estrutura com regiões de diferentes propriedades de material. Porém, do ponto de vista da aplicação na TIE isto parece não ser um problema pois, neste caso, podemos interpretar os valores intermediários como sendo uma região do corpo cuja imagem é dada por esses valores.

Considerando a aplicação do MOT na TIE para detecção das propriedades de condutividades de dois materiais no interior do domínio (ar e tecido dos pulmões, por exemplo), baseado no SIMP a propriedade efetiva $C(x)$ em cada ponto no domínio é dada da seguinte forma:

$$
C(x)=\rho(x)^{p} C_{A}+\left(1-\rho(x)^{p}\right) C_{B}
$$

onde $C_{A}$ e $C_{B}$ são os tensores constitutivos dos materiais básicos que compõem o domínio. A função contínua $\rho(x)$ podem variar de 0 (indicando a presença somente do material do tipo "B") à 1 (indicando a presença somente do material do tipo "A"). Valores intermediários de $\rho(x)$ indicam a mistura dos dois materiais e são conhecidos como "escala de cinza" na teoria do MOT. O expoente $p$ é o fator de penalidade desses valores intermediários (BENDSøE; SIGMUND, 1999) e sua aplicação na equação (3.5) é discutida a seguir.

\subsubsection{Fator de Penalidade $(p)$ do SIMP}

Sabendo-se que existe somente dois tipos de material no domínio, o MOT deve ao final do processo classificar cada ponto do domínio em material com propriedade $C_{A}$ e material com propriedade $C_{B}$, porém conforme visto a formação de materiais intermediários ("escalas de cinza") é inevitável. No entanto, esse efeito pode ser minimizado com a utilização do fator de penalidade $(p)$ no processo de otimização, ou seja, permitindo-se que o algoritmo de MOT force a variável de projeto para um valor próximo de 0 ou de 1 , priorizando a formação de um ou outro material extremo $\left(C_{A}\right.$ ou $\left.C_{B}\right)$ na região de interesse.

Para isso, o usual é utilizar um expoente $p>1$. Os gráficos da figura 3.2 mostram o comportamento do modelo de material da equação (3.5) conforme o valor de $p$ é aumentado. São ilustradas duas configurações distintas, uma com $C_{A}>C_{B}$, figura 3.2(a), e outra com $C_{A}<C_{B}$, figura 3.2(b), de onde podemos notar que o aumento no valor de $p$ produz a necessidade de uma grande perturbação no valor de $\rho(x)$ para que o modelo de material da equação (3.5) modifique o valor da propriedade efetiva do material, $C(x)$. Neste caso, o gráfico 
da figura 3.2(a) mostra que a partir de um valor de $p$ elevado o material de propriedade $C_{A}$ é obtido para um conjunto de valores de $\rho(x)$ muito próximos de 1 e para uma faixa de valores de $\rho(x)$ poucos distantes do valor 1 , obtém-se o extremo oposto (material com propriedade $C_{B}$ ). Já, a figura 3.2(b) mostra o contrário, para obter o material de menor valor de propriedade efetiva $C(x)$ os valores de $\rho(x)$ devem ser próximos de 1 .

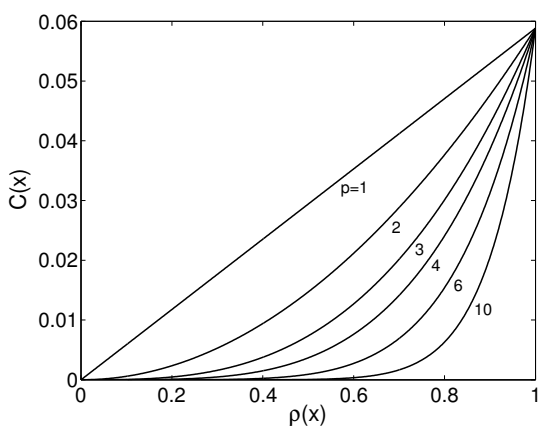

(a) $C_{A}>C_{B}$

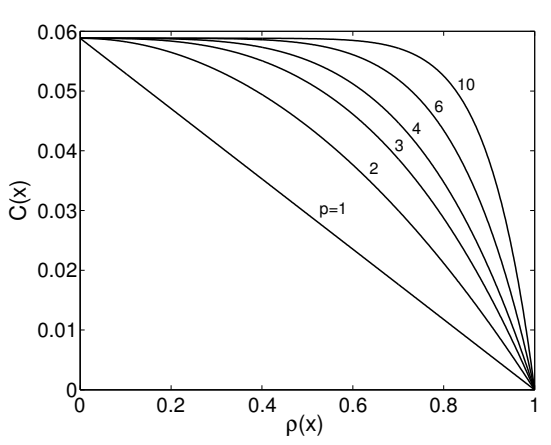

(b) $C_{A}<C_{B}$

Figura 3.2: Comportamento da curva do modelo de material conforme o valor do expoente $p$ é aumentado.

Embora, matematicamente a elevação do valor de $p$ na equação (3.5) produza o efeito do método priorizar a formação dos materiais extremos $\left(C_{A}\right.$ ou $\left.C_{B}\right)$, na prática devemos tomar cuidado quanto a excessiva penalidade dos valores intermediários de $\rho(x)$, pois a medida que aumentamos o valor de $p$ aproximamos cada vez mais o problema contínuo num problema discreto (0-1), conforme observado em Rietz (2001), retornando ao caso da não obtenção da solução do problema de otimização topológica, devido as instabilidades numéricas geradas pela variação brusca da variável de projeto no problema discreto.

Neste trabalho, a segunda configuração $\left(C_{A}<C_{B}\right)$ é adotada, com valor máximo de $p$ igual a 6 , pois em testes realizados com as duas configurações a segunda mostrou-se mais estável numericamente para aplicação do MOT na TIE. Além disso, percebe-se que o efeito da penalização, através do fator $p$, age em conjunto com a restrição do problema de otimização topológica, que também visa ressaltar as propriedades de um determinado material numa região previamente escolhida. Assim, fazendo essa região escolhida assumir valores de $\rho(x)$ próximos de 1, para destacar a imagem de um objeto qualquer no domínio, a segunda configuração $\left(C_{A}<C_{B}\right)$, neste caso, parece produzir uma menor disputa entre a penalização e a restrição do problema (veja gráfico da $3.2(\mathrm{~b})$ ). 


\section{Modelo de MEF da Seção Submetida a Tomografia}

\subsection{Introdução}

Neste trabalho, a distribuição de condutividades é simulada num plano bidimensional (2D), utilizando o MEF e um algoritmo de otimização (a PLS). Neste capítulo veremos as equações da eletricidade que governam o fenômeno da condutividade num corpo, bem como a modelagem matemática do domínio submetido à tomografia (região cuja imagem é desejada), utilizando o MEF para discretizar esse domínio. A impedância de contato entre os eletrodos e superfície do corpo (por exemplo, a pele do paciente) também é considerada.

\subsection{Equações Constitutivas do Meio Condutivo}

Considerando-se a seção do corpo como um domínio fechado $(\Omega)$ e assumindo-se que o meio possui característica puramente condutiva, o campo eletrostático resultante obedece as equações de Maxwell. No caso da TIE, algumas hipóteses simplificadoras são adotadas para reduzir a complexidade do problema. A freqüência da corrente elétrica aplica é considerada baixa e o domínio pode ser considerado como um condutor iônico. Assim, considerando-se nulo todos os gradientes em relação ao tempo, o estado estacionário das equações de Maxwell pode ser aplicado. Este trabalho concentra os estudos na obtenção de imagens dos pulmões, através da TIE usando o MOT. A permeabilidade de tecidos biológicos é muito baixa (DUCK, 1990) e praticamente podemos desconsiderá-la na formulação do meio condutivo. Assim, as equações de Maxwell que governam as propriedades elétricas do meio condutivo podem ser escritas da seguinte forma (HAYT, 1986):

$$
\begin{gathered}
\nabla \cdot \mathbf{E}=\frac{\hat{\rho}}{\varepsilon_{r} \varepsilon_{o}} \\
\nabla \times \mathbf{E}=\mathbf{0}
\end{gathered}
$$


onde $\nabla$ é o operador gradiente, $\mathbf{E}$ é o campo elétrico, $\hat{\rho}$ é densidade de carga, $\varepsilon_{r}$ e $\varepsilon_{o}$ são as permissividades relativa e específica, respectivamente.

Em termos de potenciais elétricos $(\phi)$, o campo elétrico $(\mathbf{E})$ pode ser escrito da seguinte maneira:

$$
\mathbf{E}=-\nabla \phi
$$

Substituindo a equação (4.3) na equação equação (4.1), resulta na equação de Poisson:

$$
\nabla^{2} \phi=-\hat{\rho} / \varepsilon_{r} \varepsilon_{r}
$$

A equação de Poisson pode ser escrita em termos de condutividade. Se considerarmos a forma geral da lei de Ohm para um ponto no interior de um meio condutor, temos:

$$
\mathbf{J}=\sigma \mathbf{E}
$$

onde $\mathbf{J}$ é a densidade de corrente e $\sigma$ é a condutividade. Como não há nenhuma fonte de corrente interna, podemos escrever:

$$
\nabla \cdot \mathbf{J}=\mathbf{0}
$$

Substituindo a equação (4.3) na equação (4.5) e usando a equação (4.6), temos a outra forma da equação de Poisson:

$$
\nabla \cdot(\boldsymbol{\sigma} \nabla \phi)=0
$$

A equação diferencial acima (4.7) possui um número infinito de distribuições $\phi$ que são solução da equação. Para limitar o número de soluções, são aplicadas condições de contorno que determinam alguns parâmetros de controle na superfície do domínio (HAYT, 1986), como veremos a seguir.

\subsection{Modelagem do Meio Condutivo}

Na TIE a corrente elétrica é aplicada em eletrodos posicionados no contorno da seção do corpo cuja imagem é desejada. Desta forma, as condições de contorno para a equação (4.7) são estabelecidas da seguinte maneira:

$$
\begin{cases}\sigma \frac{\partial \phi}{\partial n}=J_{i} & \text { no i-ésimo nó } \\ 0 & \text { nos demais }\end{cases}
$$

A solução do problema constituído pela equação de Poisson, equação (4.7), e condições de contorno, equação (4.8), para uma dada distribuição de condutividades $(\sigma)$ é conhecida como solução do problema direto, ou seja, 
conhecida a distribuição de condutividades no interior da seção do corpo e a corrente elétrica aplicada no contorno da seção, determinam-se os potenciais elétricos nos eletrodos. Kiber (1991) mostra que o potencial $\phi$ é dependente de $\sigma$, da geometria da seção do corpo e do posicionamento dos eletrodos. A solução do problema direto é essencial para a solução do problema inverso da TIE.

Como o domínio submetido à tomografia possui uma geometria complexa (seção do corpo humano), a solução analítica do problema direto da TIE não é facilmente encontrada. Assim, neste trabalho, a solução é obtida numericamente pelo MEF, que é um método de análise robusto, confiável e genérico o suficiente para lidar com domínios de formas complexas (como a seção transversal do tórax de uma pessoa, por exemplo). No MEF, o domínio (submetido à tomografia) é dividido em elementos finitos e analisado através de um modelo, que representa através de matrizes numéricas a geometria, os vínculos (apoios, "aterramento", etc) e o carregamento (força, pressão, corrente, etc) nesse domínio (BATHE, 1996). A formulação do MEF aplicada ao meio condutivo é descrita usando-se as equações constitutivas desse meio, dada pela equações (4.7) e (4.8). A partir do modelo de MEF podemos determinar o potencial elétrico em cada ponto do domínio discreto (MURAY; KAGAWA, 1985).

Neste trabalho, consideram-se domínios planos (2D) para a seção do corpo cuja imagem é desejada, que podem ser divididos em vários elementos finitos planos de diversos tipos e formas. A figura 4.1 ilustra um modelo de MEF do domínio discretizado em elementos finitos.

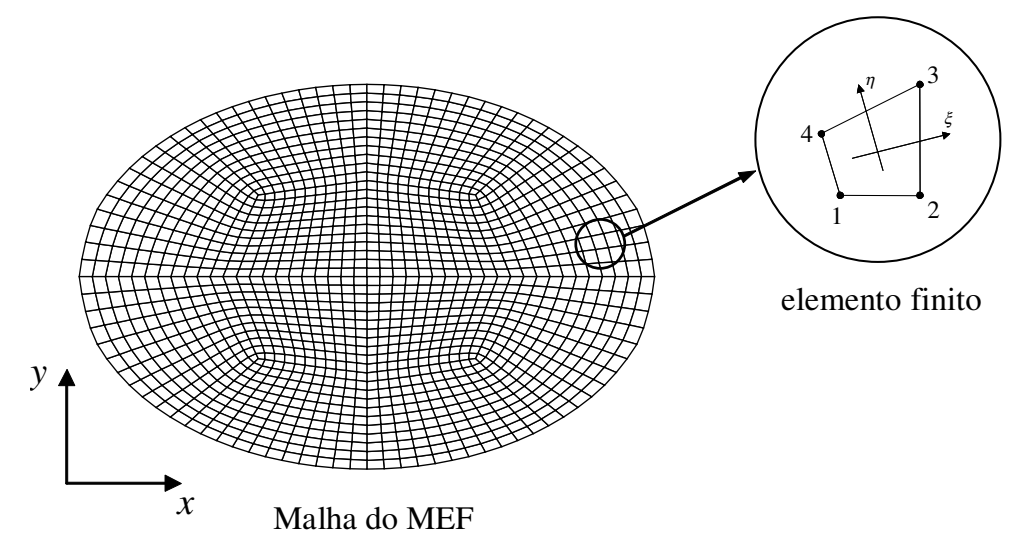

Figura 4.1: Domínio de projeto dividido em elementos finitos.

São testados os elementos finitos triangular de 3 nós e quadrilátero de 4 nós, com um grau de liberdade - o potencial elétrico. Esses elementos possuem formulações matemáticas distintas para simular a distribuição de condutividades no domínio. Na seção seguinte são mostradas as formulações teóricas da matriz de condutividade elétrica desses elementos e na seção 4.5 é feita uma breve descrição 
sobre os cálculos dos potenciais elétricos nodais no MEF.

Apenas como ilustração, a figura 4.2 apresenta um exemplo de domínio em que poder-se-ia construir a imagem mediante informação de valores de voltagens medidos em eletrodos, representados por pontos distribuídos ao longo do contorno. O domínio pode assumir uma geometria qualquer que será discretizada por uma malha de elementos finitos, na qual será realizado o processo iterativo de distribuição de material do MOT. Neste trabalho, assumem-se domínios com geometria circular e elíptica para simular a seção do corpo humano (tórax). No domínio, pode-se identificar regiões que já possuem um tipo de material definido, como osso ou um órgão do corpo do paciente, cujo tamanho e posição são conhecidos. Essas regiões podem ser eliminadas do processo de otimização, porém mantidas na análise por elementos finitos, uma vez que se está interessado apenas na determinação da presença de alguma outra substância estranha ao corpo.

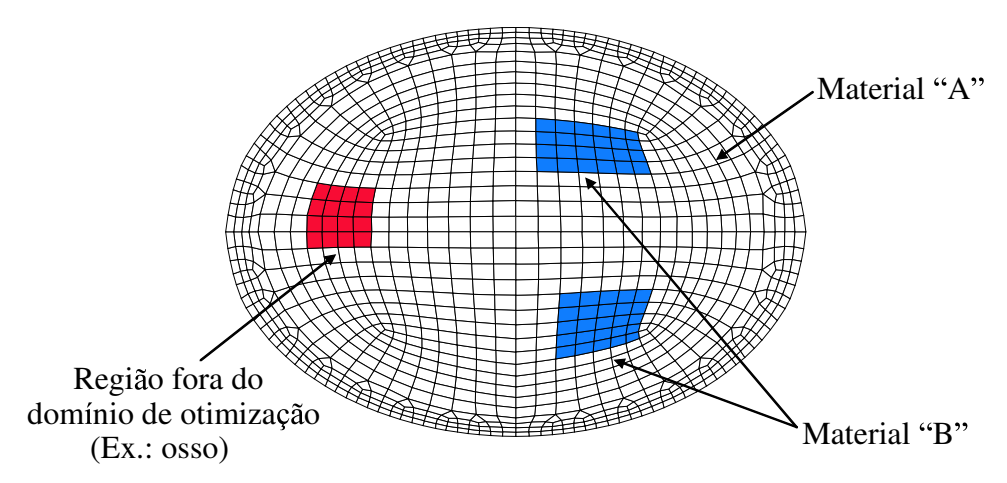

Figura 4.2: Exemplo de domínio de projeto para obtenção da imagem.

\subsection{Matriz de Condutividade do Elemento}

Nesta seção é apresentada a formulação de MEF do domínio discretizado em elementos quadrilátero e triangular, com 4 e 3 nós respectivamente. A figura 4.3 ilustra esses elementos finitos. Esses elementos possuem um grau de liberdade por nó, ou seja, um escalar que representa o valor do potencial elétrico.

O elemento quadrilátero possui uma formulação robusta, que representa com maior fidelidade o campo de potenciais no interior do elemento, porém requer o uso de métodos para solução numérica da integral que define a sua matriz de condutividade elétrica. Já, a formulação do elemento triangular é mais simples, se comparado com a do elemento quadrilátero, pois considera o potencial elétrico no interior do elemento constante. Porém, a sua matriz de condutividade pode ser obtida analiticamente, tornando a sua implementação computacional simples 


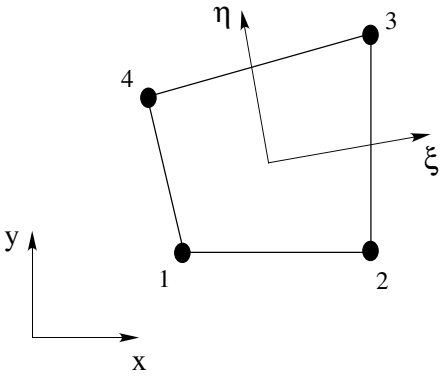

(a) quadrilátero de 4 nós

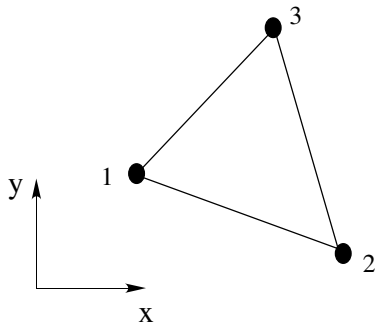

(b) triangular de 3 nós

Figura 4.3: Elementos finitos dos modelos de MEF do domínio de obtenção de imagem.

e livre de aproximações provenientes de algoritmos para integração numérica. O elemento triangular também é mais adequado para modelar o contorno de um domínio com curvatura acentuada. A seguir, nas seções 4.4.1 e 4.4.2, são apresentadas as matrizes de condutividade desses elementos.

\subsubsection{Matriz de Condutividade do Elemento Quadrilátero}

Da teoria do MEF, sabe-se que os graus de liberdade de um elemento finito relacionam-se com os potenciais elétricos nodais da seguinte forma:

$$
\phi=\mathbf{N} \psi
$$

onde $\phi$ é o vetor que contém os potenciais elétricos em cada ponto do elemento, $\boldsymbol{\psi}$ é o vetor dos potenciais elétricos nodais e $\mathbf{N}$ é a matriz das funções de forma que, para o elemento quadrilátero da figura 4.3(a), é composta pelos seguintes polinômios bilineares, dados em coordenadas locais $(\eta, \xi)$ do elemento (BATHE, 1996):

$$
\begin{aligned}
& N_{1}=\frac{1}{4}(1-\xi)(1-\eta) \\
& N_{2}=\frac{1}{4}(1+\xi)(1-\eta) \\
& N_{3}=\frac{1}{4}(1+\xi)(1+\eta) \\
& N_{4}=\frac{1}{4}(1-\xi)(1+\eta)
\end{aligned}
$$

Neste trabalho são utilizados elementos isoparamétricos. Isto significa que as coordenadas de um ponto genérico do elemento $(x, y)$, são obtidas em função das suas coordenadas nodais, usando como função de interpolação os mesmos polinômios bilineares, equações (4.10) a (4.13), da grandeza física $(\boldsymbol{\phi})$. Desta 
forma:

$$
\begin{aligned}
& x=N_{1} x_{1}+N_{2} x_{2}+N_{3} x_{3}+N_{4} x_{4} \\
& y=N_{1} y_{1}+N_{2} y_{2}+N_{3} y_{3}+N_{4} y_{4}
\end{aligned}
$$

As equações (4.14) e (4.15) representam as aproximações das coordenadas de cada ponto no domínio do elemento. Agora, segundo a teoria do MEF, a matriz de condutividade do elemento pode ser encontrada a partir da expressão do princípio dos potenciais virtuais (BATHE, 1996), deduzida a partir das equações (4.7) e (4.8) e dada por:

$$
\int_{V_{(e)}} \nabla \bar{\phi}^{T} \boldsymbol{\sigma} \nabla \phi d V_{(e)}=\int_{\Gamma_{q(e)}} \bar{\phi}_{q} \mathbf{I}_{n} d \Gamma_{(e)}
$$

onde $V$ é o volume do elemento, $\bar{\phi}$ é a distribuição virtual de potenciais elétricos, $\Gamma_{q}$ é o local da fronteira do domínio do elemento onde se aplica a condição de contorno de fluxo de corrente, $\bar{\phi}_{q}$ é a distribuição de potenciais elétricos virtuais em $\Gamma_{q}, \mathbf{I}_{n}$ é a componente da corrente elétrica na direção de $\mathbf{n}$ (vetor normal ao contorno do domínio) e $\boldsymbol{\sigma}$ é o tensor de condutividade elétrica, cuja forma matricial é dada por:

$$
\boldsymbol{\sigma}=\left[\begin{array}{cc}
\sigma_{x} & 0 \\
0 & \sigma_{y}
\end{array}\right]
$$

onde $\sigma_{x}$ e $\sigma_{y}$ são as condutividades elétricas do elemento na direção $x$ e $y$, respectivamente. A dedução da equação (4.16), a partir da equação de Poisson, equação (4.7), pode ser vista no apêndice A. Desta forma, usando o MEF para discretizar o domínio, obtém-se a seguinte forma para o princípio dos potenciais virtuais:

$$
\sum_{1}^{M} \int_{V_{(e)}} \nabla \overline{\boldsymbol{\phi}}_{(e)}^{T} \boldsymbol{\sigma}_{(e)} \nabla \boldsymbol{\phi}_{(e)} d V_{(e)}=\sum_{1}^{M} \int_{\Gamma_{q}(e)} \boldsymbol{\phi}_{q(e)} \mathbf{I}_{n(e)} d \Gamma_{(e)}
$$

onde $M$ é o número total de elementos, sendo cada termo tomado num elemento (e). Sabendo-se que:

$$
\nabla \phi_{(e)}=\left\{\begin{array}{c}
\frac{\partial \phi_{(e)}}{\partial x} \\
\frac{\partial \phi_{(e)}}{\partial y}
\end{array}\right\}
$$

Então, usando a relação da equação (4.9) resulta em:

$$
\left\{\begin{array}{c}
\frac{\partial \phi_{(e)}}{\partial x} \\
\frac{\partial \phi_{(e)}}{\partial y}
\end{array}\right\}=\left[\begin{array}{cccc}
\frac{\partial N_{1}}{\partial x} & \frac{\partial N_{2}}{\partial x} & \frac{\partial N_{3}}{\partial x} & \frac{\partial N_{4}}{\partial x} \\
\frac{\partial N_{1}}{\partial y} & \frac{\partial N_{2}}{\partial y} & \frac{\partial N_{3}}{\partial y} & \frac{\partial N_{4}}{\partial y}
\end{array}\right]\left\{\begin{array}{c}
\frac{\partial \varphi_{(e)}}{\partial x} \\
\frac{\partial \varphi_{(e)}}{\partial y}
\end{array}\right\}=\mathbf{B}_{(e)} \boldsymbol{\varphi}_{(e)}
$$

onde $\mathbf{B}_{(e)}$ é a matriz de operadores diferenciais dos polinômios bilineares da matriz de funções de forma $\mathbf{N}$, mostrados nas equações (4.10) a (4.13) em termos de coordenadas locais do elemento. 
Assim, sabendo-se que a relação da equação (4.9) é válida tanto para os potenciais $\phi$ quanto para os potenciais $\bar{\phi}$, então a equação (4.18) pode ser reescrita da seguinte maneira:

$$
\sum_{1}^{M} \overline{\boldsymbol{\varphi}}_{(e)}^{T} \int_{V(e)} \mathbf{B}_{(e)}^{T} \boldsymbol{\sigma}_{(e)} \mathbf{B}_{(e)} d V_{(e)} \boldsymbol{\varphi}_{(e)}=\sum_{1}^{M} \int_{\Gamma_{q}(e)} \bar{\phi}_{q(e)} \mathbf{I}_{n(e)} d \Gamma_{(e)}
$$

$\mathrm{Ou}$

$$
\sum_{1}^{M} \overline{\boldsymbol{\varphi}}_{(e)}^{T} \mathbf{k}_{(e)} \boldsymbol{\varphi}_{(e)}=\sum_{1}^{M} \int_{\Gamma_{q}(e)} \bar{\phi}_{q(e)} \mathbf{I}_{n(e)} d \Gamma_{(e)}
$$

onde $\mathbf{k}_{(e)}$ é a matriz de condutividade elétrica do elemento. Como visto na equação (4.22), a matriz $\mathbf{k}_{(e)}$ é definida por uma integral de volume, então se a espessura do elemento $(h)$ é constante, podemos fazer:

$$
d V_{(e)}=h_{(e)} d A_{(e)}
$$

Assim, podemos reescrever a equação que define a matriz $\mathbf{k}_{(e)}$, da seguinte maneira:

$$
\mathbf{k}_{(e)}=\int_{V(e)} \mathbf{B}_{(e)}^{T} \boldsymbol{\sigma}_{(e)} \mathbf{B}_{(e)} d V_{(e)}=\int_{V(e)} \mathbf{B}_{(e)}^{T} \boldsymbol{\sigma}_{(e)} \mathbf{B}_{(e)} h_{(e)} d A_{(e)}
$$

Desta forma, a matriz de condutividade elétrica do elemento é definida em termos das coordenadas globais $(x, y)$. No entanto, com o objetivo de facilitar o cálculo da integral da equação (4.24), utiliza-se o operador Jacobiano (BATHE, 1996) para transformar as coordenadas globais em coordenadas locais $(\eta, \xi)$ do elemento. Desta forma, obtemos:

$$
\mathbf{k}_{(e)}=\int_{-1}^{1} \int_{-1}^{1} \mathbf{B}_{(e)}^{T} \boldsymbol{\sigma}_{(e)} \mathbf{B}_{(e)} h_{(e)} \operatorname{det} \mathbf{J} d \xi d \eta
$$

onde det $\mathbf{J}$ é o determinante da matriz Jacobiana, definida por:

$$
\mathbf{J}=\left[\begin{array}{ll}
\frac{\partial x}{\partial \xi} & \frac{\partial y}{\partial \xi} \\
\frac{\partial x}{\partial \eta} & \frac{\partial y}{\partial \eta}
\end{array}\right]
$$

Como o elemento possui uma forma quadrilátera qualquer, não é possível calcular analiticamente a integral definida pela equação (4.25) na maioria dos casos. Assim, a matriz de condutividade elétrica do elemento é calculada numericamente por métodos de integração numérica. Neste trabalho, é utilizada a Quadratura de Gauss-Legendre (BATHE, 1996) para realizar a solução numérica desta integral. 


\subsubsection{Matriz de Condutividade do Elemento Triangular}

Um elemento triangular é definido no MEF através 3 nós, conforme mostrado na figura 4.3(b). O potencial elétrico no elemento triangular pode ser determinado pelo seguinte polinômio de primeira ordem (BATHE, 1996):

$$
\phi_{(e)}=a_{1}+a_{2} x+a_{3} y
$$

onde $\phi_{(e)}$ é o potencial elétrico em cada ponto do elemento, $x$ e $y$ são as coordenadas globais do elemento, $a_{1}, a_{2}$ e $a_{3}$ são os coeficientes do polinômio linear. Desta forma, considerando o valor do potencial elétrico em cada nó do elemento triangular, temos:

$$
\begin{aligned}
& \varphi_{1}^{(e)}=a_{1}+a_{2} x_{1}+a_{3} y_{1} \\
& \varphi_{2}^{(e)}=a_{1}+a_{2} x_{2}+a_{3} y_{2} \\
& \varphi_{3}^{(e)}=a_{1}+a_{2} x_{3}+a_{3} y_{3}
\end{aligned}
$$

Resolvendo o sistema de equações (4.28), para $a_{1}, a_{2}$ e $a_{3}$, obtemos:

$$
\begin{gathered}
a_{1}=\frac{1}{2 A_{(e)}}\left[\varphi_{1}^{(e)}\left(x_{2} y_{3}-x_{3} y_{2}\right)+\varphi_{2}^{(e)}\left(x_{3} y_{1}-x_{1} y_{3}\right)+\varphi_{3}^{(e)}\left(x_{1} y_{2}-x_{2} y_{1}\right)\right] \\
a_{2}=\frac{1}{2 A_{(e)}}\left[\varphi_{1}^{(e)}\left(y_{2}-y_{3}\right)+\varphi_{2}^{(e)}\left(y_{3}-y_{1}\right)+\varphi_{3}^{(e)}\left(y_{1}-y_{2}\right)\right] \\
a_{3}=\frac{1}{2 A_{(e)}}\left[\varphi_{1}^{(e)}\left(x_{3}-x_{2}\right)+\varphi_{2}^{(e)}\left(x_{1}-x_{3}\right)+\varphi_{3}^{(e)}\left(x_{2}-x_{1}\right)\right]
\end{gathered}
$$

onde $A_{(e)}$ é a área do elemento triangular dada por:

$$
A_{(e)}=\frac{1}{2}\left[\left(x_{2} y_{3}-x_{3} y_{2}\right)+\left(x_{3} y_{1}-x_{1} y_{3}\right)+\left(x_{1} y_{2}-x_{2} y_{1}\right)\right]
$$

Substituindo as equações (4.29), (4.30) e (4.31) na equação (4.27) e agrupando alguns termos, obtemos a relação da equação (4.9), ou seja, os graus de liberdade do elemento triangular relacionam-se com os potenciais elétricos nodais de maneira análoga ao elemento quadrilátero, conforme teoria do MEF. No entanto, para o elemento triangular de 3 nós a matriz das funções de forma ( $\mathbf{N}$ ) é dada por:

$$
\begin{aligned}
& N_{1}=\left(\alpha_{1}+\beta_{1} x+\gamma_{1} y\right) \\
& N_{2}=\left(\alpha_{2}+\beta_{2} x+\gamma_{2} y\right) \\
& N_{3}=\left(\alpha_{3}+\beta_{3} x+\gamma_{3} y\right)
\end{aligned}
$$


onde

$$
\begin{aligned}
& \alpha_{1}=x_{2} y_{3}-x_{3} y_{2}, \quad \beta_{1}=y_{2}-y_{3}, \quad \gamma_{1}=x_{3}-x_{2} \\
& \alpha_{2}=x_{3} y_{1}-x_{1} y_{3}, \quad \beta_{2}=y_{3}-y_{1}, \quad \gamma_{2}=x_{1}-x_{3} \\
& \alpha_{3}=x_{1} y_{2}-x_{2} y_{1}, \quad \beta_{3}=y_{1}-y_{2}, \quad \gamma_{3}=x_{2}-x_{1}
\end{aligned}
$$

Como os polinômios utilizados para a solução de MEF no elemento triangular de 3 nós são de primeira ordem, a matriz dos operadores diferenciais $\mathbf{B}_{(e)}$ da matriz de forma $(\mathbf{N})$ é constante. Desta forma, a integral da equação (4.24) pode ser resolvida analiticamente, produzindo a seguinte matriz de condutividade elétrica do elemento:

$$
\mathbf{k}_{(e)}=\frac{\sigma_{x}}{4 A_{(e)}}\left[\begin{array}{ccc}
\beta_{1}^{2} & \beta_{1} \beta_{2} & \beta_{1} \beta_{3} \\
\beta_{1} \beta_{2} & \beta_{2}^{2} & \beta_{2} \beta_{3} \\
\beta_{1} \beta_{3} & \beta_{2} \beta_{3} & \beta_{3}^{2}
\end{array}\right]+\frac{\sigma_{y}}{4 A_{(e)}}\left[\begin{array}{ccc}
\gamma_{1}^{2} & \gamma_{1} \gamma_{2} & \gamma_{1} \gamma_{3} \\
\gamma_{1} \gamma_{2} & \gamma_{2}^{2} & \gamma_{2} \gamma_{3} \\
\gamma_{1} \gamma_{3} & \gamma_{2} \gamma_{3} & \gamma_{3}^{2}
\end{array}\right]
$$

onde $\sigma_{x}$ e $\sigma_{y}$ são as condutividades elétricas do elemento na direção $x$ e $y$, respectivamente.

\subsection{Determinação dos Potenciais Elétricos Nodais}

Determinada a matriz de condutividade elétrica do elemento, essa é inserida numa matriz de condutividade global $(\mathbf{K})$ que representa todo o domínio. A inserção da matriz do elemento na matriz global é feita de acordo com uma matriz de conectividade, que associa um número a cada elemento e o número dos nós a que está ligado. Montada a matriz global $\mathbf{K}$ e conhecido o vetor de carregamento elétrico (I) aplicado nos nós, calcula-se o vetor dos potenciais elétricos nodais $(\boldsymbol{\phi})$ através do sistema de equações de equilíbrio, dado na forma matricial por:

$$
\mathbf{K} \phi=\mathbf{I}
$$

A equação (4.38) é um sistema de equações lineares que pode ser resolvido utilizando-se métodos de solução de sistemas de equações tais como o método Gradientes Conjugados, a triangularização de Gauss-Jordan, e outros (BATHE, 1996). Neste trabalho, é utilizado o método dos Gradientes Biconjugados para sistemas esparsos (PRESS et al., 1999). 


\subsection{Modelo de Eletrodos}

Até o momento foi visto que o modelo de MEF é definido por um domínio discretizado por elementos quadriláteros ou triangulares, onde aplicado um carregamento (correntes elétricas) nos nós que estão no contorno deste domínio, determinam-se os valores de potenciais elétricos dos nós de todos os elementos do domínio discretizado. A análise de MEF com esse modelo induz a aplicação da corrente elétrica diretamente na pele do paciente. Porém, na prática o que ocorre é a aplicação da corrente elétrica em eletrodos posicionados externamente ao corpo do paciente e em contato com a pele. A obtenção da imagem da seção do corpo através da TIE depende da informação dos potenciais elétricos medidos nesses eletrodos (externos ao corpo). Na verdade, para que um modelo de MEF do domínio possa fornecer resultados de potenciais elétricos mais próximos da realidade, devemos considerar um modelo de eletrodo que permite levar em conta a resistência de contato dos eletrodos com o corpo do paciente (SOMERSALO; CHENEY, 1992). A figura 4.4 mostra esquematicamente os elementos de eletrodos posicionados no contorno da seção de um corpo.

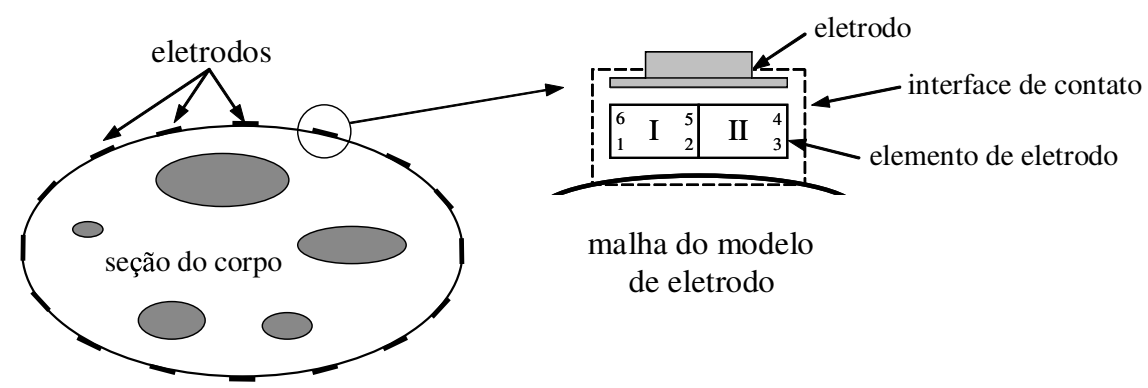

Figura 4.4: Elemento do modelo de eletrodo.

Neste trabalho, é adotado um modelo de eletrodo proposto por Hua et al. (1993) que utiliza um elemento de eletrodo cuja formulação de MEF é oriunda da composição de dois elementos quadriláteros, conforme mostrado na figura 4.4. Nesse modelo de eletrodo Hua et al. (1993) adota algumas hipóteses para simplificar a formulação matemática da matriz de condutividade elétrica do elemento, tais como espessura de contato muito pequena em relação a largura do eletrodo e potenciais elétricos iguais em todos os pontos do eletrodo metálico (nós 4, 5 e 6 mostrados figura 4.4). Desta forma a matriz do elemento de eletrodo 
pode ser escrita da seguinte maneira:

$$
\mathbf{k}_{e l}=\frac{1}{\rho t}\left[\begin{array}{cccr}
\frac{a}{2} & 0 & 0 & -\frac{a}{2} \\
0 & a & 0 & -a \\
0 & 0 & \frac{a}{2} & -\frac{a}{2} \\
-\frac{a}{2} & -a & -\frac{a}{2} & 2 a
\end{array}\right]
$$

onde $\mathbf{k}_{e l}$ é matriz de condutividade elétrica do elemento de eletrodo, a é a largura do elemento (metade da largura do eletrodo), $t$ é a espessura da interface de contato (eletrodo-pele) e $\rho$ é a resistividade (inverso da condutividade) da interface de contato. O produto $\rho$ t é denominado impedância de contato do eletrodo. Além de representar a distribuição do campo elétrico na interface de contato, o modelo de eletrodo considera os efeitos dominantes da resistência de contato dos eletrodos (HUA et al., 1993). A corrente elétrica é aplicada nos nós dos elementos de eletrodos e utiliza-se a aplicação de 32 (ou 30) eletrodos posicionados em torno do domínio submetido à tomografia para obter uma boa qualidade da imagem na TIE (TANG et al., 2002). Portanto, na matriz global K é incluído o efeito de mais 32 elementos de eletrodos. A inserção dos elementos de eletrodos na matriz global K é feita de maneira análoga a inserção dos elementos quadriláteros e triangulares (veja seção 4.5). 


\section{Formulação do Problema de OT aplicado a TIE}

Este capítulo apresenta a formulação teórica do problema de otimização topológica aplicada para a solução do problema inverso da TIE, bem como sua análise de sensibilidade.

\subsection{Estrutura Básica do Problema}

A obtenção de imagem de tomografia por impedância elétrica usando o método de otimização topológica (MOT), essencialmente pode ser interpretada como o problema de encontrar a distribuição de material no interior do domínio que reproduza os valores de voltagem medidos nos eletrodos localizados no contorno do domínio, considerando-se vários casos de aplicação de corrente elétrica no contorno do domínio. A distribuição de material está diretamente relacionada com a distribuição de condutividade no domínio submetido à tomografia. Desta forma, a estrutura básica do problema de otimização, cuja solução será estudada com o MOT, é do tipo:

$$
\begin{aligned}
\underset{\rho(x)}{\operatorname{Minimizar}:} & F=\frac{1}{2} \sum_{\mathrm{j}=1}^{n e} \sum_{\mathrm{i}=1}^{n p}\left(\phi_{\mathrm{ij}}-\phi_{\mathrm{ij} 0}\right)^{2} \\
\text { tal que }: & \text { equação do meio condutivo } \\
& 0 \leq \rho(x) \leq 1 \\
& \text { restrições adicionais }
\end{aligned}
$$

onde $F$ é a função objetivo relacionada com a diferença quadrática entre os valores de potencial elétrico medidos nos eletrodos $\left(\phi_{\mathrm{ij0}}\right)$ e os calculados num modelo computacional do domínio usando elementos finitos $\left(\phi_{\mathrm{ij}}\right)$, que deverá ser minimizada para a solução do problema. Os valores ne e $n p$ são o número de casos de carga de corrente aplicados e o número de pontos de medição (eletrodos), respectivamente. No problema de otimização topológica, as variáveis do problema $\rho(x)$ são limitadas entre 0 e 1 (restrições laterais), conforme mostrado 
na equação (5.1), e determinam a quantidade de material em cada ponto do domínio.

Assim, o MOT pode ser aplicado na solução do problema inverso da TIE para encontrar a distribuição de propriedades materiais (relacionada à distribuição de condutividades ou resistividades) no domínio da seção do corpo. Como visto anteriormente o problema inverso da TIE é não-linear e mal-posto, cuja solução não é única, ou seja, existem diferentes distribuições de condutividades (ou resistividades) no domínio que resultam nos mesmos valores de voltagem medidos nos eletrodos, considerando um mesmo padrão de excitação elétrica nos eletrodos (SYLVESTER; UHLMANN, 1987; GISSER; ISAACSON; NEWELL, 1990).

Porém o algoritmo do MOT permitem restringir facilmente o espaço de solução, evitando-se assim soluções sem significado (imagens não desejadas). Isto é feito através da inclusão de várias restrições no problema de otimização topológica, dado pela equação (5.1). Assim, nas seções seguintes deste capítulo são propostas e descritas restrições baseadas em imposição de volume mínimo para determinada região do domínio e valor médio para a condutividade do domínio. Além disso, no capítulo 6 é descrita a implementação de regularizações adicionais no problema para auxiliar na solução do problema e, assim, melhorar a resolução da imagem obtida.

\subsection{Parâmetro de Sintonia da Imagem ("tuning")}

Nesta seção é proposta uma restrição ao problema de otimização, apresentado na seção anterior, que visa "forçar" o algoritmo de MOT a elevar a intensidade dos valores absolutos de condutividade (ou resistividade) de determinadas regiões do domínio de projeto, com o objetivo de melhorar a nitidez da imagem obtida com o algoritmo. Esta restrição é dada pela seguinte equação:

$$
\int_{\Omega} \rho(x) d \Omega \geq V^{*}
$$

onde $\Omega$ é o domínio de projeto e $V^{*}$ é um valor definido para restringir a quantidade total de material no domínio.

A equação (5.2) é denominada de "tuning", ou seja, ela atua como parâmetro de sintonia da imagem desejada, regularizando o problema de otimização topológica proposto. Na prática, a utilização de um parâmetro deste tipo significa oferecer ao médico uma alternativa para que possa ajustar a imagem obtida 
mediante regulagem de parâmetros no aparelho de tomografia. É claro que a imagem a priori é desconhecida, porém acredita-se que o médico possa estimá-la, conforme sua experiência, e assim determinar qual o valor do parâmetro de sintonia a ser utilizado.

Desta maneira, com a restrição de "tuning" proposta e considerando o domínio $\Omega$ discretizado em $M$ elementos finitos o problema de otimização topológica, dado pela equação (5.1), pode ser reescrito no domínio discreto, da seguinte forma:

$$
\begin{aligned}
& \underset{\boldsymbol{\rho}, \boldsymbol{\rho} \mathbf{t}}{M i n i m i z a r}: \quad F=\frac{1}{2} \sum_{\mathrm{j}=1}^{n e} \sum_{\mathrm{i}=1}^{n p}\left(\phi_{\mathrm{ij}}-\phi_{\mathrm{ij} 0}\right)^{2} \\
& \text { tal que: equação do meio condutivo } \\
& \rho t_{\text {min }} \leq \rho t_{j} \leq \rho t_{\text {max }} ; j=1 \ldots n p \\
& 0 \leq \rho_{k} \leq 1 ; k=1 \ldots M \\
& \sum_{k=1}^{M} V_{k} \rho_{k} \geq V^{*} \quad \text { ("tuning") }
\end{aligned}
$$

A equação 5.3 é o parâmetro de sintonia da imagem ("tuning") escrito na forma discreta, onde $V_{k}$ é o volume de cada elemento do domínio discretizado. As variáveis do problema $\rho_{k}$ são limitadas entre 0 e 1 e representam a quantidade de material em cada elemento do domínio. As variáveis $\rho t_{j}$ representam a impedância de contato dos eletrodos (veja seção 4.6), denominadas parâmetros de eletrodos, que são incluídos no processo de otimização e limitados pelas restrições laterais $\rho t_{\min }$ e $\rho t_{\max }$. Neste trabalho, as variáveis $\rho t_{j}$ não são normalizadas através do modelo de material adotado e os valores de suas restrições laterais são escolhidos com base em publicações que tratam do assunto (HUA et al., 1993; TRIGO; GONZALEZ-LIMA; AMATO, 2004).

\subsection{Restrição de Condutividade Média}

Numa tentativa de tornar o processo de obtenção de imagem independente de parâmetros de regulagem, como o "tuning" apresentado na seção 5.2, e acentuar os valores de condutividades na imagem obtida, é implementado uma restrição alternativa baseada no valor médio de condutividade do meio. O princípio de ação dessa restrição alternativa é o mesmo da restrição de sintonia, porém neste caso controlamos não o volume da região da imagem desejada, mas sim o valor da condutividade média no interior da seção do corpo em relação aos valores de corrente aplicada e potenciais elétricos gerados. 
Implicitamente, esta restrição alternativa engloba a restrição de sintonia uma vez que a condutividade média da região da imagem desejada modifica-se conforme varia-se o volume de material dessa região. Nesta restrição, o valor de condutividade de cada ponto do domínio $(\Omega)$ é ponderada em relação a distância (d) de cada ponto ao centro do domínio da seguinte maneira:

$$
\int_{\Omega} \frac{1}{d^{q}} \rho(x) d \Omega \geq C^{*}
$$

onde $C^{*}$ representa o valor de condutividade (ou resistividade) média no domínio, $q$ é o expoente utilizado para intensificar o grau da restrição. A equação (5.4) é denominada nesse trabalho como restrição da condutividade média (RCM).

Sabe-se que na TIE, a sensibilidade à variação dos valores de condutividade (ou resistividade) no centro do domínio é reduzida, quando comparada à sensibilidade nos locais próximos aos eletrodos (BACRIE; GOUSSARD; GUARDO, 1997). Para minimizar esse efeito, na restrição de condutividade média, o valor da restrição é penalizada com o inverso da distância $d$, sendo que valores elevados para o expoente $q$ fazem com que as pseudo-densidades $\rho(x)$ próximo ao centro do domínio, sejam forçadas a assumirem valores altos (até o limite superior estipulado para a pseudo-densidade), considerando o sistema de coordenadas no centro do domínio, e assim destacando melhor os valores de condutividades no centro do domínio.

A restrição da equação (5.4) é incluída no problema de otimização topológica aplicado a TIE. Desta maneira, com esta restrição o problema completo no domínio discreto é definido agora da seguinte forma:

$$
\begin{aligned}
& \underset{\boldsymbol{\rho}, \boldsymbol{\rho} \mathbf{t}}{\operatorname{Minimizar}:} \quad F=\frac{1}{2} \sum_{\mathrm{j}=1}^{n e} \sum_{\mathrm{i}=1}^{n p}\left(\phi_{\mathrm{ij}}-\phi_{\mathrm{ij} 0}\right)^{2} \\
& \text { tal que: equação de equilíbrio do meio condutivo } \\
& \rho t_{\text {min }} \leq \rho t_{j} \leq \rho t_{\text {max }} ; j=1 \ldots n p \\
& 0 \leq \rho_{k} \leq 1 ; \quad k=1 \ldots M \\
& \sum_{k=1}^{M} V_{k} \rho_{k} \geq V^{*} \quad \text { ("tuning") } \\
& \sum_{k=1}^{M} \frac{1}{d_{k}^{q}} \rho_{k} \geq \sum_{k=1}^{M} \frac{1}{d_{k}^{q}} \bar{\rho}^{*} \quad \text { (restr. cond. média) }
\end{aligned}
$$

onde $\bar{\rho}^{*}$ é a pseudo-densidade média obtida a partir do valor da condutividade (ou resistividade) média no domínio.

A implementação desta restrição não é trivial, pois exige a determinação da 
resistividade média do meio $(\bar{\rho})$ cuja imagem é desejada. Neste trabalho, obtemos bons resultados estimando esse parâmetro $(\bar{\rho})$ considerando o domínio como um resistor, com resistência igual a $R_{\Omega}$. Desta forma, aplicando a Lei de Ohms temos:

$$
\frac{\bar{U}}{I}=R_{\Omega}
$$

onde $\bar{U}$ é o potencial elétrico médio no domínio, obtido com a aplicação da corrente elétrica $I$. Observa-se que no domínio discreto $\bar{U}$ é calculado efetuando-se a média dos potenciais elétricos nodais. Para converter $R_{\Omega}$ em termos de condutividade média $(\bar{C})$, adotamos a seguinte relação:

$$
\bar{C}=\frac{1}{\alpha R_{\Omega}}
$$

onde o coeficiente $\alpha$ pode ser obtido previamente calculando-se a resistência do domínio homogêneo de resistividade conhecida (17 $\Omega m$, por exemplo). Desta forma, o valor de $(\bar{\rho})$ em função de $(\bar{C})$ pode ser obtido a partir da equação (3.5), apresentada no capítulo 3 , da seguinte maneira:

$$
\bar{\rho}^{*}=\sqrt[p]{\frac{\bar{C}-C_{B}}{C_{A}-C_{B}}}
$$

onde $C_{A}$ e $C_{B}$ são as propriedades de condutividade dos materiais básicos que compõem o domínio no modelo de material.

\subsection{Análise de Sensibilidade}

Neste trabalho, a solução do problema de otimização no MOT é baseada num método determinístico (CHOI; SEONG, 1986), que necessita da informação dos gradientes (ou derivadas) da função objetivo e restrições em relação as variáveis de projeto, os quais determinam a sensibilidade de um algoritmo de MOT em atender a função objetivo especificada. Esses gradientes são utilizados na Programação Linear Sequencial (PLS) para a linearização da função objetivo, conforme descrito mais adiante no capítulo 6. Assim, nesta seção, é desenvolvida a formulação matemática para o cálculo dos gradientes da função objetivo do problema de otimização da equação (5.1).

Conforme visto na seção 5.1, a função objetivo $(F)$ do problema de otimização topológica para obtenção de imagem na TIE é escrita como sendo a diferença quadrática entre os valores de potencial elétrico medidos em eletrodos $\left(\phi_{\mathrm{ij} 0}\right)$ e os calculados num modelo computacional da seção usando elementos finitos $\left(\phi_{\mathrm{ij}}\right)$. Sabendo-se que uma vez medidos os valores de potencial elétrico 


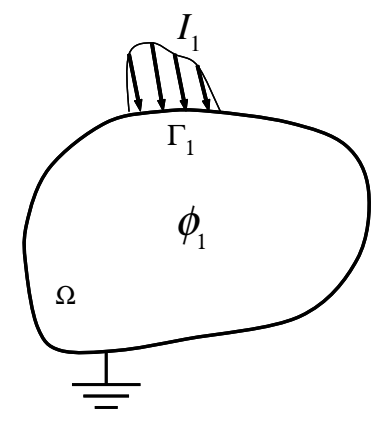

(a)

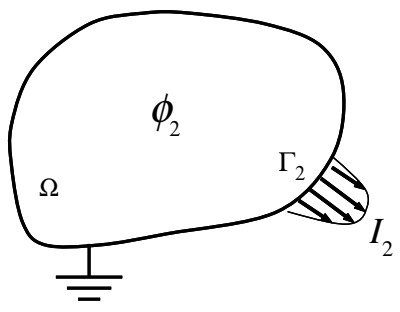

(b)

Figura 5.1: Seção do corpo submetido a dois casos diferentes de excitação.

(valores experimentais) os mesmos permanecem constantes durante o processo de obtenção de imagem na TIE. Então, aplicando a regra da cadeia, a derivada da função objetivo em relação as variáveis do problema de otimização, pode ser escrita da seguinte forma:

$$
\frac{\partial F}{\partial \rho}=\frac{\partial F}{\partial \phi_{\mathrm{ij}}} \frac{\partial \phi_{\mathrm{ij}}}{\partial \rho}=\sum_{j=1}^{n e} \sum_{i=1}^{n p}\left(\phi_{\mathrm{ij}}-\phi_{\mathrm{ij} 0}\right) \frac{\partial \phi_{\mathrm{ij}}}{\partial \rho}
$$

A derivada da equação (5.9) é determinada a seguir analiticamente usando-se o método adjunto (BYUN et al., 2000). Para ilustrar, considere a seção de um corpo representado pelo domínio $\Omega$ mostrado na figura 5.1. Agora, suponha esse domínio "aterrado" em um ponto fixo (potencial nulo) e submetido a dois casos de excitação elétrica distintos. O primeiro caso é mostrado na figura 5.1(a) e consiste na aplicação de uma excitação $I_{1}$ (corrente elétrica) na superfície $\Gamma_{1}$, o que gera ao corpo uma distribuição de potencial elétrico $\phi_{1}$. O segundo caso é mostrado na figura 5.1(b), onde é aplicada uma excitação fictícia $I_{2}$ na superfície $\Gamma_{2}$, gerando uma distribuição de potencial elétrico $\phi_{2}$.

Supondo que o corpo é submetido simultaneamente aos dois casos de excitação elétrica verifica-se que, em analogia ao teorema da reciprocidade de Maxwell (COOK; YOUNG, 1985), a potência elétrica devido à $I_{1}$ ao longo da distribuição de potencial $\phi_{2}$ na superfície $\Gamma_{2}$ é igual a potência elétrica devido à $I_{2}$ ao longo de $\phi_{1}$ na superfície $\Gamma_{1}$, ou seja:

$$
\int_{\Gamma_{1}} I_{1} \phi_{2} d \Gamma_{1}=\int_{\Gamma_{2}} I_{2} \phi_{1} d \Gamma_{2}
$$

Utilizando a formulação de MEF, podemos reescreve-se a equação (5.10) na forma matricial, da seguinte maneira:

$$
\mathbf{I}_{1}^{T} \boldsymbol{\Phi}_{2}=\mathbf{I}_{2}^{T} \boldsymbol{\Phi}_{1}
$$


onde $\mathbf{I}_{i}(i=1 ; 2)$ é a forma vetorial de $I_{i}$ (corrente elétrica aplicada) e $\boldsymbol{\Phi}_{i}$ é forma vetorial de $\phi_{i}$ (potenciais elétricos) e o índice ${ }^{T}$ indica transposição do vetor.

Inicialmente, admite-se a excitação fictícia $\mathbf{I}_{2}$ como um vetor de correntes elétricas cuja única componente não nula é uma corrente unitária aplicada no(s) ponto(s), ou seja:

$$
\mathbf{I}_{2}=\left\{\begin{array}{c}
0 \\
0 \\
\cdots \\
1 \\
\cdots \\
0 \\
0
\end{array}\right\}
$$

Lembrando da equação (4.38) (sistema de equações de equilíbrio do MEF), que relaciona corrente e potencial elétrico, e inserindo-a na equação (5.11) obtemos:

$$
\boldsymbol{\Phi}_{1}^{T} \mathbf{K} \boldsymbol{\Phi}_{2}=\phi_{1}
$$

Note que, segundo a teoria de MEF ((BATHE, 1996), a matriz K é simétrica e portanto $\mathbf{K}^{T}=\mathbf{K}$. Derivando os dois lados da igualdade da equação (5.13) em relação as variáveis do problema de otimização, resulta na seguinte equação:

$$
\frac{\partial\left(\boldsymbol{\Phi}_{1}^{T} \mathbf{K} \boldsymbol{\Phi}_{2}\right)}{\partial \rho}=\frac{\partial\left(\phi_{1}\right)}{\partial \rho}
$$

O gradiente do lado esquerdo da equação (5.14) é a derivada da energia mútua do sistema, a qual é desenvolvida da seguinte forma:

$$
\frac{\partial\left(\boldsymbol{\Phi}_{1}^{T} \mathbf{K} \boldsymbol{\Phi}_{2}\right)}{\partial \rho}=\frac{\partial \boldsymbol{\Phi}_{1}^{T}}{\partial \rho} \mathbf{K} \boldsymbol{\Phi}_{2}+\boldsymbol{\Phi}_{1}^{T} \frac{\partial \mathbf{K}}{\partial \rho} \boldsymbol{\Phi}_{2}+\boldsymbol{\Phi}_{1}^{T} \mathbf{K} \frac{\partial \boldsymbol{\Phi}_{2}}{\partial \rho}
$$

Derivando a equação de equilíbrio $\mathbf{K} \boldsymbol{\Phi}_{1}=\mathbf{I}_{1}$ em relação às variáveis do problema, temos:

$$
\frac{\partial \mathbf{K}}{\partial \rho} \boldsymbol{\Phi}_{1}+\mathbf{K} \frac{\partial \boldsymbol{\Phi}_{1}}{\partial \rho}=\frac{\partial \mathbf{I}_{1}}{\partial \rho}
$$

Como o vetor de correntes elétricas $\mathbf{I}_{1}$ não varia com as variáveis do problema, o gradiente do lado direito da igualdade da equação (5.16) é nulo. Então:

$$
\frac{\partial \mathbf{K}}{\partial \rho} \boldsymbol{\Phi}_{1}+\mathbf{K} \frac{\partial \boldsymbol{\Phi}_{1}}{\partial \rho}=0 \quad \Rightarrow \quad \frac{\partial \boldsymbol{\Phi}_{1}}{\partial \rho}=-\mathbf{K}^{-1} \frac{\partial \mathbf{K}}{\partial \rho} \boldsymbol{\Phi}_{1}
$$

Transpondo a equação (5.17), temos:

$$
\frac{\partial \boldsymbol{\Phi}_{1}^{T}}{\partial \rho}=-\boldsymbol{\Phi}_{1}^{T} \frac{\partial \mathbf{K}^{T}}{\partial \rho}\left(\mathbf{K}^{-1}\right)^{T}
$$



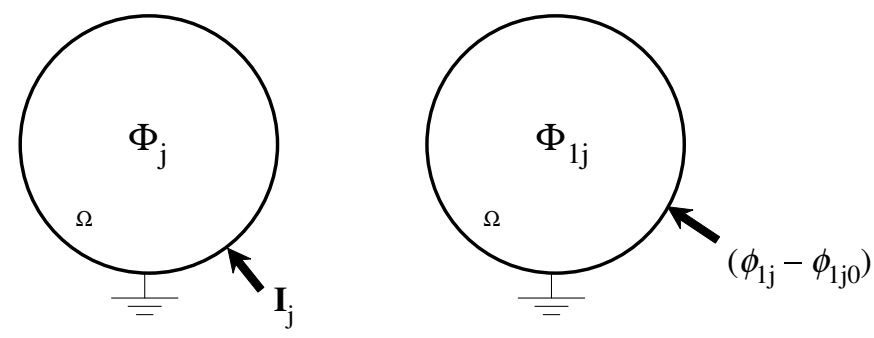

Figura 5.2: Aplicação da primeira medição de potenciais (i=1).

Como a matriz $\mathbf{K}$ é simétrica, sabe-se que $\left(\mathbf{K}^{-1}\right)^{T}=\mathbf{K}^{-1}$. Assim:

$$
\frac{\partial \boldsymbol{\Phi}_{1}^{T}}{\partial \rho}=-\boldsymbol{\Phi}_{1}^{T} \frac{\partial \mathbf{K}^{T}}{\partial \rho} \mathbf{K}^{-1}
$$

Da mesma maneira, derivando a equação de equilíbrio $\mathbf{K} \boldsymbol{\Phi}_{2}=\mathbf{I}_{2}$ (segundo caso de carregamento), obtemos:

$$
\frac{\partial \boldsymbol{\Phi}_{2}}{\partial \rho}=-\mathbf{K}^{-1} \frac{\partial \mathbf{K}}{\partial \rho} \boldsymbol{\Phi}_{2}
$$

Substituindo as equações 5.19 e 5.20 na equação (5.15) e simplificando, obtemos:

$$
\frac{\partial\left(\boldsymbol{\Phi}_{1}^{T} \mathbf{K} \boldsymbol{\Phi}_{2}\right)}{\partial \rho}=-\boldsymbol{\Phi}_{1}^{T} \frac{\partial \mathbf{K}}{\partial \rho} \boldsymbol{\Phi}_{2}
$$

Assim, a equação (5.14) pode ser escrita da seguinte maneira:

$$
-\boldsymbol{\Phi}_{1}^{T} \frac{\partial \mathbf{K}}{\partial \rho} \boldsymbol{\Phi}_{2}=\frac{\partial\left(\phi_{1}\right)}{\partial \rho}
$$

Na TIE, para um caso de carregamento, são feitas várias medições (i=1 a $n p$ ) ao redor da seção do corpo em diferentes pontos de medição (eletrodos). Assim, considere a configuração do domínio para a primeira medição $(i=1)$, conforme mostrado na figura 5.2.

Agora, a excitação fictícia da equação (5.12) é considerada um vetor cujas componentes valem:

$$
\mathbf{I}_{1 \mathrm{j}}=\left\{\begin{array}{c}
\left(\phi_{1 \mathrm{j}}-\phi_{1 \mathrm{j} 0}\right) \\
0 \\
0 \\
\cdots \\
0
\end{array}\right\}
$$

Esse vetor de corrente elétrica produz no domínio $\Omega$ uma distribuição de potencial $\Phi_{1 \mathrm{j}}$. Desta forma, sabendo-se que a corrente elétrica $\left(\phi_{\mathrm{ij}}-\phi_{\mathrm{ij} 0}\right)$ é constante 

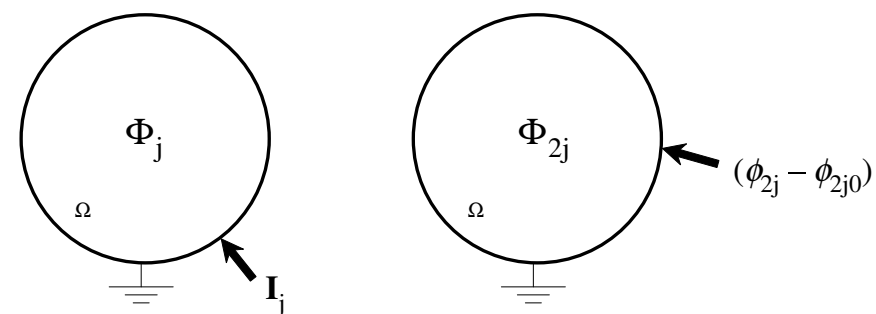

Figura 5.3: Aplicação da segunda medição de potenciais $(i=2)$.

durante o caso de carga, aplicando a equação (5.22) temos:

$$
-\boldsymbol{\Phi}_{\mathrm{j}}^{T} \frac{\partial \mathbf{K}}{\partial \rho} \boldsymbol{\Phi}_{1 \mathrm{j}}=\left(\phi_{1 \mathrm{j}}-\phi_{1 \mathrm{j} 0}\right) \frac{\partial \phi_{1 \mathrm{j}}}{\partial \rho}
$$

Considere agora a segunda medição $(\mathrm{i}=2)$ ilustrada na figura 5.3.

Observe que o ponto de aplicação de corrente elétrica é mudado. De maneira análoga à primeira medição, obtemos a seguinte equação:

$$
-\boldsymbol{\Phi}_{\mathrm{j}}^{T} \frac{\partial \mathbf{K}}{\partial \rho} \boldsymbol{\Phi}_{2 \mathrm{j}}=\left(\phi_{2 \mathrm{j}}-\phi_{2 \mathrm{j} 0}\right) \frac{\partial \phi_{2 \mathrm{j}}}{\partial \rho}
$$

Repetindo o procedimento até completar os $n p$ casos de medição, temos:

$$
-\boldsymbol{\Phi}_{\mathrm{j}}^{T} \frac{\partial \mathbf{K}}{\partial \rho} \boldsymbol{\Phi}_{(n p) \mathrm{j}}=\left(\phi_{(n p) \mathrm{j}}-\phi_{(n p) \mathrm{j} 0}\right) \frac{\partial \phi_{(n p) \mathrm{j}}}{\partial \rho}
$$

Agora, considere o desenvolvimento da primeira somatória (de 1 a $n p$ ) da equação (5.9):

$$
\begin{array}{r}
\frac{\partial F}{\partial \rho}=-\sum_{\mathrm{j}=1}^{n e}\left(\left(\phi_{1 \mathrm{j}}-\phi_{1 \mathrm{j} 0}\right) \frac{\partial \phi_{1 \mathrm{j}}}{\partial \rho}+\left(\phi_{2 \mathrm{j}}-\phi_{2 \mathrm{j} 0}\right) \frac{\partial \phi_{2 \mathrm{j}}}{\partial \rho}+\left(\phi_{3 \mathrm{j}}-\phi_{3 \mathrm{j} 0}\right) \frac{\partial \phi_{3 \mathrm{j}}}{\partial \rho}+\ldots\right. \\
\left.\ldots+\left(\phi_{(n p) \mathrm{j}}-\phi_{(n p) \mathrm{j} 0}\right) \frac{\partial \phi_{(n p) \mathrm{j}}}{\partial \rho}\right)(5.2
\end{array}
$$

Comparando a equação (5.27) com as equações 5.24 e 5.26 conclui-se que, considerando todos os $n p$ casos de medição a derivada da função objetivo em relação às variáveis de projeto é dada por:

$$
\frac{\partial F}{\partial \rho}=-\sum_{\mathrm{j}=1}^{n e}\left(\boldsymbol{\Phi}_{\mathrm{j}}^{T} \frac{\partial \mathbf{K}}{\partial \rho} \boldsymbol{\Phi}_{1 \mathrm{j}}+\boldsymbol{\Phi}_{\mathrm{j}}^{T} \frac{\partial \mathbf{K}}{\partial \rho} \boldsymbol{\Phi}_{2 \mathrm{j}}+\boldsymbol{\Phi}_{\mathrm{j}}^{T} \frac{\partial \mathbf{K}}{\partial \rho} \boldsymbol{\Phi}_{3 \mathrm{j}}+\ldots+\boldsymbol{\Phi}_{\mathrm{j}}^{T} \frac{\partial \mathbf{K}}{\partial \rho} \boldsymbol{\Phi}_{(n p) \mathrm{j}}\right)
$$

Agrupando os termos semelhantes da equação (5.28), vem:

$$
\frac{\partial F}{\partial \rho}=-\sum_{\mathrm{j}=1}^{n e} \boldsymbol{\Phi}_{\mathrm{j}}^{T} \frac{\partial \mathbf{K}}{\partial \rho} \underbrace{\left(\boldsymbol{\Phi}_{1 \mathrm{j}}+\boldsymbol{\Phi}_{2 \mathrm{j}}+\ldots+\boldsymbol{\Phi}_{(n p) \mathrm{j}}\right)}_{\boldsymbol{\Phi}_{\mathrm{j}} "}
$$

Como a formulação de MEF é linear, podemos obter a somatória de potenciais 

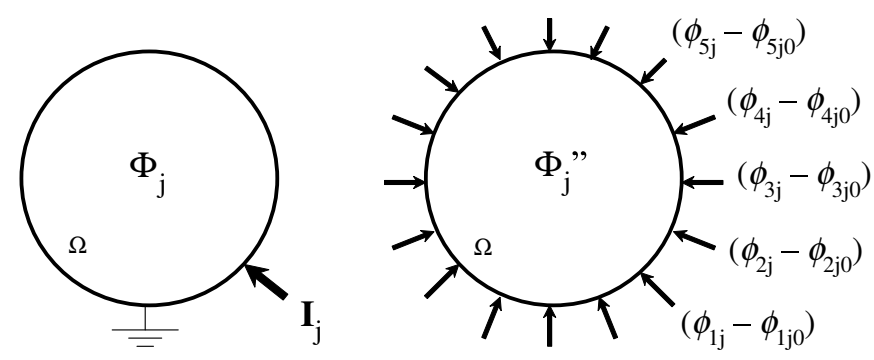

Figura 5.4: Considerando todos os $n p$ casos de medição.

$\boldsymbol{\Phi}_{\mathrm{j}}$ " aplicando simultaneamente todos os $n p$ casos de medição usando a corrente elétrica $\left(\phi_{\mathrm{ij}}-\phi_{\mathrm{ij0}}\right)$, conforme ilustrado na figura 5.4.

Assim, o vetor $\boldsymbol{\Phi}_{\mathrm{j}}$ " pode ser calculado através da seguinte equação de equilíbrio:

$$
\mathbf{K} \Phi_{\mathrm{j}}{ }^{\prime}=\mathbf{I}_{\mathrm{j}}{ }^{\prime}
$$

Onde:

$$
\mathbf{I}_{\mathrm{j}} "=\mathbf{I}_{1 \mathrm{j}}+\mathbf{I}_{2 \mathrm{j}}+\mathbf{I}_{3 \mathrm{j}}+\ldots+\mathbf{I}_{(n p) \mathrm{j}}=\left\{\begin{array}{c}
\left(\phi_{1 \mathrm{j}}-\phi_{1 \mathrm{j} 0}\right) \\
\left(\phi_{2 \mathrm{j}}-\phi_{2 \mathrm{j} 0}\right) \\
\left(\phi_{3 \mathrm{j}}-\phi_{3 \mathrm{j} 0}\right) \\
\ldots \\
\ldots \\
\left(\phi_{(n p) \mathrm{j}}-\phi_{(n p) \mathrm{j} 0}\right)
\end{array}\right\}
$$

Portanto, considerando-se todos os ne casos de carga e todos os $n p$ casos de medição, a expressão geral para o cálculo da derivada da função objetivo em relação às variáveis de projeto é dada por:

$$
\frac{\partial F}{\partial \rho}=-\sum_{\mathrm{j}=1}^{n e}\left(\boldsymbol{\Phi}_{\mathrm{j}}^{T} \frac{\partial \mathbf{K}}{\partial \rho} \boldsymbol{\Phi}_{\mathrm{j}}{ }^{\prime \prime}\right)
$$

O procedimento apresentado acima permite uma economia de tempo considerável no processamento computacional para cálculo dos gradientes da função objetivo em relação as variáveis de projeto. 


\section{Solução e Implementação Numérica do Problema}

Este capítulo apresenta o processo de solução do problema de otimização topológica aplicado a TIE, apresentado no capítulo 5, bem como sua implementação numérica num algoritmo computacional.

\subsection{Solução do Problema de Otimização Topológica Aplicado a TIE}

Existem vários algoritmos de otimização disponíveis para solução de problemas de otimização não-lineares com restrições, como o problema de otimização do MOT. A maior parte deles é baseado nas chamadas técnicas de programação matemática e métodos de aproximação seqüencial. Uma revisão detalhada desses algoritmos podem ser encontradas em Vanderplaatz (1984) e Haftka, Gürdal e Kamat (1996). Neste trabalho, o algoritmo de otimização utilizado para resolver o problema de otimização, apresentado no capítulo 5, é conhecido como Programação Linear Sequencial (PLS). Classificada entre os algoritmos baseados em métodos de aproximação seqüencial, a PLS tem sido aplicada com sucesso na solução de problemas de otimização topológica. Entre as vantagens da PLS podemos citar o fato dela permitir trabalhar com um grande número de variáveis de projeto e funções objetivo complexas. Além disso, a PLS é de fácil implementação num algoritmo computacional.

\subsubsection{Programação Linear Seqüencial (PLS)}

A PLS resolve um problema de otimização não-linear dividindo-o em uma seqüência de problemas de otimização lineares que podem ser resolvidos com a técnica de Programação Linear (PL). A técnica da PL resolve um problema de otimização em que a função objetivo e as restrições são funções lineares em relação às variáveis do problema. O problema de otimização aplicado neste trabalho é 
não-linear em relação às variáveis de projeto, que representam a quantidade de material em cada ponto do domínio. No entanto, o problema pode ser linearizado expandindo-se a sua função objetivo numa Série de Taylor e aproveitando os termos com derivada de primeira ordem. Os termos com derivada de segunda ordem ou superior são desprezados, pois o que nos interessa é a representação linear da função objetivo, para ser utilizada na PL. Assim, a função linear a ser minimizada na PL é dada por:

$$
F_{\text {linear }}=\frac{\partial F}{\partial \rho_{1}} \rho_{1}+\frac{\partial F}{\partial=\rho^{i}} \rho_{\substack{\rho \rho_{2} \\ \rho=\rho^{i}}} \rho_{2}+\frac{\partial F}{\partial \rho_{3}} \rho_{3}+\ldots+\frac{\partial F}{\partial=\rho^{i}} \rho_{M} \rho_{M}
$$

Observe que o coeficiente das variáveis $\rho_{k}$ é o gradiente (ou derivada) da função objetivo do problema de otimização em relação a variável do problema no ponto $\rho=\rho^{i}$, com $i$ variando de 1 até o número total de iterações necessárias para a convergência da função objetivo. $O$ desenvolvimento desses gradientes foi mostrado na seção 5.4 do capítulo anterior.

A solução numérica da PL pode ser desenvolvida usando-se o método Simplex (DANTZIG, 1963) ou o método Kamarkar (HAFTKA; GüRDAL; KAMAT, 1996) que buscam, dentro de um conjunto de soluções possíveis para o problema, a solução que satisfaz a função objetivo e restrições. Geralmente, rotinas computacionais de PL podem ser encontradas na literatura como, por exemplo, a rotina SIMPLX (PRESS et al., 1999) que usa o método Simplex, ou disponibilizadas gratuitamente pela rede mundial de computadores (internet), como é o caso da rotina conhecida por DSPLP (HANSON; HIEBERT, 1981) que também usa o método Simplex. Neste trabalho é utilizado a rotina DSPLP, pois essa rotina executa a PL com milhares de variáveis de projeto num tempo computacional bem menor que o tempo gasto pela rotina SIMPLX.

\subsubsection{Limites Móveis}

Como descrito na seção anterior, a idéia primária da PLS para solucionar um problema de otimização não-linear é fazer uma aproximação por sucessivos sub-problemas lineares que são resolvidos por PL. Para que essa aproximação seja válida é necessário limitar a variação do valor das variáveis de projeto em cada sub-problema linear através dos limites móveis (THOMAS; VANDERPLAATS; SHYY, 1992). Para entender melhor este conceito, considere a função não-linear $F(\rho)$, mostrada na figura 6.1 .

Considere também a função linear $f(\rho)$ como uma aproximação da função 


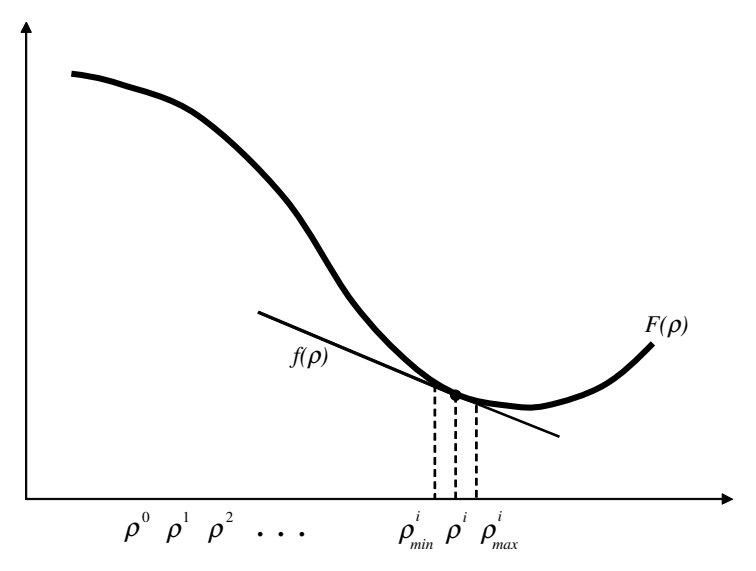

Figura 6.1: Limites móveis.

não-linear $F(\rho)$ em torno do ponto $\rho^{i}$. Observa-se que a aproximação linear $f(\rho)$ somente é válida em torno do ponto $i$, e se distancia muito do valor real da função não-linear a medida que se afasta desse ponto. Desta maneira denomina-se os valores máximo e mínimo em torno de $\rho^{i}$, onde a aproximação linear é válida, de limites móveis da variável $\rho^{i}\left(\rho_{\min }^{i}\right.$ e $\left.\rho_{\max }^{i}\right)$. Portanto, a cada iteração a rotina de PLS minimiza a função linear $f(\rho)$ no intervalo dos limites móveis e encontra o valor ótimo para a variável $\rho^{i}$, que será utilizada na iteração seguinte. Assim as iterações seguem sucessivamente, substituindo-se como valor inicial da iteração posterior o valor ótimo de $\rho^{i}$ encontrado na iteração anterior, até ocorrer a convergência da solução.

Os limites são considerados móveis pelo fato da variável $\rho^{i}$ assumir um valor diferente a cada iteração da rotina de PLS. Esses limites são definidos como valores relativos em relação ao valor dessa variável. Porém, é necessário observar que, se os valores utilizados para os limites móveis forem muito grande, o erro da aproximação linear será grande, podendo causar inclusive a perda do ponto ótimo. Em contra partida, se forem muito pequeno o custo computacional para obter a solução ótima será muito grande. Uma forma de tentar minimizar esse impasse e tornar mais rápido a convergência da solução é assumir valores grande para os limites móveis na região em que a função não-linear $F(\rho)$ apresenta maiores curvaturas (valores de segundas derivadas alto), pois nessa região a função $F(\rho)$ tem praticamente o mesmo comportamento da aproximação linear $f(\rho)$. Já, na região em que a função apresentar uma menor curvatura (valores de segundas derivadas baixo) os limites móveis devem ser pequenos. Além disso, a medida que nos aproximamos da convergência da solução (solução ótima) devemos reduzir bastante os valores dos limites móveis, caso contrário podemos ultrapassar o ponto ótimo gerando oscilação no valor da função não-linear. 
Neste trabalho, a determinação dos valores dos limites móveis em cada iteração da rotina de PLS é feita através de um algoritmo heurístico (BELEGUNDU; ARORA, 1985), que se baseia no procedimento sugerido acima e utiliza a variação de sinal da variável do problema (segunda derivada) nas últimas iterações do processo de otimização. Desta maneira, o algoritmo adotado decide a mudança dos limites móveis da seguinte forma:

$$
\begin{gathered}
\text { se }\left(\Delta \rho^{i}\right)\left(\Delta \rho^{i-1}\right) \geq 0 \text { e }\left(\Delta \rho^{i-1}\right)\left(\Delta \rho^{i-2}\right) \geq 0 \quad \text { e }\left(\Delta \rho^{i}\right)\left(\Delta \rho^{i-2}\right) \geq 0 \Rightarrow \\
\Rightarrow \quad \bar{\rho}^{i}=\max \left(\bar{\rho}_{\min }, \min \left(\alpha \bar{\rho}^{i-1}, \bar{\rho}_{\max }\right)\right) \\
\operatorname{se}\left(\Delta \rho^{i}\right)\left(\Delta \rho^{i-1}\right) \leq 0 \quad e\left(\Delta \rho^{i-1}\right)\left(\Delta \rho^{i-2}\right) \leq 0 \quad e\left(\Delta \rho^{i}\right)\left(\Delta \rho^{i-2}\right) \leq 0 \Rightarrow \\
\Rightarrow \bar{\rho}^{i}=\max \left(\bar{\rho}_{\min }, \min \left(\beta \bar{\rho}^{i-1}, \bar{\rho}_{\max }\right)\right)
\end{gathered}
$$

então:

$$
\begin{aligned}
& \rho_{\min }^{i}=\max \left(\rho_{\min }, \min \left(\rho^{i}\left(1+\bar{\rho}^{i}\right), \rho_{\max }\right)\right) \\
& \rho_{\max }^{i}=\max \left(\rho_{\min }, \min \left(\rho^{i}\left(1-\bar{\rho}^{i}\right), \rho_{\max }\right)\right)
\end{aligned}
$$

onde $\rho_{\min }^{i}$ e $\rho_{\text {max }}^{i}$ são os limites móveis inferior e superior da variável do problema na iteração $i$, os quais devem ser limitados entre os valores extremos $\rho_{\min }$ e $\rho_{\max }$ (restrições laterais do problema). $\Delta \rho^{i}, \Delta \rho^{i-1}$ e $\Delta \rho^{i-2}$ são as variações de sinal da variável do problema nas três últimas iterações, $\alpha$ é um valor maior que $1, \beta$ é um valor positivo menor que 1. A variável $\bar{\rho}^{i}$ é um valor associado a cada variável do problema, sendo $\bar{\rho}_{\min }$ e $\bar{\rho}_{\max }$ seus valores mínimo e máximo, respectivamente.

\subsection{Implementação Numérica da Solução do Problema}

O problema de otimização topológica aplicado para obtenção de imagem na TIE foi implementado num algoritmo computacional, programado em linguagem C, cujo fluxograma básico é mostrado na figura 6.2. Inicialmente, arquivos de entrada (dados iniciais) contendo informação sobre o modelo de MEF do domínio (coordenadas de nós, conectividades dos elementos, nós solicitados e vinculados, etc) são fornecidos ao algoritmo. Mediante uma análise de MEF, são obtidos os valores de potenciais elétricos utilizados no cálculo da função objetivo e restrições.

A etapa seguinte consiste na otimização das variáveis do problema (distribuição de material) que exige a informação sobre os gradientes da função objetivo e restrições em relação às variáveis de projeto (análise de sensibilidade 


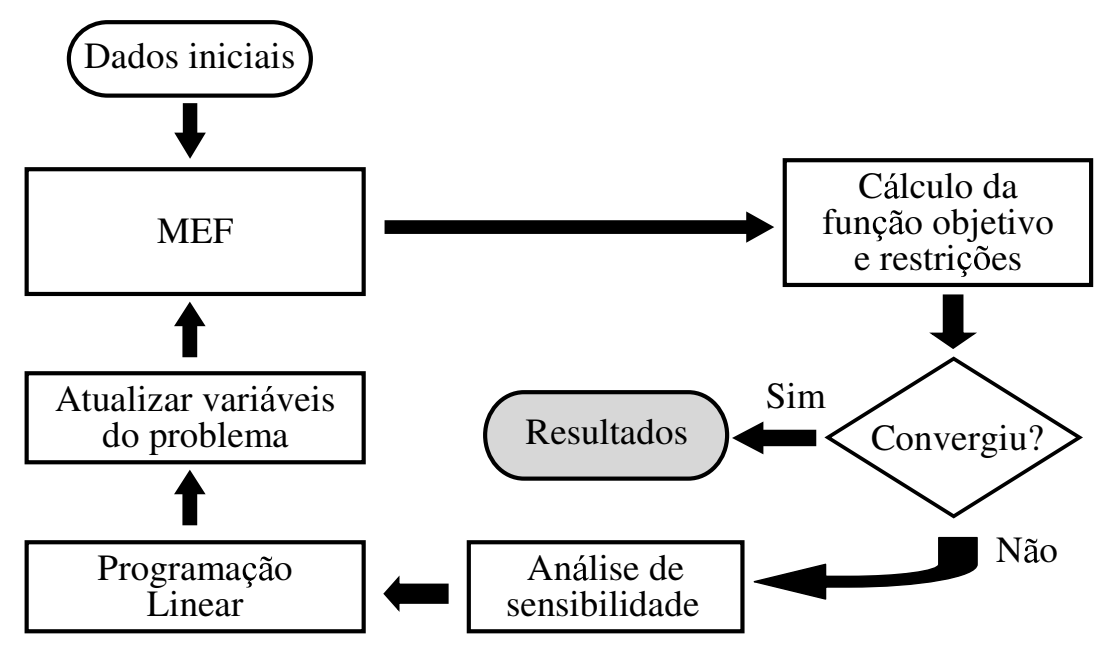

Figura 6.2: Fluxograma do algoritmo de MOT.

desenvolvida no capítulo 5). O processo de otimização topológica, inicia-se com uma distribuição uniforme de variáveis de projeto (valor inicial $\rho_{k}^{0}$ ) em todo o domínio, a qual é atualizada ao longo das iterações até que se alcance a convergência no valor da função objetivo e, conseqüentemente, a distribuição ótima de material ao longo do domínio de projeto. Considera-se que a convergência ocorre quando o valor da função objetivo torna-se constante, dentro de uma margem de erro de 0,001\%, durante as iterações.

O software implementado neste trabalho é denominado de TOMOGOT e o fluxograma detalhado de sua estrutura de funcionamento encontra-se no anexo B. A seguir são descritas implementações adicionais ao algoritmo proposto, para auxiliar no processo de solução do problema de otimização topológica aplicado a TIE.

\subsection{Estratégias para Otimização das Variáveis do Problema}

Além de encontrar a distribuição ótima de material que reproduza os valores de condutividade (ou resistividade) esperado no domínio, o software implementado (TOMOGOT) deve também ser capaz de determinar a impedância de contato dos eletrodos (parâmetros dos elementos de eletrodos no modelo de MEF), ou seja, o TOMOGOT deve encontrar o conjunto de valores de parâmetros de eletrodos (produto $\rho t$ mostrado na seção 4.6) apropriados para garantir a obtenção da imagem desejada. Neste trabalho, os parâmetros de eletrodos $\left(\rho t_{j}\right)$ e a distribuição de material no domínio (representada pelas variáveis $\rho_{k}$ ) são obtidos por otimização através do TOMOGOT. Desta forma, temos dois tipos 
distintos de variáveis de projeto a serem otimizadas $\left(\rho t_{j}\right.$ e $\left.\rho_{k}\right)$. Conforme visto no capítulo 3, um modelo de material é aplicado no processo de otimização topológica das variáveis $\rho_{k}$ (também conhecidas por pseudo-densidades), que normaliza estas variáveis entre 0 e 1 . Esse modelo de material poderia ser aplicado ao processo de otimização dos parâmetros $\rho t_{j}$, porém esse modelo dependeria do conhecimento prévio de um valor base para os parâmetros de eletrodos, que a princípio são desconhecidos. Assim, neste caso, o ideal é considerar o valor absoluto dos parâmetros de eletrodos como variáveis do problema de otimização.

Durante a realização deste trabalho, inicialmente foram testadas duas estratégias de otimização das duas variáveis distintas de projeto $\left(\rho t_{j}\right.$ e $\left.\rho_{k}\right)$. $\mathrm{Na}$ primeira, foi implementado no TOMOGOT uma rotina que executa simultaneamente a otimização das variáveis $\rho t_{j}$ e $\rho_{k}$, ou seja, nesta estratégia considera-se um único problema de otimização onde o conjunto de variáveis de projeto é a união entre os valores dos parâmetros de eletrodos e os valores de pseudo-densidades de cada elemento do domínio. Porém, não foi obtido sucesso com essa rotina, devido à diferença de escala entre os gradientes das duas variáveis de projeto $\left(\rho t_{j}\right.$ e $\left.\rho_{k}\right)$.

Após essa tentativa, foi implementada a segunda estratégia, na qual a rotina do TOMOGOT é alterada para executar duas otimizações - a otimização dos parâmetros de eletrodos e a otimização das variáveis $\rho_{k}$, separadamente. Neste caso, o problema de otimização resolvido para encontrar os valores de parâmetros de eletrodos é definido da seguinte maneira:

$$
\begin{aligned}
\underset{\boldsymbol{\rho} \mathbf{t}}{\text { Minimizar }:} & F=\frac{1}{2} \sum_{\mathrm{j}=1}^{n e} \sum_{\mathrm{i}=1}^{n p}\left(\phi_{\mathrm{ij}}-\phi_{\mathrm{ij} 0}\right)^{2} \\
\text { tal que : } & \text { equação de equilíbrio do meio condutivo } \\
& 0 \leq \rho t_{\text {min }} \leq \rho t_{j} \leq \rho t_{\max } ; j=1 \ldots n p \\
& \sum_{j=1}^{n p} \frac{1}{d_{j}^{q}} \rho t_{j} \geq \sum_{j=1}^{n p} \frac{1}{d_{j}^{q}} \overline{\rho t}^{*} \quad \text { (restr. valor médio) }
\end{aligned}
$$

onde $\rho t_{j}$ são as variáveis do problema (valor dos parâmetros de eletrodos), limitadas entre os valores mínimo $\rho t_{\text {min }}$ e máximo $\rho t_{\text {max }}$. Neste caso, o valor de $\rho t_{\text {min }}$ não pode ser considerado exatamente zero, para evitar singularidades no MEF (BATHE, 1996) e conseqüentemente o mal-condicionamento numérico da solução do problema. A restrição do valor médio mostrada na equação (6.6) é similar a restrição descrita no capítulo 5 (seção 5.3 ), onde $\overline{\rho t}^{*}$ é um valor médio estimado para a impedância de contato dos eletrodos.

Nessa segunda estratégia são implementadas duas abordagens para executar a 
otimização dos parâmetros $\rho t_{j}$ e das pseudo-densidades $\rho_{k}$ separadamente, como descrito a seguir.

\subsubsection{Abordagem 1: otimização das variáveis separadamente}

Na Abordagem 1, primeiro roda-se uma vez o TOMOGOT para realizar a otimização das variáveis $\rho t_{j}$ (problema da equação (6.6)) até a convergência. Nesta otimização, os parâmetros de eletrodos $\left(\rho t_{j}\right)$ são encontrados utilizando-se dados de potenciais elétricos medidos $\left(\phi_{\mathrm{ij0}}\right)$ de um domínio homogêneo (meio totalmente aquoso, por exemplo). Neste caso, a imagem a ser reconstruída é uma região homogênea que compreende todo o domínio, portanto a distribuição de material (ou condutividades) no domínio é conhecida e fixa previamente. Sendo assim, as únicas variáveis a serem consideradas são os parâmetros de eletrodos, que são otimizados para reproduzir os valores dos potenciais elétricos $\phi_{\mathrm{ij} 0}$ (esperados para o domínio homogêneo). Em seguida, esses parâmetros são fixados e utilizados como dados de entrada num novo processamento do TOMOGOT para obter-se as pseudo-densidades $\rho_{k}$, a partir de dados de potenciais elétricos medidos $\left(\phi_{\mathrm{ij} 0}\right)$ de um domínio cuja imagem é desejada (meio aquoso com objeto incluso, por exemplo). A figura 6.3 ilustra o procedimento da Abordagem 1, que foi utilizada para produzir os resultados apresentados na seção 7.3.1 do capítulo seguinte.

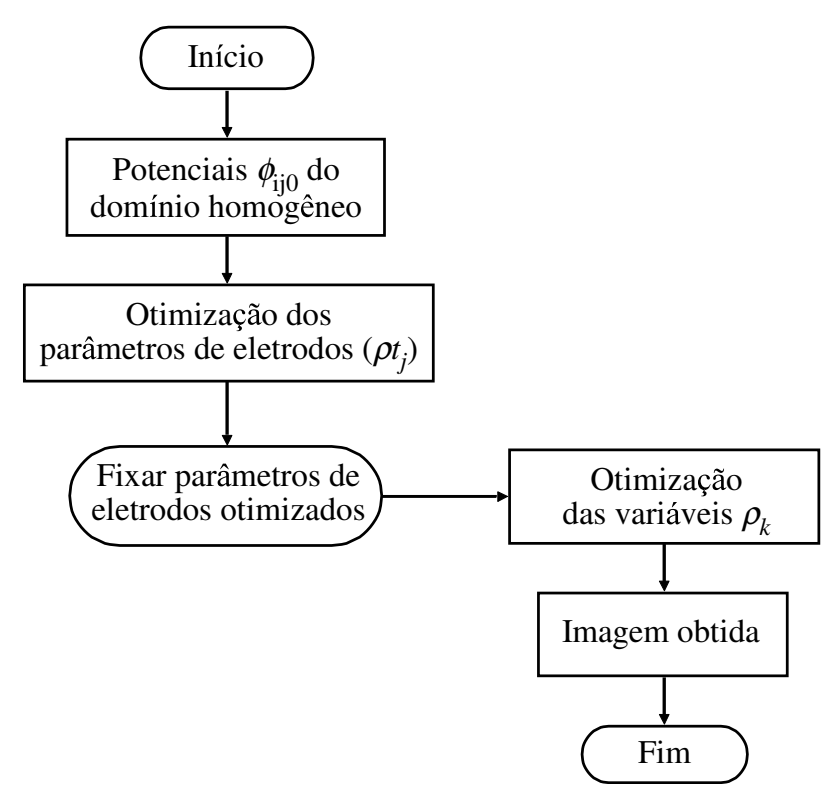

Figura 6.3: Procedimento para desenvolver as otimizações das variáveis $\rho t_{j}$ e $\rho_{k}$ (Abordagem 1). 


\subsubsection{Abordagem 2: otimização das variáveis com alternância}

Essa abordagem é tratada neste trabalho como "alternância das otimizações". Neste caso, o algoritmo do TOMOGOT foi modificado para alternar as otimizações dos parâmetros de eletrodos $\left(\rho t_{j}\right)$ e das pseudo-densidades $\left(\rho_{k}\right)$ durante o processo iterativo. A abordagem 2 é implementada para otimizar as duas variáveis $\rho t_{j}$ e $\rho_{k}$ principalmente quando se utiliza dados de potenciais elétricos obtidos experimentalmente. Percebe-se que ao utilizar dados obtidos através de fantomas numéricos o método implementado no TOMOGOT funciona bem, porém quando se utilizam dados obtidos através de fantomas experimentais o método nos fornece um conjunto de parâmetros de eletrodos que não reconstrói a imagem desejada. Conclui-se que provavelmente esses valores podem ser interpretados como mínimos locais, os quais obtém uma imagem sem significado para o caso.

Assim, para solucionar esse problema, foi adotado uma metodologia baseada na proposta de Trigo, Gonzalez-Lima e Amato (2004), que consiste em fazer com que o TOMOGOT alterne entre as duas otimizações, dos parâmetros de eletrodos e da distribuição de material, de maneira seqüencial. Ou seja, o software ora otimiza as variáveis $\rho t_{j}$, ora otimiza as variáveis $\rho_{k}$ e repete o ciclo até obter a imagem desejada, conforme ilustrado na figura 6.4.

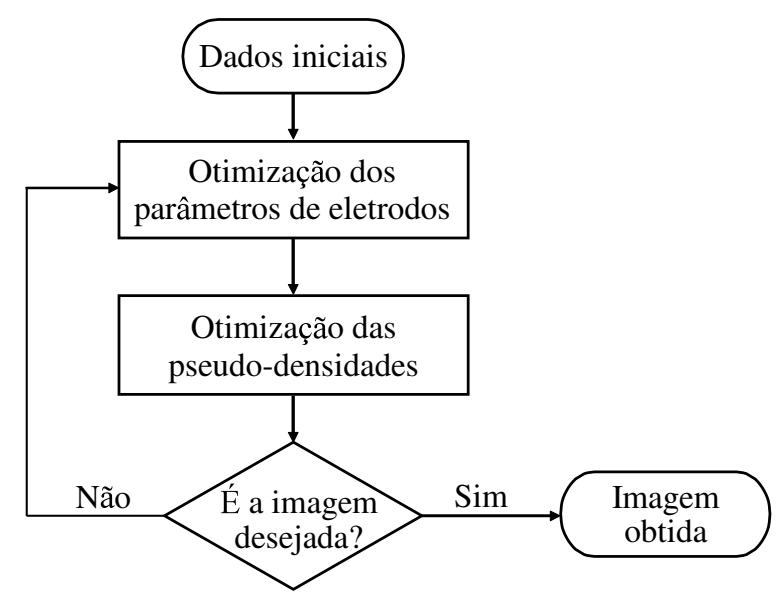

Figura 6.4: Procedimento para alternar as otimizações das variáveis $\rho t_{j}$ e $\rho_{k}$ (Abordagem 2).

Segundo Trigo, Gonzalez-Lima e Amato (2004) obter os parâmetros de eletrodos e a distribuição de material executando simultaneamente a otimização das duas variáveis $\left(\rho t_{j}\right.$ e $\left.\rho_{k}\right)$ não é numericamente vantajoso, conforme detectado também neste trabalho. Porém, executando alternadamente a otimização das duas variáveis, como proposto na figura 6.4, o resultado final é necessariamente 
o mesmo ao obtido se os dois processos de otimização forem realizados simultaneamente. Eles demonstram isso no trabalho deles, que utiliza o Filtro de Kalman Estendido (VAUHKONEN; KARJALAINEN; KAIPIO, 1998) como algoritmo de reconstrução de imagem na TIE. Assim, este procedimento também é adotado com sucesso para o propósito deste presente trabalho, conforme mostram os resultados apresentados no capítulo 7 .

Em termos de implementação de algoritmo computacional, automatizar o procedimento para alternância das duas otimizações é um processo bastante trabalhoso. Por exemplo, um fator que dificultou essa implementação foi o fato dos dois problemas de otimização envolvidos trabalharem com número de variáveis de projeto diferentes. No caso, na otimização dos parâmetros de eletrodos são 32 (ou 30) variáveis de projeto e na otimização da distribuição de material o número de variáveis é igual ao número de elementos finitos da malha, geralmente bem maior que o número de variáveis do problema de otimização dos parâmetros de eletrodos. Isto faz com que a escolha do tamanho dos vetores e matrizes declarados nas rotinas do software seja bem estruturada para não se gerar acúmulo de declarações desnecessárias ou armazenamento desnecessário de memória.

Todos esses fatores implicam no bom desempenho ou não do software implementado, em termos de velocidade e confiabilidade dos resultados obtidos. Por exemplo, neste trabalho, o vetor que recebe os valores dos gradientes da função objetivo em relação as variáveis de projeto foi dimensionado para ser comum aos dois processos de otimização, porém isto pode implicar num super dimensionamento do mesmo. Pois, quando ocorrer a otimização dos parâmetros de eletrodos, somente uma parte da memória reservada ao vetor estará sendo utilizada, o restante estará ocupando memória desnecessariamente. Uma solução para esse caso seria declarar o vetor somente quando for necessário, dentro da rotina que o utiliza, porém há um complicador devido ao fato que esse é um tipo de vetor comum a várias rotinas do software e não pode ser declarado localmente. Além disso, não é recomendável declarar e liberar memória dentro de um laço ("loop") da rotina, pois isso pode tornar o software lento e até mesmo provocar problemas na alocação de memória (ARAKAKI et al., 1990). Apesar disso, o software foi implementado com sucesso e desenvolve o processo de otimização topológica aplicada a TIE de maneira satisfatória. 


\subsection{Filtro Espacial}

Com o intuito de regularizar o algoritmo de obtenção da imagem, implementado no TOMOGOT, nesta seção é proposto a utilização de um filtro espacial para controle de gradientes.

A utilização de um filtro no problema de otimização topológica faz com que o algoritmo tenha um controle maior da variação do valor da variável de projeto. Assim, foi acrescentado ao TOMOGOT um filtro espacial proposto por Cardoso (2000). Esse filtro suaviza a distribuição espacial das variáveis de projeto ao longo do domínio, através de uma transformação matemática a cada variável do problema de otimização. O filtro espacial possui raio de abrangência variável e é aplicado sobre os limites móveis das variáveis do problema de otimização linearizado, resolvido iterativamente pela PLS.

Alguns trabalhos da literatura sugerem a aplicação do filtro diretamente nas variáveis de projeto do problema (BENDSøE; SIGMUND, 2003), mas como essas variáveis geralmente são atualizadas a cada iteração durante o processo de otimização, ao aplicarmos esse filtro modificamos os valores ótimos encontrados para essas variáveis na iteração, prejudicando a otimização realizada. A aplicação do filtro espacial sobre os limites móveis da variável de projeto permite um controle simplificado da complexidade da solução do problema de otimização topológica. O filtro espacial, utilizado neste trabalho, é uma variação espacial do filtro originalmente proposto por Swan e Kosaka (1997), que propuseram um esquema de filtragem de vizinhança fixa, em que a densidade de cada elemento depende das densidades dos elementos vizinhos, da seguinte maneira:

$$
\rho_{i}=\frac{\rho_{i} V_{i}+w_{1} \sum_{j} \rho_{j} V_{j}+w_{2} \sum_{j} \rho_{j} V_{j}}{V_{i}+w_{1} \sum_{j} V_{j}+w_{2} \sum_{j} V_{j}}
$$

onde $V_{i}$ é o volume do elemento $i$ no problema discreto, $w_{1}$ e $w_{2}$ são pesos atribuídos heuristicamente aos vizinhos de arestas e vizinhos de vértices, respectivamente.

Em filtros de vizinhança fixa somente elementos vizinhos de aresta e/ou vértice são considerados, o que torna o resultado da otimização dependente da discretização do domínio e restringe a utilização de malhas não regulares. Já nos filtros espaciais são considerados os elementos que estão dentro de um determinado raio de abrangência em torno do elemento central, conforme mostrado na figura 6.5.

Os filtros espaciais minimizam a dependência do resultado final ao refino da 


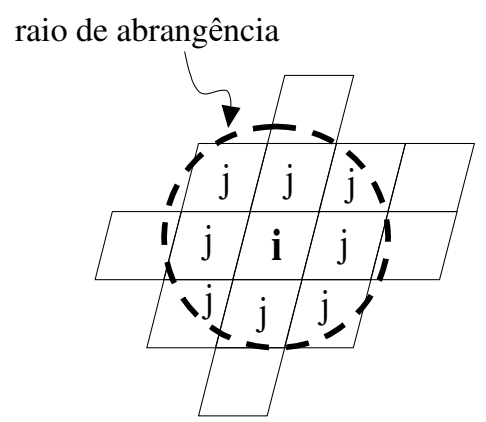

Figura 6.5: Raio de abrangência do filtro espacial.

malha de elementos finitos e permitem um controle da complexidade da solução, ou seja, uma abrangência maior de elementos em torno do elemento central permite obter distribuições mais suaves da variável do problema. No filtro espacial utilizado são considerados os elementos vizinhos que se encontram dentro de um raio $R_{\max }$ em torno do elemento central, cujos pesos da média ponderada são calculados, conforme equação abaixo:

$$
W_{i}=R_{\max }-R_{i j}
$$

onde $R_{i j}$ é a distância entre centróides (menor que $R_{\max }$ ) do elemento central $i$ e do elemento vizinho $j$. Baseado no conceito do filtro espacial linear, Cardoso (2000) propôs a seguinte alteração para tornar o filtro de Swan e Kosaka (1997) num filtro espacial:

$$
\rho_{i}=\frac{\rho_{i} V_{i}+\bar{w} \sum_{j=1}^{n v} \rho_{j} V_{j}}{V_{i}+\bar{w} \sum_{j=1}^{n v} V_{j}}
$$

com

$$
\bar{w}=\frac{\sum_{j=1}^{n v} w_{j}}{n v}
$$

onde

$$
w_{j}=\frac{R_{\max }-R_{i j}}{R_{\max }}
$$

sendo $n v$ o número de vizinhos determinados por uma varredura fixa em torno do elemento central $i$, com $j=1,2, \ldots, n v$. Percebe-se que, desta maneira os pesos fixos para vizinhos de aresta e de vértice não são mais considerados. O filtro proposto por Cardoso (2000) combina as vantagens do filtro de vizinhança fixa, com os benefícios dos filtros espaciais, e como é aplicado diretamente sobre os limites móveis da programação linear, permite obter um controle sobre o gradiente da variável do problema sem impor uma mudança artificial sobre a distribuição das variáveis de projeto, obtida da otimização, no domínio de projeto. A desvantagem da aplicação do filtro sobre os limites móveis é a dependência do desempenho do filtro com métodos de determinação dos limites móveis. Se esses métodos permitirem uma variação muito brusca dos valores dos limites 
móveis, poderão causar uma atenuação do efeito do filtro. Porém, isso não se configura num grande problema, pois as variações dos limites móveis são limitadas a pequenos valores devido a aproximação linear realizada na programação linear do problema de otimização.

\subsection{Método da Continuação}

Na tentativa de obter uma solução mais próxima de um mínimo global e evitar mínimos locais indesejados, é implementada no TOMOGOT uma técnica bastante comum nos trabalhos de Otimização Topológica conhecida por método da continuação (ROZVANY; BENDSØE; KIRSCH, 1995; SIGMUND; PETERSSON, 1998; CARDOSO, 2000).

Num problema de otimização topológica observa-se que se iniciarmos o processo de otimização topológica com altos valores de fator de penalidade $(p)$ o problema contínuo, obtido através da relaxação com o modelo de material (veja seção 3.4.2), se aproxima do caso discreto, cuja solução contém vários mínimos locais (considerando um problema de minimização da função objetivo) (BENDSøE; SIGMUND, 1999). Conseqüentemente, é possível que a solução do problema aponte para um mínimo local indesejável. Todavia, se o processo for iniciado com baixos valores de fator $p$ e aumentado gradativamente, a solução com mínimos locais indesejáveis pode ser evitada e, assim, aumenta-se a probabilidade do algoritmo conduzir a solução do problema para um mínimo local mais apropriado (mais próximo de um mínimo global, por exemplo) (ROZVANY; BENDSØE; KIRSCH, 1995). Trata-se de uma técnica semi-empírica e que embora não tenha sido comprovada na literatura é bastante usada.

O método da continuação implementado no TOMOGOT auxilia a penalização do modelo de material na obtenção de valores das variáveis de projeto próximos ou iguais aos respectivos valores de condutividade (ou resistividade) esperados. A utilização deste método implica numa mudança gradativa na definição original do problema de obtenção de imagem ao longo da solução, ou seja, o processo consiste em iniciar o problema considerando a formulação do modelo de material com $p$ igual a 1, obtendo uma solução inicial que não penaliza as pseudo-densidades intermediárias, e em seguida o problema inicial é utilizado como ponto de partida para uma formulação modificada, utilizando diferentes valores de $p$ consecutivos maior que 1. 


\subsection{Aproximação Contínua de Distribuição de Material ("CAMD")}

Sabe-se que o MOT é sujeito a problemas numéricos, tais como surgimento de excesso de "escala de cinza" (materiais intermediários), dependência da malha de elementos finitos (diferentes resposta conforme o domínio é discretizado em um número maior de elementos) e instabilidade de tabuleiros (regiões com alternância entre um material e outro na forma de um tabuleiro de xadrez). Na literatura há vários trabalhos com diversas alternativas para minimizar os efeitos destas instabilidades (DIAZ; SIGMUND, 1995; BENDSøE; SIGMUND, 1999; FUJII; KIKUCHI, 2000). Uma delas é a aplicação de técnicas filtragem, como o filtro espacial descrito na seção 6.4, que visa a eliminação das instabilidades de tabuleiro e dependência da malha (FUJII; KIKUCHI, 2000). As técnicas de filtragem fornecem restrições adicionais ao problema de otimização topológica para controle da distribuição de material no domínio e são bastante dependentes de parâmetros, que geralmente são adotados heuristicamente. A formação excessiva de "escala de cinza" é outro problema indesejável e, como já visto no capítulo 3, pode ser minimizada aumentando-se o valor do expoente $(p)$ do modelo de material SIMP (BENDSøE; SIGMUND, 1999).

Recentemente, Matsui e Terada (2004) propuseram uma técnica alternativa, conhecida por CAMD ("Continuous Approximation of Material Distribution"), ou Aproximação Contínua de Distribuição de Material, que visa a redução de instabilidades numéricas, como a de "tabuleiros" (DIAZ; SIGMUND, 1995). Esta técnica consiste em distribuir o material no interior do domínio de uma maneira contínua e, conseqüentemente, permitir uma variação contínua da propriedade física do material (a condutividade ou resistividade, por exemplo) no interior da microestrutura adotada no MOT. O algoritmo do TOMOGOT original adota uma metodologia na qual a distribuição do material no domínio é determinada pela pseudo-densidade (variável de projeto) que cada elemento assume no problema de otimização topológica. No entanto, na proposta do CAMD a pseudo-densidade varia continuamente ao longo do elemento, transformando a distribuição de material descontínua numa aproximação mais contínua possível. Desta maneira, com o intuito de explorar uma outra regularização para o problema de otimização topológica proposto para obtenção de imagem na TIE, o CAMD é implementado no TOMOGOT.

Na formulação do problema de otimização topológica proposta no capítulo 5 , a propriedade efetiva do material é interpolada para cada ponto do domínio usando 
o modelo de material SIMP da equação (3.5), que no domínio discreto é escrita da seguinte forma:

$$
\mathbf{C}_{k}=\rho_{k}^{p} \mathbf{C}_{A}+\left(1-\rho_{k}^{p}\right) \mathbf{C}_{B}
$$

onde $\mathbf{C}_{k}$ é a propriedade de condutividade de cada elemento no domínio, $\mathbf{C}_{A}$ e $\mathbf{C}_{B}$ são as propriedades de condutividade dos materiais básicos que compõem o domínio e $\rho_{k}$ é a pseudo-densidade definida para cada elemento.

No CAMD a variável de projeto ( $\rho$ ) é substituída por uma função do tipo:

$$
\rho=\sum_{i=1}^{n} N_{i} \rho_{i}
$$

onde $\rho_{i}$ são as variáveis de projeto definida em cada nó do elemento $k$, sendo $n$ o número de nós desse elemento. Observa-se que o número de variáveis de projeto passa a ser igual ao número total de nós da discretização do domínio. $N_{i}$ são os polinômios de interpolação do material em cada nó do elemento $k$.

Neste caso, os polinômios $N_{i}$ podem apresentar forma e grau qualquer, porém deve-se ter o cuidado em escolher polinômios de forma que $0 \leq \rho \leq 1$. Neste trabalho, utilizamos os mesmos polinômios de interpolação usados nas funções de forma do elemento finito utilizado para discretizar o domínio (equações (4.10) a $(4.13))$.

Sendo assim, com o CAMD a propriedade de condutividade em cada elemento $\left(\mathbf{C}_{k}\right)$ no domínio discreto passa a ser interpolado da seguinte maneira:

$$
\mathbf{C}_{k}=\left(\sum_{i=1}^{n} N_{i} \rho_{i}\right)_{k}^{p} \mathbf{C}_{A}+\left[1-\left(\sum_{i=1}^{n} N_{i} \rho_{i}\right)_{k}^{p}\right] \mathbf{C}_{B}
$$

A implementação do CAMD exigiu algumas modificações na rotina de MEF do TOMOGOT, principalmente na que realiza o cálculo da matriz de condutividade do elemento. O termo relativo as propriedades de material do elemento, $\boldsymbol{\sigma}_{(e)}$ da equação (4.24), não é mais constante como no caso anterior (sem a aplicação do CAMD), portanto sendo necessário integrá-lo.

Assim, depois de feita as modificações necessárias, a nova versão do TOMOGOT é testado em exemplos apresentados adiante no capítulo 7 . 


\section{$7 \quad$ Resultados}

\subsection{Introdução}

Neste capítulo, são apresentados exemplos que ilustram os resultados obtidos utilizando o software (denominado de TOMOGOT), implementado em linguagem C, que aplica o Método de Otimização Topológica (MOT) para obtenção de imagem de Tomografia por Impedância Elétrica (TIE).

A imagem é reconstruída a partir de um domínio de projeto (seção do corpo submetido a tomografia) bidimensional (2D), de geometria regular e bem conhecida, utilizando-se dados de voltagem numérico e experimental. Ou seja, os valores de potenciais elétricos (medidos e calculados) utilizados na função objetivo do problema de otimização topológica aplicado a TIE, mostrado no capítulo 5, são obtidos através de um modelo de MEF do domínio de projeto (fantoma numérico) ou de uma cuba preenchida com água e objeto imerso (fantoma experimental). O domínio de projeto é discretizado em elementos finitos triangulares e quadriláteros de 3 e 4 nós, respectivamente, com 1 grau de liberdade por nó - a condutividade elétrica do meio. São utilizados 32 (ou 30) eletrodos posicionados ao redor do domínio de projeto e são aplicados 32 (ou 30) casos de carga de corrente (ne), seguindo o padrão adjacente e diametral de excitação elétrica (veja seção 7.2). A impedância de contato nestes eletrodos é simulada através de elementos de eletrodos de largura igual a 10 milímetros. Em todos os exemplos mostrados neste capítulo, a corrente elétrica aplicada é considerada igual a $1 \mathrm{~mA}$ (miliampère), exceto nos exemplos onde são utilizados 30 eletrodos.

No caso em que se utiliza dados de voltagem numérico, a imagem é obtida a partir de uma configuração em que o modelo de MEF do domínio, utilizado para simular os potenciais elétricos medidos $\left(\phi_{\mathrm{ij0}}\right)$, possui um número maior de elementos finitos em relação ao modelo de MEF do domínio utilizado para obter a imagem, evitando assim o chamado "crime de inversão" (ou "inverse crime"), ou seja, reconstruir a imagem usando a mesma discretização de MEF do domínio utilizada para simular os potenciais elétricos $\phi_{\mathrm{ijo}}$ (fantoma 
numérico). Além disso, ao reconstruir a imagem numa malha de MEF "grosseira" (baixa discretização), usando valores de voltagens calculados numa malha "refinada" (alta discretização), onde são obtidos com maior precisão, estamos nos aproximando mais do caso real e economizando tempo computacional, pois ao reconstruir a imagem numa malha menos discretizada implica em redução da quantidade de variáveis no problema de otimização e, conseqüentemente, o tempo de processamento computacional gasto. Desta forma, através desta configuração que evita o "crime de inversão", verifica-se que o método implementado neste trabalho é robusto para lidar com os erros oriundos de duas discretizações distintas do modelo de MEF do domínio.

O método de otimização topológica (MOT) utiliza alguns parâmetros para a obtenção da imagem da seção do corpo na TIE, tais como o valor inicial $\left(\rho_{k}^{0}\right)$ atribuído a todas variáveis de projeto no início da otimização da distribuição de material no interior do domínio e o fator de penalidade $(p)$ aplicado ao modelo de material, descrito no capítulo 3. Assim, neste capítulo, explora-se também qual é a influência desses parâmetros nos resultados obtidos com o TOMOGOT.

\subsection{Padrões de Excitação Elétrica}

Para obter uma qualidade de imagem aceitável para aplicação clínica na TIE, são utilizados, na maioria dos exemplos apresentados neste capítulo, 32 (ou 30) elementos de eletrodos posicionados uniformemente ao longo do contorno do modelo de MEF do domínio de projeto (TANG et al., 2002). Os valores de potenciais elétricos em cada nó dos elementos de eletrodos são obtidos mediante excitação elétrica em um par de eletrodos, onde um deles é o "terra" (potencial nulo) e o outro é o ponto de aplicação de corrente elétrica de baixa amplitude. Neste trabalho, essa excitação elétrica é realizada seguindo um certo padrão estipulado, que pode ser adjacente ou diametral (CHENEY; ISAACSON; NEWELL, 1999), conforme mostrado na figura 7.1.

Para se obter a imagem desejada, percorrem-se todos os elementos de eletrodos localizados ao redor do domínio de projeto, mudando-se sucessivamente o eletrodo em que se aplica a corrente elétrica (I) e também o eletrodo com potencial nulo ("terra"), de forma a se obter um número de observações suficientes sob diferentes ângulos. Portanto, no total, é aplicada uma seqüência de 32 casos de padrões de excitação elétrica de um mesmo tipo (adjacente ou diametral) e efetuado 32 medições (uma em cada eletrodo) em cada caso para a obtenção da imagem. 


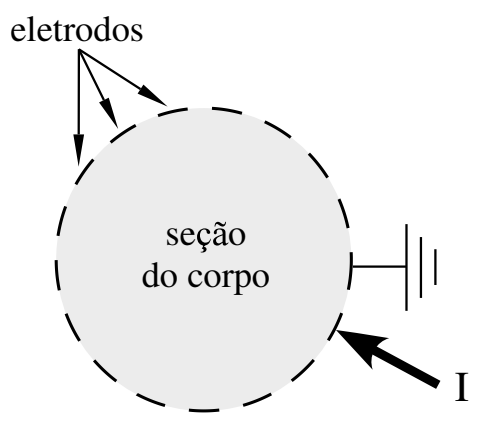

(a) padrão adjacente

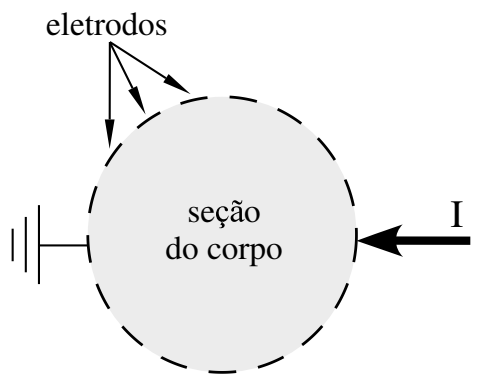

(b) padrão diametral

Figura 7.1: Padrões de excitação elétrica.

Na seção 7.4.2 é apresentado um outro padrão de excitação elétrica para explorar o método, denominado "diferencial". Como será visto, o padrão "diferencial" é derivado do padrão adjacente, pulando um dos eletrodos vizinhos, sendo aplicado uma seqüência de 30 casos deste padrão de excitação e efetuado 30 medições em cada caso para a obtenção da imagem.

\subsection{Resultados Obtidos com Dados Numéricos}

Nesta seção, são mostrados vários exemplos onde o TOMOGOT é usado para reproduzir a imagem de fantomas numéricos, a partir de geometrias circular e elíptica adotada para o domínio discretizado. O fantoma numérico é um modelo de MEF do domínio que contém a imagem desejada (PAULSON; BRECKON; PIDCOCK, 1992), construído para simular os potenciais elétricos $\left(\phi_{\mathrm{ij} 0}\right)$ que na prática são obtidos experimentalmente. Assim, por enquanto, a verificação do potencial do TOMOGOT para obter imagens na TIE será realizada através dos potenciais elétricos obtidos numericamente através destes fantomas. O comportamento do TOMOGOT em lidar com dados obtidos experimentalmente, é verificado mais adiante, na seção 7.4 .

\subsubsection{Reprodução da Imagem num Domínio Elíptico}

Para todos os exemplos mostrados a seguir considera-se no interior do domínio (seção do corpo submetido a tomografia), a existência de líquido e outro material imerso (cuja imagem se deseja obter). Esses materiais são representados pela sua condutividade (ou resistividade) elétrica, cujos valores são definidos na seção.

Para ilustrar o potencial do TOMOGOT para obter a imagem na TIE num domínio qualquer, nesta seção são apresentados exemplos de obtenção de imagem a partir de um domínio elíptico, cuja medida do maior eixo é igual a 400 
milímetros. O motivo para a escolha de um domínio elíptico deve-se ao fato da semelhança dessa geometria com a do contorno do tórax de um corpo humano.

Os resultados mostrados nesta seção são obtidos utilizando-se a Abordagem 1, descrita na seção 6.3.1 (capítulo 6).

\subsubsection{Modelo de MEF do Domínio para Obtenção da Imagem e Fantoma Numérico}

O modelo de MEF do domínio, utilizado para reconstrução da imagem desejada, é construído com uma malha de 1120 elementos quadriláteros de 4 nós (espessura igual a 35 milímetros), utilizando-se um número maior de elementos (refinamento) no contorno do domínio, conforme mostrado na figura 7.2, para representar melhor numericamente os efeitos na fronteira do domínio com os elementos de eletrodos.

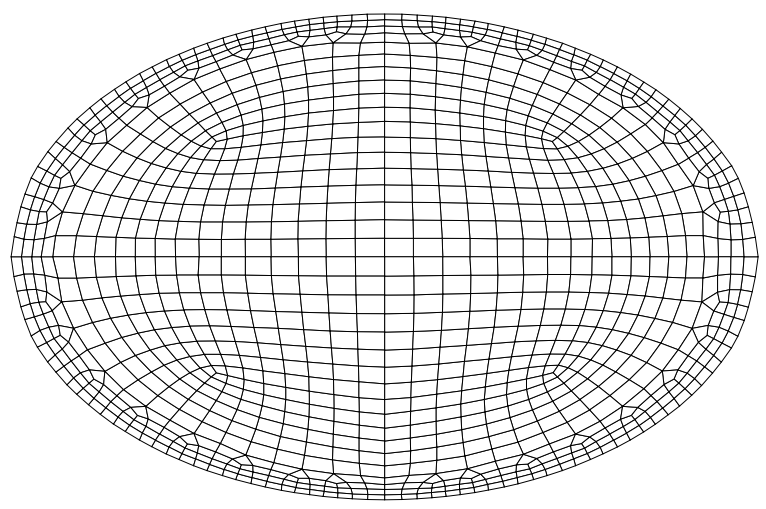

Figura 7.2: Malha com 1120 elementos, utilizada para obtenção da imagem.

A figura 7.3 apresenta os fantomas numéricos e imagens distintas a serem reconstruídas no domínio elíptico. O domínio do fantoma numérico é discretizado em 3072 elementos quadriláteros de 4 nós, com espessura igual a 35 milímetros. Observa-se que no fantoma numérico é utilizado um modelo de MEF com uma discretização maior que a discretização da malha utilizada para reconstruir a imagem (veja figura 7.2), para tentar simular com mais precisão a distribuição nodal de potenciais elétricos no domínio, e conseqüentemente obter valores de potenciais elétricos mais próximo do caso real, além de evitar o "crime de inversão".

Para testar o TOMOGOT, foram criadas duas situações distintas. Uma situação onde há uma região de material diferente do restante do domínio de projeto (região escura mostrada na figura 7.3(a)) e outra situação onde o domínio contém duas regiões de mesmo material, porém diferente do material do restante do domínio de projeto (regiões escuras mostradas na figura 7.3(b)). Em 


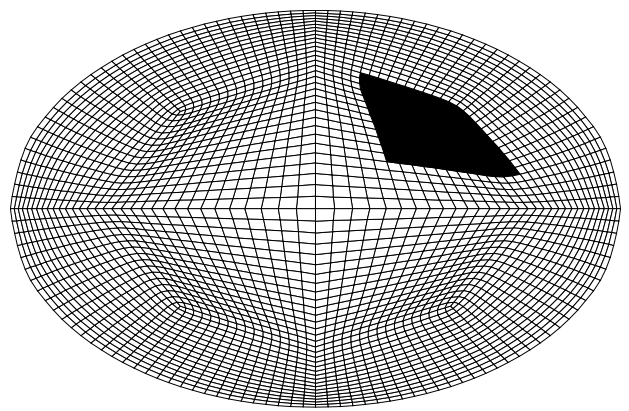

(a)

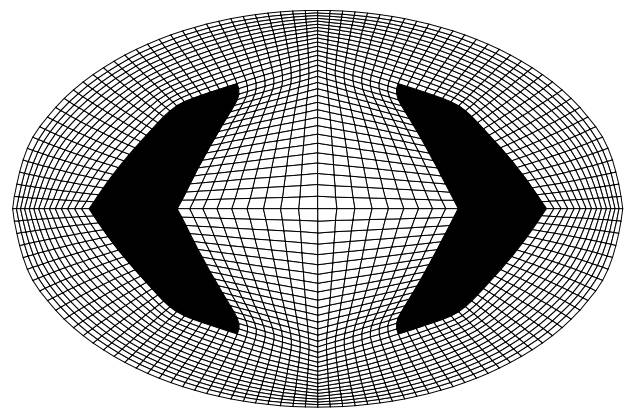

(b)

Figura 7.3: Fantomas numéricos com 3072 elementos quadriláteros e imagens a serem reconstruídas no domínio elíptico da figura 7.2.

ambos os casos, as regiões escuras simulam um material de baixa condutividade, $10^{-6}(\Omega m)^{-1}$, em relação a condutividade do material do restante do domínio, considerada igual a $1 / 17(\Omega m)^{-1}$ (região clara do domínio). Na prática, essas situações seriam equivalentes a se obter, na tomografia de um meio aquoso, uma ou duas regiões com ar, por exemplo. Observa-se que o TOMOGOT é implementado com uma formulação que admite apenas dois materiais (veja modelo de material no capítulo 3), porém em trabalhos futuros esta formulação pode ser redefinida para admitir mais materiais.

OBSERVAÇÃO: Os valores de potenciais elétricos capturados para o cálculo da função objetivo do problema de otimização são os potenciais elétricos de nós que estão em torno do domínio, próximos ao contorno da malha e que correspondem aos nós dos elementos de eletrodos, que não estão desenhados nas figuras apresentadas acima.

\subsubsection{Obtenção dos Parâmetros de Eletrodos}

Como visto no capítulo 6 , os parâmetros de eletrodos $\left(\rho t_{j}\right)$ são considerados variáveis de projeto e são obtidos através do processo iterativo do TOMOGOT que, nos exemplo mostrados a seguir, utiliza o procedimento da Abordagem 1 para desenvolver as otimizações dos parâmetros de eletrodos e das pseudo-densidades. Nesta abordagem, o software determina os parâmetros de eletrodos a partir de valores de potenciais elétricos obtidos em um fantoma (numérico ou experimental) de um domínio homogêneo. Os parâmetros de eletrodos, otimizados pelo TOMOGOT, são utilizados como valores constantes para a reconstrução de qualquer imagem desejada dentro do domínio de projeto (veja seção 6.3.1).

Para exemplificar, considere o modelo de MEF de um domínio elíptico homogêneo, discretizado em 3072 elementos quadriláteros (similar ao domínio 
mostra na figura 7.3, sem regiões escuras e com as mesmas dimensões), e com 32 elementos de eletrodos posicionados equidistantes no contorno do domínio. A cada um dos 32 elementos de eletrodos utilizados no modelo de MEF do domínio é atribuído um parâmetro $\left(\rho t_{j}\right)$ igual a $0,01 \Omega m^{2}$. Aplicando esses parâmetros ao fantoma numérico do domínio homogêneo e através de uma análise de MEF, são obtidos os valores de potenciais elétricos nodais, que são considerados na seqüência do processo como potenciais elétricos $\phi_{\mathrm{ij} 0}$. A partir desses potenciais elétricos e do domínio de obtenção de imagem mostrado na figura 7.2, cujo modelo de MEF é discretizado em 1120 elementos quadriláteros, executa-se o processo iterativo do TOMOGOT para reconstituir os parâmetros a serem utilizados nos elementos de eletrodos. Neste caso, espera-se reconstituir os valores de parâmetros de eletrodos adotados no fantoma numérico $\left(0,01 \Omega m^{2}\right.$ para todos os elementos de eletrodos). Os valores de parâmetros encontrados ao aplicar os padrões adjacente e diametral de excitação elétrica são mostrados nas tabelas 7.1 e 7.2 , respectivamente.

Tabela 7.1: Valores dos parâmetros de eletrodos para o padrão adjacente

\begin{tabular}{|cc|cc|cc|cc|}
\hline eletrodo & $\rho t_{j}$ & eletrodo & $\rho t_{j}$ & eletrodo & $\rho t_{j}$ & eletrodo & $\rho t_{j}$ \\
\hline 1 & 0,020 & 9 & 0,016 & 17 & 0,029 & 25 & 0,012 \\
2 & 0,010 & 10 & 0,011 & 18 & 0,011 & 26 & 0,011 \\
3 & 0,011 & 11 & 0,011 & 19 & 0,012 & 27 & 0,011 \\
4 & 0,012 & 12 & 0,012 & 20 & 0,011 & 28 & 0,011 \\
5 & 0,012 & 13 & 0,011 & 21 & 0,011 & 29 & 0,011 \\
6 & 0,012 & 14 & 0,012 & 22 & 0,011 & 30 & 0,011 \\
7 & 0,015 & 15 & 0,012 & 23 & 0,012 & 31 & 0,010 \\
8 & 0,008 & 16 & 0,010 & 24 & 0,011 & 32 & 0,009 \\
\hline
\end{tabular}

Tabela 7.2: Valores dos parâmetros de eletrodos para o padrão diametral

\begin{tabular}{|cc|cc|cc|cc|}
\hline eletrodo & $\rho t_{j}$ & eletrodo & $\rho t_{j}$ & eletrodo & $\rho t_{j}$ & eletrodo & $\rho t_{j}$ \\
\hline 1 & 0,022 & 9 & 0,015 & 17 & 0,020 & 25 & 0,015 \\
2 & 0,010 & 10 & 0,008 & 18 & 0,010 & 26 & 0,008 \\
3 & 0,010 & 11 & 0,010 & 19 & 0,012 & 27 & 0,010 \\
4 & 0,012 & 12 & 0,012 & 20 & 0,012 & 28 & 0,010 \\
5 & 0,012 & 13 & 0,010 & 21 & 0,010 & 29 & 0,010 \\
6 & 0,010 & 14 & 0,012 & 22 & 0,010 & 30 & 0,010 \\
7 & 0,012 & 15 & 0,012 & 23 & 0,010 & 31 & 0,012 \\
8 & 0,008 & 16 & 0,008 & 24 & 0,008 & 32 & 0,010 \\
\hline
\end{tabular}

De acordo com as tabelas, a maioria dos parâmetros de eletrodos foi obtida num valor bem próximo aos dos valores esperados. Exceto alguns parâmetros (eletrodos 1, 7, 9 e 17 da tabela 7.1 e eletrodos 1, 9, 17, 25 da tabela 7.2), a 
diferença média encontrada para os parâmetros de eletrodos foi de 11,1\% no padrão adjacente de excitação elétrica e de 10,6\% para o padrão diametral. Observa-se que o método utilizado no algoritmo do TOMOGOT nessa primeira abordagem obtém os parâmetros dos eletrodos a partir de um valor inicial adotado aleatóriamente. A diferença média entre os valores obtidos e esperados para os parâmetros de eletrodos é justificável, já que o método obtém o conjunto ótimo de valores usando uma malha menos discretizada que a malha utilizada no fantoma numérico.

\subsubsection{Obtenção das Imagens Desejadas}

Considerando os valores dos potenciais elétricos calculados através dos fantomas numéricos da figura 7.3 (com uma e duas regiões) como potenciais elétricos $\phi_{\mathrm{ij} 0}$ e utilizando os valores dos parâmetros de eletrodos otimizados, mostrados nas tabelas 7.1 e 7.2, o TOMOGOT procede a reconstrução das imagens desejadas. Neste caso, considera-se o valor inicial para as variáveis de projeto no $\operatorname{MOT}\left(\rho_{k}^{0}\right)$ igual a 0,15 e fator de penalidade $(p)$ do modelo de material igual a 2 .

Assim, a seguir são mostradas as imagens (distribuição de condutividades) geradas no domínio elíptico após algumas iterações no TOMOGOT. As imagens são obtidas com a aplicação dos padrões adjacente e diametral de excitação elétrica e sem a introdução de nenhuma restrição no problema de otimização do algoritmo implementado. A figuras 7.4 e 7.5 mostram as imagens e as curvas de convergência da função objetiva, obtidas com a aplicação do padrão adjacente de excitação elétrica.

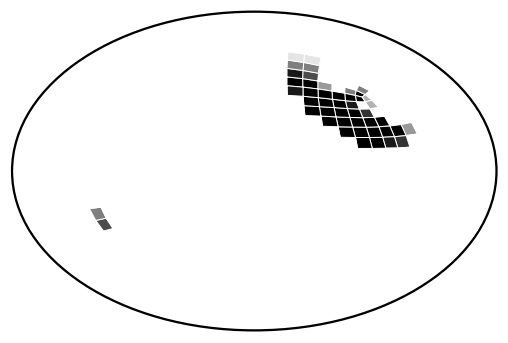

(a) imagem obtida

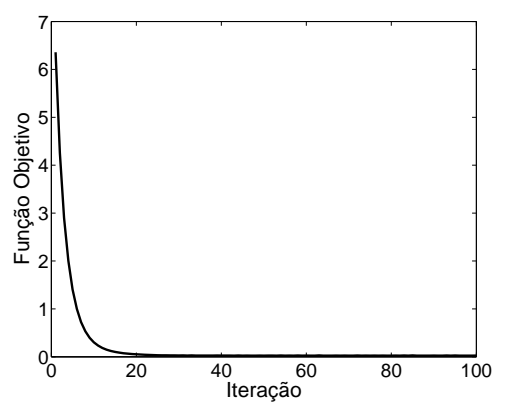

(b) curva de convergência

Figura 7.4: Resultado obtido no domínio elíptico (uma região), aplicando-se o padrão adjacente.

Para comparação, são apresentados também os resultados obtidos adotando-se o padrão diametral de excitação elétrica. As figuras 7.6 e 7.7 mostram as imagens e curvas de convergência obtidas como o TOMOGOT. 


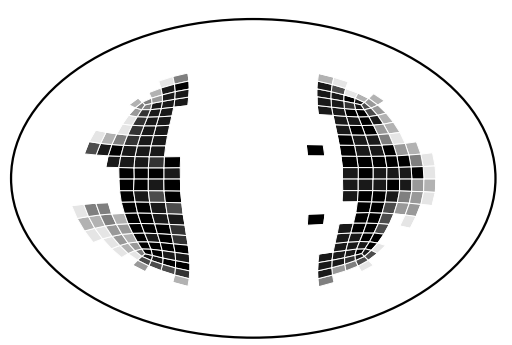

(a) imagem obtida

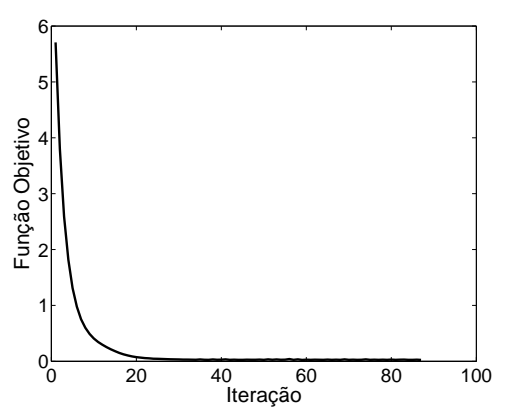

(b) curva de convergência

Figura 7.5: Resultado obtido no domínio elíptico (duas regiões), aplicando-se o padrão adjacente.

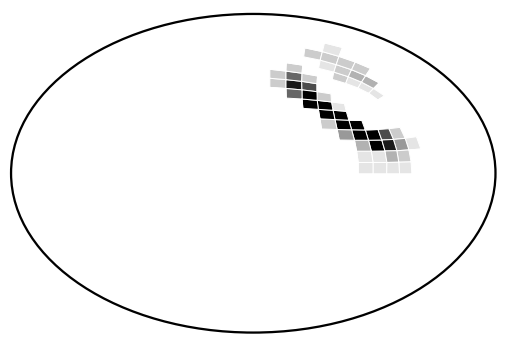

(a) imagem obtida

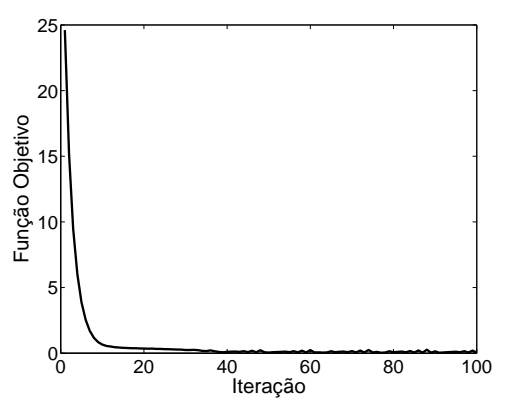

(b) curva de convergência

Figura 7.6: Resultado obtido no domínio elíptico (uma região), aplicando-se o padrão diametral.

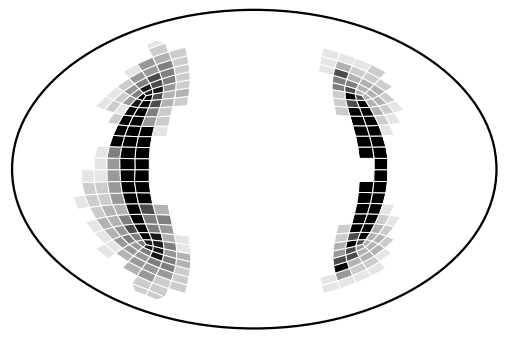

(a) imagem obtida

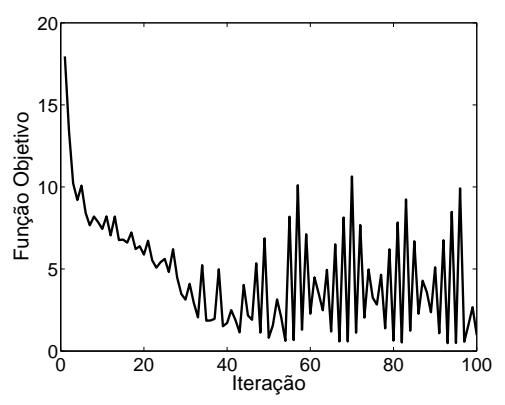

(b) curva de convergência

Figura 7.7: Resultado obtido no domínio elíptico (duas regiões), aplicando-se o padrão diametral. 
De acordo com as imagens obtidas, pode-se notar que o TOMOGOT é capaz de detectar a presença do objeto de baixa condutividade (região escura da imagem) no interior do domínio de maior condutividade (região clara da imagem), tanto para o caso de aplicação do padrão adjacente de excitação elétrica como para o caso em que aplica-se o padrão diametral. Porém, nota-se que com o padrão adjacente o tamanho da imagem da região escura é pelo menos duas vezes maior que a imagem obtida com o padrão diametral, portanto aproximando-se muito mais da imagem mostrada nos fantomas das figuras 7.3.

Conforme os gráficos de convergência mostrados nas figuras 7.4(b), 7.5(b), 7.6(b) e 7.7(b), nota-se que a função objetivo cai a um valor mínimo em poucas iterações $(\sim 20)$, porém permanece o restante do processo iterativo com uma pequena oscilação até que a imagem desejada seja encontrada, exceto o resultado mostrado na figura 7.7, obtido com a aplicação do padrão diametral de excitação elétrica para o domínio com duas imagens, onde a função objetivo cai a um valor mínimo e permanece oscilando consideravelmente até o final do processo iterativo. Observa-se que para as imagens mostradas nas figuras 7.4(a) e 7.5(a), obtidas com o padrão adjacente de excitação elétrica, a função objetivo converge para o valor mínimo igual a 0,0253 e 0,0249, respectivamente. Já, a função objetivo para as imagens mostradas nas figuras 7.6(a) e 7.7(a), obtidas com o padrão diametral de excitação elétrica, converge para um valor mínimo igual a 0,0319 e 0,9650, respectivamente. Isto mostra que a aplicação do padrão adjacente de excitação elétrica atendeu melhor a função objetivo do problema de otimização topológica implementado no TOMOGOT.

Os valores absolutos de condutividade, em $(\Omega m)^{-1}$, e resistividade, em $\Omega m$, dos elementos que constituem as regiões escuras (material imerso no domínio aquoso) mostradas nas imagens das figuras 7.4 e 7.6 (domínio com uma região escura) são apresentados nos gráficos das figuras 7.8 e 7.9 .

Os gráficos das figuras 7.10 e 7.11 apresentam os resultados, também em termos de valores absolutos de condutividade e resistividade elétrica, obtidos para as regiões escuras das imagens mostradas nas figuras 7.5 e 7.7 (domínio com duas regiões).

Conforme os gráficos apresentados, os valores absolutos de condutividades (ou resistividades) das regiões escuras, que indicam a presença de outro material no domínio, estão um pouco abaixo do valor esperado. Isto devido ao fato dos valores das variáveis de projeto referentes aos elementos da região escura das imagens mostradas nas figuras 7.4 e 7.5, obtidas com o padrão adjacente de 


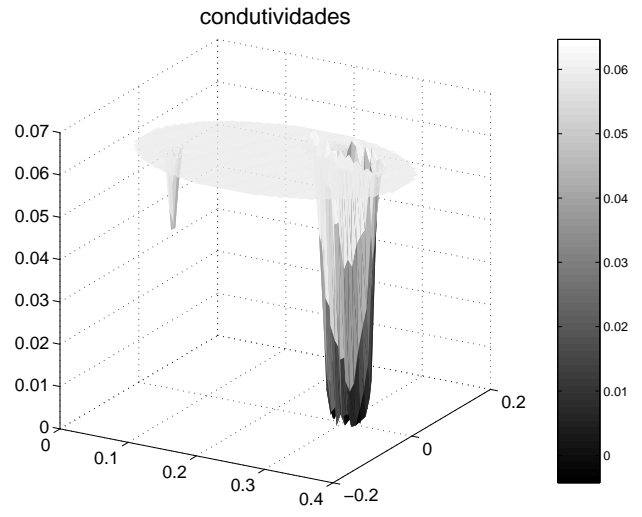

(a) padrão adjacente

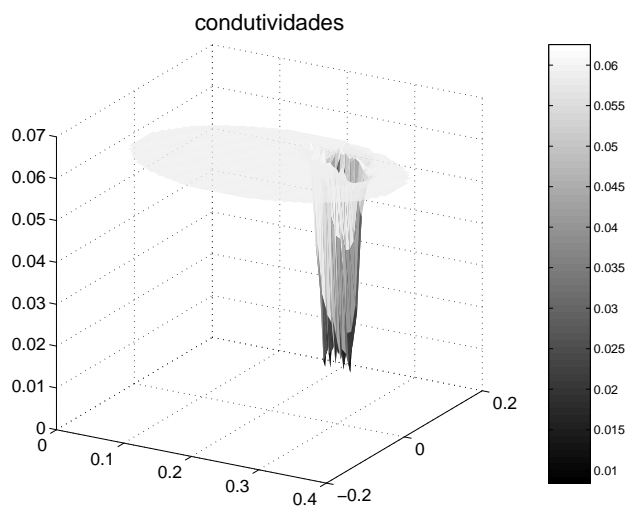

(b) padrão diametral

Figura 7.8: Valores absolutos de condutividade elétrica das regiões escuras das figuras 7.4 e 7.6 .

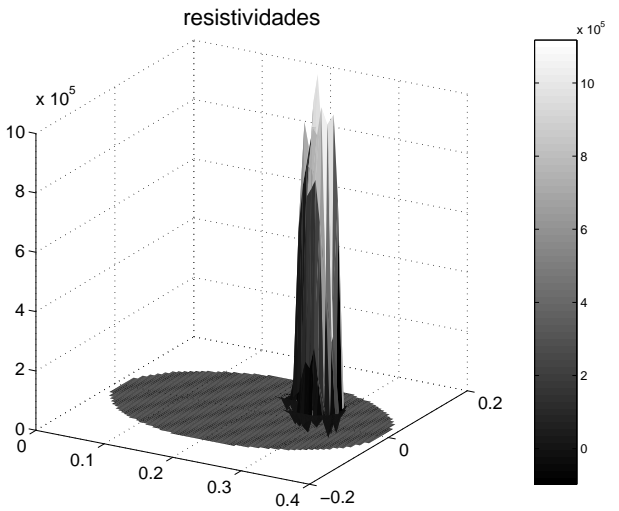

(a) padrão adjacente

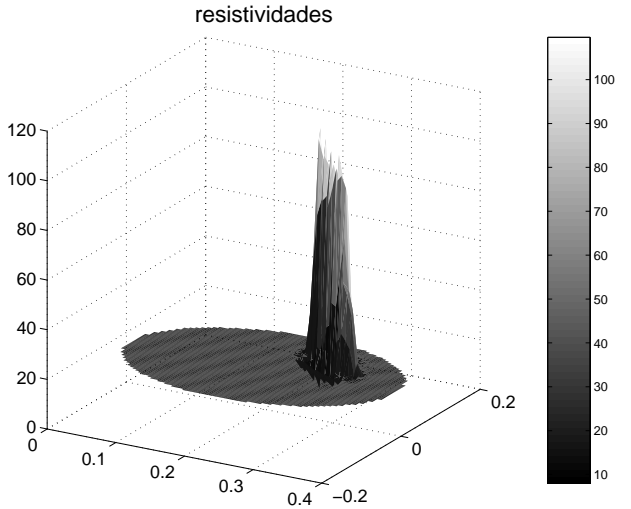

(b) padrão diametral

Figura 7.9: Valores absolutos de resistividade elétrica das regiões escuras das figuras 7.4 e 7.6 .

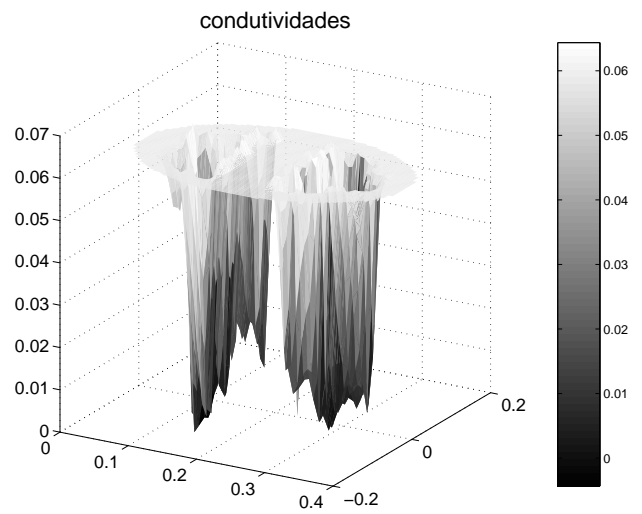

(a) padrão adjacente

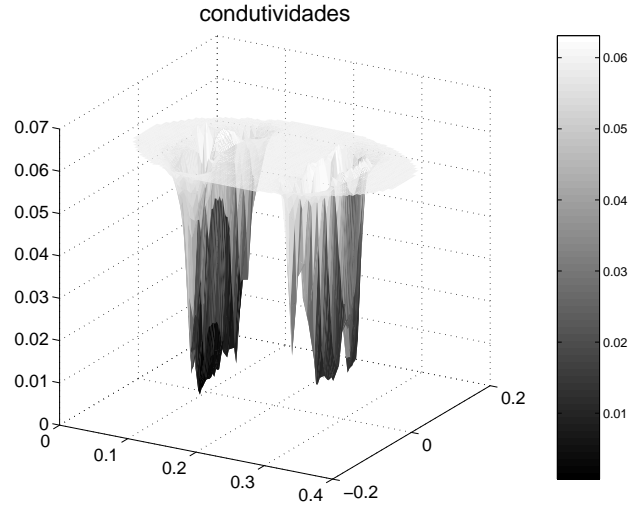

(b) padrão diametral

Figura 7.10: Valores absolutos de condutividade elétrica das regiões escuras das figuras 7.5 e 7.7 . 


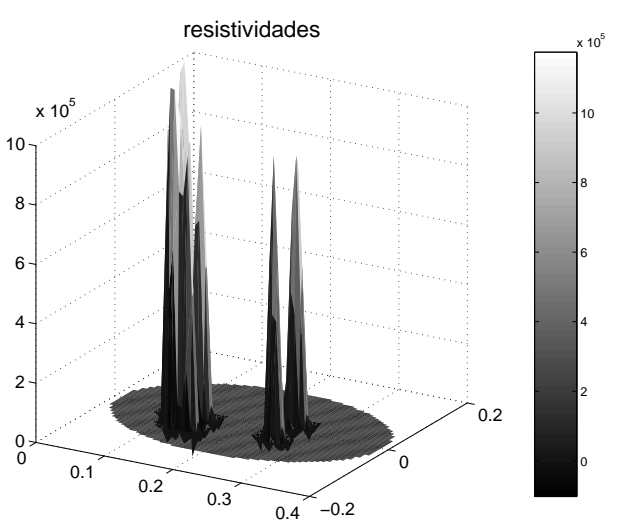

(a) padrão adjacente

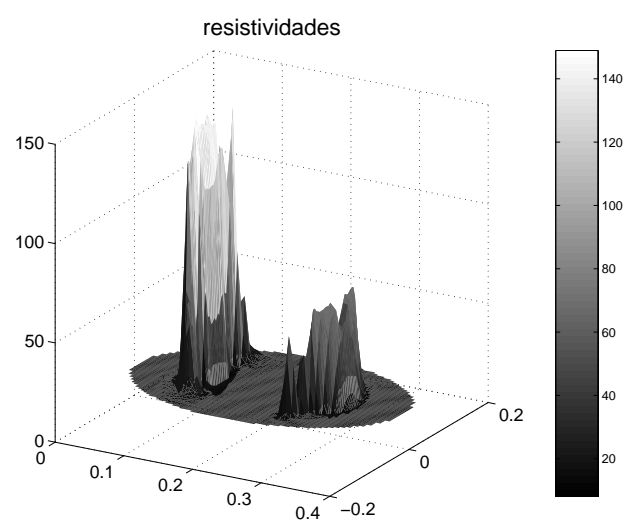

(b) padrão diametral

Figura 7.11: Valores absolutos de resistividade elétrica das regiões escuras das figuras 7.5 e 7.7 .

excitação elétrica, atingir em média somente valores iguais a $88 \%$ e $76 \%$ do valor esperado $\left(\rho_{k}=1\right)$, respectivamente. Enquanto, os elementos das regiões escuras das imagens mostradas nas figuras 7.6 e 7.7, obtidas com o padrão diametral, atingiram em média apenas $39 \%$ e $47 \%$ do valor de variável de projeto esperado, respectivamente. Lembrando que os valores de condutividades ou resistividades são calculados em função destas variáveis de projeto através do modelo de material adotado (veja capítulo 3). Apesar disso, pode-se notar através dos gráficos das figuras 7.9(a) e 7.11(a) que alguns elementos das regiões escuras mostradas nas figuras 7.4(a) e 7.5(a) alcançaram o maior valor de resistividade esperado $\left(10^{6} \Omega m\right)$, enquanto os elementos do restante do domínio (região clara) também alcançam o seu respectivo valor de resistividade $(17 \Omega m)$.

\subsubsection{Resultados Obtidos com Parâmetro de Sintonia ("tuning")}

Conforme visto na seção anterior, em todos os resultados apresentados até o momento os valores absolutos de condutividade (ou resistividade) elétrica das regiões escuras da imagem (material imerso no domínio) foram obtidos abaixo do valor esperado. Sendo assim, nesta seção propõe-se a utilização do parâmetro de sintonia da imagem ("tuning") descrito na seção 5.2 com o objetivo de melhorar esses resultados.

Assim, a seguir são mostrados os resultados obtidos com a aplicação do "tuning", para se obter as imagens apresentadas na figura 7.3. Neste caso, a obtenção de imagens é realizada aplicando-se os casos adjacente e diametral de excitação elétrica. Para exemplificar, sabe-se que as regiões de baixa condutividade (regiões escuras) da figura 7.3 representam aproximadamente $5 \%$ 
(uma região escura) e 18\% (duas regiões escuras) do volume total do domínio elíptico, respectivamente. Esses parâmetros são utilizados na equação (5.2) como restrição de material $\left(V^{*}\right)$. Neste exemplo, os resultados são obtidos a partir dos mesmos dados (inclusive parâmetros de eletrodos) e configurações utilizados na reconstrução das imagens apresentadas na seção 7.3.1.3. Assim, são obtidas as seguintes imagens e respectivas curvas de convergência.

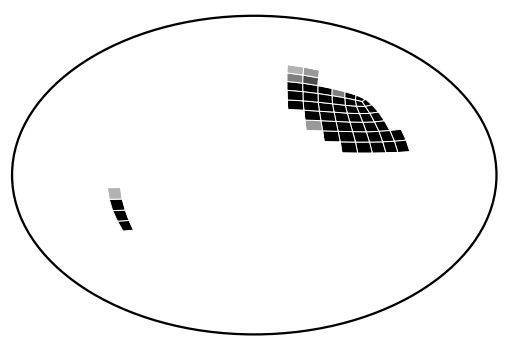

(a) imagem obtida

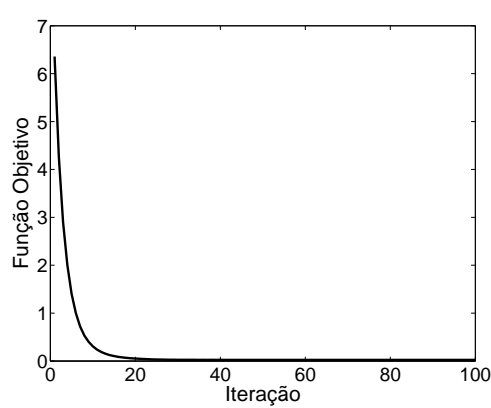

(b) curva de convergência

Figura 7.12: Imagem obtida (uma região), usando o padrão adjacente e $V^{*}=5 \%$.

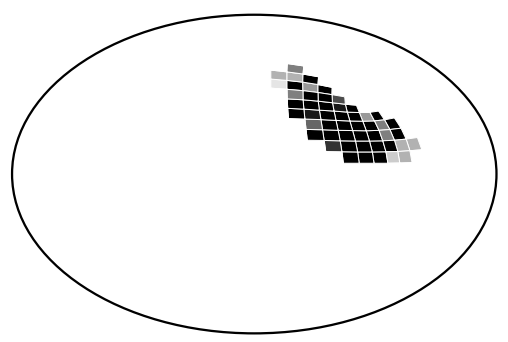

(a) imagem obtida

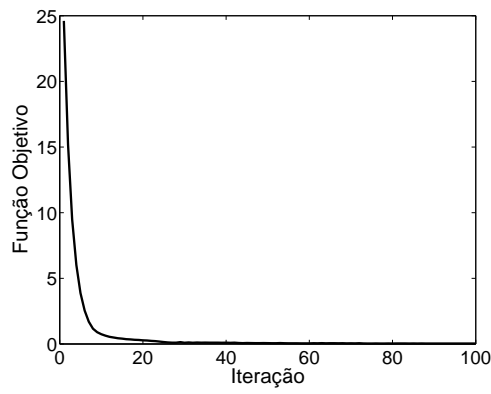

(b) curva de convergência

Figura 7.13: Imagem obtida (uma região), usando o padrão diametral e $V^{*}=5 \%$.

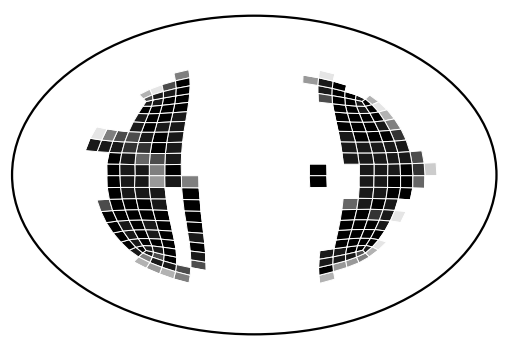

(a) imagem obtida

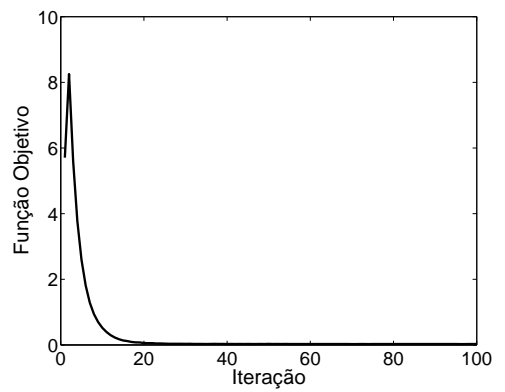

(b) curva de convergência

Figura 7.14: Imagem obtida (duas regiões), usando o padrão adjacente e $V^{*}=18 \%$.

Conforme os resultados mostrados nas figuras 7.12 a 7.15 , nota-se que o uso do "tuning" fez com que o volume das regiões escuras das imagens obtidas 


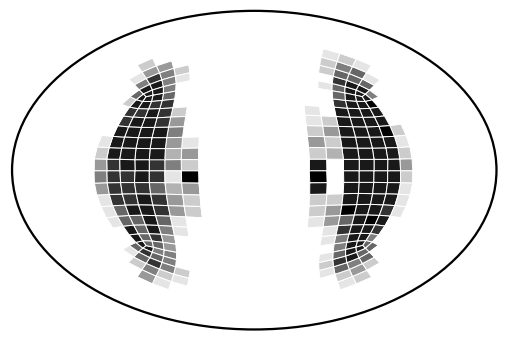

(a) imagem obtida

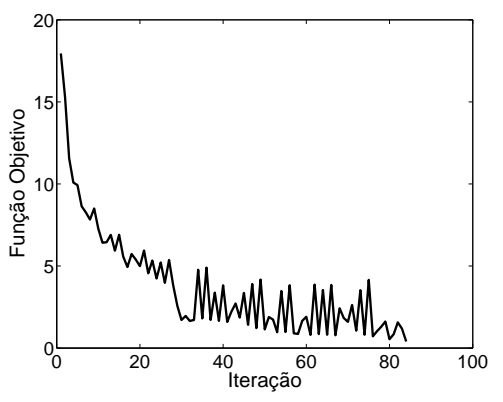

(b) curva de convergência

Figura 7.15: Imagem obtida (duas regiões), usando o padrão diametral e $V^{*}=18 \%$.

aumentassem em torno de 1,5 vezes em comparação com os resultados anteriores sem "tuning", o que melhorou consideravelmente a definição da imagem obtida. As curvas de convergência da função objetivo referente as imagens do domínio com apenas uma região escura (figuras 7.12(b) e 7.13(b)) mostram que a função objetivo converge para um valor mínimo igual 0,024 no caso adjacente e 0,030 no caso diametral, ao final das iterações. Já, os gráficos de convergência das figuras 7.14(b) e 7.15(b) (domínio com duas regiões escuras) mostram que a função objetivo converge para 0,026 no caso adjacente e 0,401 no caso diametral. Em ambos os casos (domínios com uma e duas regiões) a convergência da função objetivo repetiu o comportamento observado nos resultados sem "tuning", ou seja, a função cai a um valor mínimo em poucas iterações $(\sim 20)$ e permanece o restante do processo iterativo com uma pequena oscilação, exceto a curva de convergência do resultado mostrado na figura 7.15(b) obtido para o domínio com duas regiões e com aplicação do padrão diametral de excitação elétrica.

Os valores absolutos de condutividade e resistividade dos elementos que constituem as regiões escuras (material imerso no domínio aquoso) mostradas nas imagens das figuras 7.12 e 7.13 (domínio com uma região escura) são apresentados nos gráficos das figuras 7.16 e 7.17 .

Os gráficos das figuras 7.18 e 7.19 apresentam os resultados, em termos de valores absolutos de condutividade e resistividade elétrica, obtidos para as regiões escuras das imagens mostradas nas figuras 7.14 e 7.15 (domínio com duas regiões).

Observe que os valores de condutividade e resistividade elétrica da maioria dos elementos das regiões escuras (elementos com condutividade ou resistividade acentuadas) estão bem próximos do valores esperados. Neste caso, as variáveis de projeto dos elementos da região escura das imagens mostradas nas figuras 7.12 e 7.13 (uma região escura) atingiram em média valores iguais a 93\% e 80\% do valor máximo esperado $\left(\rho_{k}=1\right)$ nos casos adjacente e diametral, respectivamente. 


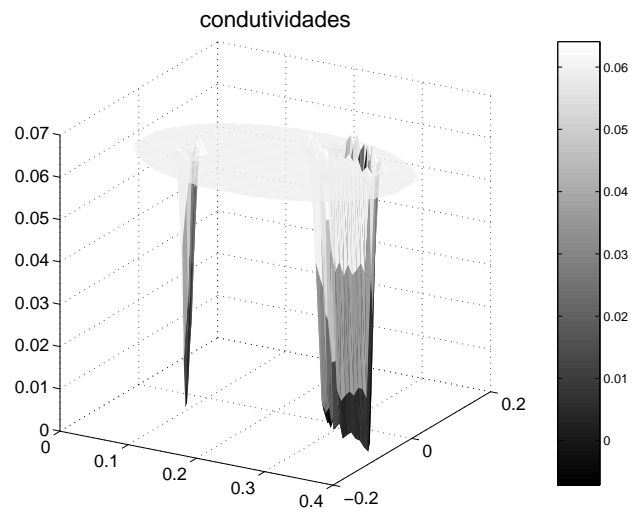

(a) padrão adjacente

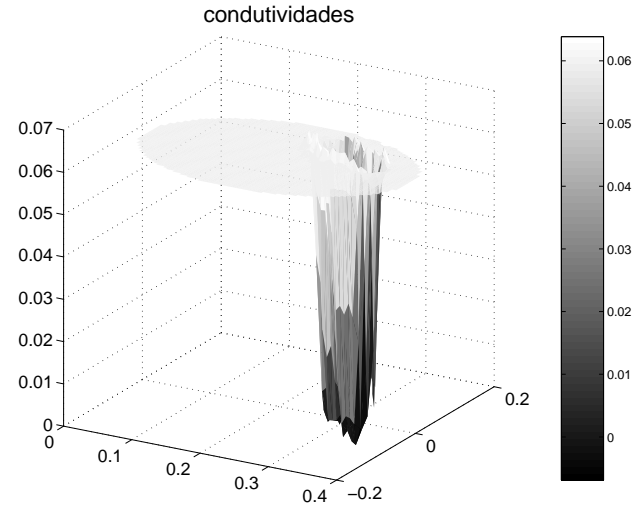

(b) padrão diametral

Figura 7.16: Valores absolutos de condutividade elétrica das regiões escuras das figuras 7.12 e 7.13 .

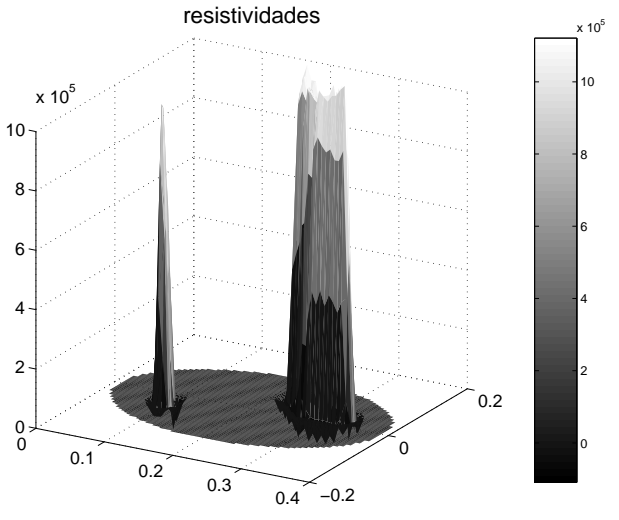

(a) padrão adjacente

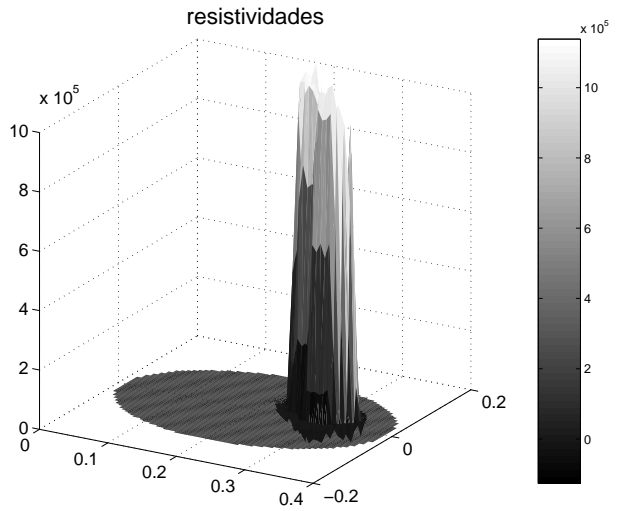

(b) padrão diametral

Figura 7.17: Valores absolutos de resistividade elétrica das regiões escuras das figuras 7.12 e 7.13 .

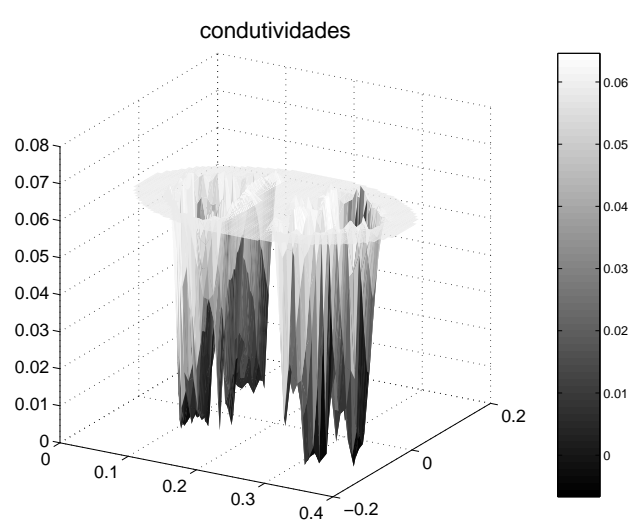

(a) padrão adjacente

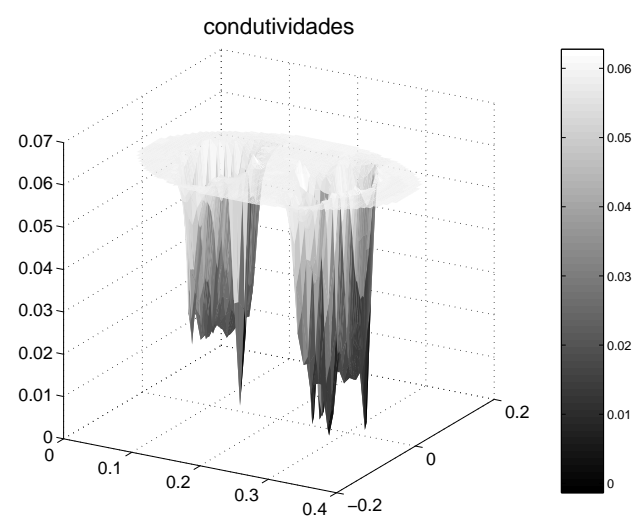

(b) padrão diametral

Figura 7.18: Valores absolutos de condutividade elétrica das regiões escuras das figuras 7.14 e 7.15 . 


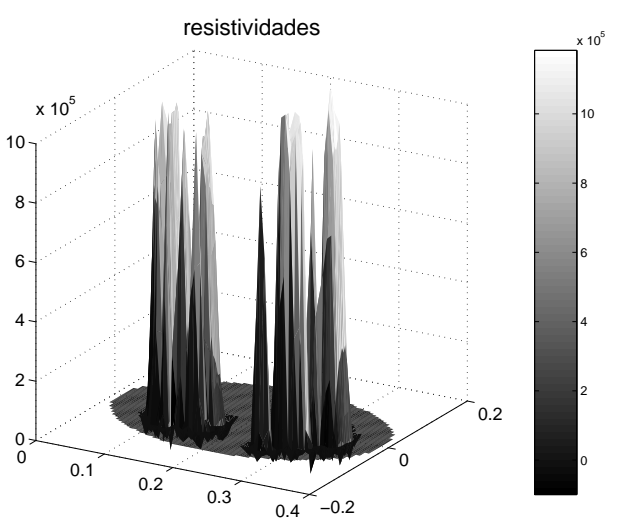

(a) padrão adjacente

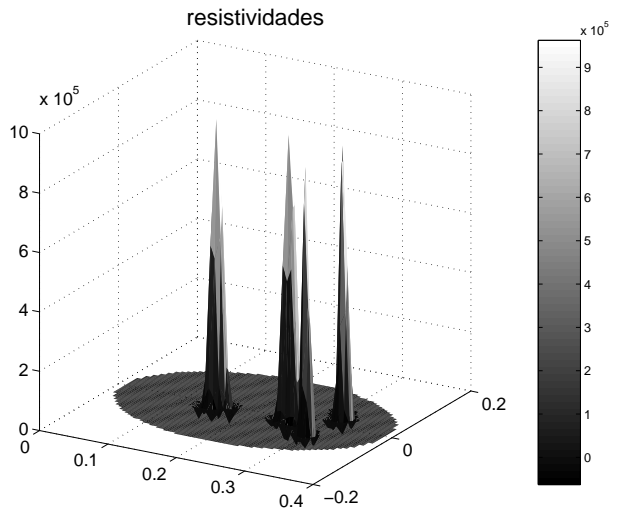

(b) padrão diametral

Figura 7.19: Valores absolutos de resistividade elétrica das regiões escuras das figuras 7.14 e 7.15 .

Enquanto, os elementos das regiões escuras das imagens mostradas nas figuras 7.14 e 7.15 (duas regiões escuras) atingiram em média $82 \%$ no caso adjacente e $63 \%$ no caso diametral. Se compararmos esses resultados (com "tuning") com os resultados mostrados na seção 7.3.1.3 (sem "tuning") conclui-se que a restrição melhorou os resultados, forçando os valores das variáveis de projeto a um patamar maior que o caso onde a restrição não é utilizada e, conseqüentemente destacando os valores absolutos de condutividade (ou resistividade) das regiões que indicam a presença de um material diferente no domínio. Neste caso, nota-se que houve um acréscimo médio de 6,8\% e 69,6\% nos valores das variáveis de projeto encontrados nos casos adjacente e diametral, respectivamente, em relação aos valores obtidos anteriormente na seção 7.3.1.3. Isto representa um acréscimo considerável no número de elementos das regiões escuras das imagem obtidas que atingem o valor absoluto de condutividade (ou resistividade) esperado, conforme pode ser visto nos gráficos das figuras 7.16 a 7.19 .

Portanto, conclui-se que a utilização do parâmetro de sintonia ("tuning) auxilia na obtenção dos valores absolutos de condutividade (ou resistividade) elétrica do domínio através do TOMOGOT. No entanto, observa-se que a utilização deste parâmetro não é uma operação trivial e pode gerar uma resposta indesejada, como é o caso da imagem da figura 7.12(a) que mostra uma pequena região escura, formada por alguns elementos com valores de condutividade acentuados, que não pertencem a região da imagem esperada (uma região escura) e que pode prejudicar a interpretação da imagem obtida. 


\subsubsection{Inclusão de Ruído nos Valores de Voltagens}

Para verificar a capacidade e potencialidade do método para trabalhar com dados obtidos experimentalmente, onde o ruído é considerável, nesta seção o TOMOGOT é testado introduzindo-se uma variação aleatória entre zero e $15 \%$ (positiva e negativa) em cada valor de potencial elétrico $\phi_{\mathrm{ij} 0}$ obtido através dos fantomas numéricos, apresentados na figura 7.3. Este ruído artificial tenta simular os possíveis ruídos encontrados na prática ao se medir os potenciais elétricos nos eletrodos através do aparato eletrônico (METHERALL, 1998; BERTEMES-FILHO, 2002). Observa-se que o teste é feito tanto na obtenção dos parâmetros de eletrodos como na reconstrução da imagem desejada, ou seja, o TOMOGOT deve reconstruir a imagem a partir de valores de parâmetros de eletrodos que foram otimizados considerando-se o ruído artificial e valores de potenciais elétricos $\phi_{\mathrm{ij} 0}$ obtidos numericamente também com o ruído.

Para exemplificar, as figuras 7.20 e 7.21 mostram a comparação entre as imagens obtidas com o parâmetro de sintonia ("tuning"), mostradas nas figuras 7.14 e 7.15 (domínio com duas regiões escuras), e as respectivas imagens obtidas (também com parâmetro de sintonia) após a introdução do ruído artificial.

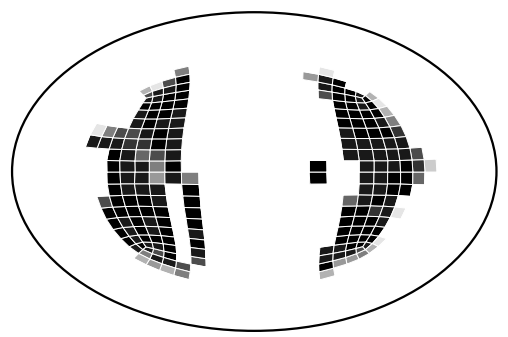

(a) sem ruído

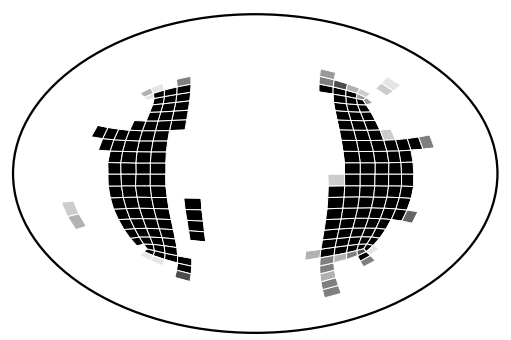

(b) com ruído

Figura 7.20: Introdução do ruído artificial no padrão adjacente.

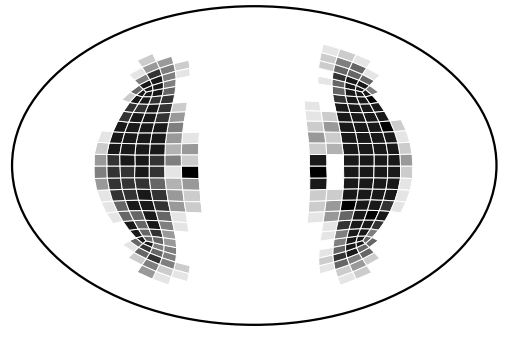

(a) sem ruído

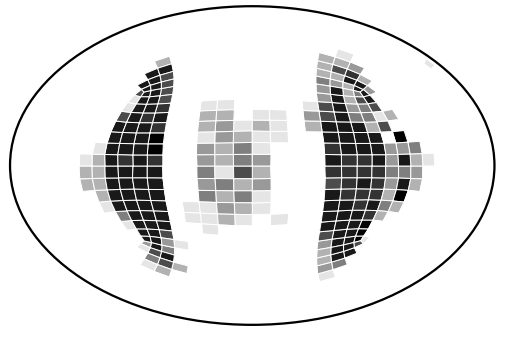

(b) com ruído

Figura 7.21: Introdução do ruído artificial no padrão diametral.

Constata-se que mesmo com o nível de ruído artificial introduzido (máximo de 15\%) o TOMOGOT é capaz de absorvê-lo e reconstruir a imagem desejada tanto para o padrão de excitação elétrica adjacente como para o padrão diametral. 
Os gráficos das figuras 7.22 e 7.23 plotam os valores absolutos de condutividade, em $(\Omega m)^{-1}$, e resistividade, em $\Omega m$, dos elementos das duas regiões escuras mostradas nas imagens das figuras 7.20 e 7.21 , para cada caso de padrão de excitação elétrica aplicado.

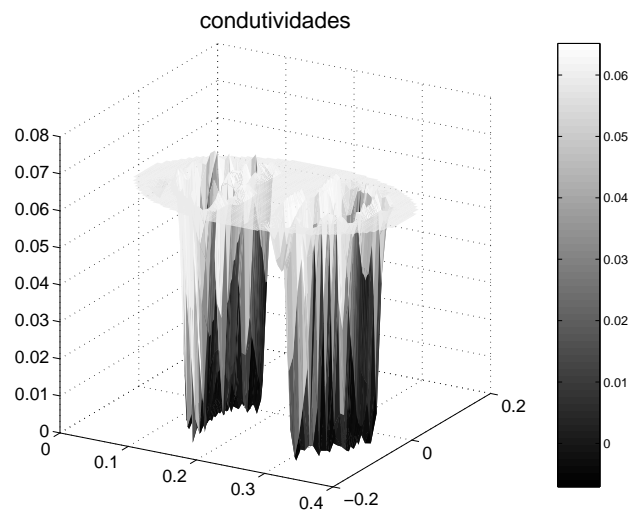

(a) padrão adjacente

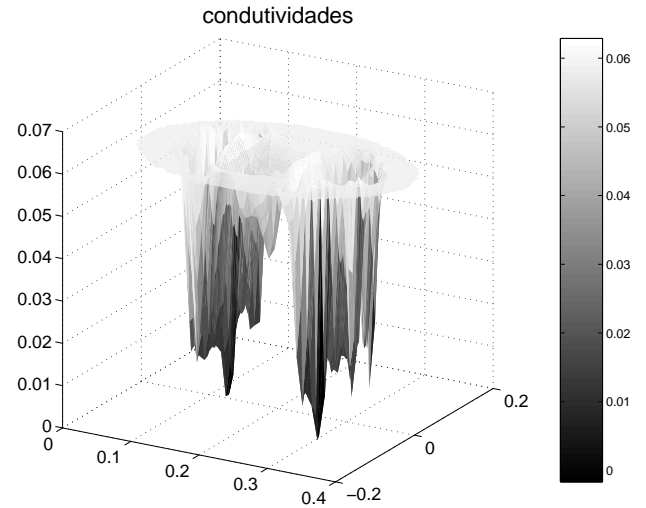

(b) padrão diametral

Figura 7.22: Valores absolutos de condutividade elétrica das regiões escuras das figuras 7.20 e 7.21 .

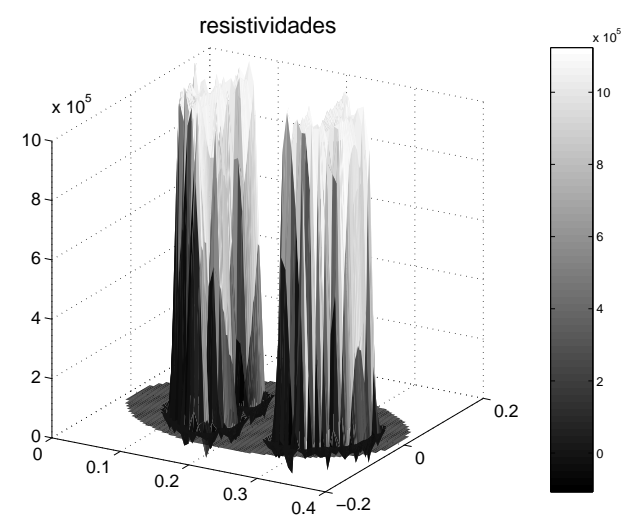

(a) padrão adjacente

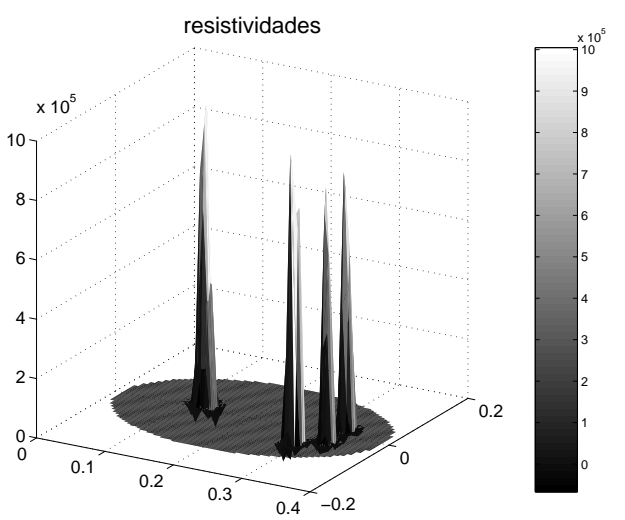

(b) padrão diametral

Figura 7.23: Valores absolutos de resistividade elétrica das regiões escuras das figuras 7.20 e 7.21 .

Neste caso, observa-se que o padrão adjacente novamente produziu melhores resultados, pois os valores absolutos de condutividade (ou resistividade) dos elementos das regiões escuras estão mais próximos do valor esperado. Para exemplificar, com aplicação do padrão adjacente de excitação elétrica, em termos de variáveis de projetos o TOMOGOT obtém em média para os elementos da região escura da imagem valores com $82 \%$ do valor máximo esperado $\left(\rho_{k}=1\right)$, que corresponde a destacar no domínio os valores de condutividade (ou resistividade) destes elementos e, conseqüentemente definir a imagem desejada. No entanto, com a aplicação do padrão diametral, os valores das variáveis de projeto da região escura são em média $64 \%$ do valor esperado. Observa-se também que o 
padrão diametral é mais sensível a introdução de ruídos nos potenciais elétricos, conforme pode ser visto na imagem da figura 7.21(b) que apresenta a imagem de uma "mancha" entre as duas regiões escuras, não prevista na imagem original apresentada no fantoma da figura 7.3(b).

\subsubsection{Obtenção de Imagem no Domínio com Elementos Quadriláteros e Triangulares}

Até o momento, os resultados foram obtidos a partir de uma domínio elíptico cuja malha de elementos finitos é constituída de elementos quadriláteros. Desta seção em diante, são mostrados resultados obtidos num domínio circular, com diâmetro igual a 230 milímetros. A configuração da malha de MEF do domínio de obtenção de imagem com elementos quadriláteros é mostrada na seção 7.3.4.1. Além disso, é utilizado também um domínio de obtenção de imagem discretizado em elementos triangulares (veja seção 7.3.4.1), para efeitos de comparação com resultados obtidos com elementos quadriláteros e como tentativa de melhorar a imagem obtida.

Neste caso, a imagem a ser obtida é mostrada na figura 7.24(a), onde a região escura simula a presença de um objeto cilíndrico de baixa condutividade, considerada igual a $10^{-6}(\Omega m)^{-1}$. O volume dessa região representa $5,4 \%\left(V^{*}\right)$ do volume total do domínio circular. O restante do domínio possui um material de maior condutividade, $1 / 17(\Omega m)^{-1}$, em relação à região escura (objeto cilíndrico). O centróide da região escura está localizada a aproximadamente 46 milímetros do centro do domínio, tanto na direção do eixo horizontal $(x)$ como na direção do eixo vertical $(y)$, conforme mostrado na figura 7.24(a).

Para obtenção das imagens apresentadas nesta seção, são utilizados os valores de potenciais elétricos $\phi_{\mathrm{ij} 0}$ extraídos do fantoma numérico mostrado na figura 7.24(b). O domínio desse fantoma numérico é discretizado uniformemente em 4056 elementos quadriláteros de 4 nós, com espessura igual a 35 milímetros. Para obtenção dos potenciais $\phi_{\mathrm{ij} 0}$, utiliza-se um parâmetro de eletrodo igual a 0,02 $\Omega m^{2}$ (valor adotado) para todos os elementos de eletrodos do fantoma numérico.

\subsubsection{Domínios de Obtenção de Imagem}

Conforme visto no capítulo 4, o elemento quadrilátero possui uma formulação que representa com maior fidelidade o campo de potenciais no interior do elemento, porém requer o uso de métodos numéricos para definição da sua matriz de condutividade elétrica (veja seção 4.4.1). Assim, propõe-se a configuração 


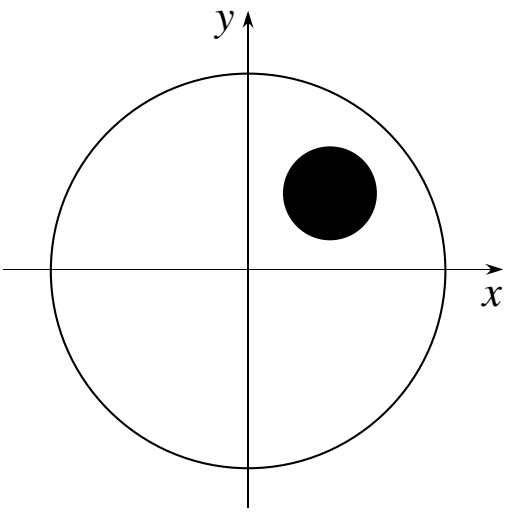

(a) $V^{*}=5,4 \% ; \mathrm{x}=46,2 ; \mathrm{y}=46,7$

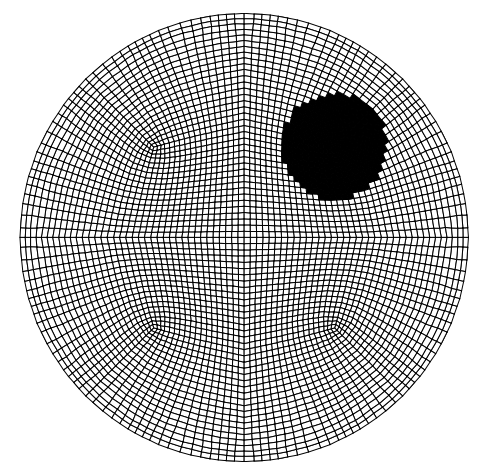

(b) 4056 elementos

Figura 7.24: a) imagem a ser obtida; b) fantoma numérico utilizado.

mostrada na figura 7.25 para a malha de MEF do domínio de obtenção de imagem de TIE, através do TOMOGOT. Neste caso, o modelo de MEF adotado para o domínio circular, onde a imagem deve ser obtida, possui uma malha com 576 elementos finitos quadriláteros de 4 nós, gerada manualmente no ANSYS (veja anexo B), e 32 elementos de eletrodos posicionados uniformemente ao longo do contorno da malha, conforme mostrado na figura 7.25. A espessura dos elementos quadriláteros é considerada igual a 35 milímetros e a largura de cada elemento de eletrodo é igual a 10 milímetros. Observa-se que no modelo de MEF é previsto uma faixa do domínio, próximo ao contorno, discretizada em elementos menores (refinamento) para representar melhor a interface entre elementos de eletrodos e elementos do interior do domínio.

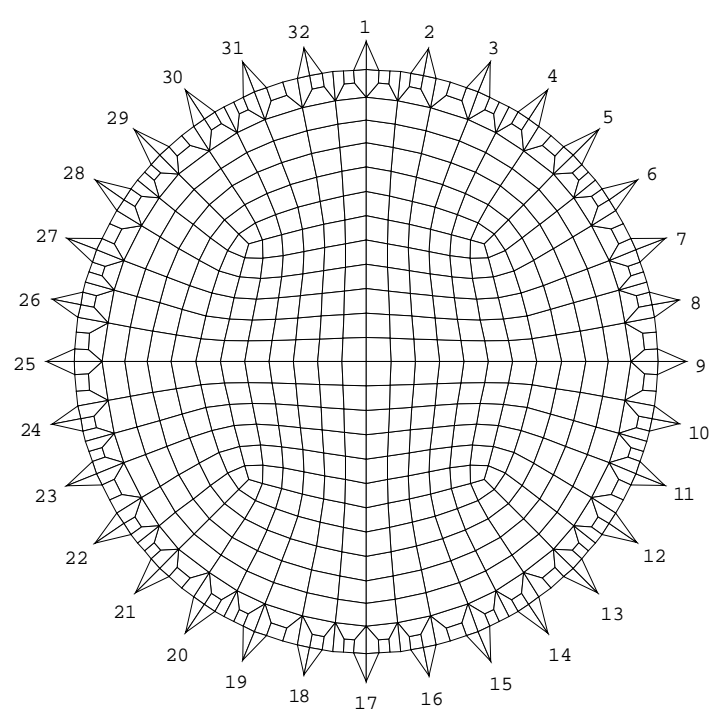

Figura 7.25: Domínio de obtenção da imagem com 576 elementos quadriláteros e 32 elementos de eletrodos.

Diferente do elemento quadrilátero, a formulação da matriz de condutividade do elemento triangular pode ser obtida analiticamente, tornando a sua 
implementação computacional simples e livre de aproximações provenientes de algoritmos para integração numérica (veja seção 4.4.2). Desta forma, a configuração alternativa mostrada na figura 7.26 é proposta para malha de $\mathrm{MEF}$ do domínio de obtenção de imagem. Nela, o modelo de MEF do domínio discretizado em elementos triangulares foi construído manualmente a partir do domínio discretizado em elementos quadriláteros. Para aproveitar o trabalho realizado na geração da malha de MEF do domínio mostrado na figura 7.25, cada elemento quadrilátero foi dividido em dois elementos triangulares de 3 nós cada. Neste caso, manteve-se as mesmas dimensões do domínio circular e o mesmo número de eletrodos (32 eletrodos) em volta do domínio mostrado na figura 7.25. Desta forma, a nova malha de MEF proposta para o domínio de obtenção da imagem de TIE possui 1248 elementos triangulares (697 nós) e pode ser vista na figura 7.26. Observa-se que o refinamento da malha na borda do domínio foi mantido para simular melhor os efeitos da impedância de contato entre eletrodos e superfície do domínio.

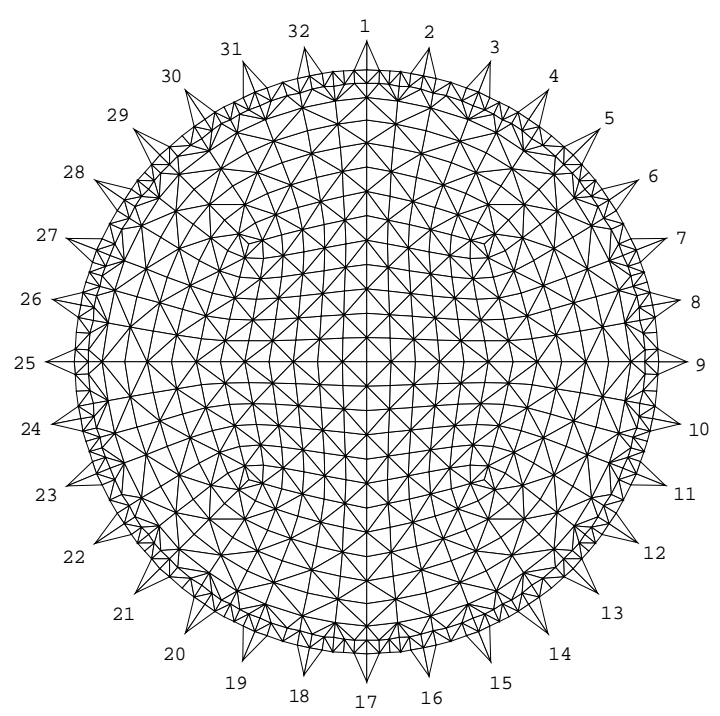

Figura 7.26: Domínio de obtenção da imagem com 1248 elementos triangulares e 32 elementos de eletrodos.

\subsubsection{Primeiros Resultados Utilizando o Domínio Circular}

Para ilustrar, as figuras 7.27 e 7.28 mostram as imagens obtidas, em termos de condutividade, com o domínio discretizado em elementos triangulares, com a aplicação dos padrões adjacente e diametral de excitação elétrica apresentados na seção 7.2 e o parâmetro de sintonia "tuning" descrito na seção 5.2. Além disso, as imagens são obtidas a partir de um valor inicial das variáveis de projeto do MOT $\left(\rho_{k}^{0}\right)$ igual a 0,85 e fator de penalidade $(p)$ do modelo de material igual a 2.

Os valores absolutos de condutividade, em $(\Omega m)^{-1}$, e resistividade, em $\Omega m$, 


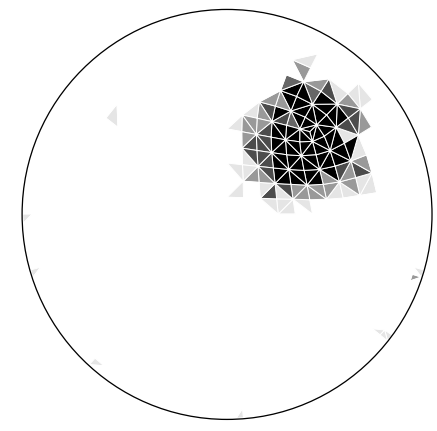

(a) imagem obtida

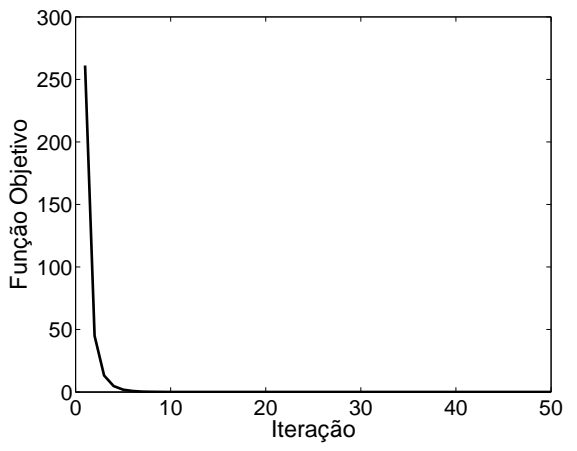

(b) curva de convergência

Figura 7.27: Resultado obtido no domínio discretizado em elementos triangulares, aplicando-se padrão adjacente.

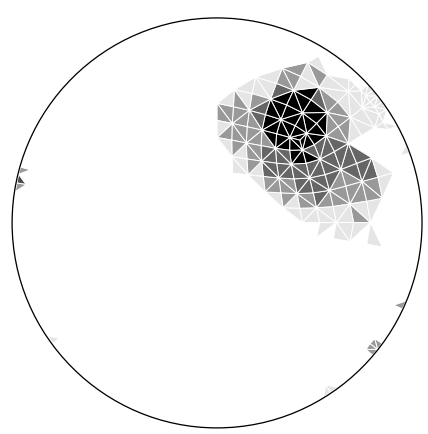

(a) imagem obtida

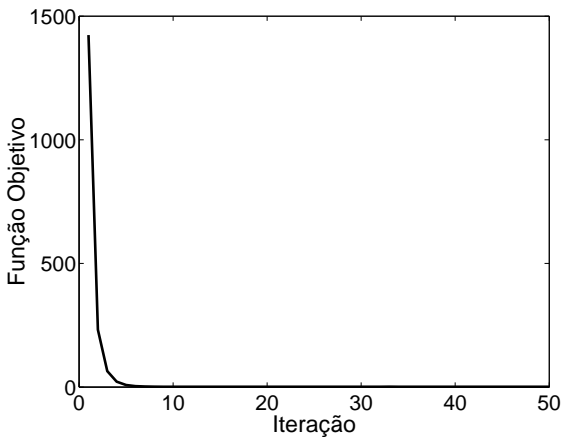

(b) curva de convergência

Figura 7.28: Resultado obtido no domínio discretizado em elementos triangulares, aplicando-se padrão diametral. 
dos elementos das imagens mostradas nas figuras 7.27 e 7.28 são apresentados nos gráficos das figuras 7.29 e 7.30, respectivamente.

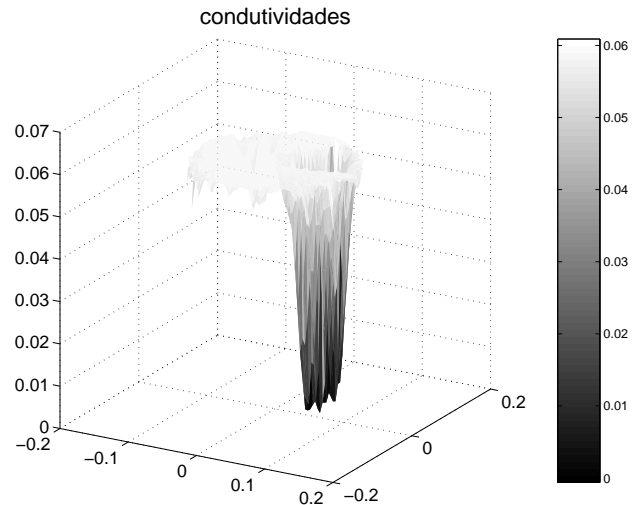

(a) padrão adjacente

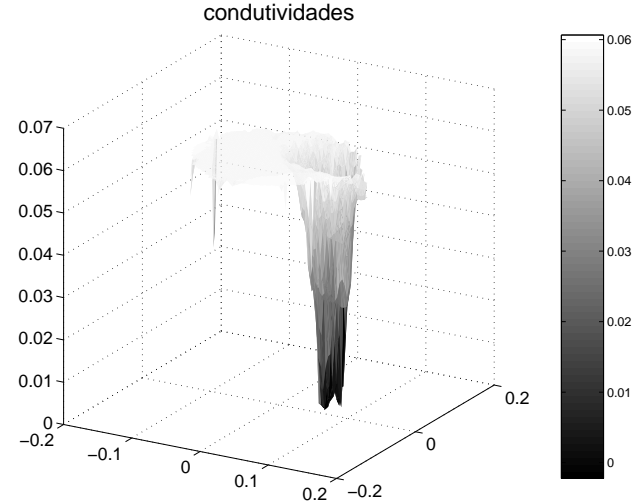

(b) padrão diametral

Figura 7.29: Valores absolutos de condutividade elétrica das imagens mostradas nas figuras 7.27 e 7.28 .

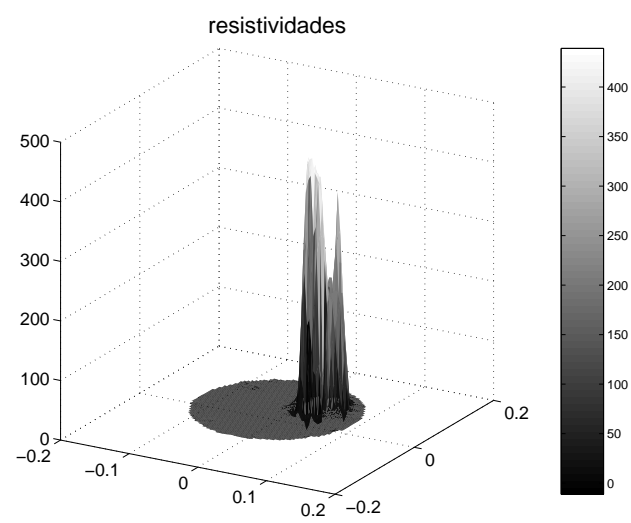

(a) padrão adjacente

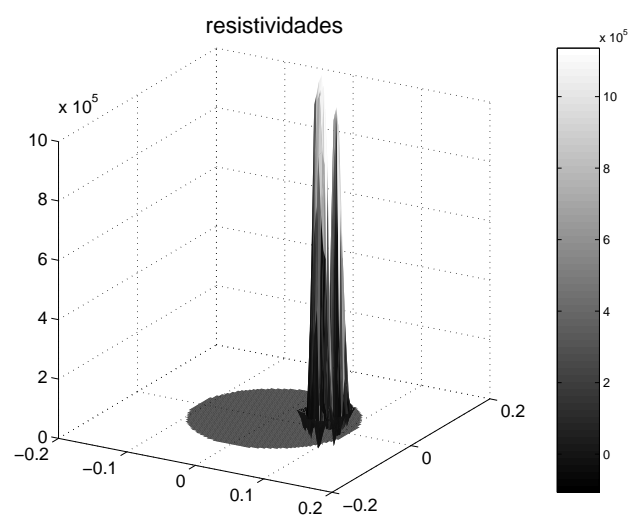

(b) padrão diametral

Figura 7.30: Valores absolutos de resistividade elétrica das imagens mostradas nas figuras 7.27 e 7.28 .

De acordo com os resultados obtidos, pode-se notar que o TOMOGOT é capaz de detectar a presença do objeto cilíndrico de baixa condutividade (região escura da imagem) no interior do domínio circular, discretizado em elementos triangulares. No resultado obtido com a aplicação do padrão adjacente de excitação elétrica (figura 7.27), a coordenada do centróide da região escura da imagem (objeto cilíndrico), em relação ao centro do domínio, é obtida com um erro de $0,9 \%$ na direção do eixo horizontal $(x=45,8 \mathrm{~mm})$ e $10 \%$ na direção do eixo vertical $(y=42,0 \mathrm{~mm})$. O volume da imagem da região escura, neste caso, é 18,5\% menor em relação ao tamanho original mostrado na figura 7.24(a).

Para maiores esclarecimentos, observa-se que o erro é calculado de maneira clássica, comparando-se a diferença entre o valor obtido e o valor esperado para 
a grandeza (volume e coordenadas dados na figura 7.24), da seguinte maneira:

$$
\text { erro }=\frac{\text { valor }_{\text {obtido }}-\text { valor }_{\text {esperado }}}{\text { valor }_{\text {esperado }}} \times 100 \quad(\%)
$$

Analisando os resultados obtidos com a aplicação do padrão diametral de excitação elétrica, nota-se que a imagem mostrada na figura 7.28 apresenta excesso de "escalas de cinza" (valores intermediários de variáveis de projeto) e, apesar da imagem obtida para o objeto cilíndrico ser aparentemente maior que o tamanho esperado, o cálculo do volume da mesma, que leva em consideração as "escalas de cinza", mostra um tamanho bem menor (51,8\% de diferença). Além disso, o centróide dessa imagem está deslocado 4,5\% na direção do eixo horizontal $(x=44,1 \mathrm{~mm})$ e $18,6 \%$ na direção do eixo vertical $(y=55,4 \mathrm{~mm})$, em relação a posição original mostrada na figura $7.24(\mathrm{a})$.

As curvas de convergência apresentadas nos gráficos das figuras 7.27(b) e 7.28(b) mostram que, independente do padrão de excitação elétrica aplicado (adjacente ou diametral), a função objetivo cai rapidamente a um valor mínimo e permanece o restante do processo iterativo do algoritmo de otimização topológica com uma pequena oscilação até que a imagem seja obtida. Os gráficos 3D de condutividades e de resistividades mostrados nas figuras 7.29 e 7.30, respectivamente, complementam a informação contida nas imagens das figuras 7.27 e 7.28, através dos quais pode-se visualizar melhor quais os pontos da região escura (objeto cilíndrico) conseguem alcançar o valor de condutividade ou resistividade esperado. No caso, o gráfico da figura 7.30(a) (padrão adjacente) mostra que os valores de resistividades dos elementos da região que indica a presença do objeto cilíndrico foram obtidos muito aquém do esperado, apesar da respectiva imagem (figura 7.27(a)) ser melhor definida em relação a imagem obtida com a aplicação do padrão diametral (figura 7.28(a)). Já, o gráfico da figura 7.30(b) mostra que, apesar da imagem obtida com o padrão diametral (figura 7.28(a)) não apresentar um bom resultado, em termos de definição e localização do centróide, alguns elementos da imagem que indica a presença do objeto cilíndrico alcançaram o valor de resistividade esperada $\left(10^{-6}(\Omega m)^{-1}\right)$.

Para efeitos de comparação a seguir são apresentadas as imagens obtidas para o mesmo caso explorado acima, utilizando o modelo de MEF mostrado na figura 7.25, que discretiza o domínio em elementos quadriláteros. São utilizados também os padrões adjacente e diametral de excitação elétrica, dados extraídos do fantoma numérico mostrado na figura 7.24(b) (potenciais $\phi_{\mathrm{ij0}}$ ) e demais parâmetros aplicados à obtenção dos resultados mostrados anteriormente nesta 
seção (resultados com o domínio discretizado em elementos triangulares).

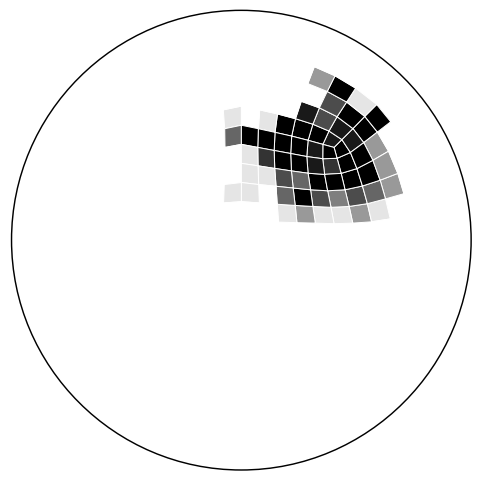

(a) imagem obtida

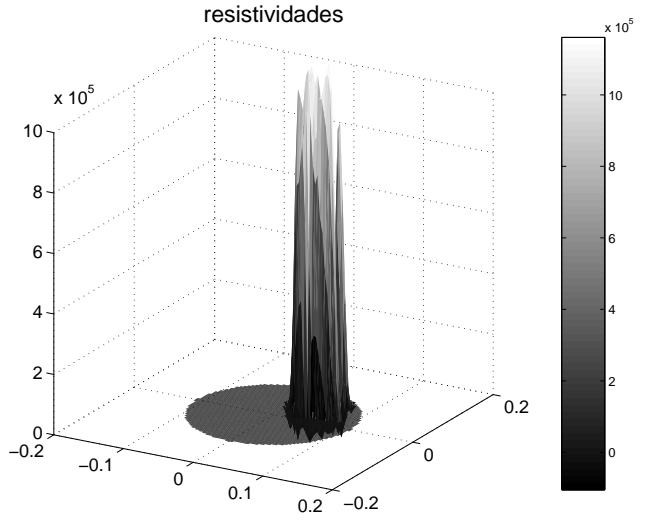

(b) distribuição de resistividades

Figura 7.31: Resultado obtido no domínio discretizado em elementos quadriláteros, aplicando-se padrão adjacente.

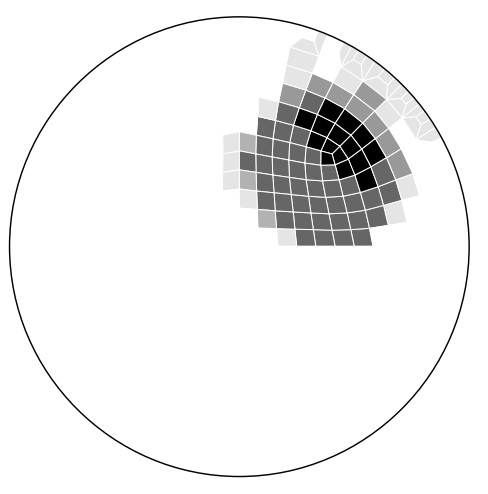

(a) imagem obtida

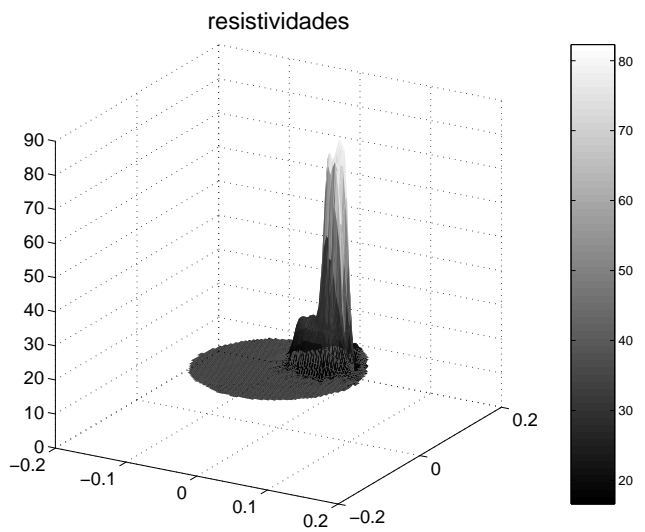

(b) distribuição de resistividades

Figura 7.32: Resultado obtido no domínio discretizado em elementos quadriláteros, aplicando-se padrão diametral.

Neste caso, o padrão adjacente novamente produziu melhores resultados, pois verifica-se que o volume da região escura (objeto cilíndrico) mostrada na figura 7.31(a) é obtida com uma diferença de apenas $11 \%$ do volume original mostrada na figura 7.24(a), sendo que a localização do centróide da imagem em relação aos eixos horizontal ( $x$ ) e vertical (y) é 40,8 $\mathrm{mm}$ ( $\operatorname{erro}(x)=11,7 \%$ ) e 47,4 $m m(\operatorname{erro}(y)=1,5 \%)$, respectivamente. Já, os resultados com o padrão diametral mostram que a imagem do objeto cilíndrico é obtida com volume correspondente $57,4 \%$ menor que o volume esperado (considerando as "escalas de cinza"), cuja localização do centróide tem coordenada igual $x=51,6 \mathrm{~mm}$ e $y=51,9 \mathrm{~mm}$, ou seja, um erro de posicionamento de aproximadamente $11 \%$ nas duas direções (horizontal e vertical). Os gráficos das figuras 7.31(b) e 7.32(b) mostram que os valores absolutos de resistividades da imagem são melhores definidos no caso de aplicação do padrão adjacente, inclusive pode-se notar que a região escura (objeto 
cilíndrico) possui vários elementos que alcançam o valor de resistividade esperado para essa região $\left(10^{6} \Omega m\right)$, enquanto que no padrão diametral os valores absolutos de resistividades alcançados são muito abaixo do esperado.

Desta maneira, através dos resultados apresentados nesta seção, conclui-se que o padrão adjacente de excitação elétrica continua fornecendo melhores resultados e portanto daqui em diante será adotado somente esse padrão de excitação elétrica para todos os exemplos apresentados neste trabalho. Além disso, os resultados mostram que a utilização do domínio de obtenção de imagem discretizado em elementos triangulares produziu resultados equivalentes aos produzidos com o domínio discretizado em elementos quadriláteros. Assim, a princípio o estudo realizado nesta seção indica que o método adotado neste trabalho para obtenção de imagem na TIE não se mostrou tão sensível aos dois tipos de discretização do domínio de obtenção de imagem, porém acredita-se que este aspecto deva ser mais explorado e portanto nas seções seguintes deste trabalho o domínio com elementos triangulares continuará sendo utilizado, em paralelo com o domínio com elementos quadriláteros, para efeitos de maiores comparações.

\subsubsection{Imagem de um Objeto em Diferentes Posições no Domínio}

Para maior detalhamento e esclarecimentos, a partir deste ponto são apresentados vários exemplos de aplicação do TOMOGOT para obter a imagem em três posições distintas de um objeto de baixa condutividade imerso numa região de alta condutividade, utilizando-se os dois domínios de obtenção de imagem mostrados na figura 7.25 (domínio com 576 elementos quadriláteros) e figura 7.26 (domínio com 1248 elementos triangulares). Assim, compara-se o desempenho do TOMOGOT quanto a utilização de diferentes modelos de MEF para o domínio de obtenção de imagem e quanto a mudança da posição da imagem no domínio. Além disso, também investiga-se o comportamento da solução obtida no problema de otimização topológica quando o valor inicial da variável de projeto $\left(\rho_{0}\right)$ e o fator de penalidade do modelo de material $(p)$ são modificados.

Visando explorar o método proposto, nas próximas seções deste capítulo são apresentados resultados obtidos com a inclusão da restrição da condutividade média (RCM), descrita na seção 5.3, no problema de otimização topológica aplicado à TIE. Observa-se que, para os exemplos apresentados daqui em diante, o TOMOGOT utiliza a Abordagem 2 descrita na seção 6.3 .2 (esquema de 


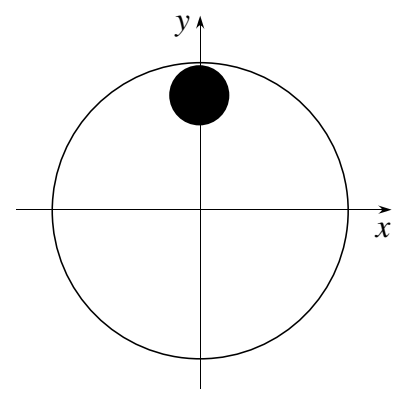

(a) $\mathrm{x}=0 ; \mathrm{y}=90 \mathrm{~mm}$

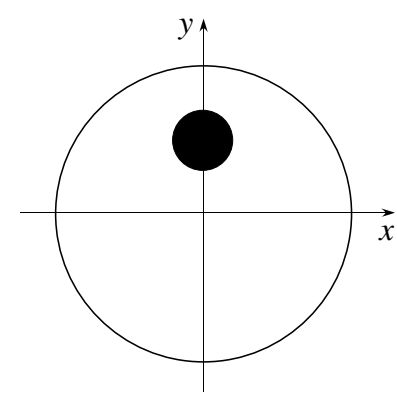

(b) $\mathrm{x}=0 ; \mathrm{y}=53 \mathrm{~mm}$

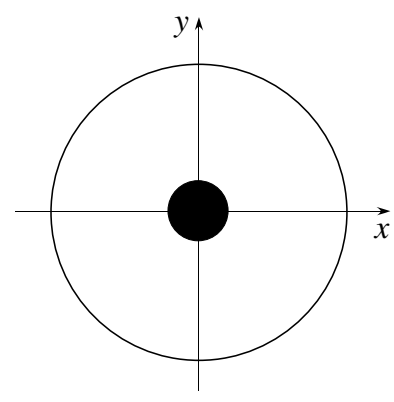

(c) $\mathrm{x}=0 ; \mathrm{y}=0$

Figura 7.33: Imagens a serem obtidas no domínio circular $\left(V^{*}=3,8 \%\right)$.

alternância das variáveis de projeto $\rho t_{j}$ e $\rho_{k}$ ). Além disso, também são utilizados as técnicas alternativas implementadas no TOMOGOT, como o filtro espacial (seção 6.4), o método da continuação (seção 6.5) e o "CAMD" (seção 6.6), que visam a regularização do problema inverso envolvido e conseqüentemente a melhoria da qualidade da imagem obtida.

Neste caso, as imagens a serem obtidas são mostradas na figura 7.33, onde a região escura simula a presença de um objeto cilíndrico de baixa condutividade, $10^{-6}(\Omega m)^{-1}$, cujo volume representa $3,8 \%\left(V^{*}\right)$ do volume total do domínio. O restante do domínio circular é caracterizado por um material de maior condutividade, $1 / 17(\Omega m)^{-1}$, em relação ao objeto cilíndrico (região escura). Na prática esta situação simularia a obtenção da imagem de posições distintas de um copo de vidro inserido numa cuba circular preenchida com água salina, por exemplo. Portanto, o desempenho do algoritmo implementado é avaliado em três casos distintos. No primeiro deles, o centróide do objeto cilíndrico está alinhado com o eixo vertical $(y)$ e localizado próximo a borda do domínio circular, ou seja, a 90 milímetros do eixo horizontal $(x)$ que passa pelo centro do domínio, conforme mostrado na figura 7.33(a). No segundo caso, o centróide do objeto está localizado a 53 milímetros do eixo horizontal $(x)$, entre a borda e o centro do domínio conforme mostrado na figura 7.33(b). Finalmente, no terceiro caso, o objeto está localizado no centro do domínio circular, conforme pode ser visto na figura $7.33(\mathrm{c})$.

Nos exemplos apresentados nas seguintes seções, os potenciais elétricos $\phi_{\mathrm{ij} 0}$ são simulados através de fantomas numéricos. Assim, são construídos um fantoma numérico para cada domínio mostrado na figura 7.33. O domínio desses fantomas numéricos são discretizados uniformemente em 4056 elementos quadriláteros de 4 nós, com espessura igual a 35 milímetros, conforme mostrado nas figuras 7.34(a), 7.34(b) e 7.34(c). Para determinação dos potenciais $\phi_{\mathrm{ij0}}$, utiliza-se um parâmetro 
de eletrodo igual a $0,02 \Omega m^{2}$ (valor adotado) para todos os elementos de eletrodos do fantoma numérico.

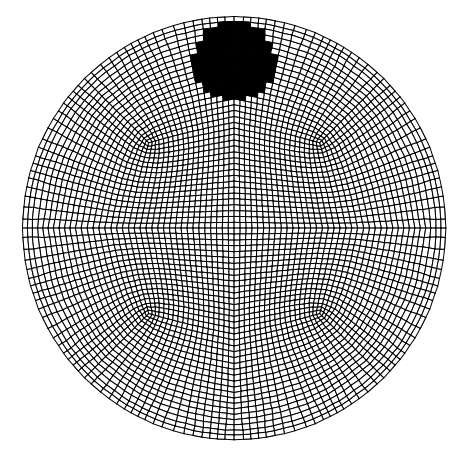

(a)

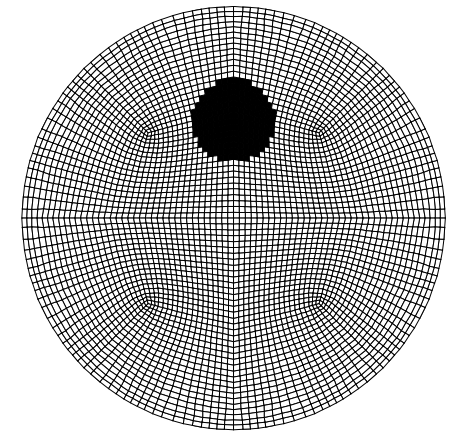

(b)

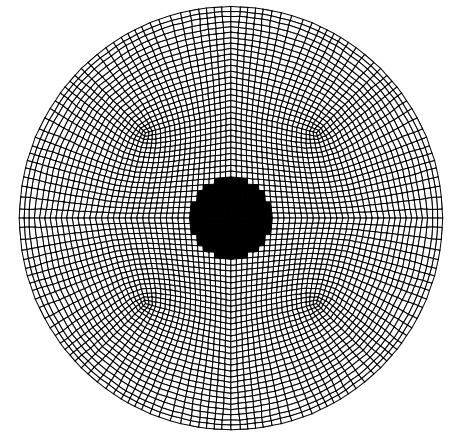

(c)

Figura 7.34: Fantomas numéricos do domínio circular: a) objeto na borda; b) objeto entre a borda e o centro; c) objeto no centro.

\subsubsection{Resultados Obtidos com a Aplicação da Restrição de Condutividade Média}

Nesta seção são mostrados os resultados alcançados utilizando-se o domínio de obtenção de imagem discretizado em elementos quadriláteros (veja figura 7.25) ou elementos triangulares (veja figura 7.26) e a RCM apresentada na seção 5.3. Para cada caso apresentado na figura 7.33, inicialmente o TOMOGOT é testado utilizando-se o fator de penalidade $p$ igual 2 e, depois disso, também é testado com o fator $p$ igual a 4 . Em ambos os testes, são aplicados diferentes valores iniciais $\left(\rho_{k}^{0}\right)$ para a variável de projeto. O objetivo é comparar os resultados obtidos, verificando-se o tamanho e posição das imagens obtidas, em relação aos valores prescritos na figura 7.33. Além disso, é realizado uma verificação dos valores absolutos de condutividades (ou resistividades) obtidos. O expoente $q$ da distância $d_{k}$ na RCM, equação (5.4), é adotado igual a 2 e utilizado em todos os exemplos apresentados, exceto no caso em que a imagem do objeto (região escura) está localizada no centro do domínio. Neste caso, é aplicado um expoente $q$ igual a 4 para destacar melhor os valores de condutividades na região central do domínio, forçando o algoritmo a definir melhor a imagem nesta região, conforme descrito na seção 5.3.

\subsubsection{Imagens Obtidas no Domínio Discretizado em Elementos Quadriláteros}

As figuras a seguir mostram os resultados obtidos com a utilização do domínio de obtenção de imagem discretizado em 576 elementos quadriláteros de 4 nós, 
apresentado na figura 7.25, para os três casos distintos mostrados na figura 7.33 (objeto na borda do domínio (a), objeto entre a borda e o centro do domínio (b) e objeto no centro do domínio (c)).

Inicialmente, as figuras 7.35, 7.36 e 7.37 mostram as imagens da distribuição de condutividades obtidas com o TOMOGOT, utilizando-se $p$ igual 2 para $\rho_{k}^{0}$ iguais a $0,15,0,50$ e 0,85 .

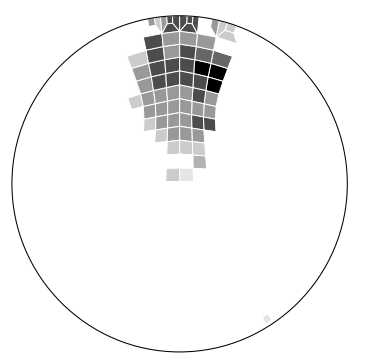

(a) $V^{*}=2,9 \% ; \mathrm{x}=3,4 ; \mathrm{y}=79,6$

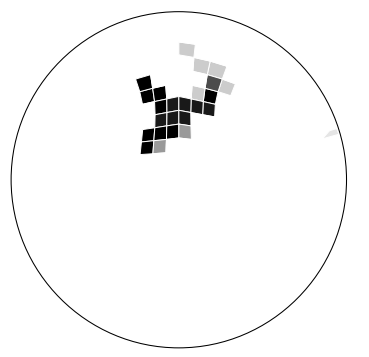

(b) $V^{*}=3,1 \% ; \mathrm{x}=-4,2 ; \mathrm{y}=47,6$

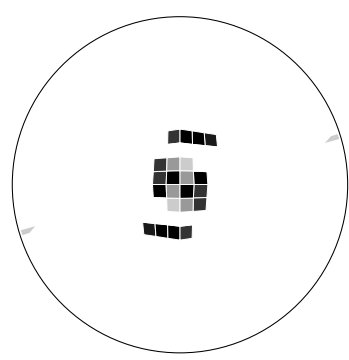

(c) $V^{*}=2,8 \% ; \mathrm{x}=0 ; \mathrm{y}=0$

Figura 7.35: Imagens obtidas com $p=2, \rho_{k}^{0}=0,15$ e elementos quadriláteros.

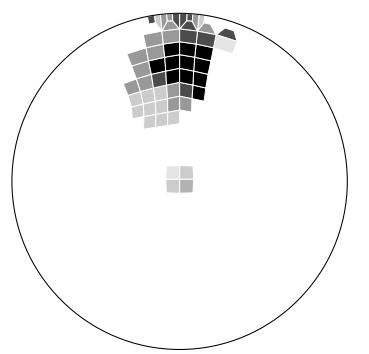

(a) $V^{*}=3,7 \% ; \mathrm{x}=5,1 ; \mathrm{y}=82,7$

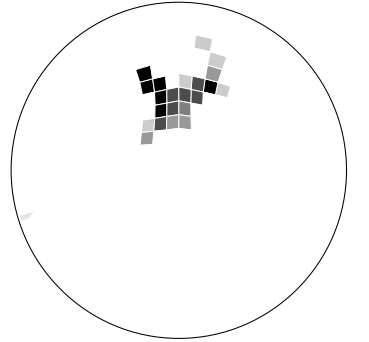

(b) $V^{*}=2,1 \% ; \mathrm{x}=-5,1 ; \mathrm{y}=52,4$

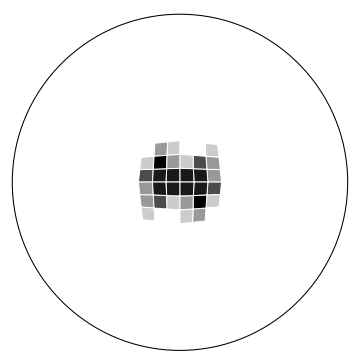

(c) $V^{*}=2,6 \% ; \mathrm{x}=0 ; \mathrm{y}=0$

Figura 7.36: Imagens obtidas com $p=2, \rho_{k}^{0}=0,50$ e elementos quadriláteros.

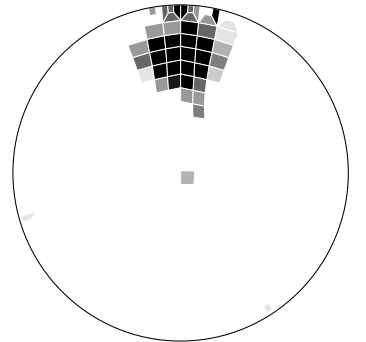

(a) $V^{*}=3,8 \% ; \mathrm{x}=1 ; \mathrm{y}=81,5$

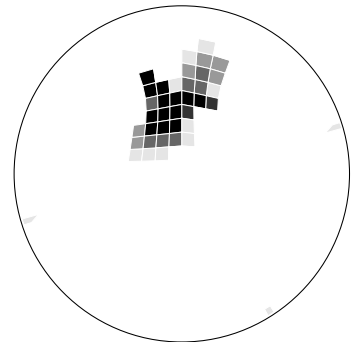

(b) $V^{*}=2,8 \% ; \mathrm{x}=-7,8 ; \mathrm{y}=46,9$

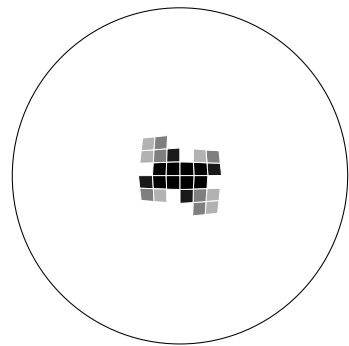

(c) $V^{*}=2 \% ; \mathrm{x}=0 ; \mathrm{y}=0$

Figura 7.37: Imagens obtidas com $p=2, \rho_{k}^{0}=0,85$ e elementos quadriláteros.

De acordo com os resultados obtidos, pode-se notar que o TOMOGOT é capaz de detectar a presença do objeto de baixa condutividade (região escura da imagem) no interior do domínio de maior condutividade (região clara da imagem). Nos resultados apresentados nas próxima seções, os valores de volumes relativos $\left(V^{*}\right)$ da região de baixa condutividade e das coordenadas $(x, y)$ do centróide dessa região são calculados ponderando-se o volume e as coordenadas $(x, y)$ de 
cada elemento, que se encontra na região de baixa condutividade, com os valores de pseudo-densidades (variáveis de projeto) obtidas pelo TOMOGOT. Neste caso, entra no cálculo somente valores de densidade maior que $80 \%$ do valor máximo de densidade obtida. Isto significa que, mesmo que a imagem obtida apresente uma grande área de baixa condutividade (região escura), se ela for constituída de valores de pseudo-densidade baixos, o volume encontrado para ela poderá ser muito distante do esperado. Por exemplo, a imagem da figura 7.35(a) apresenta $V^{*}$ igual 2,9\% (erro de 23,7\%) apesar da grande área encontrada para a região de baixa condutividade. Neste caso, a maior parte da área encontrada para a região escura é constituída de condutividade intermediária a esperada (escala de cinza) e portanto não contabilizada no cálculo do volume na imagem $\left(V^{*}\right)$. O valor de $V^{*}$ e da coordenada $(x, y)$ do centróide da região de baixa condutividade pode ser visto em cada imagem apresentada nas figuras 7.35, 7.36 e 7.37.

Detalhando os resultados obtidos podemos observar que o TOMOGOT é capaz de detectar a presença do objeto, esteja ele na borda, no centro ou entre a borda e o centro do domínio circular. Porém, percebe-se que a solução do problema de otimização implementado no TOMOGOT é sensível a mudança do valor inicial $\rho_{k}^{0}$ das variáveis de projeto. Neste caso, nota-se que quando o objeto está posicionado na borda do domínio obtém-se um resultado satisfatório adotando-se 0,85 como valor inicial $\rho_{k}^{0}$. Neste caso, o volume $V^{*}$ coincidiu com o valor esperado (3,8\%), obteve-se um desalinhamento de apenas 1 milímetro do centróide da região escura da imagem em relação ao eixo y e um erro de 9,4\% no posicionamento do centróide em relação ao eixo $x$ (distância entre o centróide e o centro do domínio).

Porém, quando o objeto está posicionado entre a borda e o centro do domínio, os resultados mostram que o melhor valor para $\rho_{k}^{0}$ é 0,15 . Sendo que, neste caso, o erro obtido para o volume $V^{*}$ e para a distância em $y$ do centróide da região escura da imagem foi de 18,4\% e 10,2\%, respectivamente. Obteve-se um desalinhamento de 4,2 milímetros do centróide em relação ao eixo y. Já, quando o objeto está no centro do domínio os erros obtidos para qualquer valor de $\rho_{k}^{0}$ são significativamente maiores.

A tabela 7.3 mostra um resumo do erro obtido para $V^{*}$ e para a coordenada $(x, y)$ do centróide da região escura da imagem, bem como o máximo valor de pseudo-densidade (variável de projeto) obtida pelo TOMOGOT, para os três diferentes valores de $\rho_{k}^{0}$ em cada caso de posicionamento do objeto no domínio. 
Tabela 7.3: Erro de $V^{*}$ e da coordenada $(x, y)$ do centróide da imagem do objeto e valor máximo de $\rho_{k}$, com $p=2, \mathrm{RCM}$ e elementos quadriláteros

\begin{tabular}{|c|c|c|c|c|c|c|}
\hline posição & figura & $\rho_{k}^{0}$ & $e\left(V^{*}\right)[\%]$ & $e(x)[\mathrm{mm}]$ & $e(y)[\%]$ & $\rho_{k}^{\max }$ \\
\hline \multirow{5}{*}{ borda } & $7.35(\mathrm{a})$ & 0,15 & 23,7 & 3,4 & 11,5 & 1 \\
& $7.36(\mathrm{a})$ & 0,50 & 2,6 & 5,1 & 8,1 & 1 \\
& $7.37(\mathrm{a})$ & 0,85 & 0 & 1 & 9,4 & 1 \\
\hline \hline \multirow{3}{*}{ meio } & $7.35(\mathrm{~b})$ & 0,15 & 18,4 & 4,2 & 10,2 & 1 \\
& $7.36(\mathrm{~b})$ & 0,50 & 44,7 & 5,1 & 1,1 & 1 \\
& $7.37(\mathrm{~b})$ & 0,85 & 26,3 & 7,8 & 11,5 & 1 \\
\hline \hline \multirow{3}{*}{ centro } & $7.35(\mathrm{c})$ & 0,15 & 26,3 & 0 & 0 & 0,98 \\
& $7.36(\mathrm{c})$ & 0,50 & 31,6 & 0 & 0 & 1 \\
& $7.37(\mathrm{c})$ & 0,85 & 47,4 & 0 & 0 & 0,83 \\
\hline
\end{tabular}

1. A coluna "posição" da tabela indica o posicionamento do objeto no domínio. Assim, "borda" significa que o objeto está localizado na borda do domínio, conforme figura 7.33(a), "meio" significa que o objeto está entre a borda e o centro do domínio, conforme figura 7.33(b), e "centro" significa que o objeto está localizado no centro do domínio, conforme figura 7.33(c).

2. O erro de posicionamento $e(x)$ é dado em milímetros $(m m)$ e expressa o desalinhamento do centróide da imagem obtida do objeto cilíndrico em relação ao eixo vertical $(y)$, na direção do eixo horizontal $(x)$.

Os gráficos das figuras 7.38 a 7.46 mostram as curvas de convergência da função objetivo do processo de obtenção das imagens mostradas nas figuras 7.35, 7.36 e 7.37, bem como ilustram uma imagem 3D da distribuição de resistividades gerada a partir das imagens obtidas.

Observando as curvas de convergência dos resultados apresentados nota-se que elas possuem comportamento similar ao apresentado nos resultados mostrados nas seções anteriores, ou seja, a função objetivo cai a um valor mínimo em poucas iterações $(\sim 15)$ e permanece o restante do processo iterativo com uma pequena oscilação até que a imagem seja encontrada. Observa-se que a maioria delas possuem este comportamento, exceto as curvas das figuras 7.38(a) e 7.41(a) que apresentam uma grande oscilação durante todo o processo de obtenção de imagem. Inclusive estas curvas possuem alguns pontos onde o valor da função objetivo retorna e estabelece valor maior ao iniciado no processo de otimização. Por exemplo, na curva de convergência mostrada na figura 7.38(a) nota-se que nas iterações 31 e 44 a função objetivo assume valores iguais a 3,646 e 4,127, 


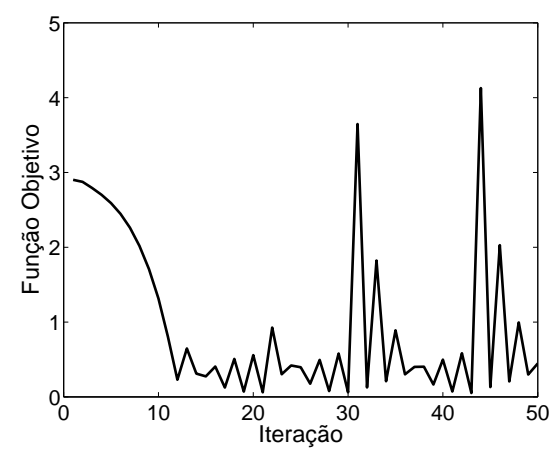

(a) gráfico de convergência

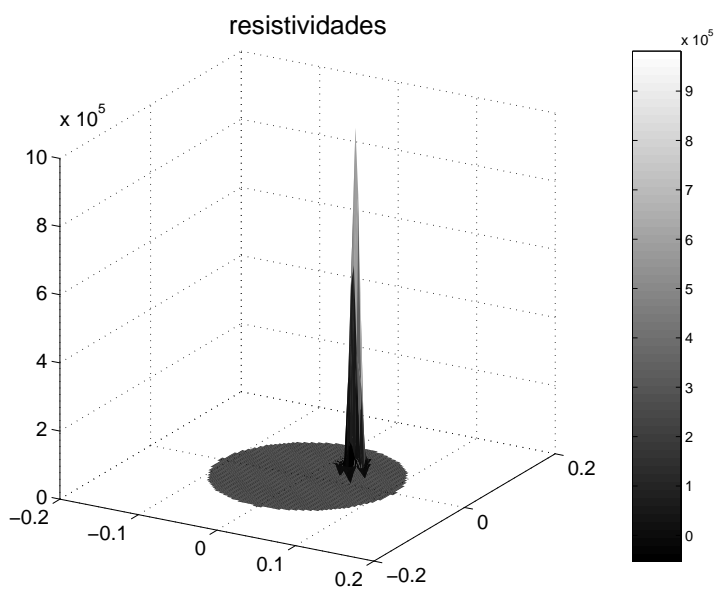

(b) gráfico de resistividades

Figura 7.38: Gráficos de convergência e resistividades da imagem obtida com $p=2$ e $\rho_{k}^{0}=0,15$, mostrada na figura 7.35 (a).

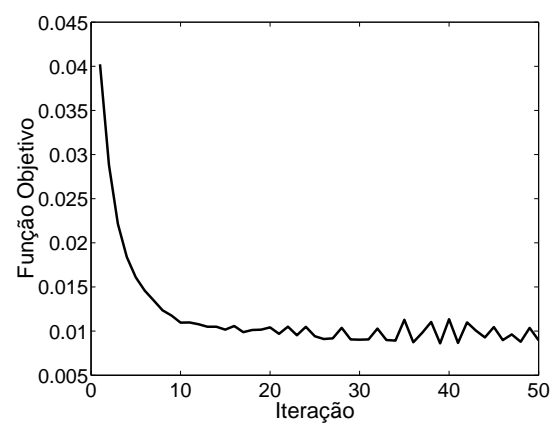

(a) gráfico de convergência

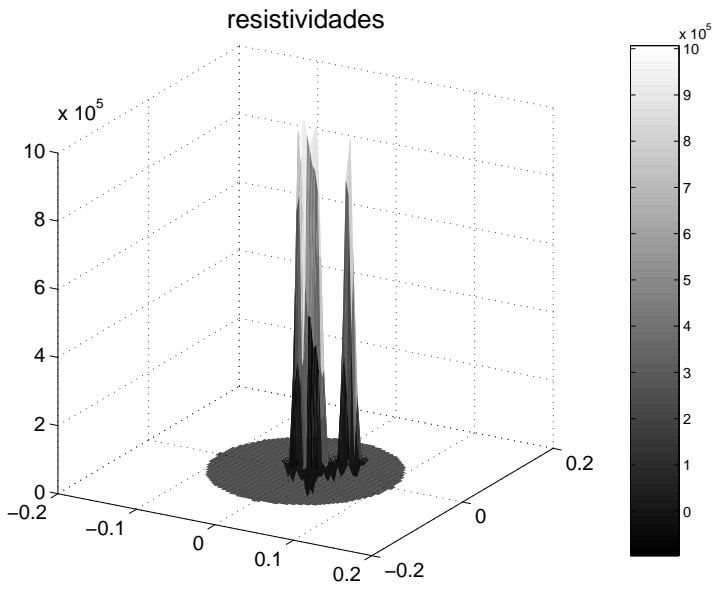

(b) gráfico de resistividades

Figura 7.39: Gráficos de convergência e resistividades da imagem obtida com $p=2$ e $\rho_{k}^{0}=0,15$, mostrada na figura $7.35(\mathrm{~b})$.

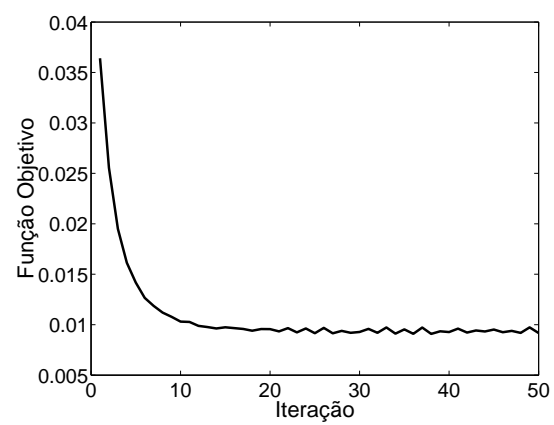

(a) gráfico de convergência

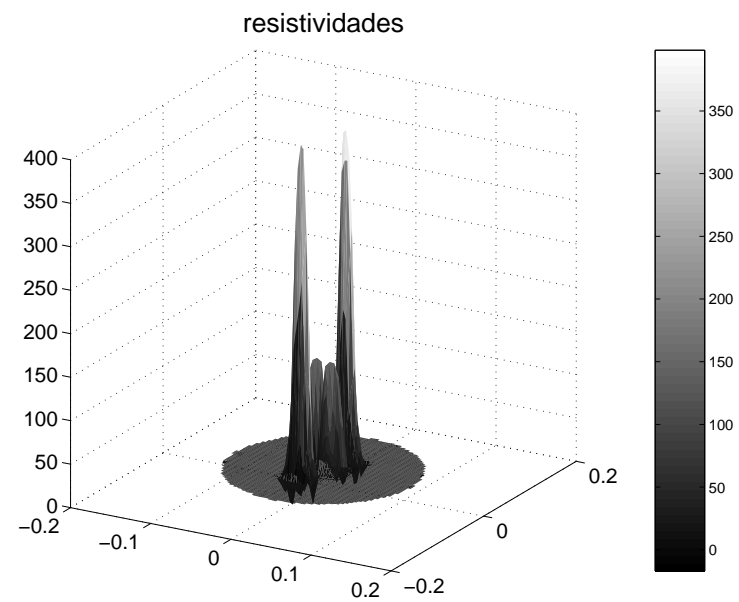

(b) gráfico de resistividades

Figura 7.40: Gráficos de convergência e resistividades da imagem obtida com $p=2, \rho_{k}^{0}=0,15$, mostrada na figura $7.35(\mathrm{c})$. 


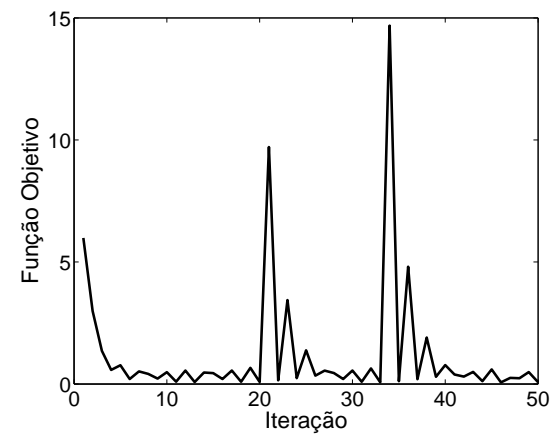

(a) gráfico de convergência

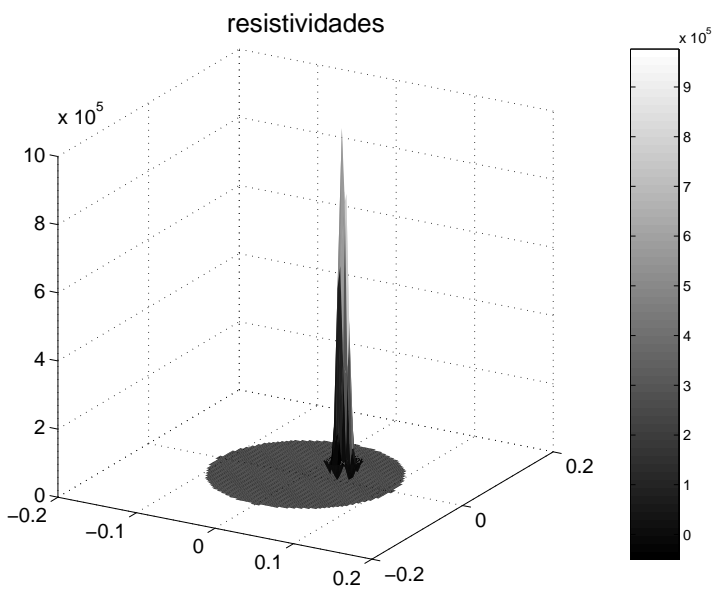

(b) gráfico de resistividades

Figura 7.41: Gráficos de convergência e resistividades da imagem obtida com $p=2$ e $\rho_{k}^{0}=0,50$, mostrada na figura 7.36(a).

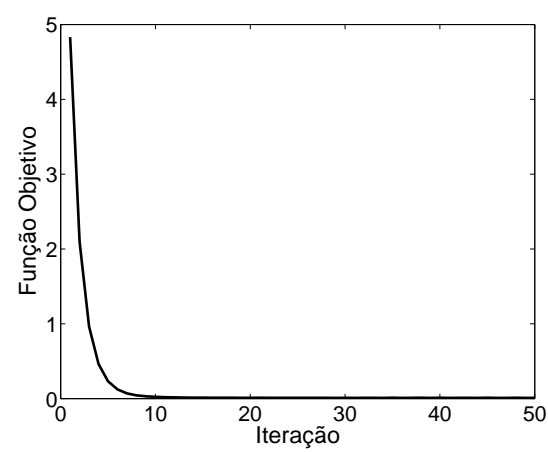

(a) gráfico de convergência

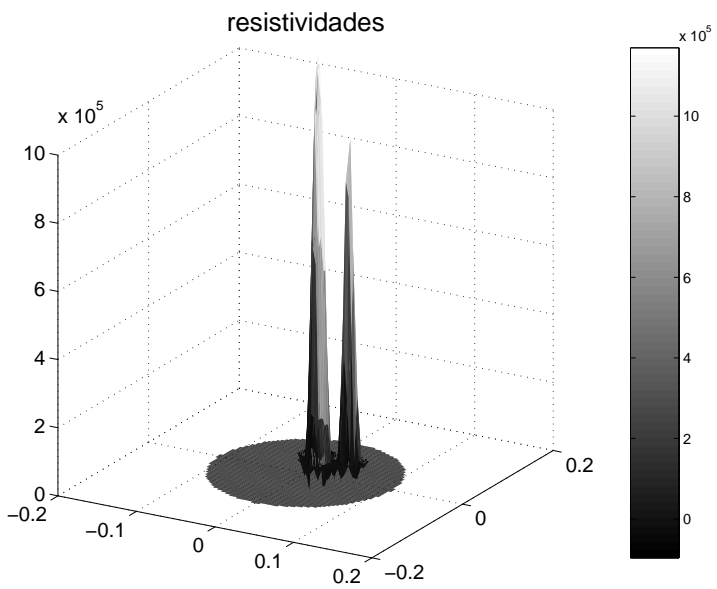

(b) gráfico de resistividades

Figura 7.42: Gráficos de convergência e resistividades da imagem obtida com $p=2$ e $\rho_{k}^{0}=0,50$, mostrada na figura $7.36(\mathrm{~b})$.

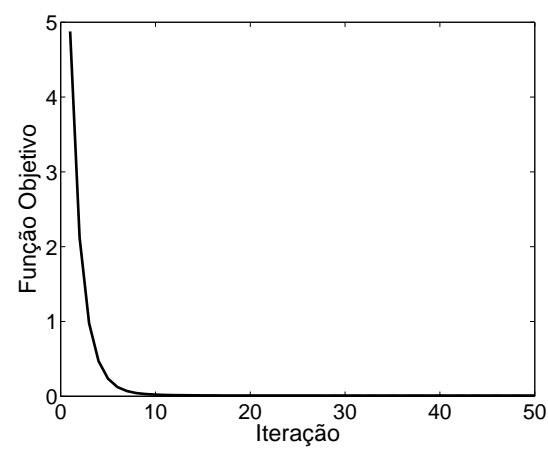

(a) gráfico de convergência

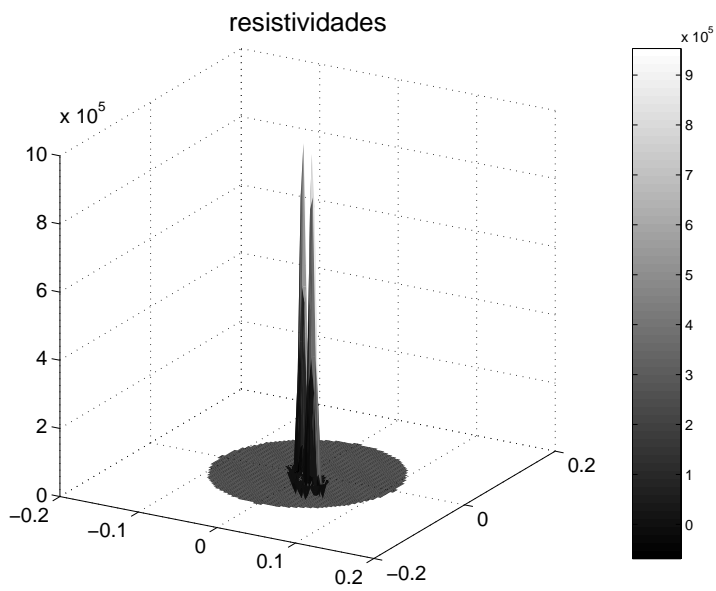

(b) gráfico de resistividades

Figura 7.43: Gráficos de convergência e resistividades da imagem obtida com $p=2$ e $\rho_{k}^{0}=0,50$, mostrada na figura $7.36(\mathrm{c})$. 


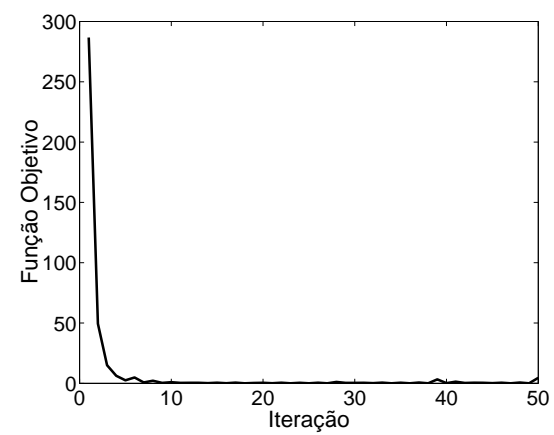

(a) gráfico de convergência

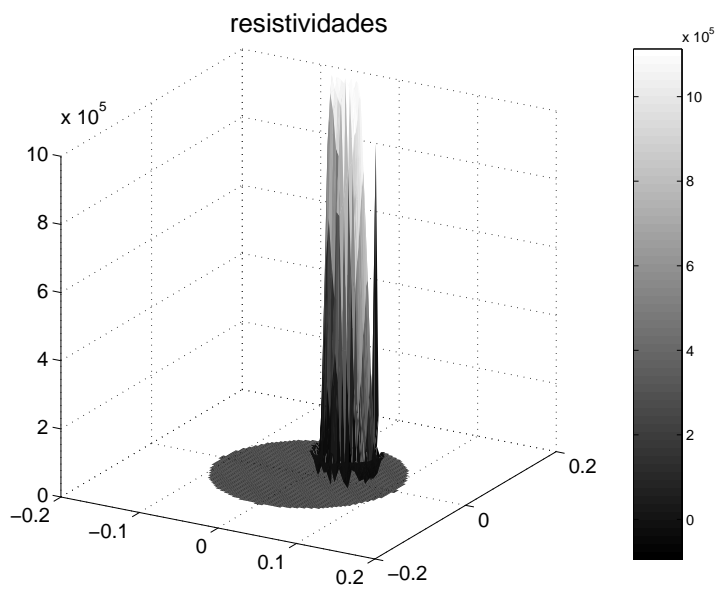

(b) gráfico de resistividades

Figura 7.44: Gráficos de convergência e resistividades da imagem obtida com $p=2$ e $\rho_{k}^{0}=0,85$, mostrada na figura $7.37(\mathrm{a})$.

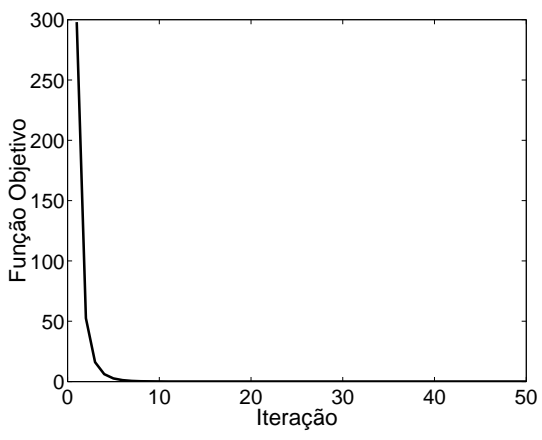

(a) gráfico de convergência

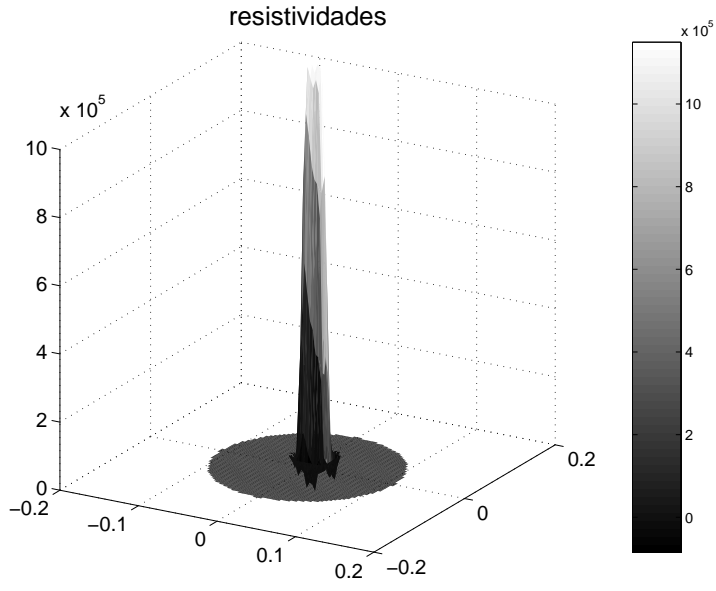

(b) gráfico de resistividades

Figura 7.45: Gráficos de convergência e resistividades da imagem obtida com $p=2$ e $\rho_{k}^{0}=0,85$, mostrada na figura $7.37(\mathrm{~b})$.

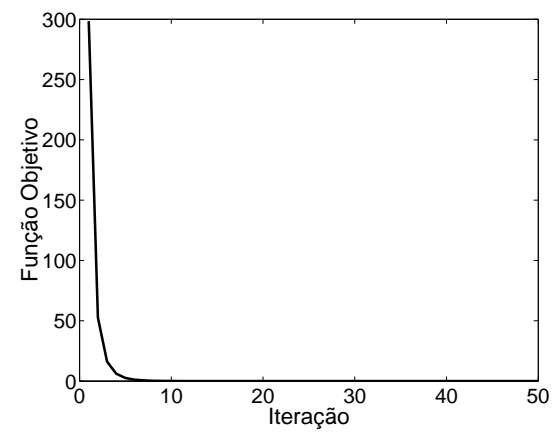

(a) gráfico de convergência

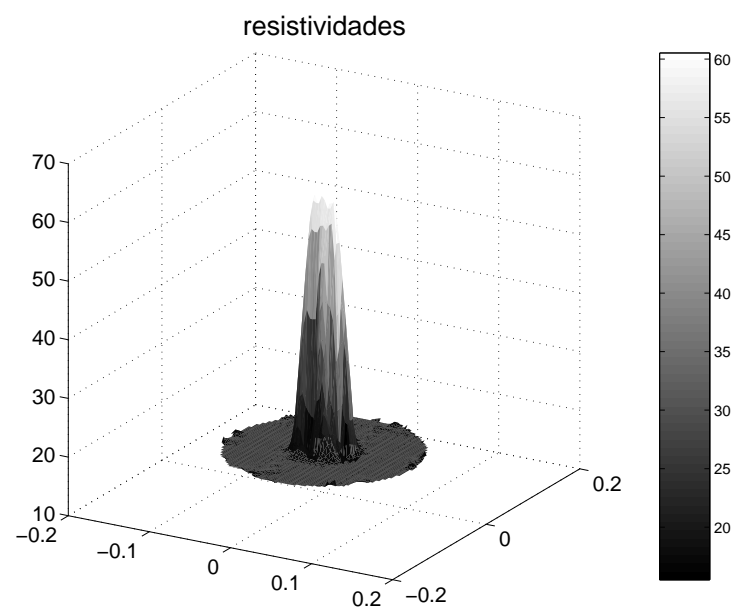

(b) gráfico de resistividades

Figura 7.46: Gráficos de convergência e resistividades da imagem obtida com $p=2$ e $\rho_{k}^{0}=0,85$, mostrada na figura $7.37(\mathrm{c})$. 
respectivamente, superando o valor da função no inicio do processo $(2,901)$. De maneira similar a curva da figura 7.41(a) apresenta valores de função objetivo iguais a 9,709 e 14,681 nas iterações 21 e 34, respectivamente, sendo que o valor inicial neste caso é de 5,983. Porém, o TOMOGOT se mostra robusto no sentido de, mesmo com esta oscilação, fazer com que os valores da função objetivo volte para a região de mínimo valor na iteração seguinte e assim alcançar a convergência. Essas curvas referem-se ao caso em que o objeto é posicionado na borda do domínio e provavelmente essa oscilação elevada seja explicada devido a influência de alguma instabilidade numérica na transição de elementos de eletrodos para elementos quadriláteros no modelo de MEF da borda do domínio. Neste caso, é notório a importância da escolha do valor inicial $\rho_{k}^{0}$, pois percebe-se que com $\rho_{k}^{0}$ igual a 0,85 a convergência da função objetivo possui o comportamento da maioria das curvas obtidas, resultando numa imagem mais próxima da esperada.

Os gráficos 3D de resistividades são mostrados para visualizar melhor quais os pontos da imagem obtida conseguem alcançar o valor de resistividade (ou condutividade) esperada. Por exemplo, o resultado da figura 7.38(b) mostra que apesar da imagem da figura 7.35(a) apresentar uma quantidade grande de elementos na região de baixa condutividade (região escura que representa o objeto), apenas poucos elementos alcançaram o valor máximo de resistividade esperada para essa região $\left(10^{-6}(\Omega m)^{-1}\right)$. Entretanto, os gráficos mostram que em todos os casos de diferentes posições do objeto no interior do domínio e de aplicações distintas do valor inicial das variáveis de projeto $\left(\rho_{k}^{0}\right)$, com utilização de fator $p$ igual a 2, o TOMOGOT é capaz de obter regiões da imagem do objeto que atingem o valor máximo de resistividade esperado, exceto para o caso da imagem mostrada na figura 7.37(c), cujo gráfico de resistividades (figura 7.46(b)) mostra que, apesar da uniformidade dos valores de resistividades dos elementos na região da imagem do objeto, nenhum alcançou o valor de resistividade esperado. Isso mostra que, neste caso, a partir do valor inicial adotado $(0,85)$ o TOMOGOT convergiu a função objetivo para ponto de ótimo local distinto que restringiu o processo de obtenção da imagem de tal forma a não aceitar diferenças elevadas nas variáveis de projeto.

No intuito de investigar e explorar mais o algoritmo proposto para a obtenção de imagem na TIE, bem como melhorar alguns dos resultados mostrados nas figuras 7.35, 7.36 e 7.37, a seguir é realizada a mesma análise anterior aplicando o fator de penalidade $(p)$ igual a 4 . Conforme teoria do MOT, espera-se que o aumento do fator $p$ penalize os valores intermediários de pseudo-densidades 
(variáveis de projeto) dos elementos da região da imagem do objeto (elementos com cor cinza), forçando o algoritmo a distinguir melhor a região da imagem do objeto do restante do domínio. Assim, as figuras 7.47, 7.48 e 7.49 mostram as imagens da distribuição de condutividades obtidas utilizando o fator $p$ igual a 4, para os diferentes valores de $\rho_{k}^{0}(0,15,0,50$ e 0,85$)$. Na seqüencia, são mostrados os gráficos das curvas de convergência da função objetivo, bem como as imagens 3D da distribuição de resistividades geradas a partir da imagens obtidas (figuras 7.50 a 7.58$)$.

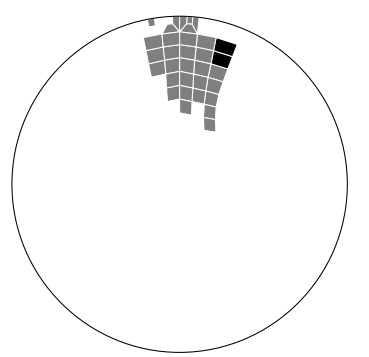

(a) $V^{*}=5,6 \% ; \mathrm{x}=7,6 ; \mathrm{y}=81,1$

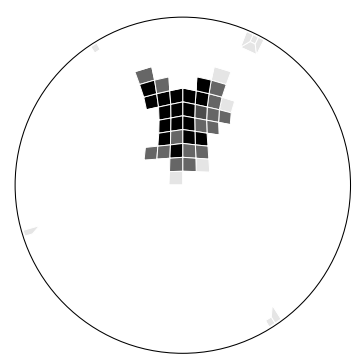

(b) $V^{*}=5,9 \% ; \mathrm{x}=0 ; \mathrm{y}=46$

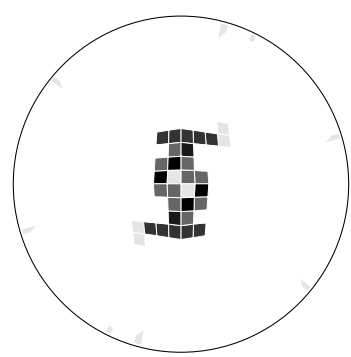

(c) $V^{*}=4,6 \% ; \mathrm{x}=0 ; \mathrm{y}=0$

Figura 7.47: Imagens obtidas com $p=4, \rho_{k}^{0}=0,15$ e elementos quadriláteros.

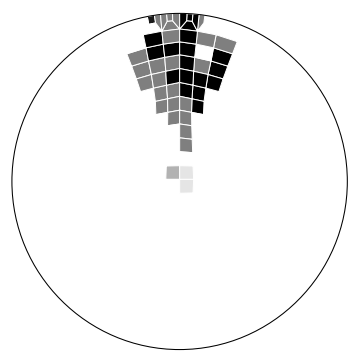

(a) $V^{*}=6,9 \% ; \mathrm{x}=1 ; \mathrm{y}=76,1$

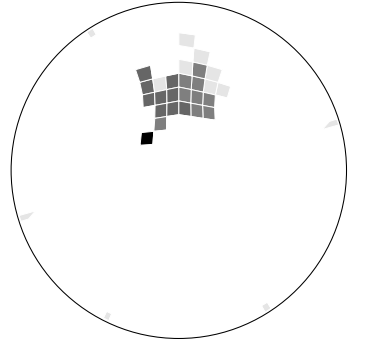

(b) $V^{*}=2,9 \% ; \mathrm{x}=-1,7 ; \mathrm{y}=50,5$

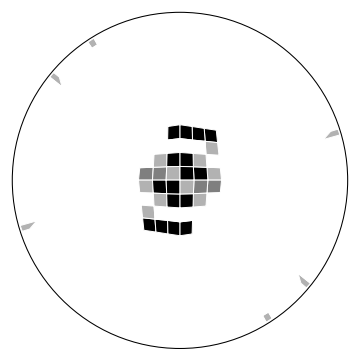

(c) $V^{*}=3,2 \% ; \mathrm{x}=0 ; \mathrm{y}=0$

Figura 7.48: Imagens obtidas com $p=4, \rho_{k}^{0}=0,50$ e elementos quadriláteros.

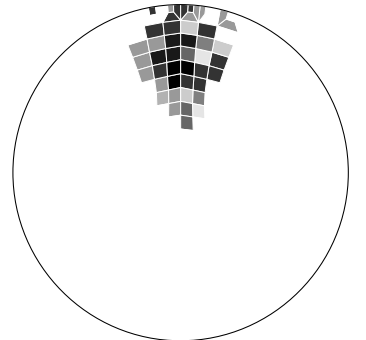

(a) $V^{*}=4,8 \% ; \mathrm{x}=2,9 ; \mathrm{y}=77,6$

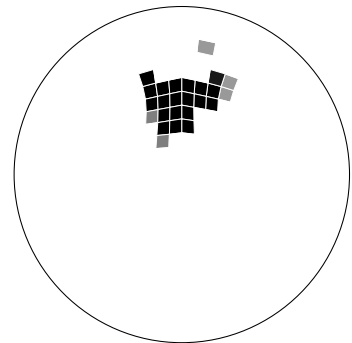

(b) $V^{*}=3,9 \% ; \mathrm{x}=-1,9 ; \mathrm{y}=50,7$

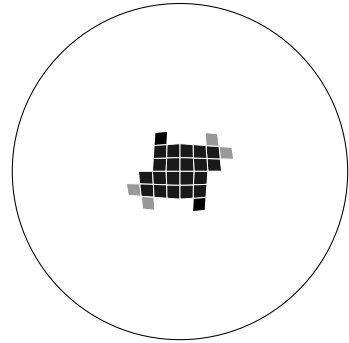

(c) $V^{*}=4,2 \% ; \mathrm{x}=0 ; \mathrm{y}=0$

Figura 7.49: Imagens obtidas $\operatorname{com} p=4, \rho_{k}^{0}=0,85$ e elementos quadriláteros.

O valor de $V^{*}$ e da coordenada $(x, y)$ do centróide da região de baixa condutividade pode ser visto em cada imagem apresentada nas figuras 7.47, $7.48 \mathrm{e}$ 7.49. A tabela 7.4 mostra um resumo do erro obtido para $V^{*}$ e para a coordenada $(x, y)$ do centróide da região da imagem do objeto (região escura da imagem) e 


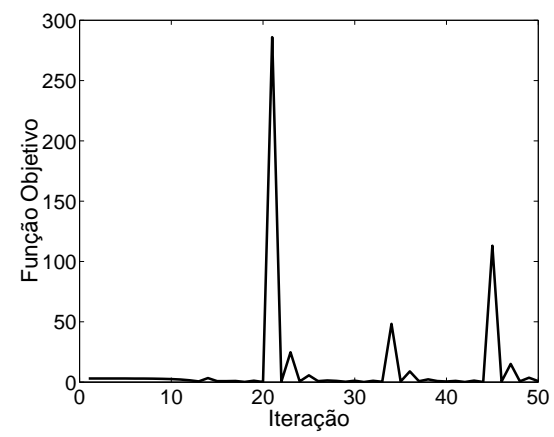

(a) gráfico de convergência

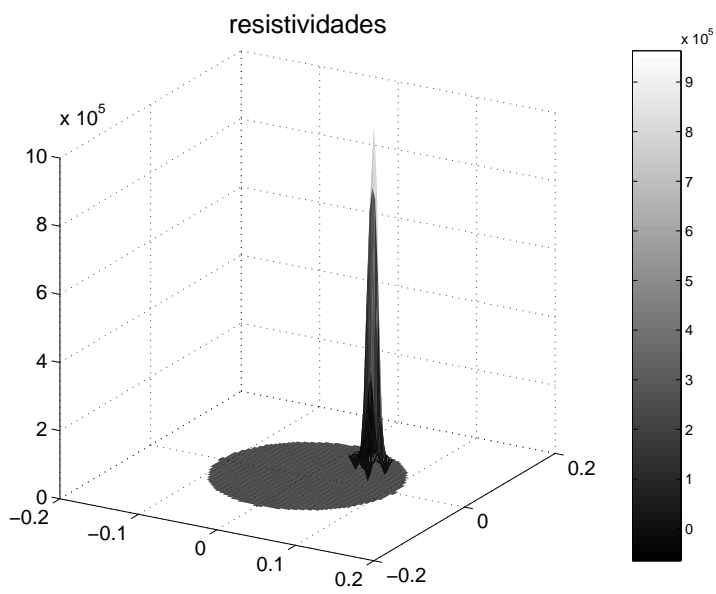

(b) gráfico de resistividades

Figura 7.50: Gráficos de convergência e resistividades da imagem obtida com $p=4$ e $\rho_{k}^{0}=0,15$, mostrada na figura 7.47 (a).

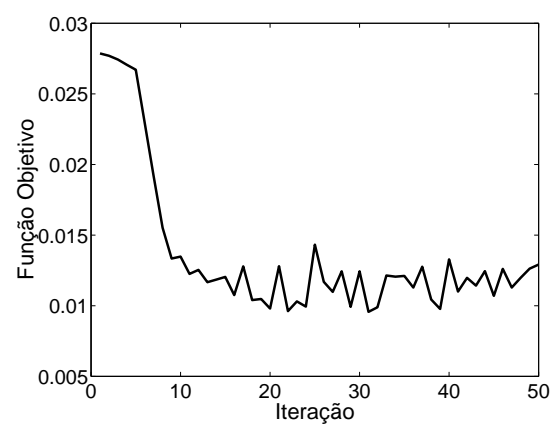

(a) gráfico de convergência

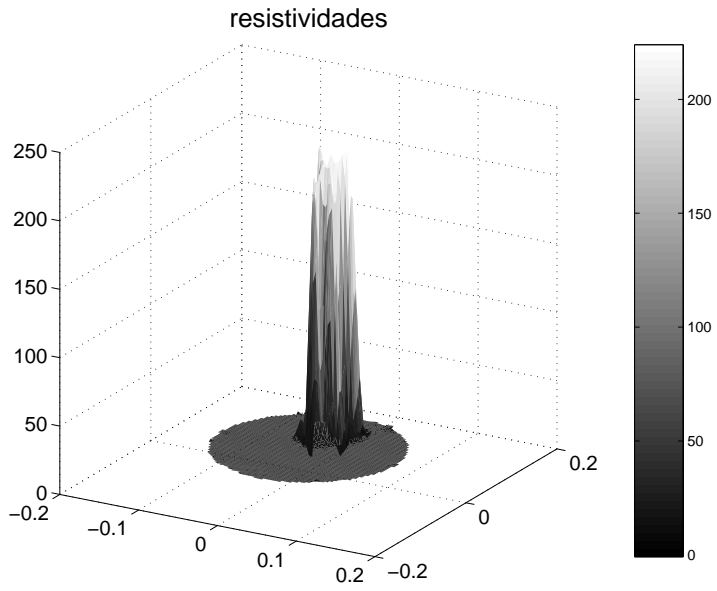

(b) gráfico de resistividades

Figura 7.51: Gráficos de convergência e resistividades da imagem obtida com $p=4$ e $\rho_{k}^{0}=0,15$, mostrada na figura $7.47(\mathrm{~b})$.

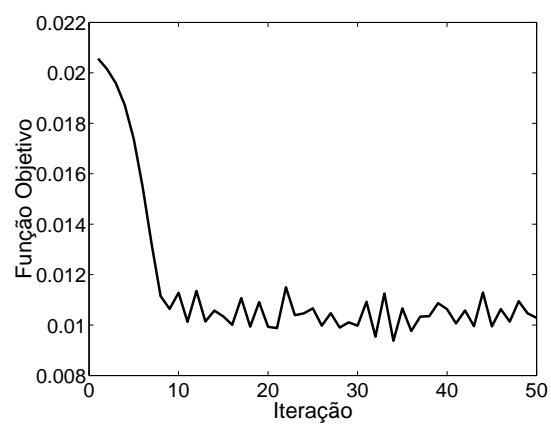

(a) gráfico de convergência

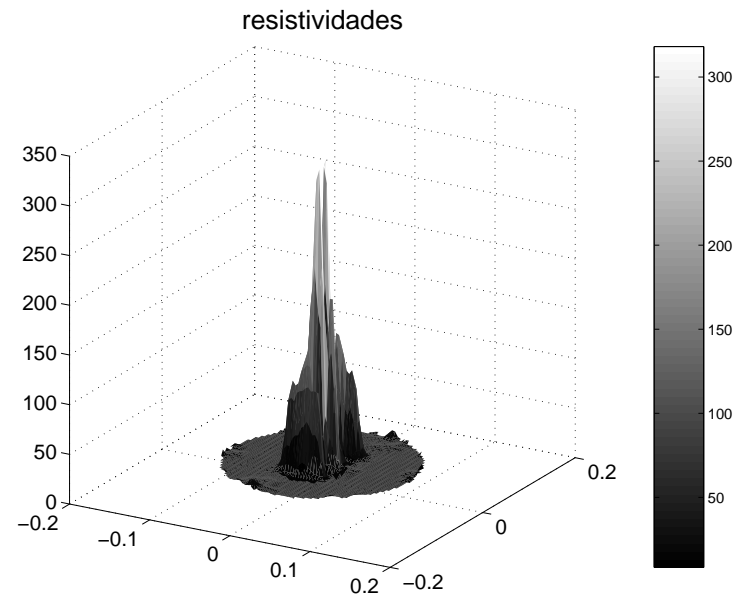

(b) gráfico de resistividades

Figura 7.52: Gráficos de convergência e resistividades da imagem obtida com $p=4$ e $\rho_{k}^{0}=0,15$, mostrada na figura $7.47(\mathrm{c})$. 


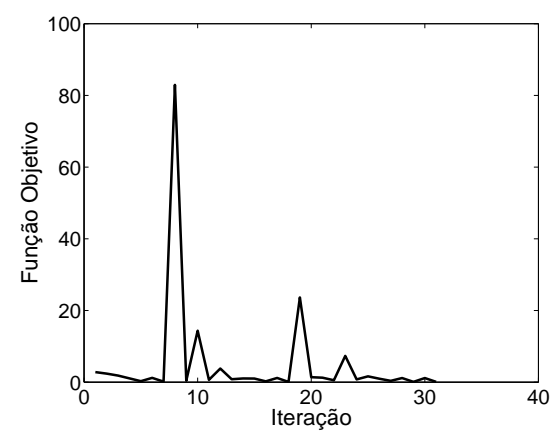

(a) gráfico de convergência

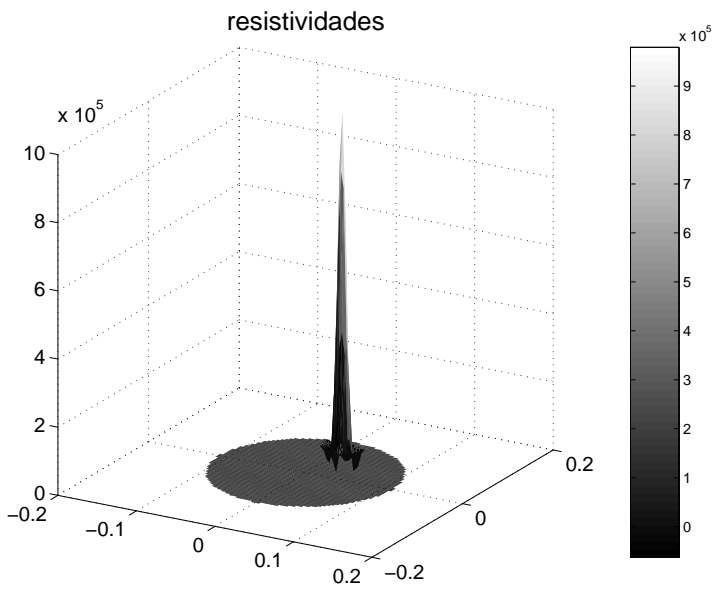

(b) gráfico de resistividades

Figura 7.53: Gráficos de convergência e resistividades da imagem obtida com $p=4$ e $\rho_{k}^{0}=0,50$, mostrada na figura $7.48(\mathrm{a})$.

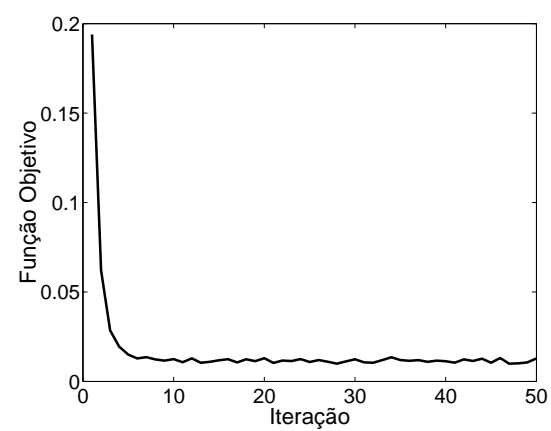

(a) gráfico de convergência

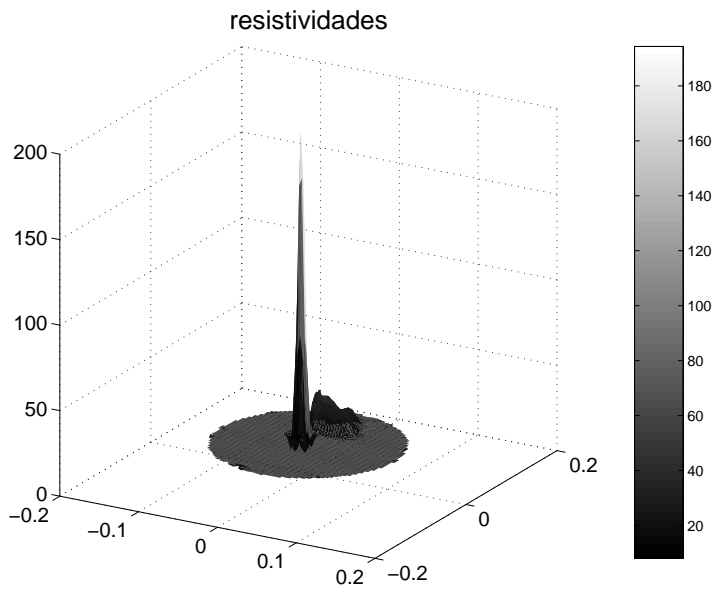

(b) gráfico de resistividades

Figura 7.54: Gráficos de convergência e resistividades da imagem obtida com $p=4$ e $\rho_{k}^{0}=0,50$, mostrada na figura $7.48(\mathrm{~b})$.

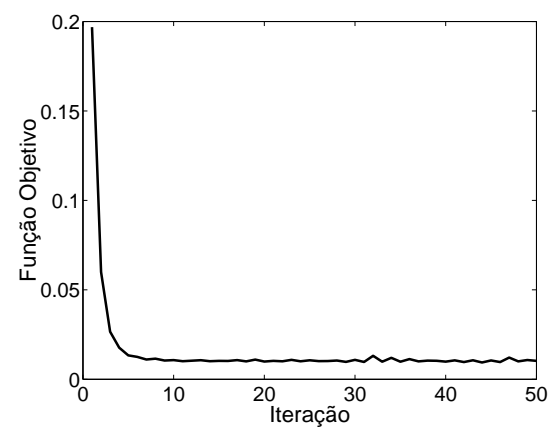

(a) gráfico de convergência

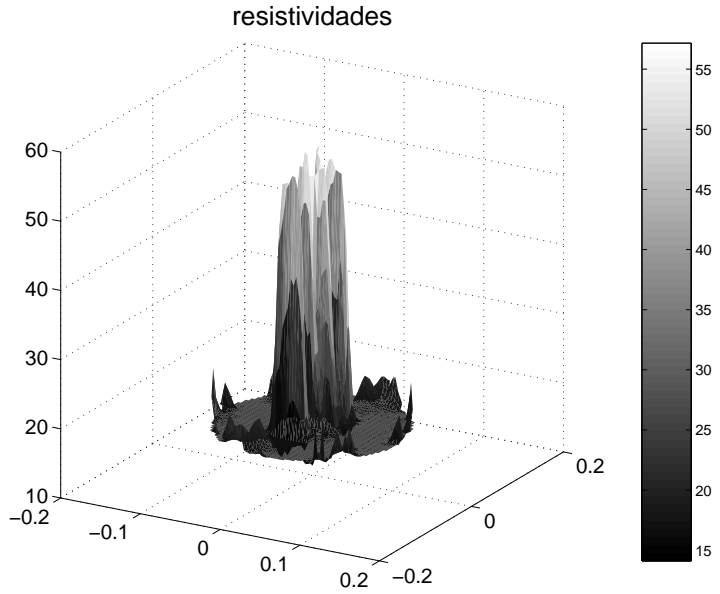

(b) gráfico de resistividades

Figura 7.55: Gráficos de convergência e resistividades da imagem obtida com $p=4$ e $\rho_{k}^{0}=0,50$, mostrada na figura $7.48(\mathrm{c})$. 


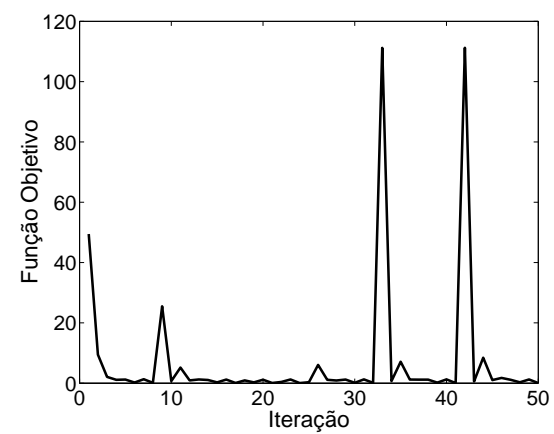

(a) gráfico de convergência

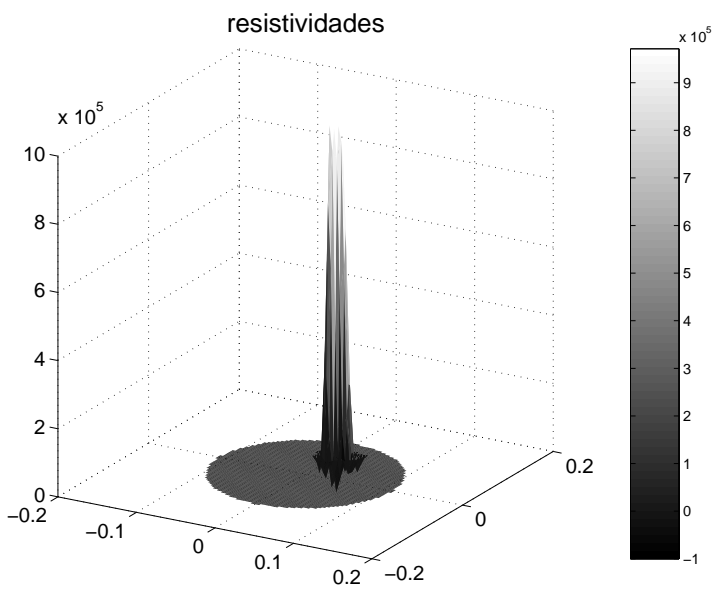

(b) gráfico de resistividades

Figura 7.56: Gráficos de convergência e resistividades da imagem obtida com $p=4$ e $\rho_{k}^{0}=0,85$, mostrada na figura $7.49(\mathrm{a})$.

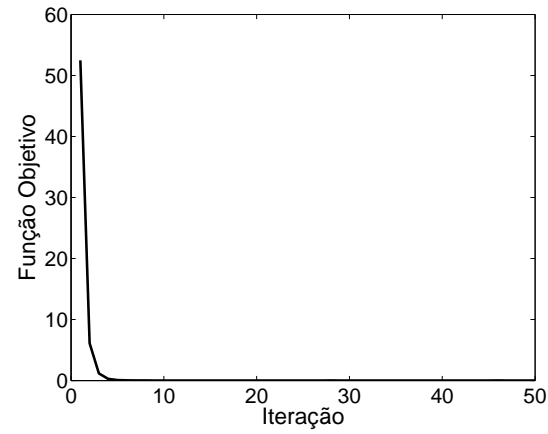

(a) gráfico de convergência

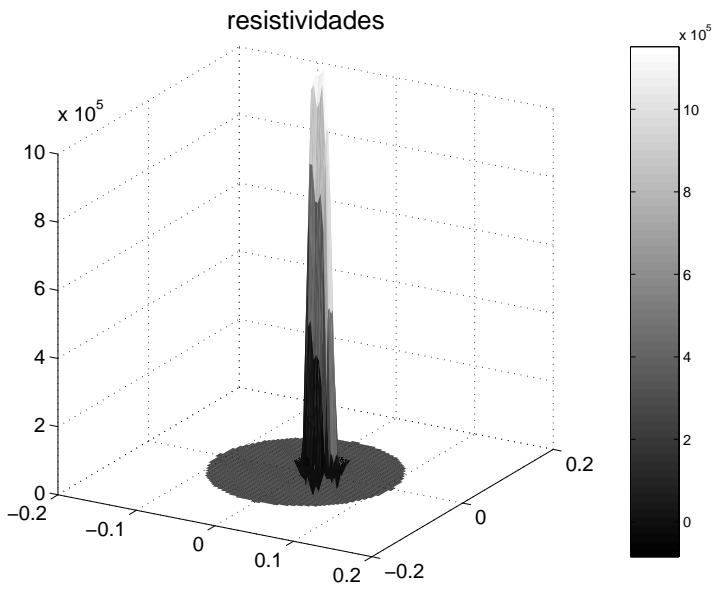

(b) gráfico de resistividades

Figura 7.57: Gráficos de convergência e resistividades da imagem obtida com $p=4$ e $\rho_{k}^{0}=0,85$, mostrada na figura $7.49(\mathrm{~b})$.

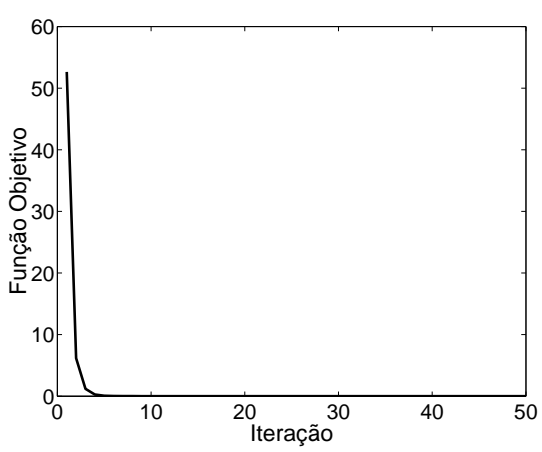

(a) gráfico de convergência

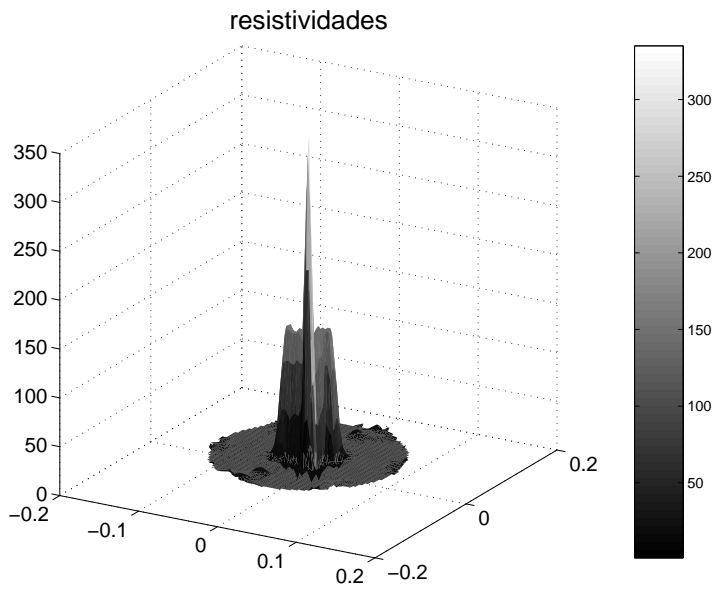

(b) gráfico de resistividades

Figura 7.58: Gráficos de convergência e resistividades da imagem obtida com $p=4$ e $\rho_{k}^{0}=0,85$, mostrada na figura $7.49(\mathrm{c})$. 
o máximo valor de pseudo-densidade obtida pelo TOMOGOT, para os diferentes valores de $\rho_{k}^{0}$ para os casos mostrados na figura 7.33.

Tabela 7.4: Erro de $V^{*}$ e da coordenada $(x, y)$ do centróide da imagem do objeto e valor máximo de $\rho_{k}$, com $p=4, \mathrm{RCM}$ e elementos quadriláteros

\begin{tabular}{|c|c|c|c|c|c|c|}
\hline posição & figura & $\rho_{k}^{0}$ & $e\left(V^{*}\right)[\%]$ & $e(x)[\mathrm{mm}]$ & $e(y)[\%]$ & $\rho_{k}^{\max }$ \\
\hline \multirow{5}{*}{ borda } & $7.47(\mathrm{a})$ & 0,15 & 47,4 & 7,6 & 9,9 & 1 \\
& $7.48(\mathrm{a})$ & 0,50 & 81,5 & 1 & 15,4 & 1 \\
& $7.49(\mathrm{a})$ & 0,85 & 26,3 & 2,9 & 13,8 & 1 \\
\hline \hline \multirow{3}{*}{ meio } & $7.47(\mathrm{~b})$ & 0,15 & 55,2 & 0 & 13,2 & 0,98 \\
& $7.48(\mathrm{~b})$ & 0,50 & 23,7 & 1,7 & 4,7 & 0,98 \\
& $7.49(\mathrm{~b})$ & 0,85 & 2,6 & 1,9 & 4,3 & 1 \\
\hline \hline \multirow{3}{*}{ centro } & $7.47(\mathrm{c})$ & 0,15 & 21,0 & 0 & 0 & 0,97 \\
& $7.48(\mathrm{c})$ & 0,50 & 15,8 & 0 & 0 & 0,83 \\
& $7.49(\mathrm{c})$ & 0,85 & 10,5 & 0 & 0 & 0,97 \\
\hline
\end{tabular}

De acordo com os resultados obtidos, pode-se notar que o TOMOGOT detecta as diferentes posições do objeto de baixa condutividade (região escura da imagem) no interior do domínio, conforme constatado na aplicação anterior (com $p=2)$. Com os resultados, nota-se novamente que a solução do problema de otimização implementado no TOMOGOT é sensível a mudança do valor inicial $\rho_{k}^{0}$ das variáveis de projeto. Nota-se também que o TOMOGOT obtém resultados satisfatórios para qualquer um dos casos apresentados na figura 7.33 adotando-se 0,85 como valor inicial $\rho_{k}^{0}$. Por exemplo, o algoritmo obteve a imagem do objeto posicionado entre a borda e o centro do domínio com $2,6 \%$ de erro no volume $V^{*}$, um desalinhamento do centróide da região da imagem do objeto de apenas 1,9 milímetros na direção do eixo horizontal $(x)$ e somente $4,3 \%$ de erro na distância entre o centróide e o centro do domínio (distância em $y$ ).

Observando as curvas de convergência neste caso, nota-se que elas possuem comportamento similar ao apresentado nos resultados anteriores (com $p=2$ ), ou seja, a função objetivo cai a um valor mínimo em aproximadamente 10 iterações e permanece o restante do processo iterativo com uma pequena oscilação até que a imagem seja encontrada. Entretanto, análogo ao caso anterior, a convergência da função objetivo apresenta um comportamento diferente para o caso em que o objeto é posicionado na borda do domínio e principalmente quando se utiliza 0,15 como valor inicial $\rho_{k}^{0}$, conforme pode ser visto nas figuras 7.50(a), 7.53(a) e 7.56(a). Estas curvas apresentam vários pontos onde o valor da função objetivo se torna bem maior que o valor iniciado no processo de otimização. Por exemplo, 
na curva de convergência mostrada na figura 7.50(a) nota-se que na iteração 21 a função objetivo assume um valor quase 100 vezes o valor o valor da função no início do processo. De maneira similar a curva da figura 7.53(a) mostra um valor de função objetivo 30 vezes o valor inicial da função na iteração 8. Porém, conforme verificado anteriormente, o TOMOGOT neste caso também se mostra robusto para fazer com que, mesmo com os desvios da função objetivo, o algoritmo a retornasse para a região de mínimo valor na iteração seguinte até alcançar a convergência.

Os gráficos 3D de resistividades das figuras 7.50(b), 7.53(b) e 7.56(b) mostram que vários elementos das imagens mostradas nas figuras 7.47(a), 7.48(a) e 7.49(a) atingem o valor de resistividade (ou condutividade) esperada $\left(10^{-6}(\Omega m)^{-1}\right)$. Entretanto, os demais gráficos mostram que em todos os casos de diferentes posições do objeto no interior do domínio, exceto na borda com $\rho_{k}^{0}$ igual a 0,15 , os valores de resistividade estão bem abaixo do valor esperado, apesar de em alguns casos apresentar uma região da imagem do objeto uniforme. Isso mostra que, neste caso, utilizar um fator $p$ elevado desde o início do processo de obtenção da imagem pode restringir demais o problema e apesar de obter imagens mais nítidas (com poucas pseudo-densidades intermediárias) sacrifica o algoritmo quanto a obtenção dos valores absolutos de condutividades (ou resistividades).

\subsubsection{Imagens Obtidas com o Domínio Discretizado em Elementos Triangulares}

As figuras a seguir mostram os resultados obtidos com a utilização do domínio de obtenção de imagem discretizado em 1248 elementos triangulares de 3 nós, apresentado na figura 7.26, para os três casos que vem sendo estudados, onde o objeto é posicionado na borda do domínio, entre a borda e o centro do domínio e no centro do domínio (veja figura 7.33).

De maneira análoga ao estudo realizado com elementos quadriláteros, inicialmente são mostradas as imagens da distribuição de condutividades obtidas com o TOMOGOT, utilizando-se $p$ igual 2 para $\rho_{k}^{0}$ iguais a $0,15,0,50$ e 0,85 (figuras 7.59, 7.60 e 7.61). Em seguida, os gráficos das figuras 7.62 a 7.70 mostram as curvas de convergência da função objetivo, bem como a imagem 3D da distribuição de resistividades gerada a partir das imagens obtidas.

O valor de $V^{*}$ e da coordenada $(x, y)$ do centróide da região da imagem do objeto (região escura da imagem obtida) pode ser visto em cada resultado apresentado nas figuras 7.59, 7.60 e 7.61. A tabela 7.5 mostra um resumo do erro 


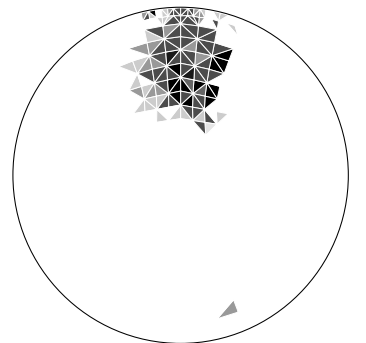

(a) $V^{*}=5,1 \% ; \mathrm{x}=4,7 ; \mathrm{y}=77,5$

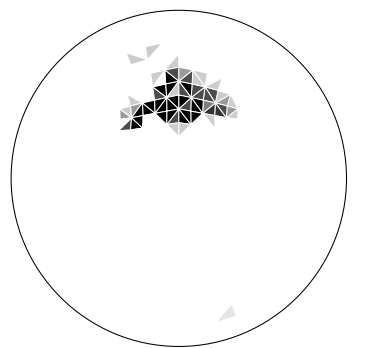

(b) $V^{*}=3 \% ; \mathrm{x}=-1,2 ; \mathrm{y}=51,8$

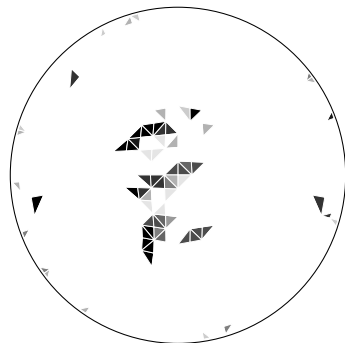

(c) $V^{*}=2,9 \% ; \mathrm{x}=-12,7 ; \mathrm{y}=-4,1$

Figura 7.59: Imagens obtidas com $p=2, \rho_{k}^{0}=0,15$ e elementos triangulares.

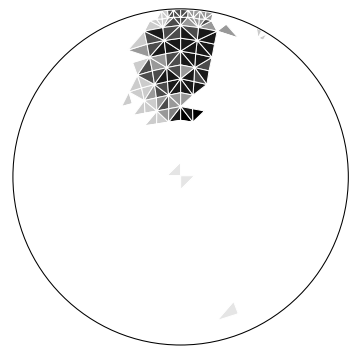

(a) $V^{*}=4,6 \% ; \mathrm{x}=0 ; \mathrm{y}=80,1$

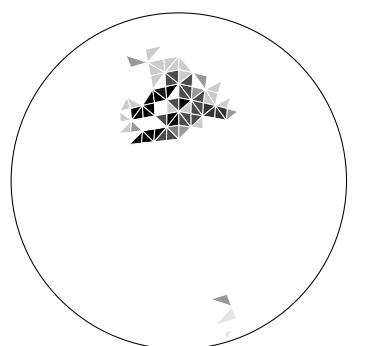

(b) $V^{*}=2,3 \% ; \mathrm{x}=-6,5 ; \mathrm{y}=49,6$

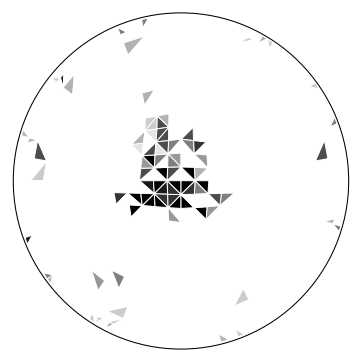

(c) $V^{*}=2,5 \% ; \mathrm{x}=-10,6 ; \mathrm{y}=-3,1$

Figura 7.60: Imagens obtidas com $p=2, \rho_{k}^{0}=0,50$ e elementos triangulares.

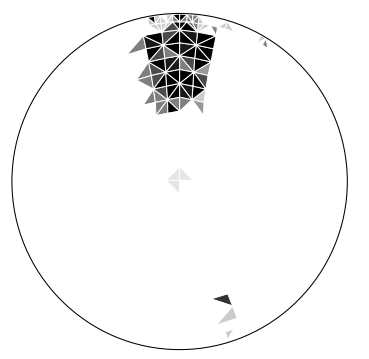

(a) $V^{*}=3,3 \% ; \mathrm{x}=2,4 ; \mathrm{y}=78,7$

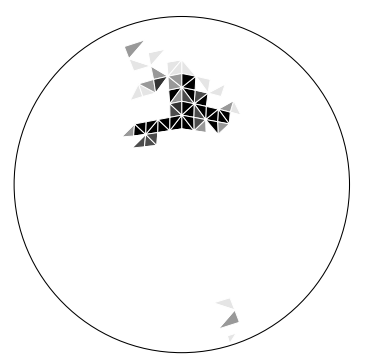

(b) $V^{*}=2,6 \% ; \mathrm{x}=0 ; \mathrm{y}=48,6$

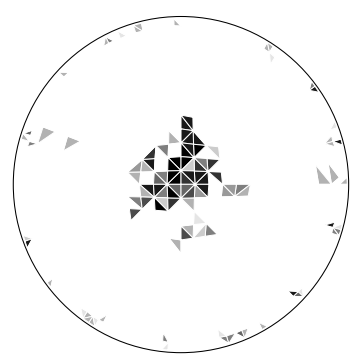

(c) $V^{*}=3 \% ; \mathrm{x}=2,2 ; \mathrm{y}=8,2$

Figura 7.61: Imagens obtidas com $p=2, \rho_{k}^{0}=0,85$ e elementos triangulares.

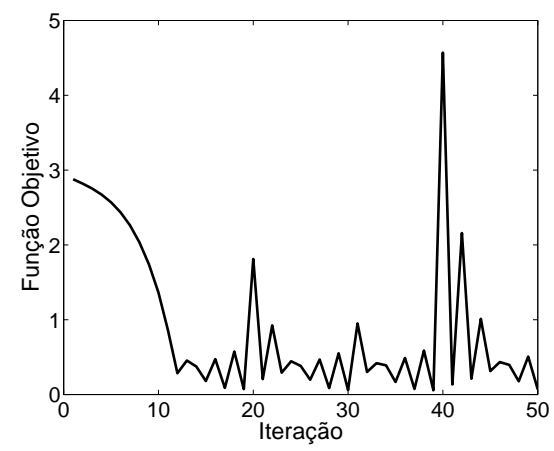

(a) gráfico de convergência

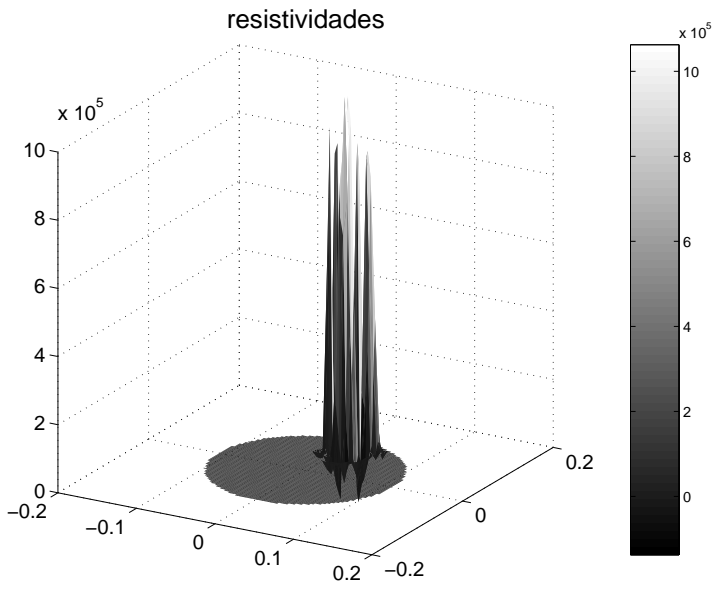

(b) gráfico de resistividades

Figura 7.62: Gráficos de convergência e resistividades da imagem obtida com $p=2$ e $\rho_{k}^{0}=0,15$, mostrada na figura 7.59 (a). 


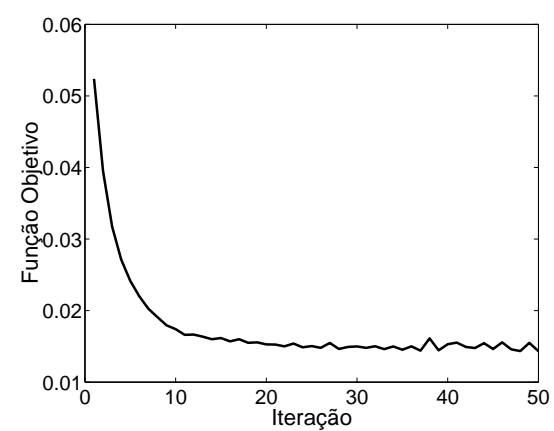

(a) gráfico de convergência

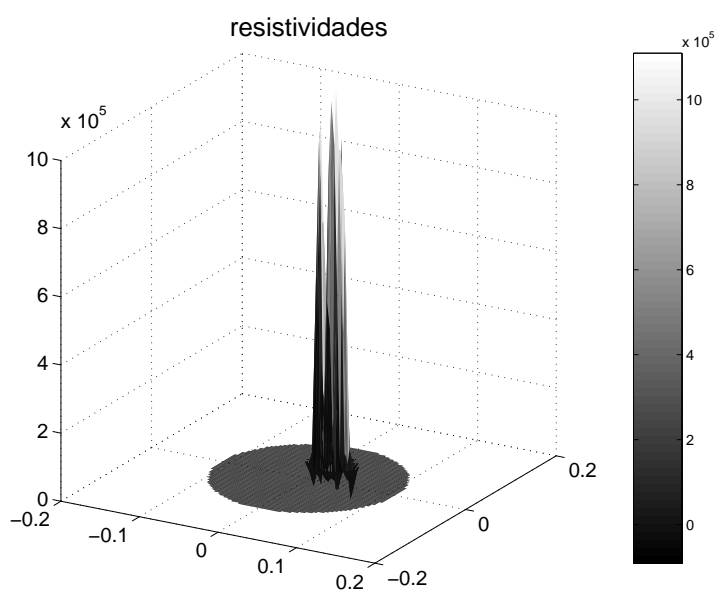

(b) gráfico de resistividades

Figura 7.63: Gráficos de convergência e resistividades da imagem obtida com $p=2$ e $\rho_{k}^{0}=0,15$, mostrada na figura $7.59(\mathrm{~b})$.

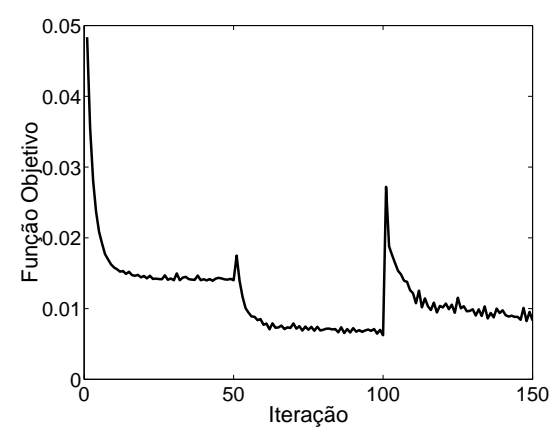

(a) gráfico de convergência

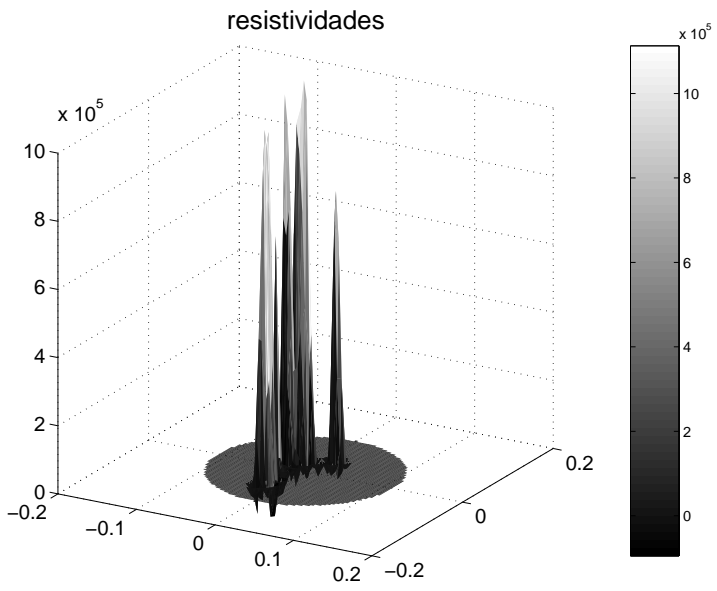

(b) gráfico de resistividades

Figura 7.64: Gráficos de convergência e resistividades da imagem obtida com $p=2$ e $\rho_{k}^{0}=0,15$, mostrada na figura 7.59 (c).

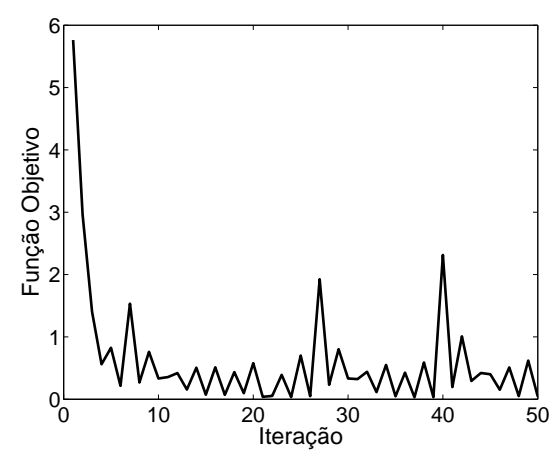

(a) gráfico de convergência

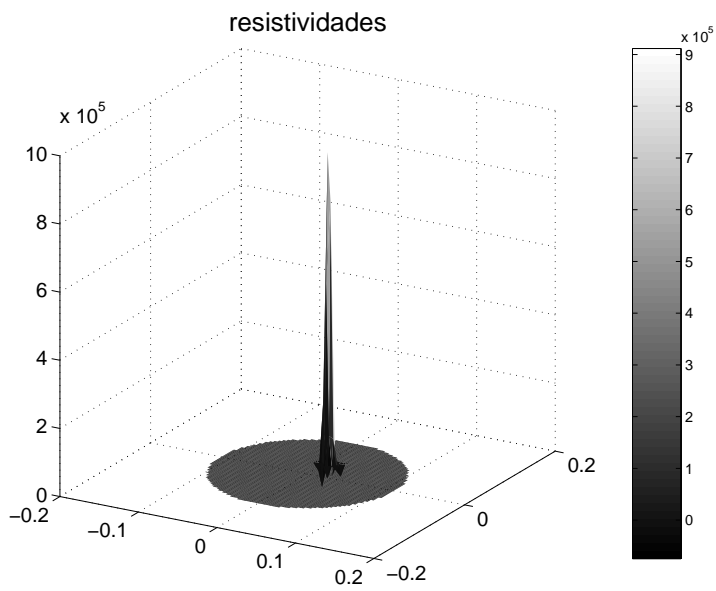

(b) gráfico de resistividades

Figura 7.65: Gráficos de convergência e resistividades da imagem obtida com $p=2$ e $\rho_{k}^{0}=0,50$, mostrada na figura 7.60 (a). 


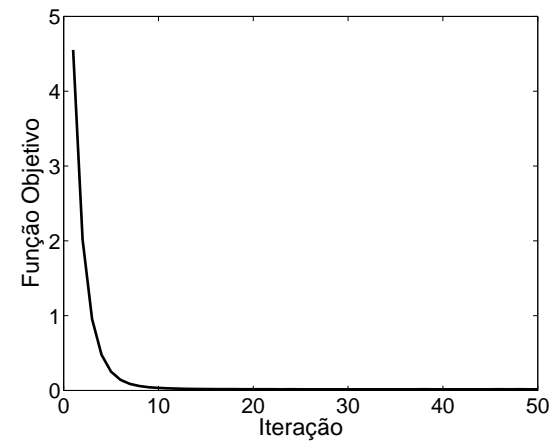

(a) gráfico de convergência

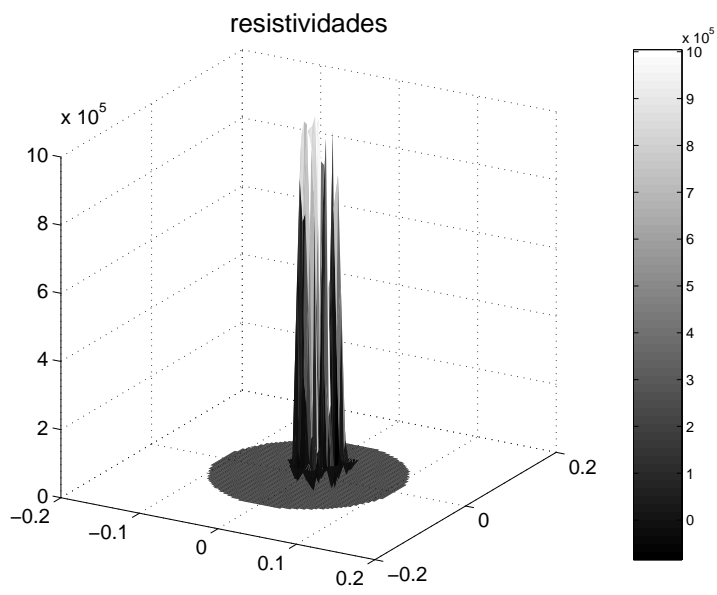

(b) gráfico de resistividades

Figura 7.66: Gráficos de convergência e resistividades da imagem obtida com $p=2$ e $\rho_{k}^{0}=0,50$, mostrada na figura $7.60(\mathrm{~b})$.

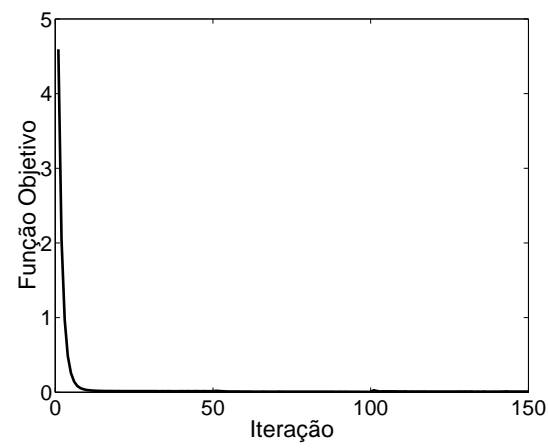

(a) gráfico de convergência

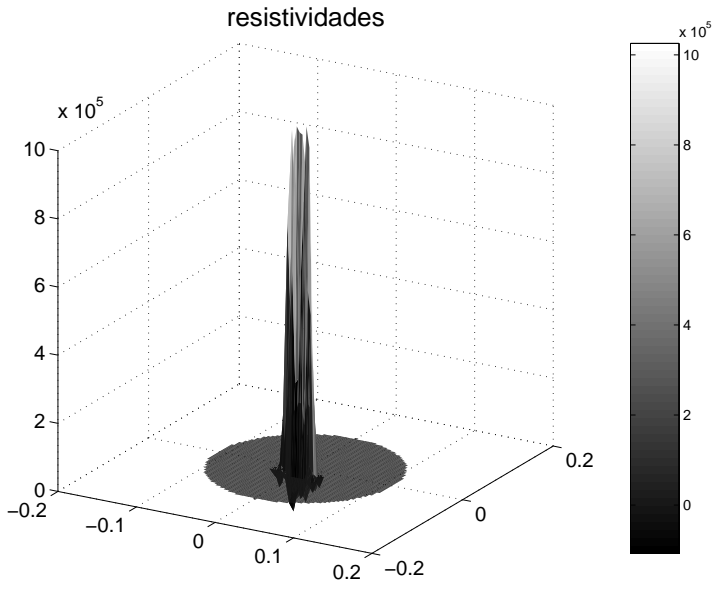

(b) gráfico de resistividades

Figura 7.67: Gráficos de convergência e resistividades da imagem obtida com $p=2$ e $\rho_{k}^{0}=0,50$, mostrada na figura $7.60(\mathrm{c})$.

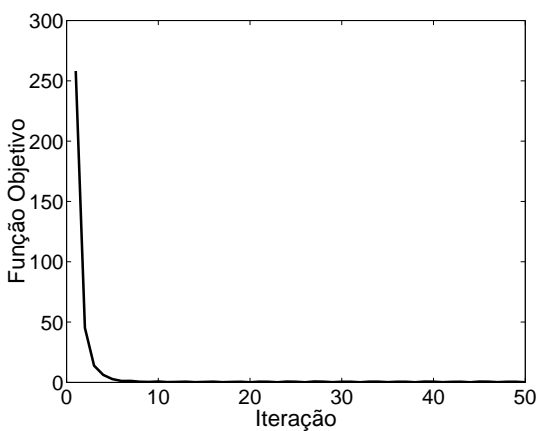

(a) gráfico de convergência

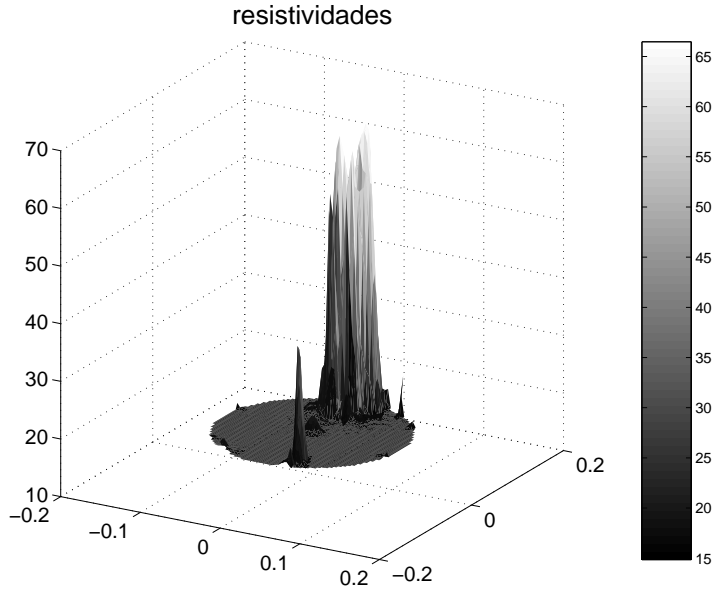

(b) gráfico de resistividades

Figura 7.68: Gráficos de convergência e resistividades da imagem obtida com $p=2$ e $\rho_{k}^{0}=0,85$, mostrada na figura 7.61(a). 


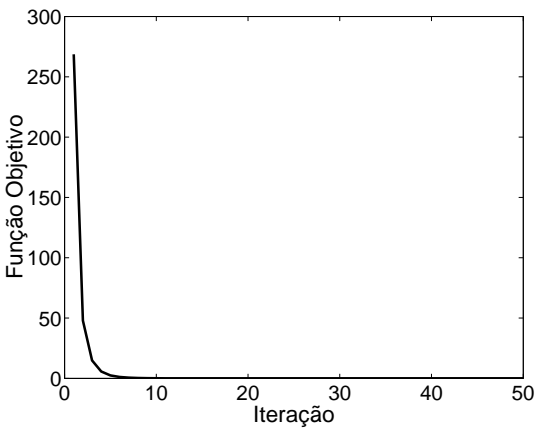

(a) gráfico de convergência

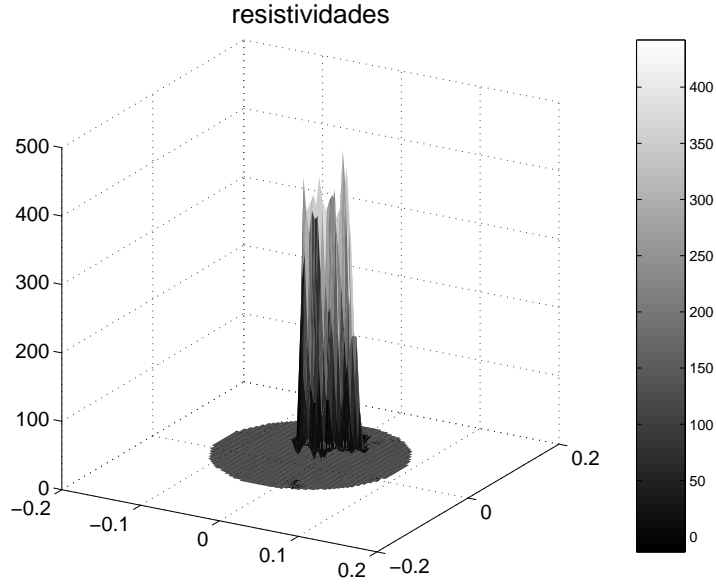

(b) gráfico de resistividades

Figura 7.69: Gráficos de convergência e resistividades da imagem obtida com $p=2$ e $\rho_{k}^{0}=0,85$, mostrada na figura $7.61(\mathrm{~b})$.

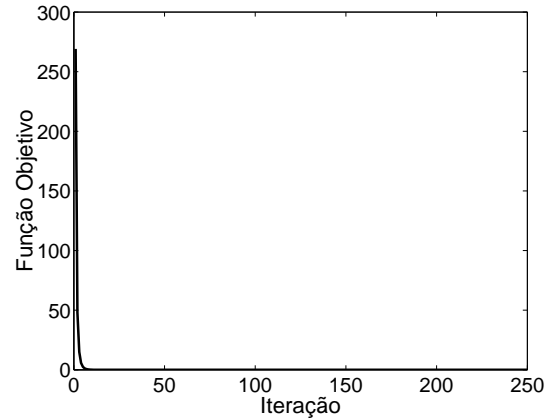

(a) gráfico de convergência

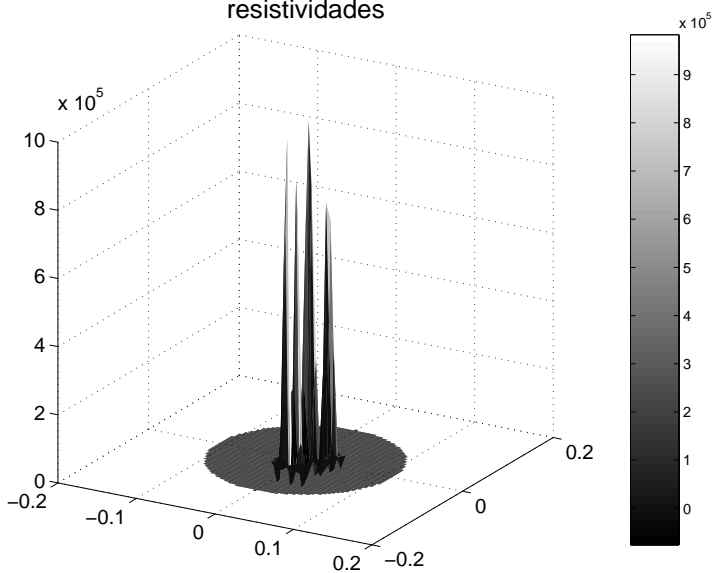

(b) gráfico de resistividades

Figura 7.70: Gráficos de convergência e resistividades da imagem obtida com $p=2$ e $\rho_{k}^{0}=0,85$, mostrada na figura $7.61(\mathrm{c})$. 
obtido para $V^{*}$ e para a coordenada $(x, y)$ do centróide da região da imagem do objeto e o máximo valor de pseudo-densidade obtida pelo TOMOGOT, para os diferentes valores de $\rho_{k}^{0}$ para os casos mostrados na figura 7.33.

Tabela 7.5: Erro de $V^{*}$ e da coordenada $(x, y)$ do centróide da imagem do objeto e valor máximo de $\rho_{k}$, com $p=2, \mathrm{RCM}$ e elementos triangulares

\begin{tabular}{|c|c|c|c|c|c|c|}
\hline posição & figura & $\rho_{k}^{0}$ & $e\left(V^{*}\right)[\%]$ & $e(x)[\mathrm{mm}]$ & $e(y)[\%]$ & $\rho_{k}^{\text {max }}$ \\
\hline \multirow{5}{*}{ borda } & $7.59(\mathrm{a})$ & 0,15 & 34,2 & 4,7 & 13,9 & 1 \\
& $7.60(\mathrm{a})$ & 0,50 & 21,0 & 0 & 11,0 & 1 \\
& $7.61(\mathrm{a})$ & 0,85 & 13,1 & 2,4 & 12,5 & 0,85 \\
\hline \hline \multirow{3}{*}{ meio } & $7.59(\mathrm{~b})$ & 0,15 & 21,0 & 1,2 & 2,3 & 1 \\
& $7.60(\mathrm{~b})$ & 0,50 & 39,5 & 6,5 & 6,4 & 1 \\
& $7.61(\mathrm{~b})$ & 0,85 & 31,6 & 0 & 8,3 & 0,98 \\
\hline \hline \multirow{5}{*}{ centro } & $7.59(\mathrm{c})$ & 0,15 & 23,7 & 12,7 & $4,1 \mathrm{~mm}$ & 1 \\
& $7.60(\mathrm{c})$ & 0,50 & 34,2 & 10,6 & $3,1 \mathrm{~mm}$ & 1 \\
& $7.61(\mathrm{c})$ & 0,85 & 21,0 & 2,2 & $8,2 \mathrm{~mm}$ & 1 \\
\hline
\end{tabular}

De acordo com as imagens mostradas nas figuras 7.59, 7.60 e 7.61 podemos observar que, neste caso, a resolução da imagem do caso onde o objeto se encontra no centro do domínio não é satisfatória, pois há vários elementos difusos que tentam constituir a imagem de maneira não uniforme e elementos desconexos. Podemos verificar também, em termos quantitativos, o desalinhamento na posição da imagem do objeto, que deveria está localizado no centro do domínio ( $\mathrm{x}=0$ e $\mathrm{y}=0$ ). Conforme mostrado na 7.5 , a imagem está deslocada do centro independentemente do valor inicial $\rho_{k}^{0}$ aplicado. Também observa-se que se compararmos as imagens, os melhores resultados são obtidos quando utiliza-se 0,85 como valor inicial $\rho_{k}^{0}$. Desta forma a imagem aparenta boa uniformidade, sem elementos desconexos, porém surge um efeito colateral - os valores de resistividades da região da imagem do objeto são penalizados. Por exemplo, o resultado mostrado na figura 7.61(a) apresenta uma imagem com boa resolução, menor erro de tamanho $\left(V^{*}\right)$ e localização $(x, y)$ no domínio (veja tabela 7.5 ), porém observa-se que devido ao máximo valor de pseudo-densidade $\left(\rho_{k}^{\max }\right)$ encontrado ser 0,85 os valores de resistividade da região da imagem do objeto estão muito abaixo do esperado, conforme pode ser visto no gráfico da figura 7.68(b). Exceto os gráficos das figuras 7.68(b) e 7.69(b), todos os gráficos de resistividades mostram que há elementos da região da imagem que atingem o valor de resistividade (ou condutividade) esperado.

Observando as curvas de convergência dos resultados apresentados nota-se 
que elas possuem comportamento típico observado até o momento - a função objetivo cai a um valor mínimo em poucas iterações e permanece o restante do processo iterativo com uma pequena oscilação. Neste caso, o processo de obtenção de imagem necessita em média somente 10 iterações para encontrar a região de convergência. Conforme observado anteriormente (com o uso de elementos quadriláteros) no caso onde o objeto se encontra na borda do domínio os resultados apresentam grande oscilação na convergência da função objetivo durante as iterações. Por exemplo, isto pode ser confirmado observando a curva de convergência da figura 7.62(a), bastante similar ao resultado mostrado na figura 7.38(a) (resultado obtido utilizando-se elementos quadriláteros).

A seguir é mostrada a análise realizada para a aplicação do fator de penalidade (p) igual a 4. As figuras 7.71, 7.72 e 7.73 mostram as imagens da distribuição de condutividades obtidas para $\rho_{k}^{0}$ iguais a $0,15,0,50$ e 0,85 e, na seqüencia, são mostrados os gráficos das curvas de convergência da função objetivo, bem como as imagem 3D da distribuição de resistividades (figuras 7.74 a 7.82).

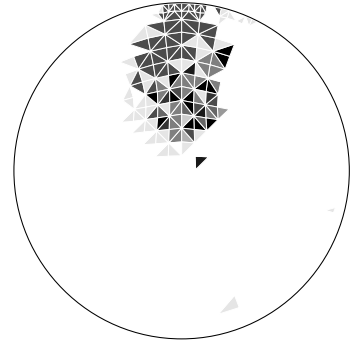

(a) $V^{*}=7,5 \% ; \mathrm{x}=0 ; \mathrm{y}=70,5$

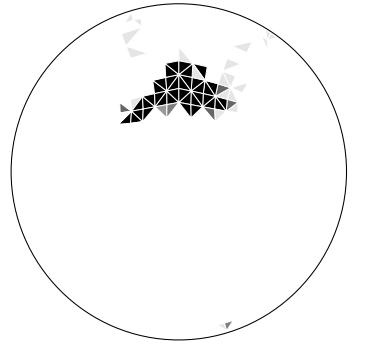

(b) $V^{*}=3,8 \% ; \mathrm{x}=1,4 ; \mathrm{y}=52,3$

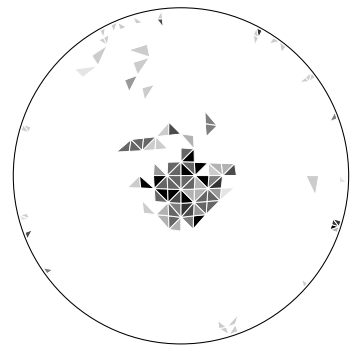

(c) $V^{*}=3,8 \% ; \mathrm{x}=3,1 ; \mathrm{y}=-2,5$

Figura 7.71: Imagens obtidas com $p=4, \rho_{k}^{0}=0,15$ e elementos triangulares.

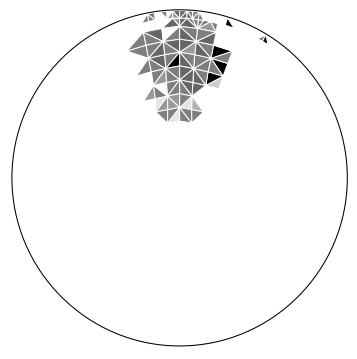

(a) $V^{*}=5,4 \% ; \mathrm{x}=2,5 ; \mathrm{y}=83,5$

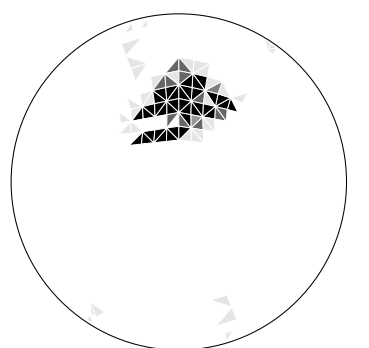

(b) $V^{*}=4,2 \% ; \mathrm{x}=2,1 ; \mathrm{y}=52,9$

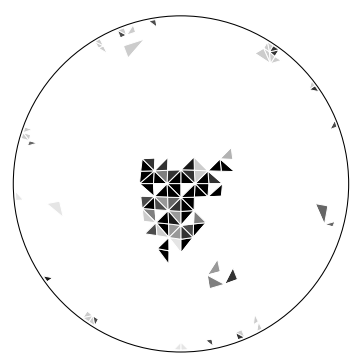

(c) $V^{*}=4,8 \% ; \mathrm{x}=2,1 ; \mathrm{y}=-10,2$

Figura 7.72: Imagens obtidas com $p=4, \rho_{k}^{0}=0,50$ e elementos triangulares.

O valor de $V^{*}$ e da coordenada $(x, y)$ do centróide da região da imagem do objeto (região escura da imagem obtida) pode ser visto em cada resultado apresentado nas figuras 7.71, 7.72 e 7.73. A tabela 7.6 mostra um resumo do erro obtido para $V^{*}$ e para a coordenada $(x, y)$ do centróide da região da imagem do objeto e o máximo valor de pseudo-densidade obtida pelo TOMOGOT, para os diferentes valores de $\rho_{k}^{0}$ para os casos mostrados na figura 7.33. 


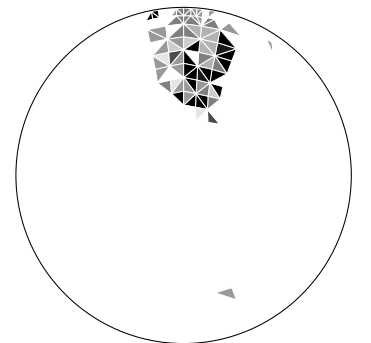

(a) $V^{*}=2,4 \% ; \mathrm{x}=13,8 ; \mathrm{y}=72,4$

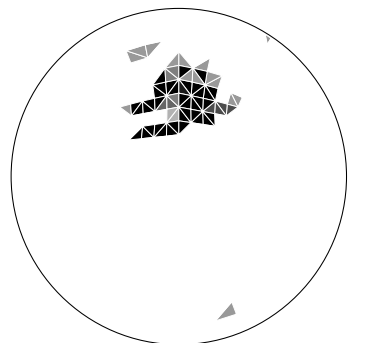

(b) $V^{*}=4,2 \% ; \mathrm{x}=1 ; \mathrm{y}=50,2$

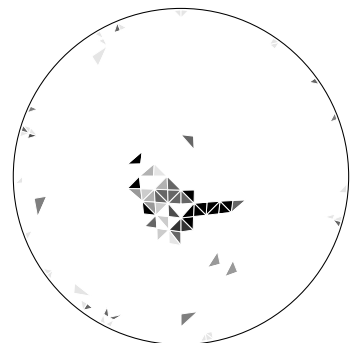

(c) $V^{*}=2,7 \% ; \mathrm{x}=-4,7 ; \mathrm{y}=-19,1$

Figura 7.73: Imagens obtidas com $p=4, \rho_{k}^{0}=0,85$ e elementos triangulares.

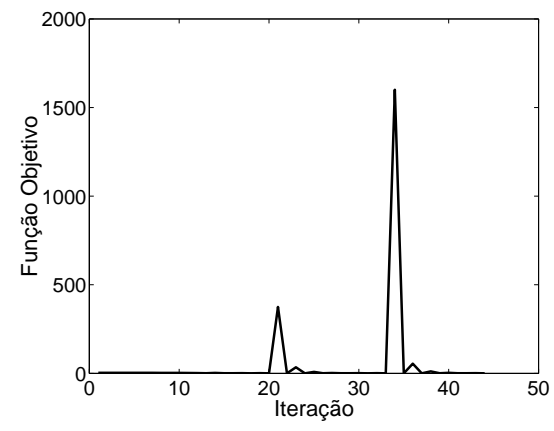

(a) gráfico de convergência

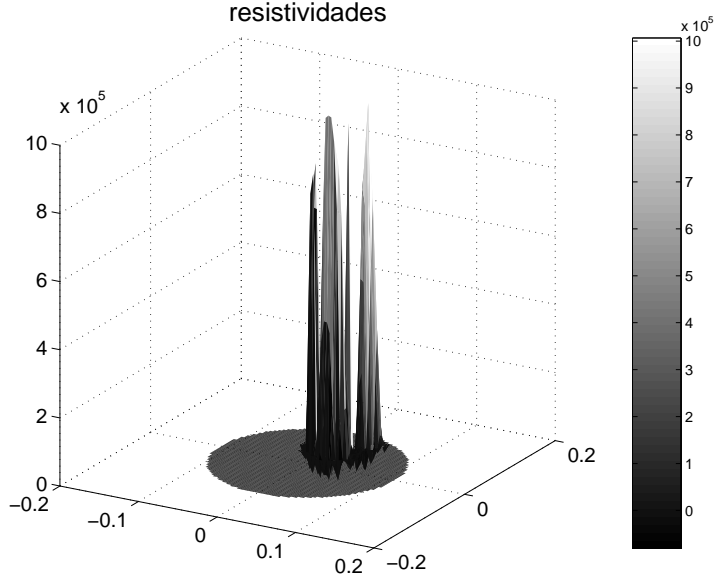

(b) gráfico de resistividades

Figura 7.74: Gráficos de convergência e resistividades da imagem obtida com $p=4$ e $\rho_{k}^{0}=0,15$, mostrada na figura 7.71(a).

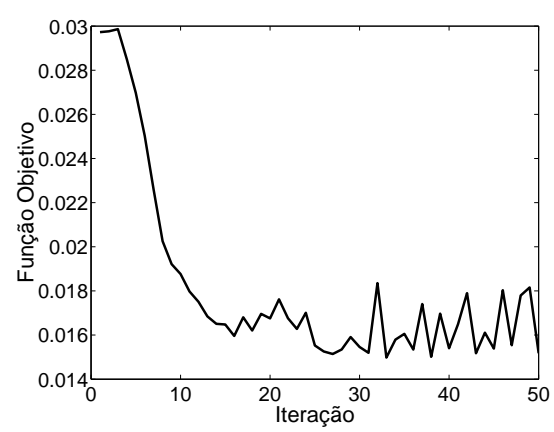

(a) gráfico de convergência

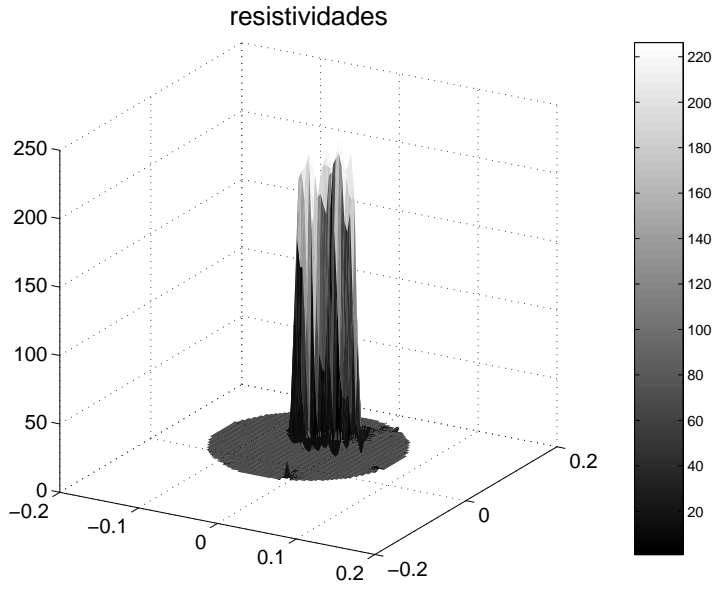

(b) gráfico de resistividades

Figura 7.75: Gráficos de convergência e resistividades da imagem obtida com $p=4$ e $\rho_{k}^{0}=0,15$, mostrada na figura $7.71(\mathrm{~b})$. 


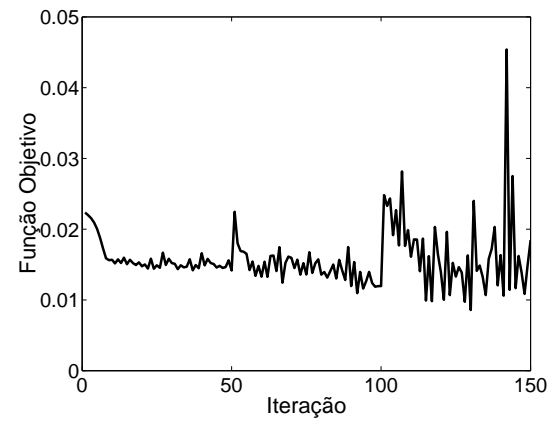

(a) gráfico de convergência

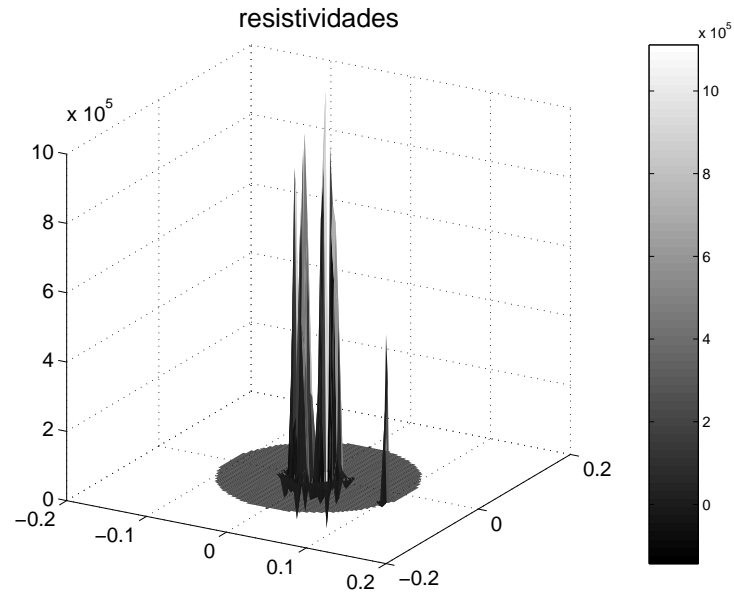

(b) gráfico de resistividades

Figura 7.76: Gráficos de convergência e resistividades da imagem obtida com $p=4$ e $\rho_{k}^{0}=0,15$, mostrada na figura 7.71 (c).

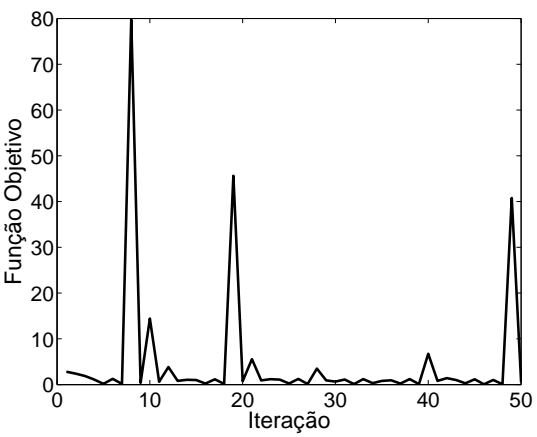

(a) gráfico de convergência

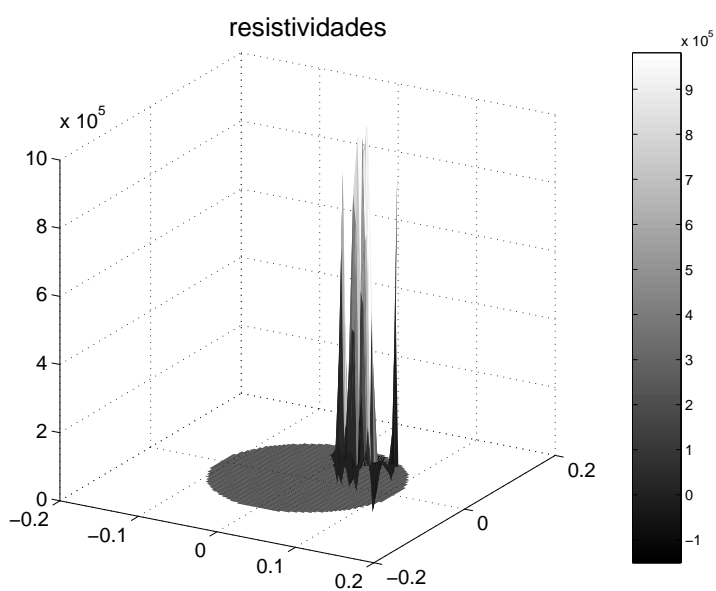

(b) gráfico de resistividades

Figura 7.77: Gráficos de convergência e resistividades da imagem obtida com $p=4$ e $\rho_{k}^{0}=0,50$, mostrada na figura $7.72(\mathrm{a})$.

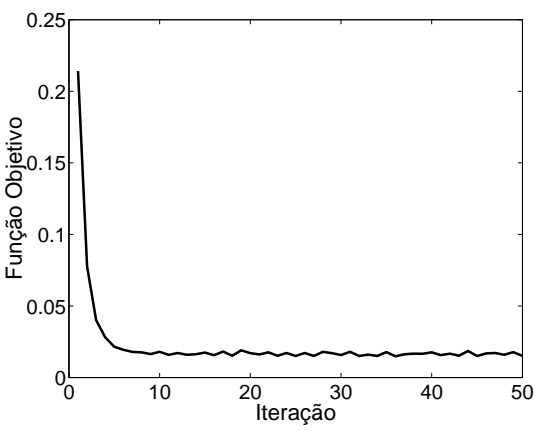

(a) gráfico de convergência

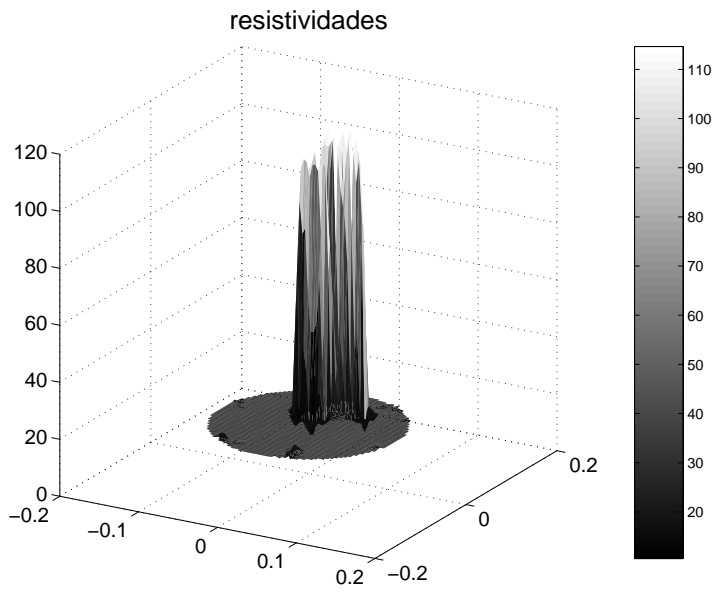

(b) gráfico de resistividades

Figura 7.78: Gráficos de convergência e resistividades da imagem obtida com $p=4$ e $\rho_{k}^{0}=0,50$, mostrada na figura $7.72(\mathrm{~b})$. 


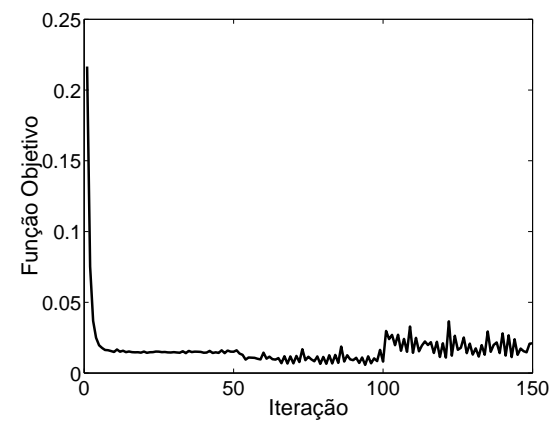

(a) gráfico de convergência

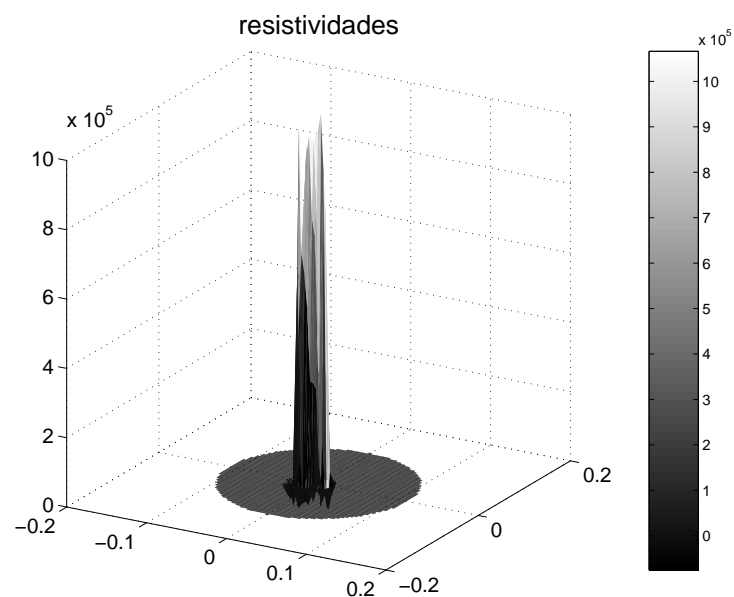

(b) gráfico de resistividades

Figura 7.79: Gráficos de convergência e resistividades da imagem obtida com $p=4$ e $\rho_{k}^{0}=0,50$, mostrada na figura $7.72(\mathrm{c})$.

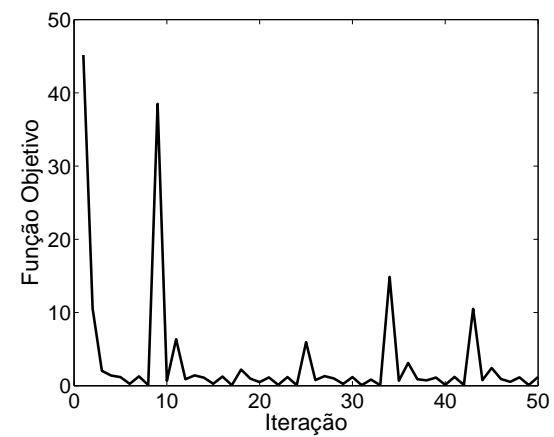

(a) gráfico de convergência

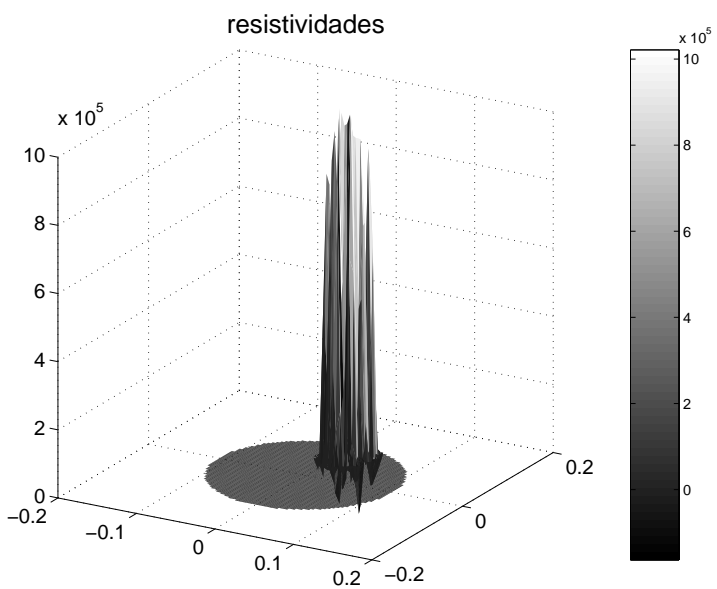

(b) gráfico de resistividades

Figura 7.80: Gráficos de convergência e resistividades da imagem obtida com $p=4$ e $\rho_{k}^{0}=0,85$, mostrada na figura $7.73(\mathrm{a})$.

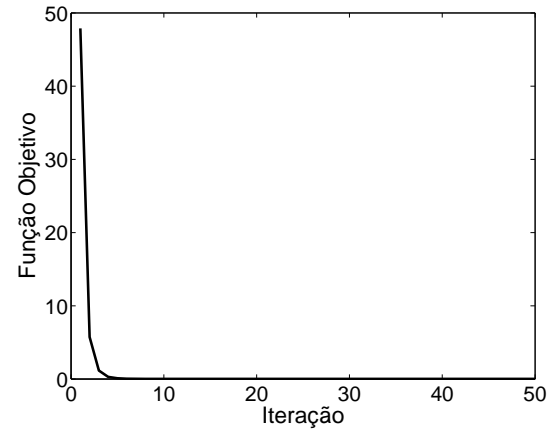

(a) gráfico de convergência

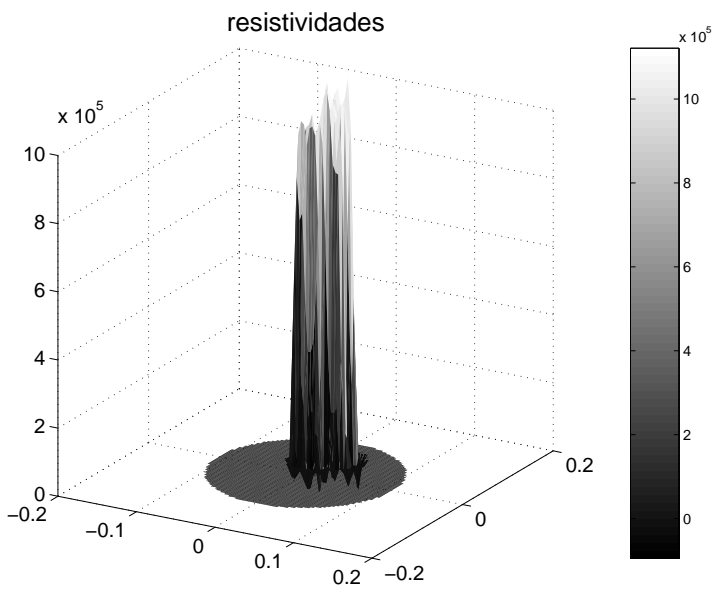

(b) gráfico de resistividades

Figura 7.81: Gráficos de convergência e resistividades da imagem obtida com $p=4$ e $\rho_{k}^{0}=0,85$, mostrada na figura 7.73(b). 


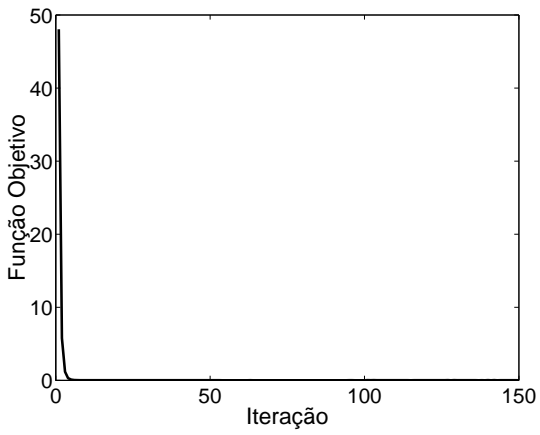

(a) gráfico de convergência

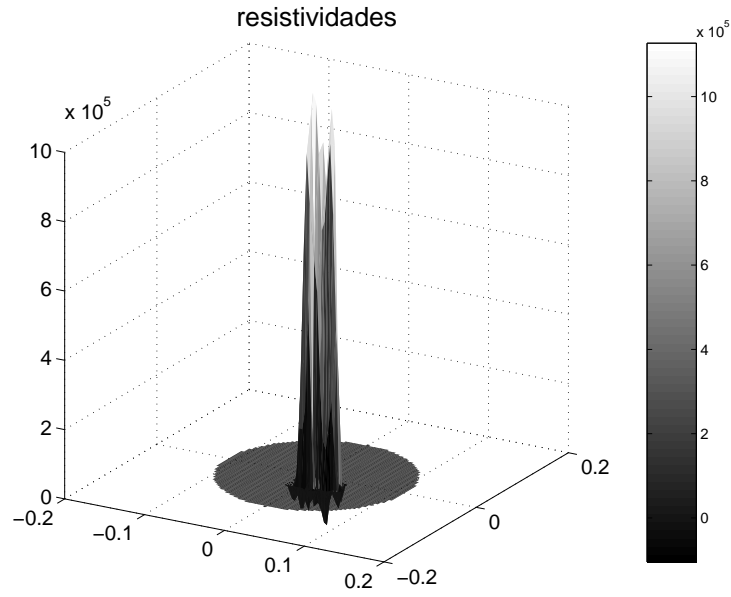

(b) gráfico de resistividades

Figura 7.82: Gráficos de convergência e resistividades da imagem obtida com $p=4$ e $\rho_{k}^{0}=0,85$, mostrada na figura $7.73(\mathrm{c})$.

Tabela 7.6: Erro de $V^{*}$ e da coordenada $(x, y)$ do centróide da imagem do objeto e valor máximo de $\rho_{k}$, com $p=4$, RCM e elementos triangulares

\begin{tabular}{|c|c|c|c|c|c|c|}
\hline posição & figura & $\rho_{k}^{0}$ & $e\left(V^{*}\right)[\%]$ & $e(x)[\mathrm{mm}]$ & $e(y)[\%]$ & $\rho_{k}^{\max }$ \\
\hline \multirow{5}{*}{ borda } & $7.71(\mathrm{a})$ & 0,15 & 97,4 & 0 & 21,7 & 1 \\
& $7.72(\mathrm{a})$ & 0,50 & 42,1 & 2,5 & 7,2 & 1 \\
& $7.73(\mathrm{a})$ & 0,85 & 36,8 & 13,8 & 19,5 & 1 \\
\hline \hline \multirow{5}{*}{ meio } & $7.71(\mathrm{~b})$ & 0,15 & 0 & 1,4 & 1,3 & 0,98 \\
& $7.72(\mathrm{~b})$ & 0,50 & 10,5 & 2,1 & 0 & 0,96 \\
& $7.73(\mathrm{~b})$ & 0,85 & 10,5 & 1 & 5,3 & 1 \\
\hline \hline \multirow{3}{*}{ centro } & $7.71(\mathrm{c})$ & 0,15 & 0 & 3,1 & $2,5 \mathrm{~mm}$ & 1 \\
& $7.72(\mathrm{c})$ & 0,50 & 26,3 & 2,1 & $10,2 \mathrm{~mm}$ & 1 \\
& $7.73(\mathrm{c})$ & 0,85 & 28,9 & 4,7 & $19,1 \mathrm{~mm}$ & 1 \\
\hline
\end{tabular}

De acordo com as imagens obtidas, podemos notar que novamente não foram obtidos resultados satisfatórios com a elevação do valor de $p$ para 4 para detectar as diferentes posições do objeto de baixa condutividade (região escura da imagem) no interior do domínio, conforme constatado na aplicação mostrada na seção 7.3.6.1 (com elementos quadriláteros e $p=4$ ). O erros de tamanho e localização da região da imagem do objeto são bastante acentuados neste caso, conforme pode ser verificado na tabela 7.6 , onde podemos observar um erro de $97,4 \%$ para $V^{*}$ da região da imagem do objeto e $21,7 \%$ de erro na determinação da distância entre o centróide da imagem do objeto e o centro do domínio (distância no eixo $y$ ), quando utiliza-se 0,15 como valor inicial $\rho_{k}^{0}$ para determinar a imagem do objeto posicionado na borda do domínio. Menores erros são encontrados nos resultados mostrados na tabela 7.6 quando o objeto se encontra entre a borda e 
o centro do domínio (posição "meio") e no centro do domínio (posição "centro"), onde podemos perceber que o erro para $V^{*}$ é nulo e os erros nas coordenadas $(x, y)$ de posicionamento da região da imagem do objeto são pequenos. Porém, observando as imagens, pode-se verificar que as imagens obtidas não são uniformes e possuem elementos desconexos (veja figuras 7.71(b) e 7.71(c)).

Observando os gráficos das figuras 7.74 a 7.82, a convergência da função objetivo apresenta um comportamento diferente do esperado para o caso em que o objeto é posicionado na borda do domínio e principalmente quando se utiliza 0,15 como valor inicial $\rho_{k}^{0}$, conforme pode ser visto nas figuras 7.74(a) e 7.77(a). Estas curvas apresentam vários pontos onde o valor da função objetivo se torna bem maior que o valor iniciado no processo de otimização, conforme verificado também nos resultados apresentados na seção 7.3.6.1 (com elementos quadriláteros e $p=4)$. Porém, de maneira análoga aos resultados apresentados na seção 7.3.6.1, o TOMOGOT também se mostrou robusto neste caso para manter a curva da função objetivo na região de mínimo valor até a convergência.

Observa-se também que a região da imagem do objeto mostradas nas figuras 7.71(b) e 7.72(b) apresentam valores de resistividades bem abaixo do valor esperado $\left(10^{-6}(\Omega m)^{-1}\right)$, conforme pode ser visto nos gráficos das figuras 7.75(b) e 7.78(b). Nota-se que esses resultados apresentaram valores máximo de pseudo-densidades $\left(\rho_{k}^{\max }\right)$ menores que 1 (veja tabela 7.6), porém a diferença mínima para alcançar o valor igual a 1 é suficiente para fazer com que o TOMOGOT não alcance valores de resistividades iguais ao valor esperado.

Assim, a partir dos resultados mostrados nesta seção e na seção 7.3.6.1 conclui-se que a aplicação da restrição da condutividade média (RCM) auxilia no processo de obtenção de imagem na TIE, através do TOMOGOT, principalmente para obter a imagem do objeto quando o mesmo se encontra no centro do domínio, embora a resolução ainda precise ser melhorada. Além disso, notam-se algumas diferenças entre os resultados apresentados nesta seção e na seção 7.3.6.1, sendo que os resultados obtidos a partir do domínio discretizado em elementos quadriláteros (seção 7.3.6.1) produziram imagens melhores para os casos investigados.

\subsubsection{Resultados Obtidos Utilizando o Filtro Espacial}

Observando os resultados obtidos até o momento percebe-se que o TOMOGOT obtém a imagem desejada, com um certo nível de precisão e com valores absolutos de condutividade (ou resistividade) próximos ao esperado. Porém, em certos casos 
a resolução da imagem é ruim. Algumas imagens são obtidas de forma que os elementos que a compõem estão difusos, ou seja, há uma espalhamento desses elementos no domínio, como pode ser notado nas imagens mostradas nas seções 7.3.6.1 e 7.3.6.2. Isto significa que o método implementado busca a distribuição ótima de condutividades, porém ainda define o valor de duas variáveis de projeto vizinhas de uma maneira brusca, onde provavelmente o gradiente de uma sobrepõe a outra. Assim, no intuito de melhorar os resultados obtidos até então, nesta seção é proposto a utilização do filtro espacial descrito na seção 6.4. Para exemplificar, são mostrados vários exemplos com a aplicação desse filtro.

Além disso, também são empregados o domínio de obtenção de imagem discretizado em elementos quadriláteros (figura 7.25) ou triangulares (figura 7.26) e a RCM (descrita na seção 5.3). Neste caso, o TOMOGOT é aplicado para obter a imagem dos três casos mostrados na figura 7.33. Nos resultados mostrados nesta seção, também são experimentados os mesmos valores do fator de penalidade $p$ e do valor inicial $\left(\rho_{k}^{0}\right)$ da variável de projeto aplicados nos exemplos mostrados na seção 7.3.6, ou seja, $p$ igual a 2 e $4, \rho_{k}^{0}$ igual a 0,15, 0,50 e 0,85. Além disso, a estratégia para utilização do expoente $q$ da distância $d_{k}$ na RCM continua a mesma, ou seja, $q$ é igual 2, exceto para o caso em que a imagem do objeto (região escura) está localizada no centro do domínio. Neste caso, é aplicado um expoente $q$ igual a 4, para destacar melhor os valores de condutividades na região central do domínio. O objetivo novamente é comparar os resultados obtidos, verificando-se o tamanho $\left(V^{\star}\right)$ e localização $(x, y)$ das imagens obtidas, em relação aos valores prescritos na figura 7.33. Além disso, são verificados os valores absolutos de condutividades (ou resistividades) obtidos.

As imagens são obtidas considerando-se um raio de abrangência para o filtro que envolva aproximadamente oito elementos vizinhos $j$ em torno de um elemento central $i$ (veja figura 6.5 do capítulo 6), segundo sugestão encontrada na literatura (CARDOSO, 2000).

\subsubsection{Imagens Obtidas com o Domínio Discretizado em Elementos Quadriláteros}

As figuras a seguir mostram os resultados obtidos com a utilização do domínio de obtenção de imagem apresentado na figura 7.25 (discretizado em 576 elementos quadriláteros), para os três casos mostrados na figura 7.33 (objeto na borda do domínio (a), objeto entre a borda em o centro do domínio (b) e objeto no centro do domínio (c)). 
As figuras 7.83, 7.84 e 7.85 mostram as imagens da distribuição de condutividades obtidas com o TOMOGOT, utilizando-se $p$ igual 2 para $\rho_{k}^{0}$ iguais a 0,15, 0,50 e 0,85. Em seguida, os gráficos das figuras 7.86 a 7.94 mostram as curvas de convergência da função objetivo e os gráficos da distribuição de resistividades gerados a partir das imagens obtidas.

A tabela 7.7 mostra um resumo do erro obtido para $V^{*}$ e para a coordenada $(x, y)$ do centróide da região da imagem do objeto, bem como o máximo valor de pseudo-densidade (variável de projeto) obtida pelo TOMOGOT, para os três diferentes valores de $\rho_{k}^{0}$ em cada caso de posicionamento do objeto no domínio.

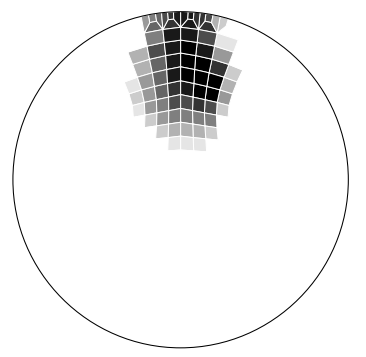

(a) $V^{*}=6,2 \% ; \mathrm{x}=2,8 ; \mathrm{y}=77$

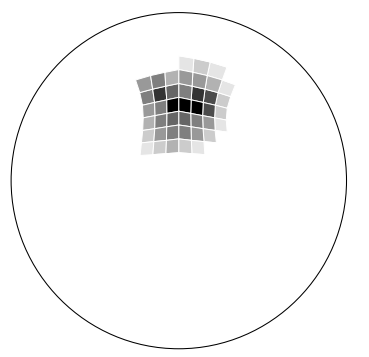

(b) $V^{*}=2,7 \% ; \mathrm{x}=0 ; \mathrm{y}=51,4$

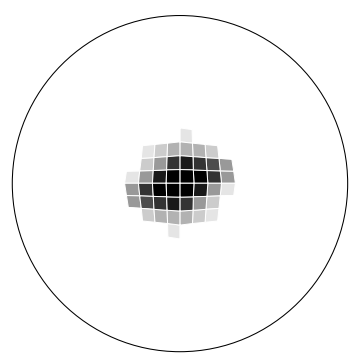

(c) $V^{*}=3,2 \% ; \mathrm{x}=0 ; \mathrm{y}=0$

Figura 7.83: Imagens obtidas com $p=2, \rho_{k}^{0}=0,15$ e elementos quadriláteros.

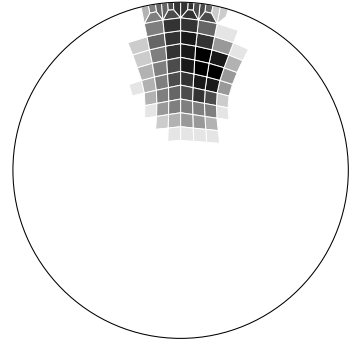

(a) $V^{*}=6,1 \% ; \mathrm{x}=4,8 ; \mathrm{y}=77,5$

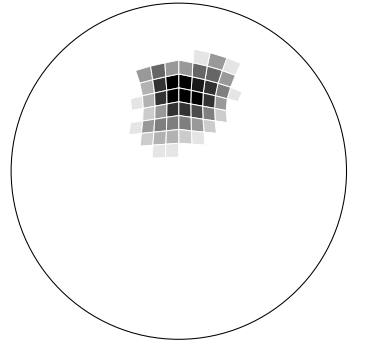

(b) $V^{*}=3,4 \% ; \mathrm{x}=6,1 ; \mathrm{y}=51,4$

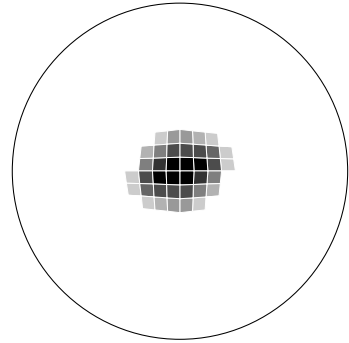

(c) $V^{*}=3,4 \% ; \mathrm{x}=0 ; \mathrm{y}=0$

Figura 7.84: Imagens obtidas com $p=2, \rho_{k}^{0}=0,50$ e elementos quadriláteros.

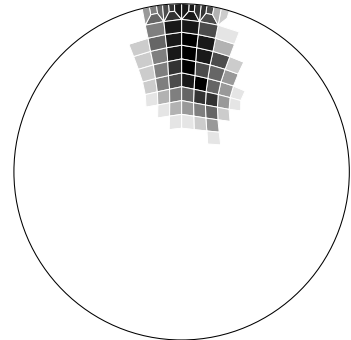

(a) $V^{*}=5,6 \% ; \mathrm{x}=4,5 ; \mathrm{y}=79,4$

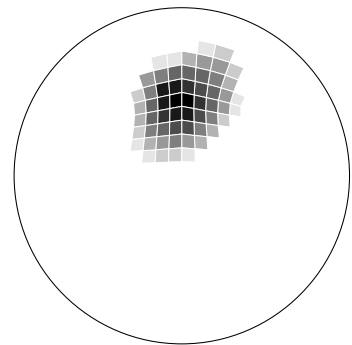

(b) $V^{*}=4,1 \% ; \mathrm{x}=0 ; \mathrm{y}=48,9$

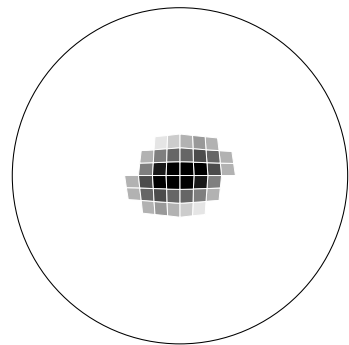

(c) $V^{*}=3,4 \% ; \mathrm{x}=0 ; \mathrm{y}=0$

Figura 7.85: Imagens obtidas com $p=2, \rho_{k}^{0}=0,85$ e elementos quadriláteros.

A seguir a mesma análise realizada para a aplicação do fator de penalidade $(p)$ igual a 4. Desta forma, as figuras 7.95, 7.96 e 7.97 mostram as imagens da distribuição de condutividades obtidas para $\rho_{k}^{0}$ iguais a 0,15, 0,50 e 0,85 e, 


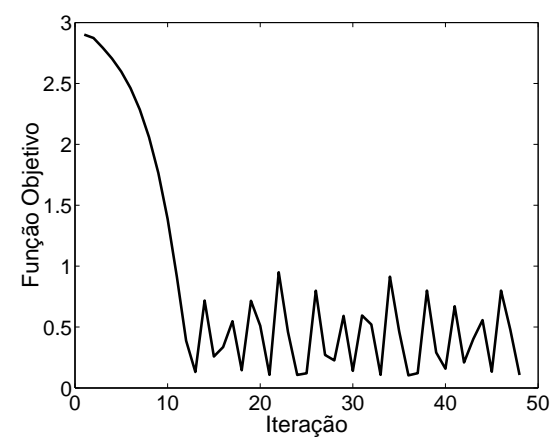

(a) gráfico de convergência

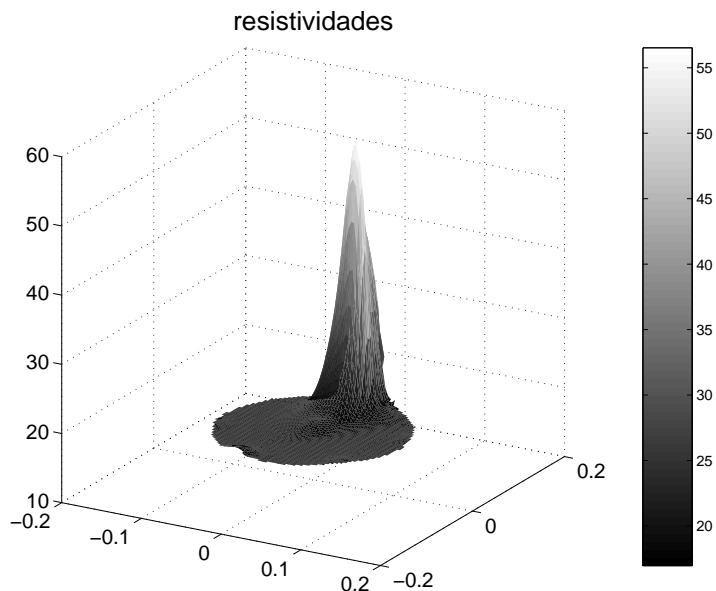

(b) gráfico de resistividades

Figura 7.86: Gráficos de convergência e resistividades da imagem obtida com $p=2$ e $\rho_{k}^{0}=0,15$, mostrada na figura 7.83(a).

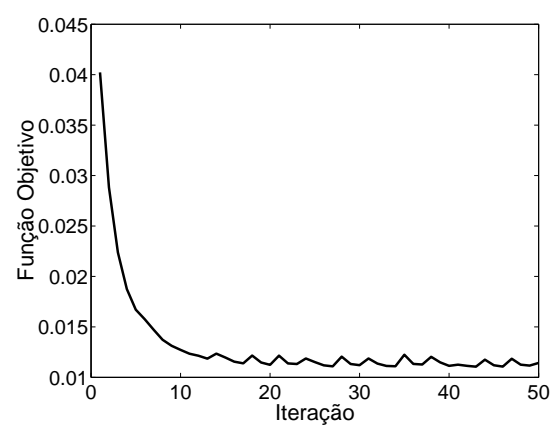

(a) gráfico de convergência

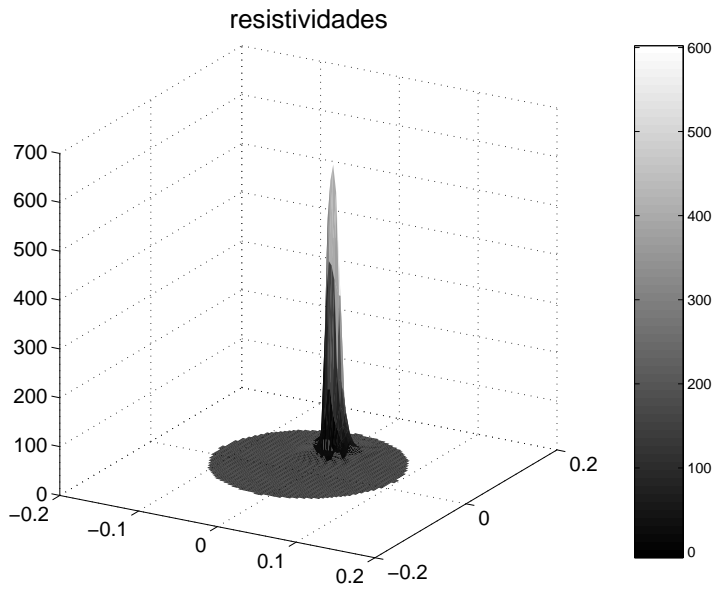

(b) gráfico de resistividades

Figura 7.87: Gráficos de convergência e resistividades da imagem obtida com $p=2$ e $\rho_{k}^{0}=0,15$, mostrada na figura $7.83(\mathrm{~b})$.

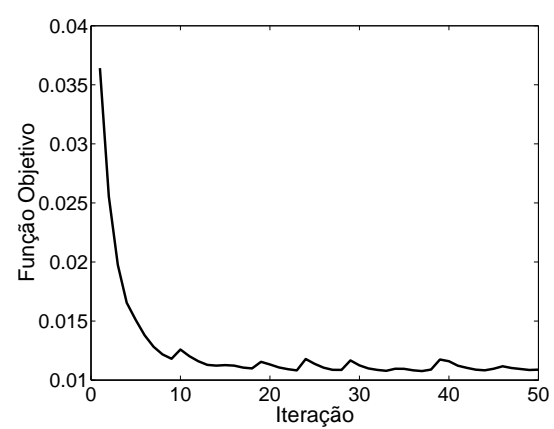

(a) gráfico de convergência

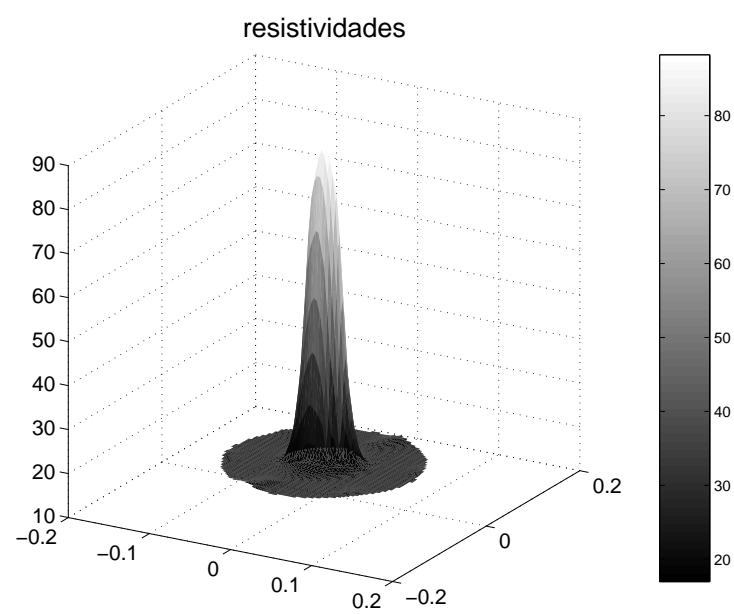

(b) gráfico de resistividades

Figura 7.88: Gráficos de convergência e resistividades da imagem obtida com $p=2$ e $\rho_{k}^{0}=0,15$, mostrada na figura $7.83(\mathrm{c})$. 


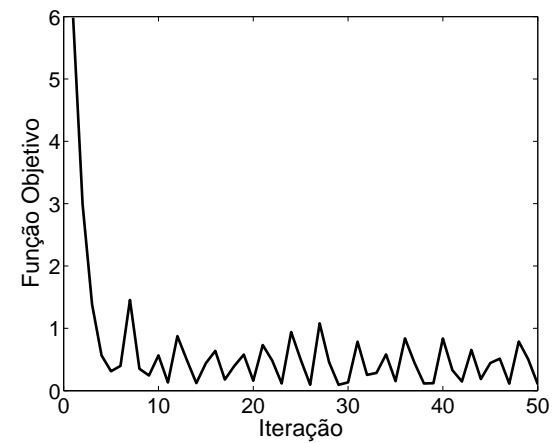

(a) gráfico de convergência

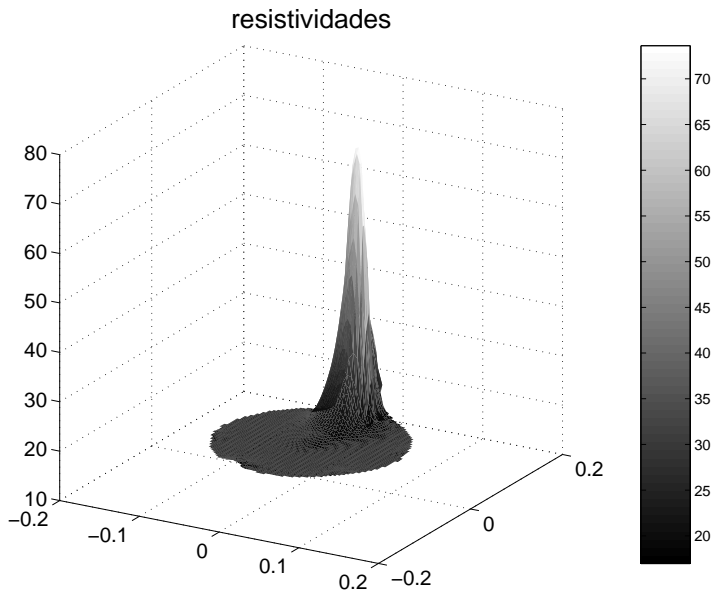

(b) gráfico de resistividades

Figura 7.89: Gráficos de convergência e resistividades da imagem obtida com $p=2$ e $\rho_{k}^{0}=0,50$, mostrada na figura $7.84(\mathrm{a})$.

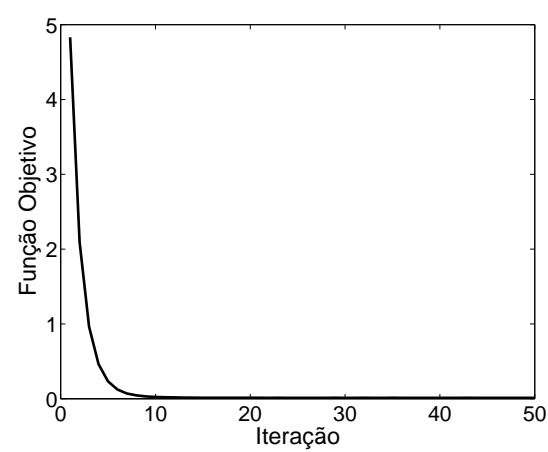

(a) gráfico de convergência

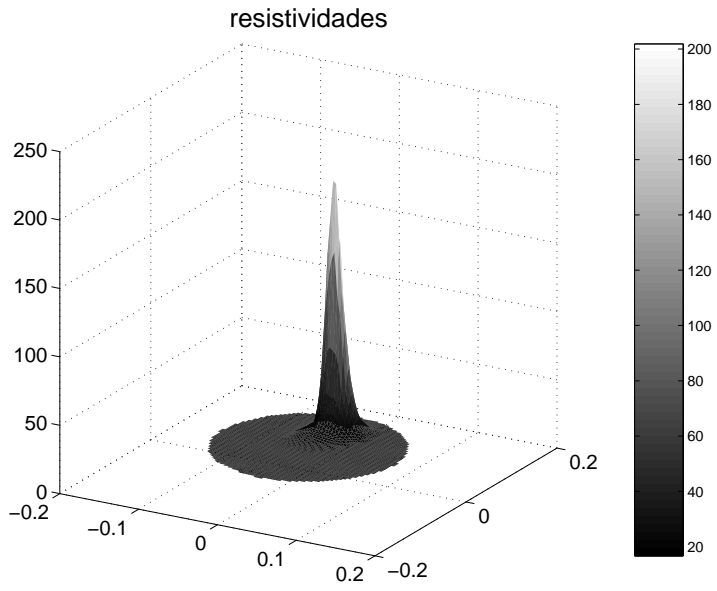

(b) gráfico de resistividades

Figura 7.90: Gráficos de convergência e resistividades da imagem obtida com $p=2$ e $\rho_{k}^{0}=0,50$, mostrada na figura $7.84(\mathrm{~b})$.

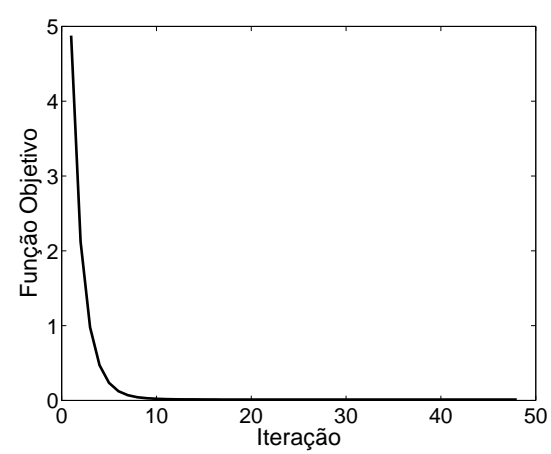

(a) gráfico de convergência

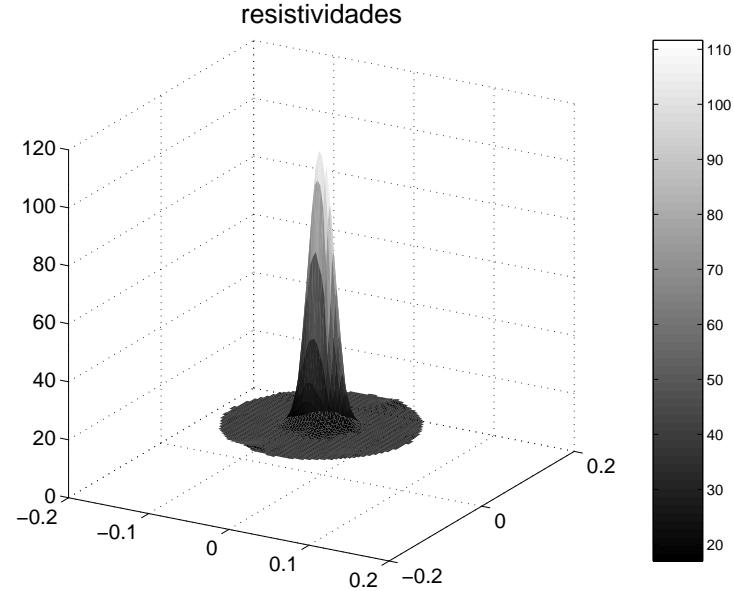

(b) gráfico de resistividades

Figura 7.91: Gráficos de convergência e resistividades da imagem obtida com $p=2$ e $\rho_{k}^{0}=0,50$, mostrada na figura $7.84(\mathrm{c})$. 


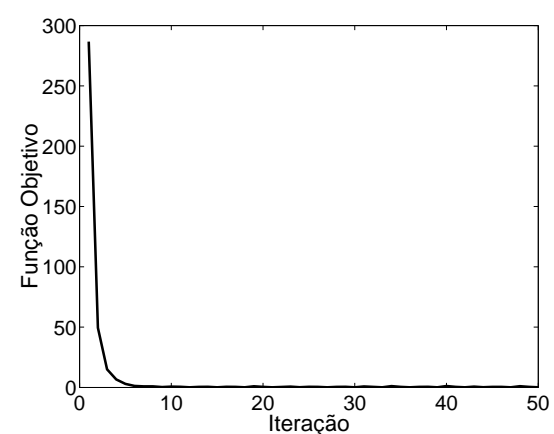

(a) gráfico de convergência

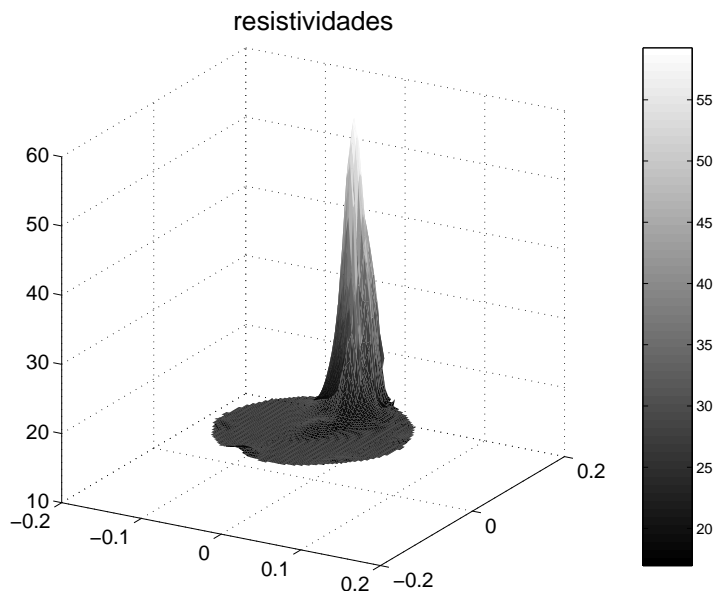

(b) gráfico de resistividades

Figura 7.92: Gráficos de convergência e resistividades da imagem obtida com $p=2$ e $\rho_{k}^{0}=0,85$, mostrada na figura $7.85(\mathrm{a})$.

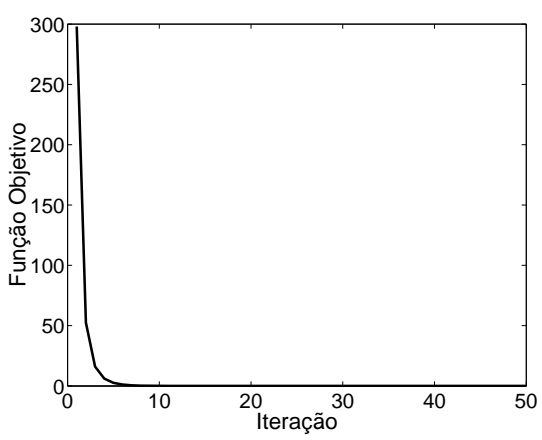

(a) gráfico de convergência

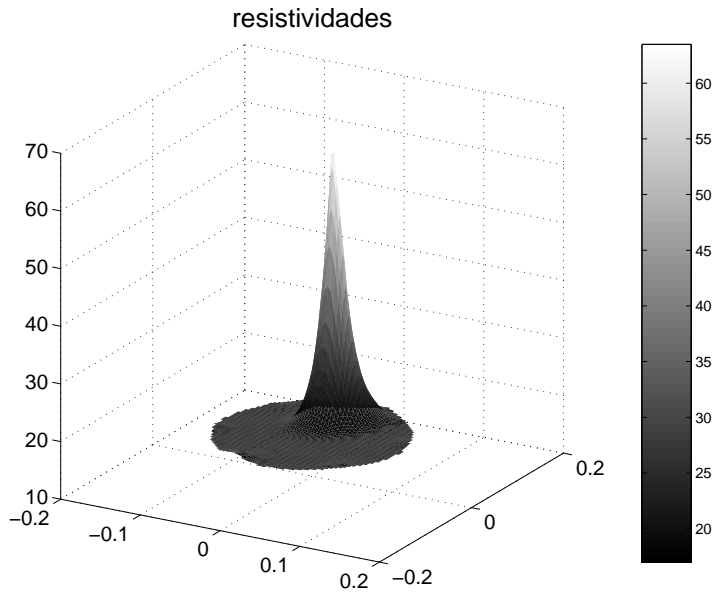

(b) gráfico de resistividades

Figura 7.93: Gráficos de convergência e resistividades da imagem obtida com $p=2$ e $\rho_{k}^{0}=0,85$, mostrada na figura $7.85(\mathrm{~b})$.

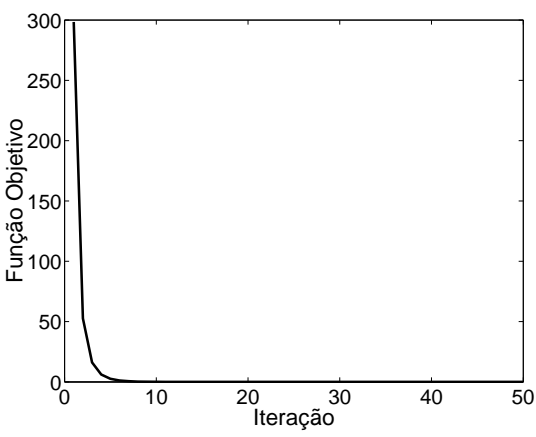

(a) gráfico de convergência

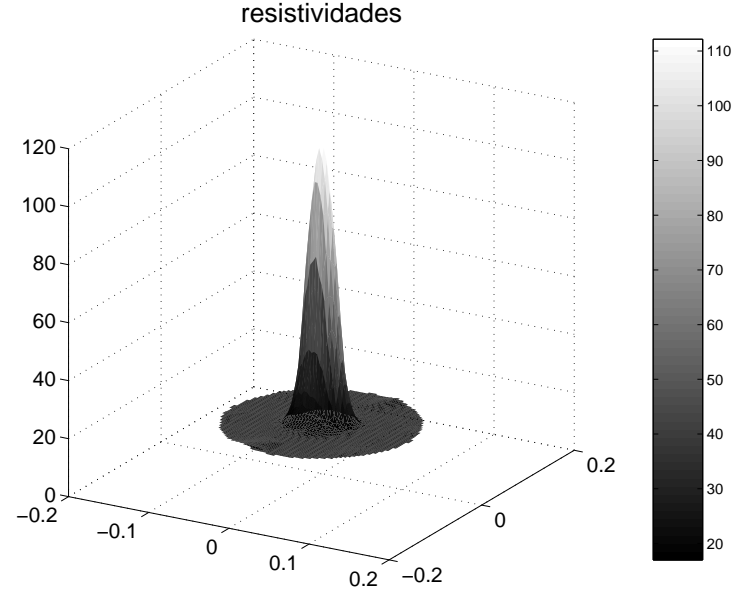

(b) gráfico de resistividades

Figura 7.94: Gráficos de convergência e resistividades da imagem obtida com $p=2$ e $\rho_{k}^{0}=0,85$, mostrada na figura $7.85(\mathrm{c})$. 
Tabela 7.7: Erro de $V^{*}$ e da coordenada $(x, y)$ do centróide da imagem do objeto e valor máximo de $\rho_{k}, \operatorname{com} p=2, \mathrm{RCM}$, filtro e elementos quadriláteros

\begin{tabular}{|c|c|c|c|c|c|c|}
\hline posição & figura & $\rho_{k}^{0}$ & $e\left(V^{*}\right)[\%]$ & $e(x)[\mathrm{mm}]$ & $e(y)[\%]$ & $\rho_{k}^{\max }$ \\
\hline \multirow{3}{*}{ borda } & $7.83(\mathrm{a})$ & 0,15 & 63,1 & 2,8 & 14,4 & 0,84 \\
& $7.84(\mathrm{a})$ & 0,50 & 60,5 & 4,8 & 13,9 & 0,87 \\
& $7.85(\mathrm{a})$ & 0,85 & 47,4 & 4,5 & 11,8 & 0,84 \\
\hline \hline \multirow{3}{*}{ meio } & $7.83(\mathrm{~b})$ & 0,15 & 28,9 & 0 & 3,0 & 0,98 \\
& $7.84(\mathrm{~b})$ & 0,50 & 10,5 & 6,1 & 3,0 & 0,96 \\
& $7.85(\mathrm{~b})$ & 0,85 & 7,9 & 0 & 7,7 & 0,86 \\
\hline \hline \multirow{3}{*}{ centro } & $7.83(\mathrm{c})$ & 0,15 & 15,8 & 0 & 0 & 0,89 \\
& $7.84(\mathrm{c})$ & 0,50 & 10,5 & 0 & 0 & 0,91 \\
& $7.85(\mathrm{c})$ & 0,85 & 10,5 & 0 & 0 & 0,91 \\
\hline
\end{tabular}

na seqüência, são mostrados os gráficos das curvas de convergência da função objetivo, bem como as imagem 3D da distribuição de resistividades gerada a partir da imagens obtidas (figuras 7.98 a 7.106).

A tabela 7.8 mostra um resumo do erro obtido para $V^{*}$ e para a coordenada $(x, y)$ do centróide da região da imagem do objeto. Elas mostram também o máximo valor de pseudo-densidade (variável de projeto) obtida pelo TOMOGOT, para os três diferentes valores de $\rho_{k}^{0}$ em cada caso de posicionamento do objeto no domínio.

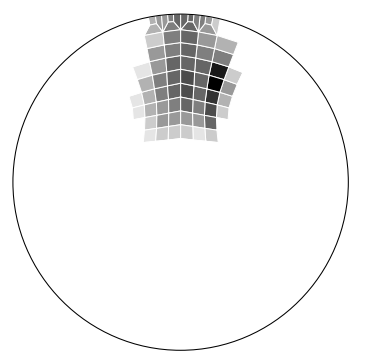

(a) $V^{*}=4,6 \% ; \mathrm{x}=8,1 ; \mathrm{y}=75,6$

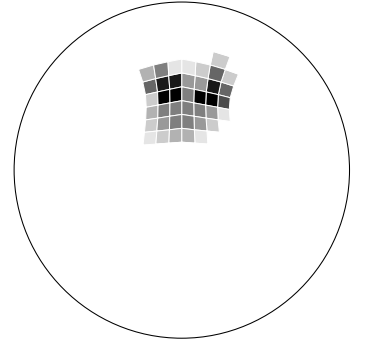

(b) $V^{*}=3,8 \% ; \mathrm{x}=3,7 ; \mathrm{y}=50,5$

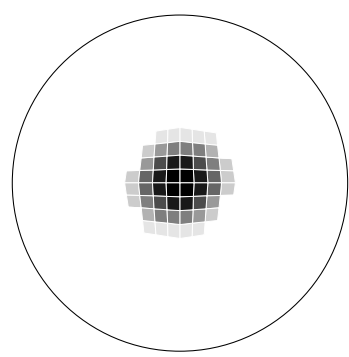

(c) $V^{*}=4,2 \% ; \mathrm{x}=0 ; \mathrm{y}=0$

Figura 7.95: Imagens obtidas com $p=4, \rho_{k}^{0}=0,15$ e elementos quadriláteros.

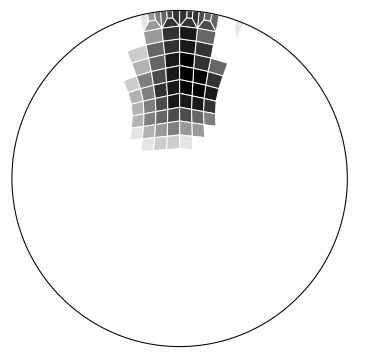

(a) $V^{*}=7,8 \% ; \mathrm{x}=2,6 ; \mathrm{y}=73,2$

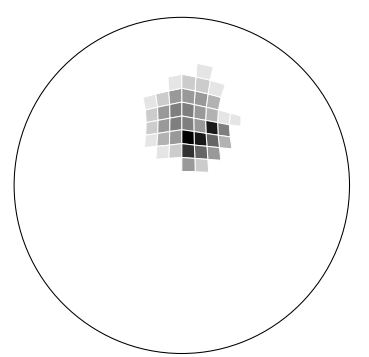

(b) $V^{*}=2,9 \% ; \mathrm{x}=6,6 ; \mathrm{y}=39,5$

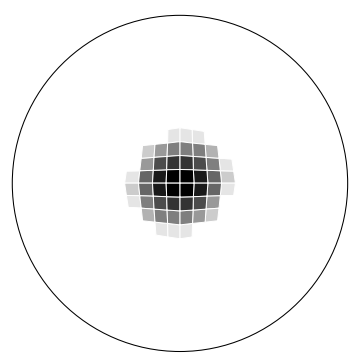

(c) $V^{*}=4,4 \% ; \mathrm{x}=0 ; \mathrm{y}=0$

Figura 7.96: Imagens obtidas com $p=4, \rho_{k}^{0}=0,50$ e elementos quadriláteros. 


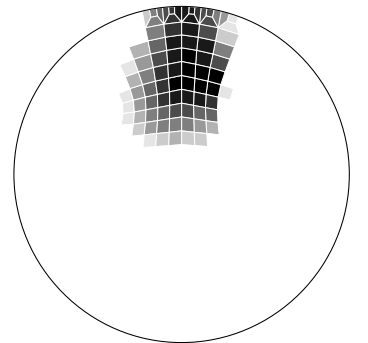

(a) $V^{*}=8,1 \% ; \mathrm{x}=2,5 ; \mathrm{y}=72,9$

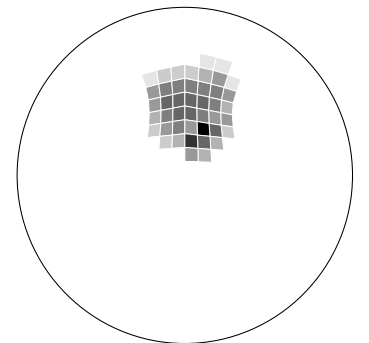

(b) $V^{*}=3,9 \% ; \mathrm{x}=6,1 ; \mathrm{y}=44$

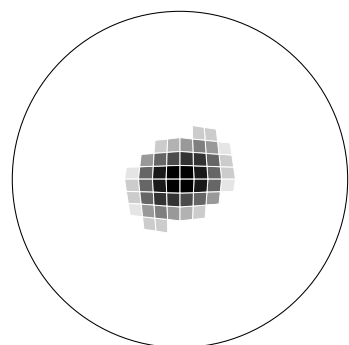

(c) $V^{*}=3,7 \% ; \mathrm{x}=0 ; \mathrm{y}=0$

Figura 7.97: Imagens obtidas com $p=4, \rho_{k}^{0}=0,85$ e elementos quadriláteros.

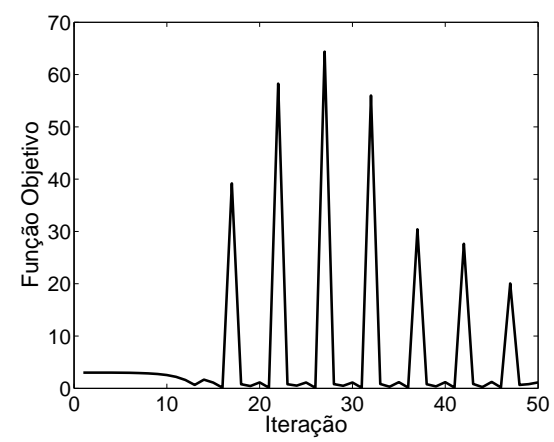

(a) gráfico de convergência

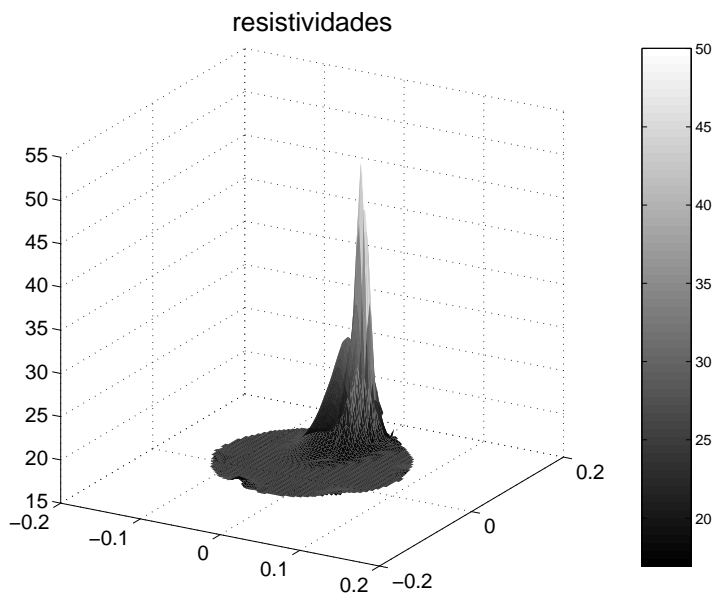

(b) gráfico de resistividades

Figura 7.98: Gráficos de convergência e resistividades da imagem obtida com $p=4$ e $\rho_{k}^{0}=0,15$, mostrada na figura 7.95 (a).

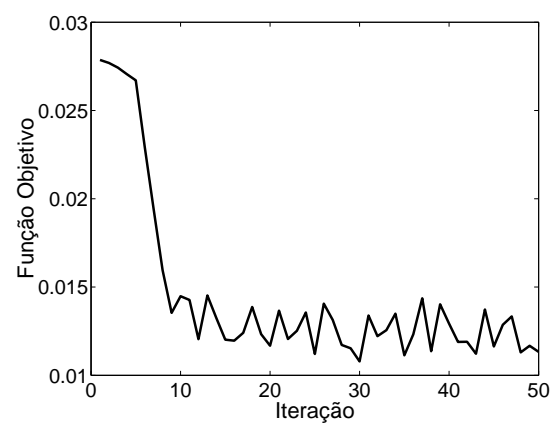

(a) gráfico de convergência

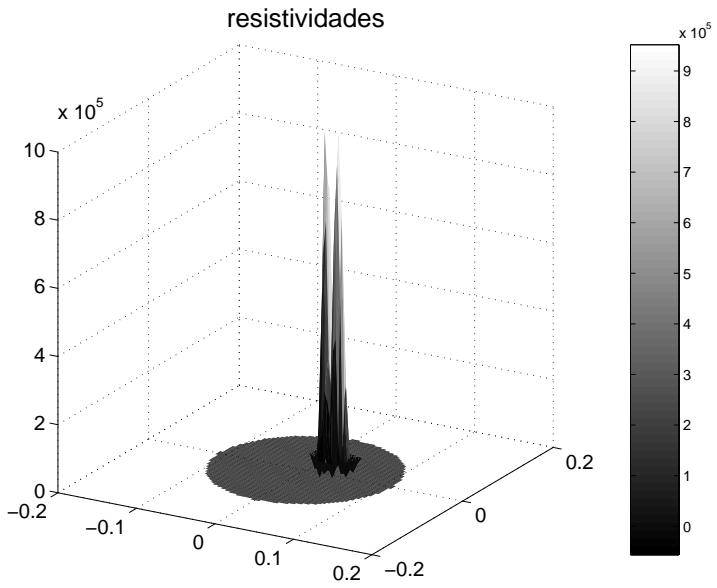

(b) gráfico de resistividades

Figura 7.99: Gráficos de convergência e resistividades da imagem obtida com $p=4$ e $\rho_{k}^{0}=0,15$, mostrada na figura $7.95(\mathrm{~b})$. 


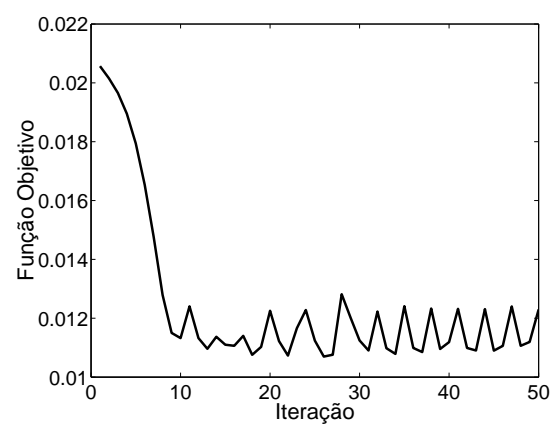

(a) gráfico de convergência

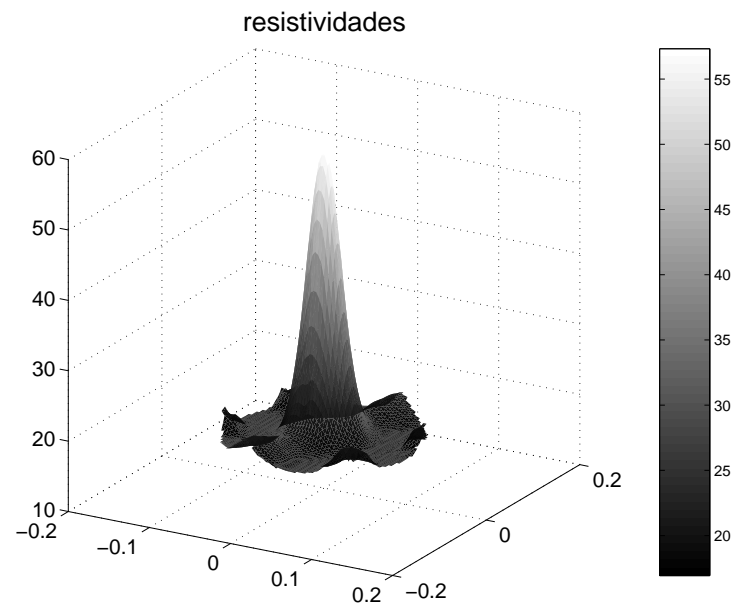

(b) gráfico de resistividades

Figura 7.100: Gráficos de convergência e resistividades da imagem obtida com $p=4$ e $\rho_{k}^{0}=0,15$, mostrada na figura 7.95 (c).

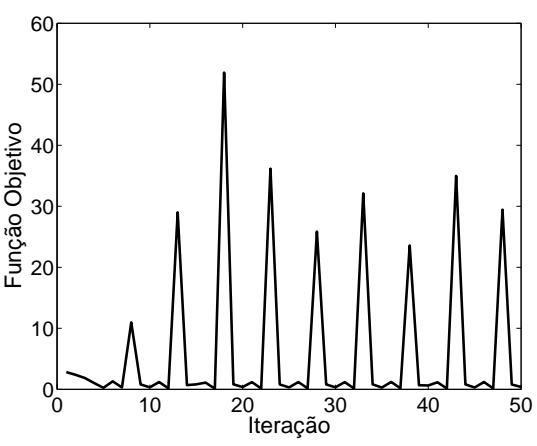

(a) gráfico de convergência

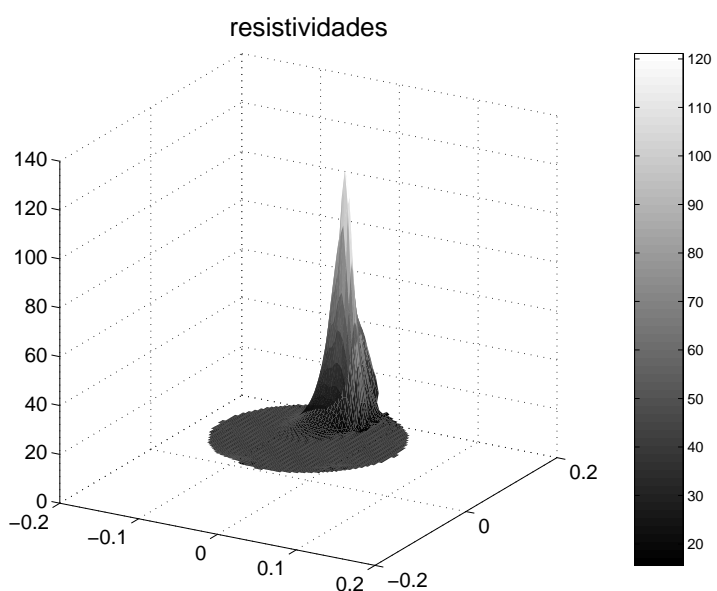

(b) gráfico de resistividades

Figura 7.101: Gráficos de convergência e resistividades da imagem obtida com $p=4$ e $\rho_{k}^{0}=0,50$, mostrada na figura 7.96(a).

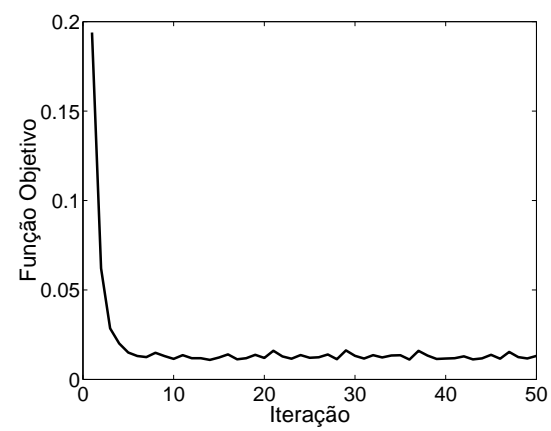

(a) gráfico de convergência

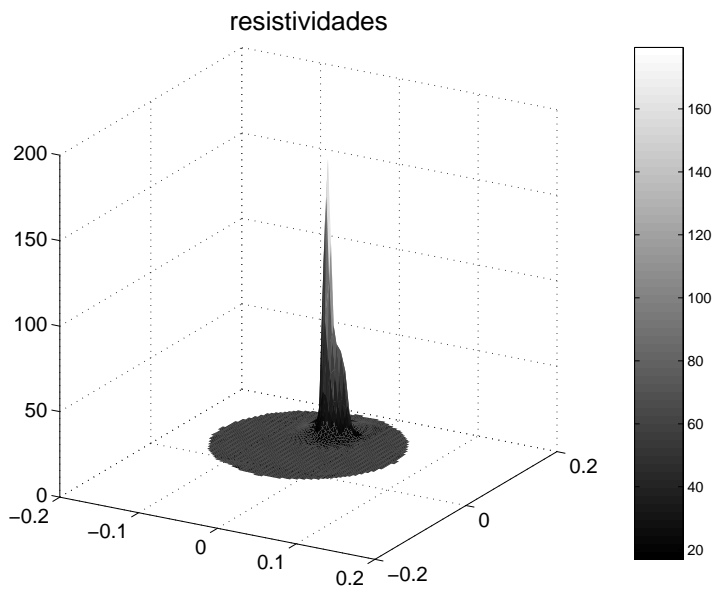

(b) gráfico de resistividades

Figura 7.102: Gráficos de convergência e resistividades da imagem obtida com $p=4$ e $\rho_{k}^{0}=0,50$, mostrada na figura 7.96(b). 


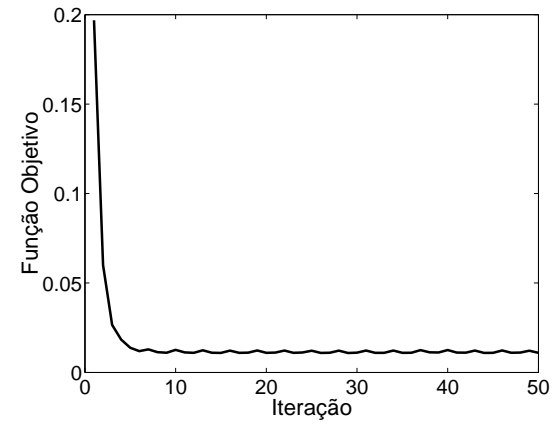

(a) gráfico de convergência

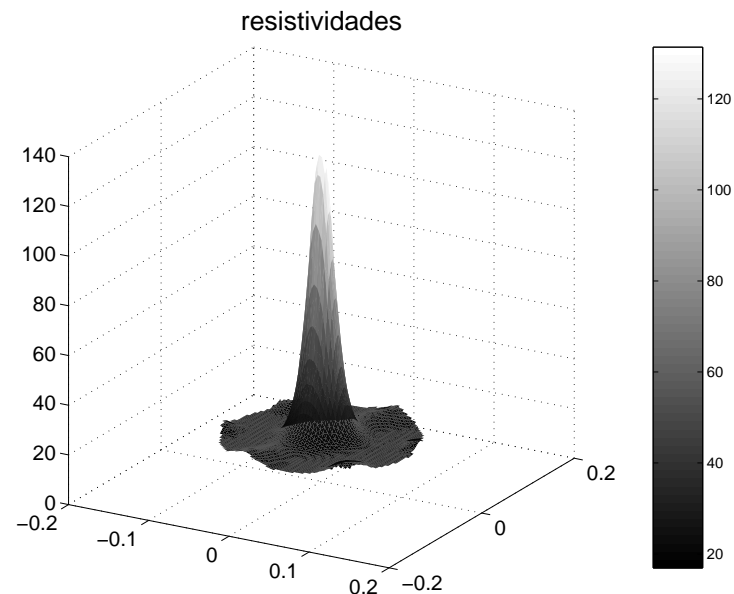

(b) gráfico de resistividades

Figura 7.103: Gráficos de convergência e resistividades da imagem obtida com $p=4$ e $\rho_{k}^{0}=0,50$, mostrada na figura 7.96(c).

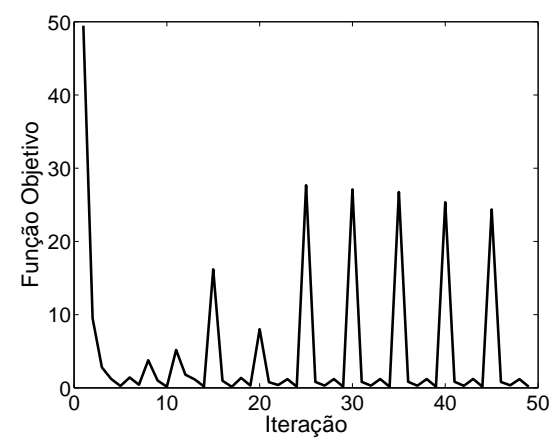

(a) gráfico de convergência

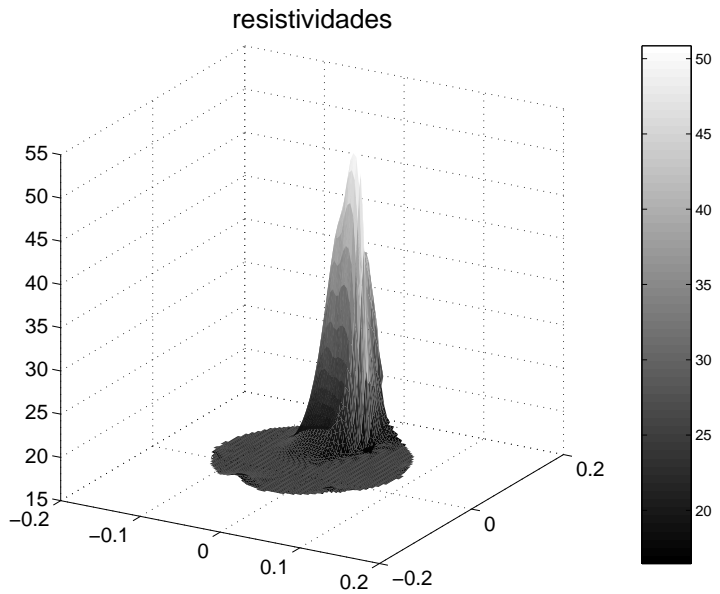

(b) gráfico de resistividades

Figura 7.104: Gráficos de convergência e resistividades da imagem obtida com $p=4$ e $\rho_{k}^{0}=0,85$, mostrada na figura $7.97(\mathrm{a})$.

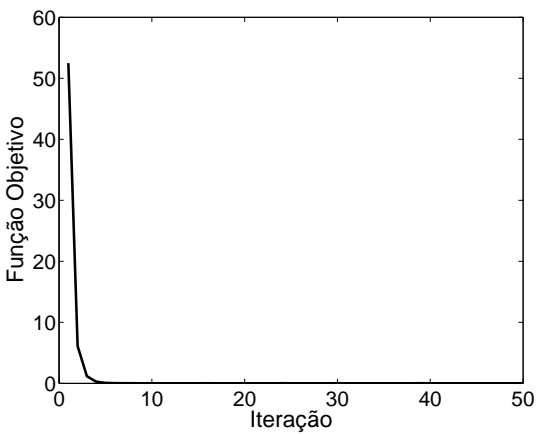

(a) gráfico de convergência

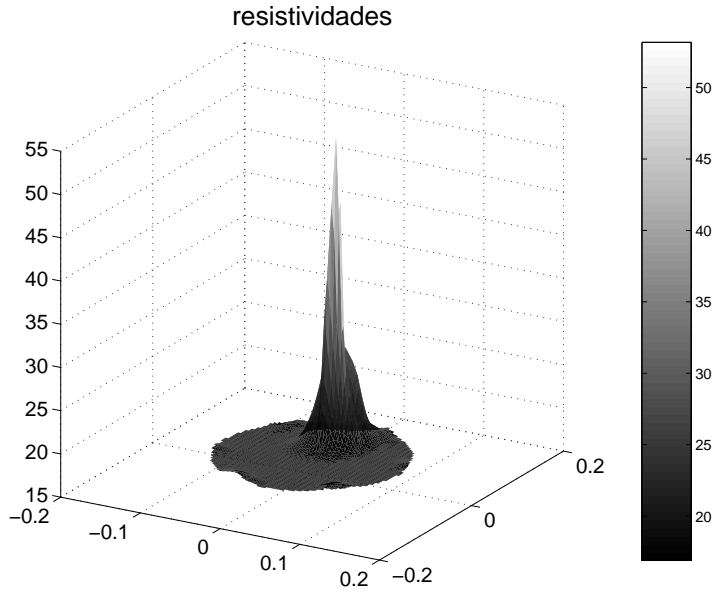

(b) gráfico de resistividades

Figura 7.105: Gráficos de convergência e resistividades da imagem obtida com $p=4$ e $\rho_{k}^{0}=0,85$, mostrada na figura $7.97(\mathrm{~b})$. 


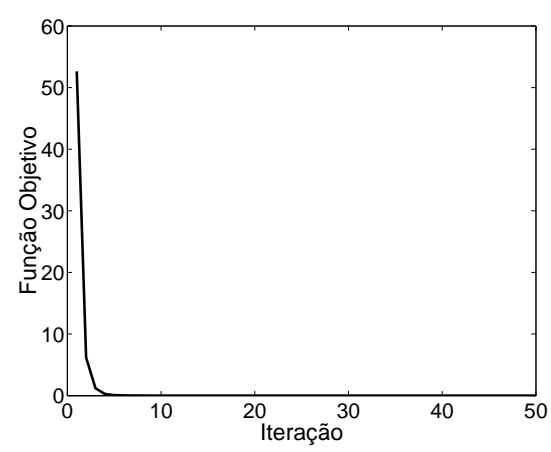

(a) gráfico de convergência

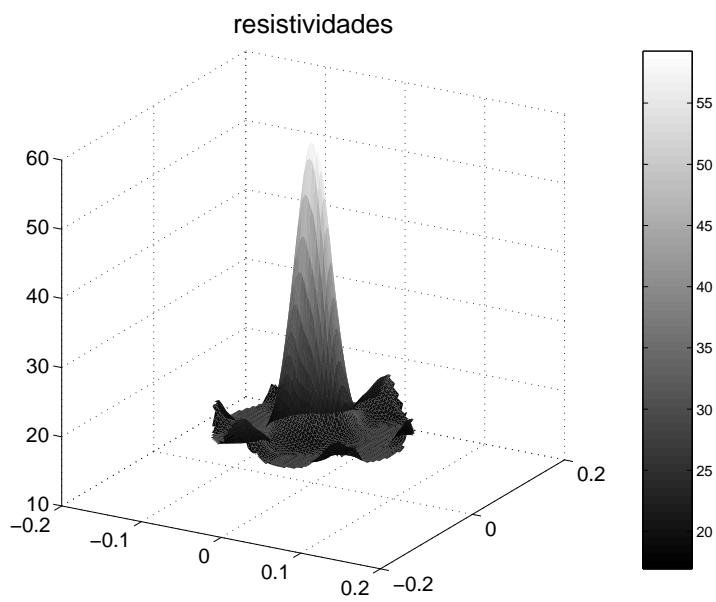

(b) gráfico de resistividades

Figura 7.106: Gráficos de convergência e resistividades da imagem obtida com $p=4$ e $\rho_{k}^{0}=0,85$, mostrada na figura $7.97(\mathrm{c})$.

Tabela 7.8: Erro de $V^{*}$ e da coordenada $(x, y)$ do centróide da imagem do objeto e valor máximo de $\rho_{k}$, com $p=4$, RCM, filtro e elementos quadriláteros

\begin{tabular}{|c|c|c|c|c|c|c|}
\hline posição & figura & $\rho_{k}^{0}$ & $e\left(V^{*}\right)[\%]$ & $e(x)[\mathrm{mm}]$ & $e(y)[\%]$ & $\rho_{k}^{\max }$ \\
\hline \multirow{5}{*}{ borda } & $7.95(\mathrm{a})$ & 0,15 & 21,0 & 8,1 & 16,0 & 0,90 \\
& $7.96(\mathrm{a})$ & 0,50 & 105 & 2,6 & 18,7 & 0,96 \\
& $7.97(\mathrm{a})$ & 0,85 & 113 & 2,5 & 19,0 & 0,90 \\
\hline \hline \multirow{3}{*}{ meio } & $7.95(\mathrm{~b})$ & 0,15 & 0 & 3,7 & 4,7 & 1 \\
& $7.96(\mathrm{~b})$ & 0,50 & 23,7 & 6,6 & 25,5 & 0,98 \\
& $7.97(\mathrm{~b})$ & 0,85 & 2,6 & 6,1 & 17,0 & 0,91 \\
\hline \hline \multirow{3}{*}{ centro } & $7.95(\mathrm{c})$ & 0,15 & 10,5 & 0 & 0 & 0,83 \\
& $7.96(\mathrm{c})$ & 0,50 & 15,8 & 0 & 0 & 0,93 \\
& $7.97(\mathrm{c})$ & 0,85 & 2,6 & 0 & 0 & 0,84 \\
\hline
\end{tabular}

\subsubsection{Imagens Obtidas com o Domínio Discretizado em Elementos Triangulares}

As figuras 7.107, 7.108 e 7.109 mostram os resultados obtidos com a utilização do domínio de obtenção de imagem apresentado na figura 7.26 (discretizado em 1248 elementos triangulares), para os três casos distintos mostrados na figura 7.33.

De maneira análoga ao que vem sendo realizado para o domínio discretizado em elementos quadriláteros, inicialmente são mostradas as imagens da distribuição de condutividades obtidas com o TOMOGOT, utilizando-se $p$ igual 2 para $\rho_{k}^{0}$ igual a $0,15,0,50$ e 0,85 (figuras $7.107,7.108$ e 7.109). Em seguida, os gráficos das figuras 7.110 a 7.118 mostram as curvas de convergência da função objetivo, bem como a imagem 3D da distribuição de resistividades gerada a partir 
das imagens obtidas.

A tabela 7.9 mostra um resumo do erro obtido para $V^{*}$ e para a coordenada $(x, y)$ do centróide da região da imagem do objeto, bem como o máximo valor de pseudo-densidade (variável de projeto) obtida pelo TOMOGOT, para os três diferentes valores de $\rho_{k}^{0}$ em cada caso de posicionamento do objeto no domínio.

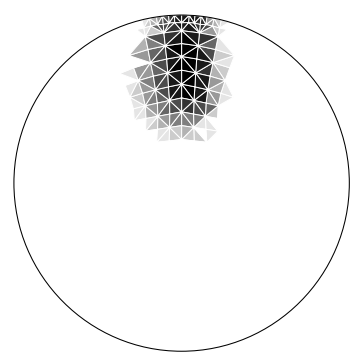

(a) $V^{*}=5,7 \% ; \mathrm{x}=0 ; \mathrm{y}=78,9$

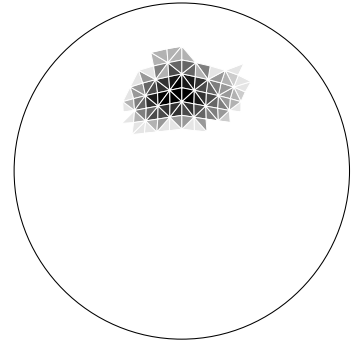

(b) $V^{*}=3,7 \% ; \mathrm{x}=-1,4 ; \mathrm{y}=53$

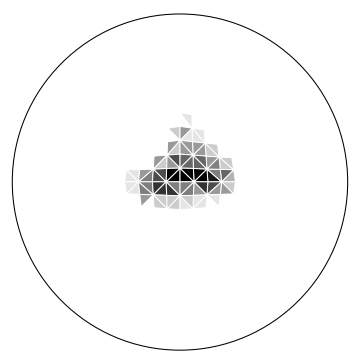

(c) $V^{*}=2,6 \% ; \mathrm{x}=3,3 ; \mathrm{y}=3,9$

Figura 7.107: Imagens obtidas com $p=2, \rho_{k}^{0}=0,15$ e elementos triangulares.

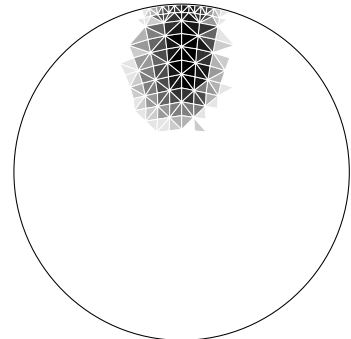

(a) $V^{*}=5,8 \% ; \mathrm{x}=1 ; \mathrm{y}=78,6$

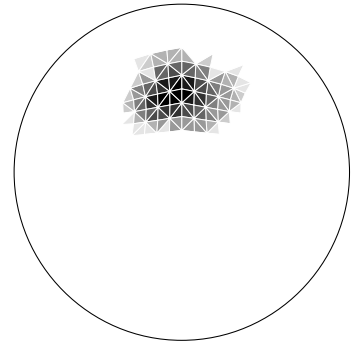

(b) $V^{*}=3,9 \% ; \mathrm{x}=-2 ; \mathrm{y}=54,1$

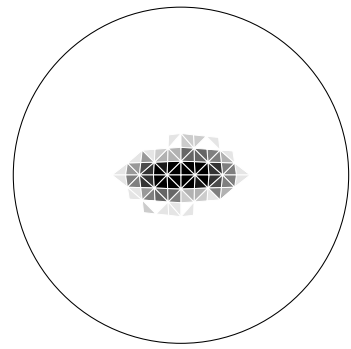

(c) $V^{*}=3,3 \% ; \mathrm{x}=0 ; \mathrm{y}=0$

Figura 7.108: Imagens obtidas com $p=2, \rho_{k}^{0}=0,50$ e elementos triangulares.

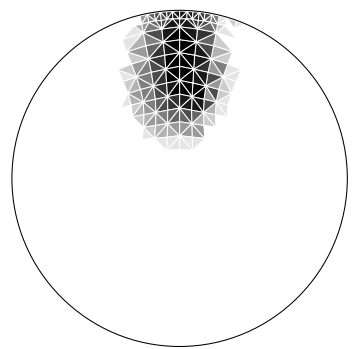

(a) $V^{*}=6,1 \% ; \mathrm{x}=0 ; \mathrm{y}=78,2$

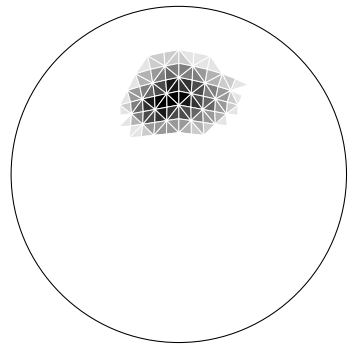

(b) $V^{*}=3,3 \% ; \mathrm{x}=-2,2 ; \mathrm{y}=52,8$

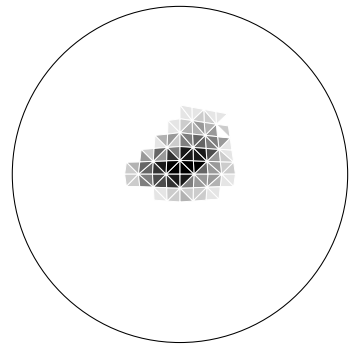

(c) $V^{*}=2,9 \% ; \mathrm{x}=1,4 ; \mathrm{y}=6,7$

Figura 7.109: Imagens obtidas com $p=2, \rho_{k}^{0}=0,85$ e elementos triangulares.

A seguir, o fator de penalidade $(p)$ é alterado para 4 e é feito um estudo análogo ao realizado com $p$ igual a 2. Desta forma, as figuras 7.119, 7.120 e 7.121 mostram as imagens da distribuição de condutividades obtidas para $\rho_{k}^{0}$ iguais a 0,15, 0,50 e 0,85 e, na seqüencia, são mostrados os gráficos das curvas de convergência da função objetivo, bem como as imagem 3D da distribuição de resistividades gerada a partir da imagens obtidas (figuras 7.122 a 7.130). 


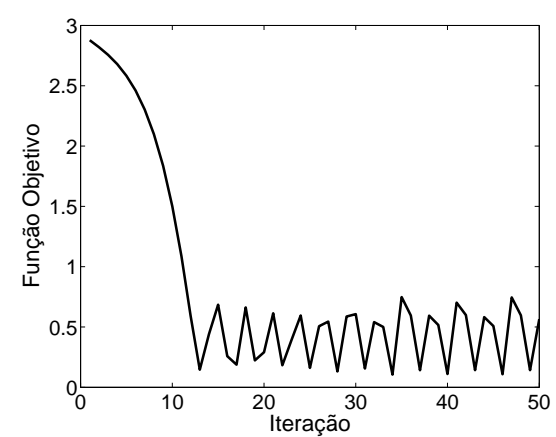

(a) gráfico de convergência

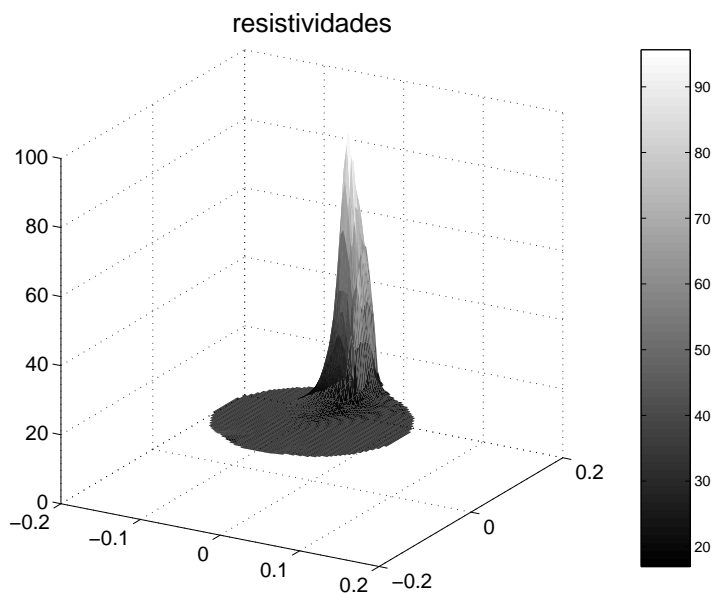

(b) gráfico de resistividades

Figura 7.110: Gráficos de convergência e resistividades da imagem obtida com $p=2$ e $\rho_{k}^{0}=0,15$, mostrada na figura $7.107(\mathrm{a})$.

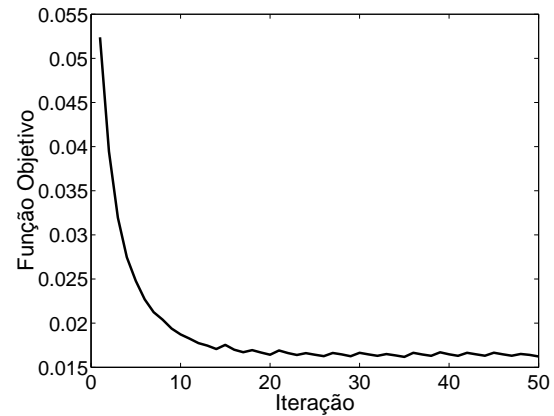

(a) gráfico de convergência

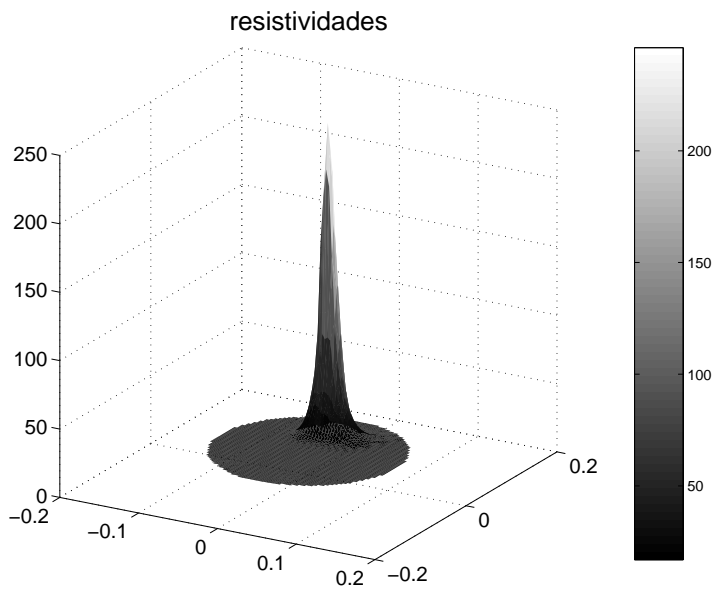

(b) gráfico de resistividades

Figura 7.111: Gráficos de convergência e resistividades da imagem obtida com $p=2$ e $\rho_{k}^{0}=0,15$, mostrada na figura $7.107(\mathrm{~b})$.

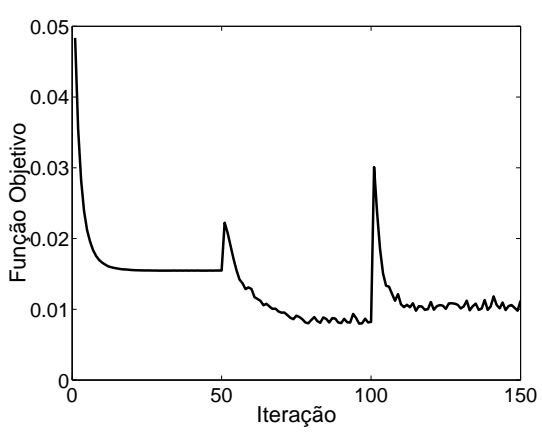

(a) gráfico de convergência

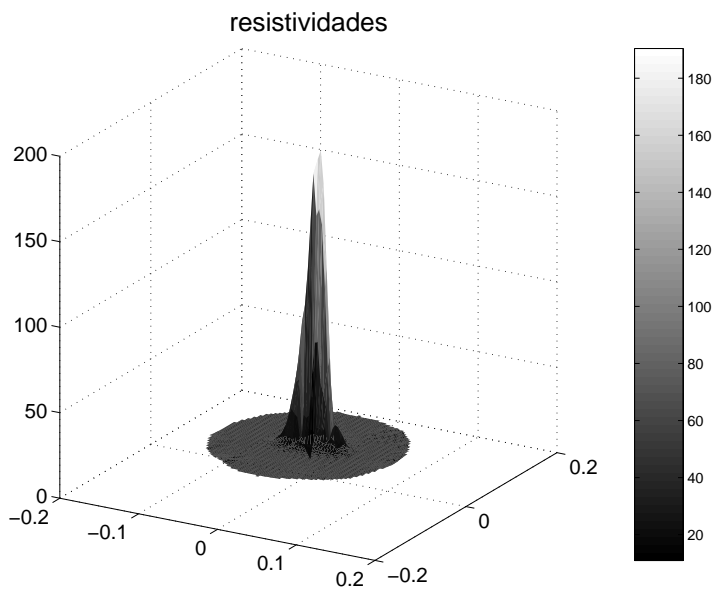

(b) gráfico de resistividades

Figura 7.112: Gráficos de convergência e resistividades da imagem obtida com $p=2$ e $\rho_{k}^{0}=0,15$, mostrada na figura $7.107(\mathrm{c})$. 


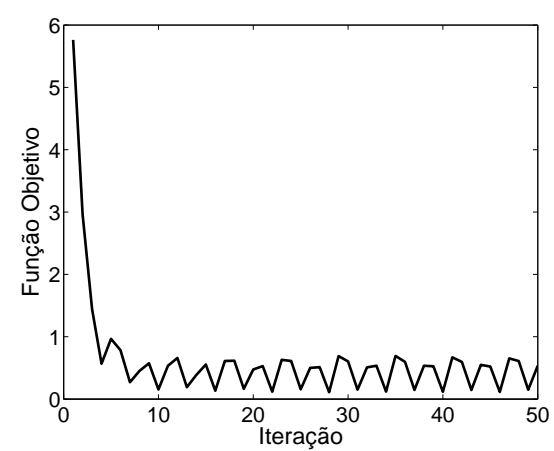

(a) gráfico de convergência

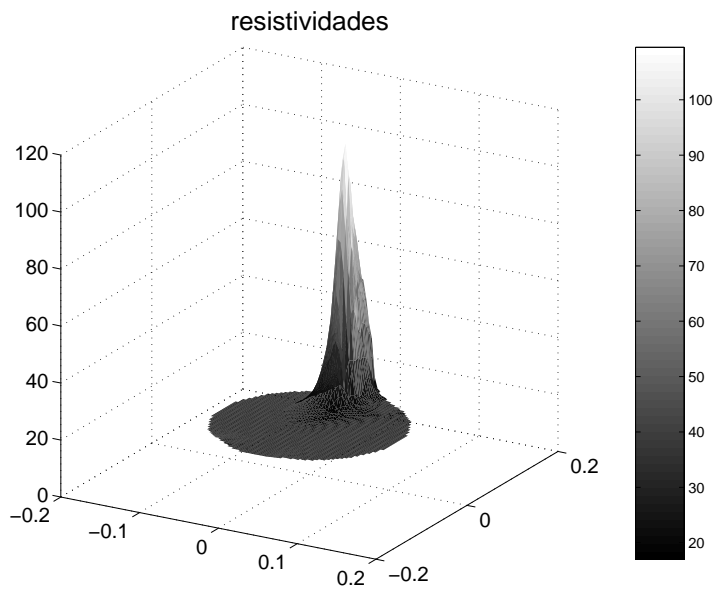

(b) gráfico de resistividades

Figura 7.113: Gráficos de convergência e resistividades da imagem obtida com $p=2$ e $\rho_{k}^{0}=0,50$, mostrada na figura $7.108(\mathrm{a})$.

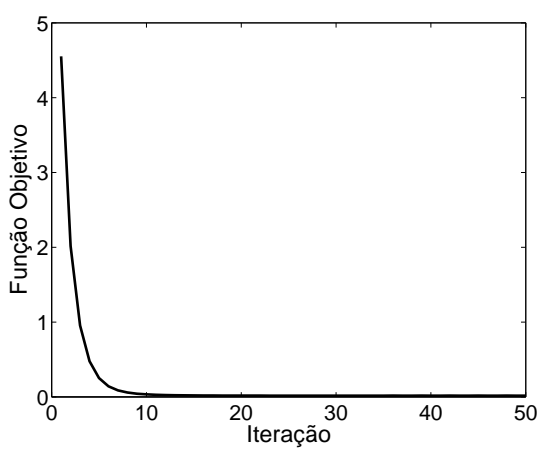

(a) gráfico de convergência

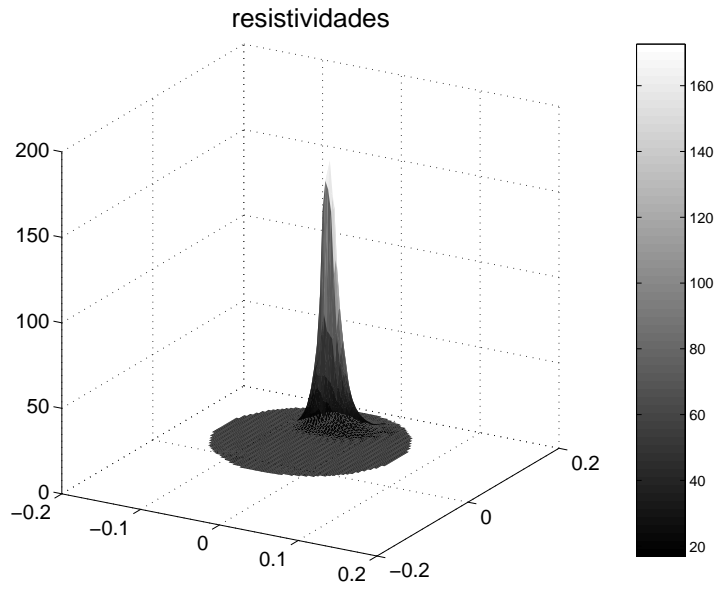

(b) gráfico de resistividades

Figura 7.114: Gráficos de convergência e resistividades da imagem obtida com $p=2$ e $\rho_{k}^{0}=0,50$, mostrada na figura $7.108(\mathrm{~b})$.

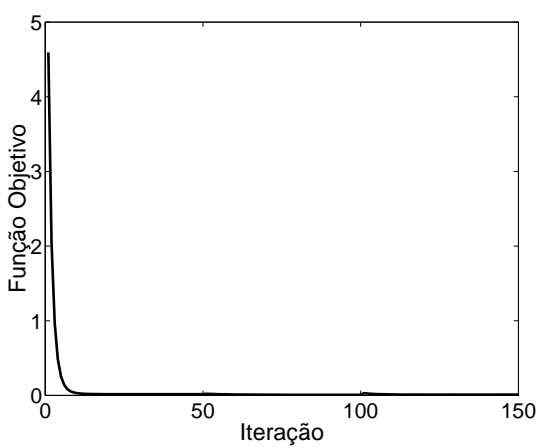

(a) gráfico de convergência

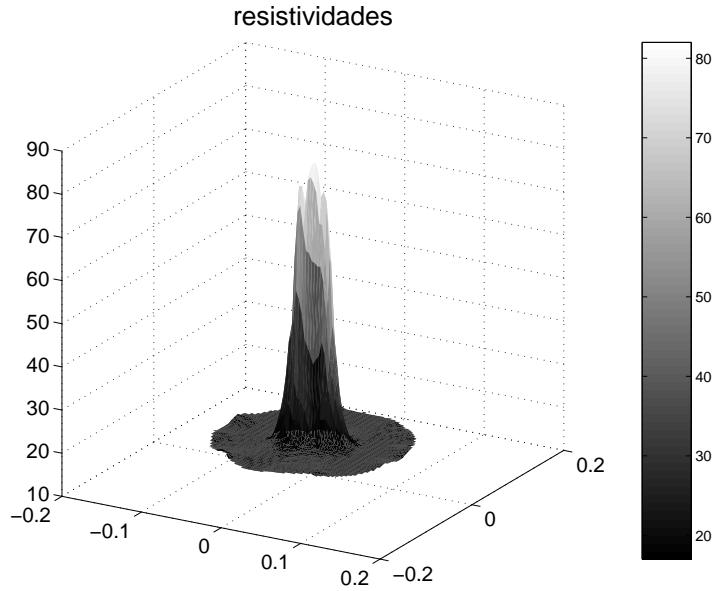

(b) gráfico de resistividades

Figura 7.115: Gráficos de convergência e resistividades da imagem obtida com $p=2$ e $\rho_{k}^{0}=0,50$, mostrada na figura $7.108(\mathrm{c})$. 


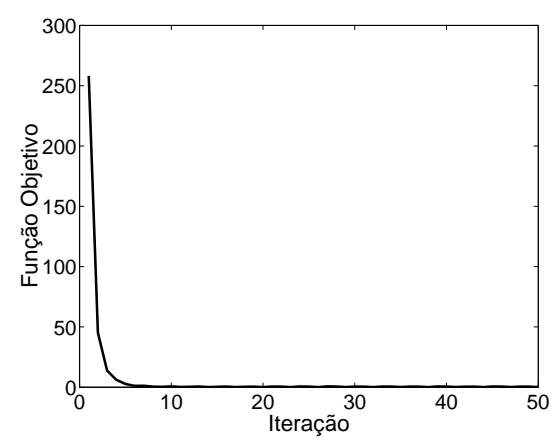

(a) gráfico de convergência

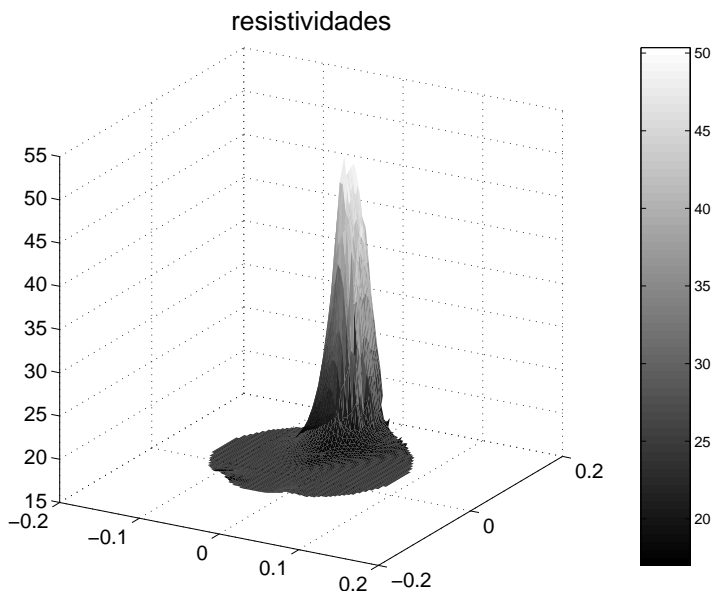

(b) gráfico de resistividades

Figura 7.116: Gráficos de convergência e resistividades da imagem obtida com $p=2$ e $\rho_{k}^{0}=0,85$, mostrada na figura 7.109(a).

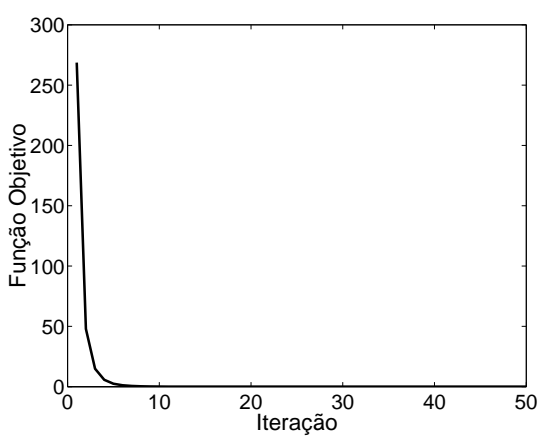

(a) gráfico de convergência

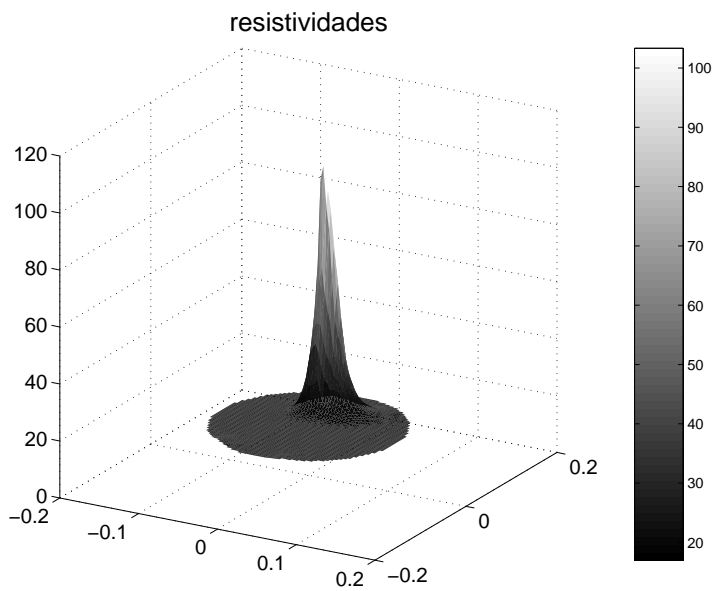

(b) gráfico de resistividades

Figura 7.117: Gráficos de convergência e resistividades da imagem obtida com $p=2$ e $\rho_{k}^{0}=0,85$, mostrada na figura $7.109(\mathrm{~b})$.

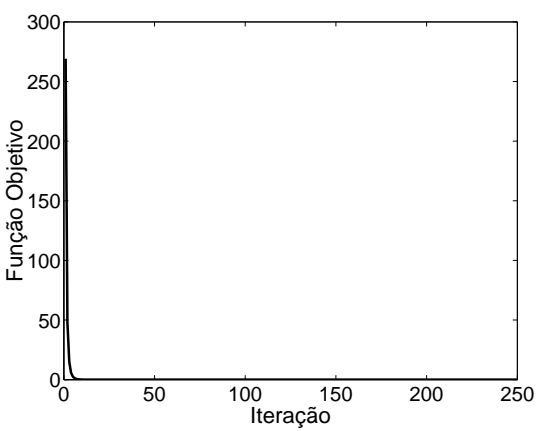

(a) gráfico de convergência

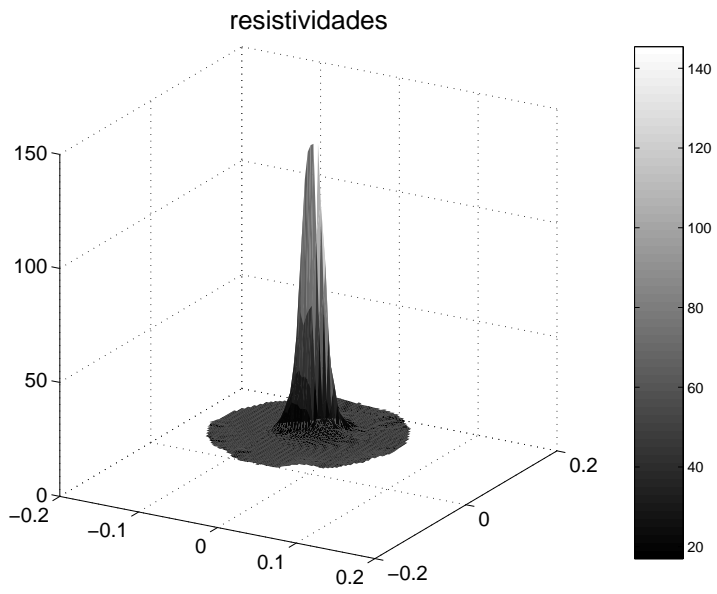

(b) gráfico de resistividades

Figura 7.118: Gráficos de convergência e resistividades da imagem obtida com $p=2$ e $\rho_{k}^{0}=0,85$, mostrada na figura $7.109(\mathrm{c})$. 
Tabela 7.9: Erro de $V^{*}$ e da coordenada $(x, y)$ do centróide da imagem do objeto e valor máximo de $\rho_{k}$, com $p=2, \mathrm{RCM}$, filtro e elementos triangulares

\begin{tabular}{|c|c|c|c|c|c|c|}
\hline posição & figura & $\rho_{k}^{0}$ & $e\left(V^{*}\right)[\%]$ & $e(x)[\mathrm{mm}]$ & $e(y)[\%]$ & $\rho_{k}^{\max }$ \\
\hline \multirow{5}{*}{ borda } & $7.107(\mathrm{a})$ & 0,15 & 50,0 & 0 & 12,3 & 0,91 \\
& $7.108(\mathrm{a})$ & 0,50 & 52,6 & 1,0 & 12,7 & 0,92 \\
& $7.109(\mathrm{a})$ & 0,85 & 60,5 & 0 & 13,1 & 0,81 \\
\hline \hline \multirow{3}{*}{ meio } & $7.107(\mathrm{~b})$ & 0,15 & 2,6 & 1,4 & 0 & 0,96 \\
& $7.108(\mathrm{~b})$ & 0,50 & 2,6 & 2,0 & 2,1 & 0,95 \\
& $7.109(\mathrm{~b})$ & 0,85 & 13,1 & 2,2 & 0,4 & 0,92 \\
\hline \hline \multirow{3}{*}{ centro } & $7.107(\mathrm{c})$ & 0,15 & 31,6 & 3,3 & $3,9 \mathrm{~mm}$ & 0,95 \\
& $7.108(\mathrm{c})$ & 0,50 & 13,1 & 0 & 0 & 0,89 \\
& $7.109(\mathrm{c})$ & 0,85 & 23,7 & 1,4 & $6,7 \mathrm{~mm}$ & 0,94 \\
\hline
\end{tabular}

A tabela 7.10 mostra um resumo do erro obtido para $V^{*}$ e para a coordenada $(x, y)$ do centróide da região da imagem do objeto. Também é mostrado o máximo valor de pseudo-densidade (variável de projeto) obtida pelo TOMOGOT, para os três diferentes valores de $\rho_{k}^{0}$ em cada caso de posicionamento do objeto no domínio.

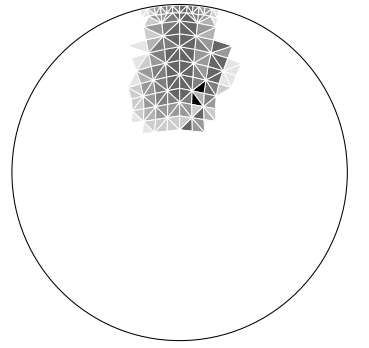

(a) $V^{*}=4,3 \% ; \mathrm{x}=4,2 ; \mathrm{y}=75,9$

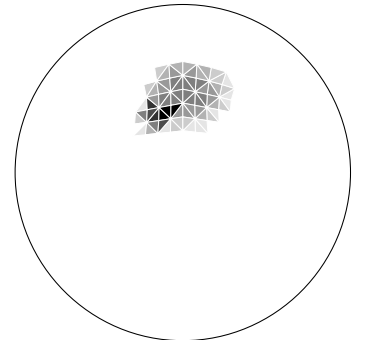

(b) $V^{*}=2,4 \% ; \mathrm{x}=-3,6 ; \mathrm{y}=49,1$

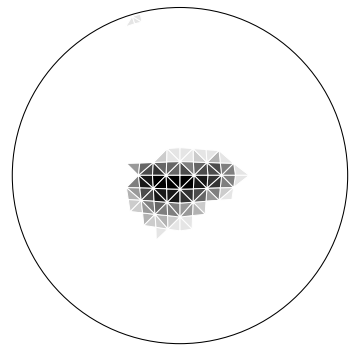

(c) $V^{*}=3,8 \% ; \mathrm{x}=0 ; \mathrm{y}=-5,6$

Figura 7.119: Imagens obtidas com $p=4, \rho_{k}^{0}=0,15$ e elementos triangulares.

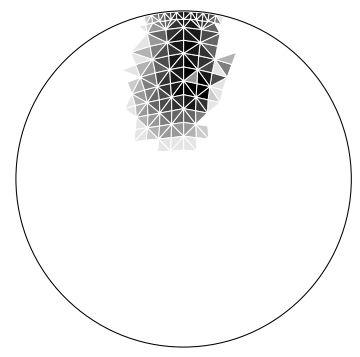

(a) $V^{*}=6,7 \% ; \mathrm{x}=0 ; \mathrm{y}=77,5$

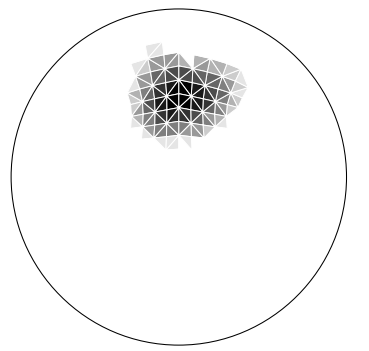

(b) $V^{*}=5,4 \% ; \mathrm{x}=2,1 ; \mathrm{y}=53,5$

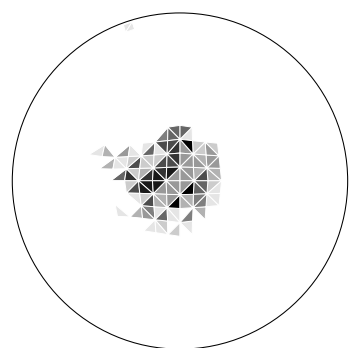

(c) $V^{*}=2,8 \% ; \mathrm{x}=-10,3 ; \mathrm{y}=5,2$

Figura 7.120: Imagens obtidas com $p=4, \rho_{k}^{0}=0,50$ e elementos triangulares.

\subsubsection{Comentários Gerais Sobre os Resultados Obtidos com o Filtro}

Observando as imagens mostradas nas seções 7.3.7.1 e 7.3.7.2, para o caso onde o objeto está posicionado na borda do domínio, constata-se que a imagem obtida 


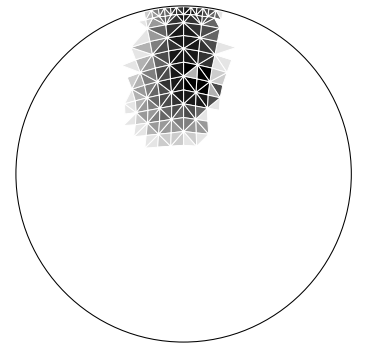

(a) $V^{*}=6,9 \% ; \mathrm{x}=0 ; \mathrm{y}=76,5$

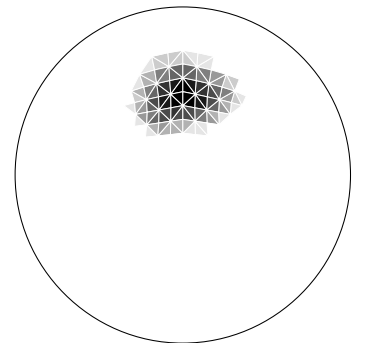

(b) $V^{*}=3,8 \% ; \mathrm{x}=0 ; \mathrm{y}=54,5$

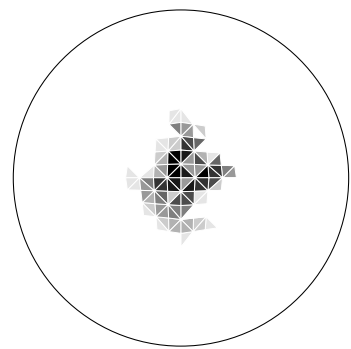

(c) $V^{*}=2,9 \% ; \mathrm{x}=2,6 ; \mathrm{y}=0$

Figura 7.121: Imagens obtidas com $p=4, \rho_{k}^{0}=0,85$ e elementos triangulares.

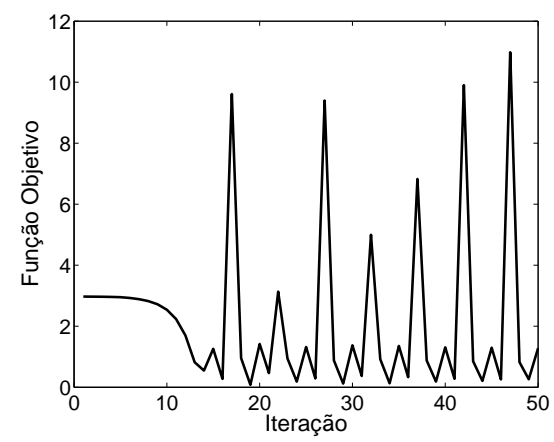

(a) gráfico de convergência

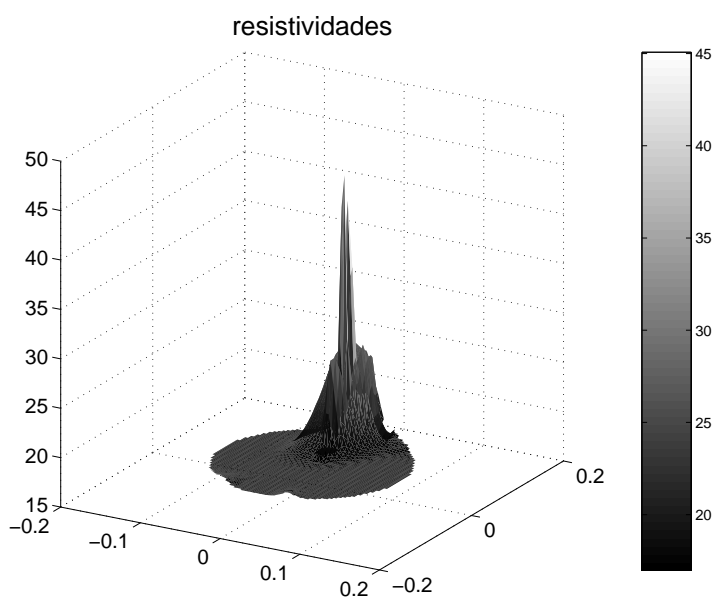

(b) gráfico de resistividades

Figura 7.122: Gráficos de convergência e resistividades da imagem obtida com $p=4$ e $\rho_{k}^{0}=0,15$, mostrada na figura 7.119(a).

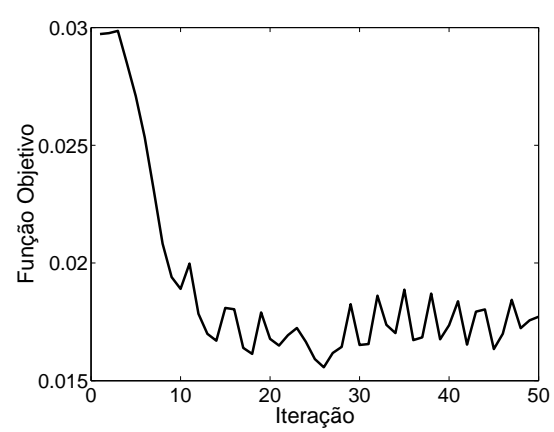

(a) gráfico de convergência

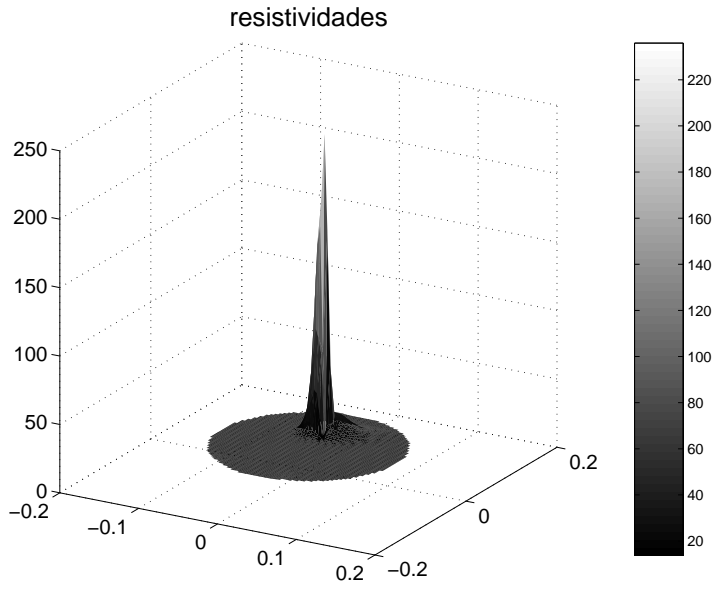

(b) gráfico de resistividades

Figura 7.123: Gráficos de convergência e resistividades da imagem obtida com $p=4$ e $\rho_{k}^{0}=0,15$, mostrada na figura $7.119(\mathrm{~b})$. 


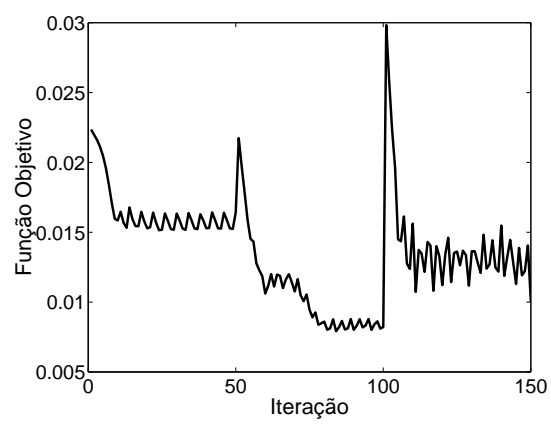

(a) gráfico de convergência

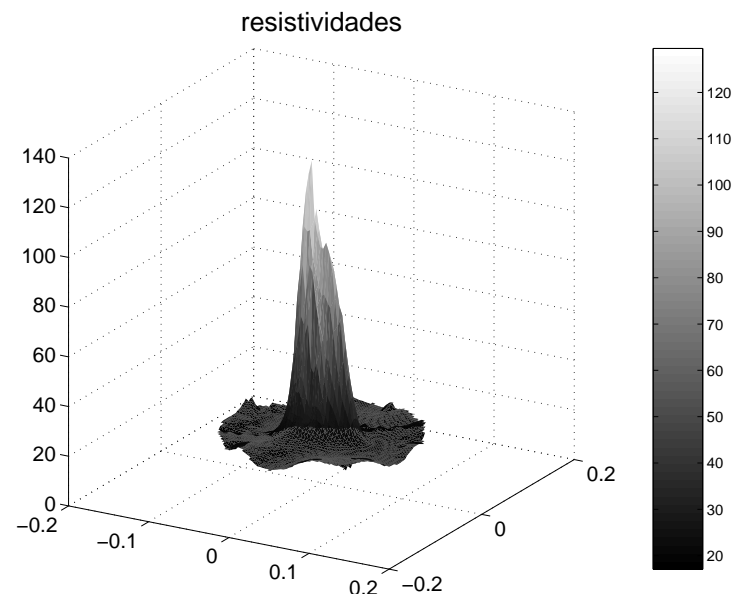

(b) gráfico de resistividades

Figura 7.124: Gráficos de convergência e resistividades da imagem obtida com $p=4$ e $\rho_{k}^{0}=0,15$, mostrada na figura 7.119 (c).

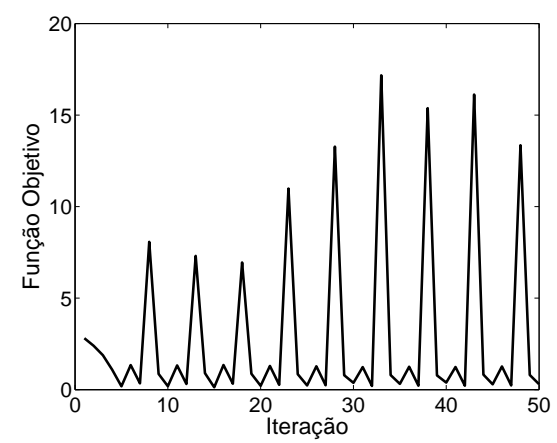

(a) gráfico de convergência

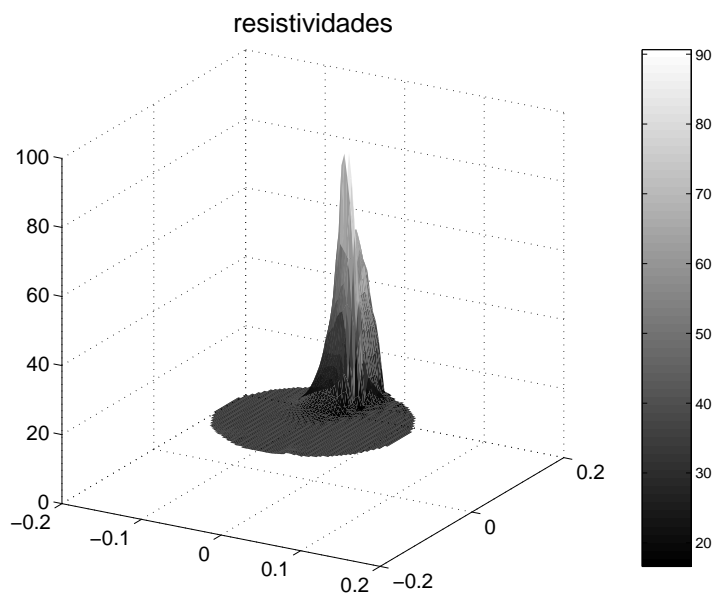

(b) gráfico de resistividades

Figura 7.125: Gráficos de convergência e resistividades da imagem obtida com $p=4$ e $\rho_{k}^{0}=0,50$, mostrada na figura 7.120 (a).

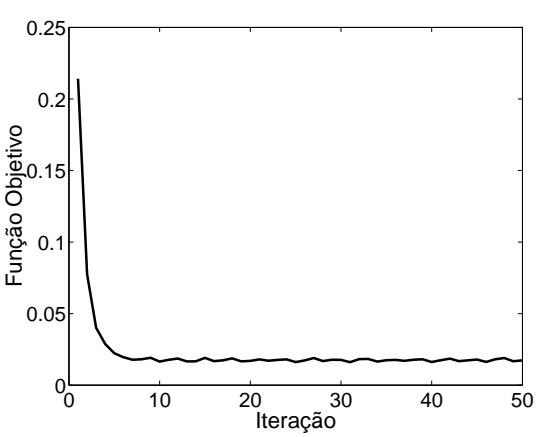

(a) gráfico de convergência

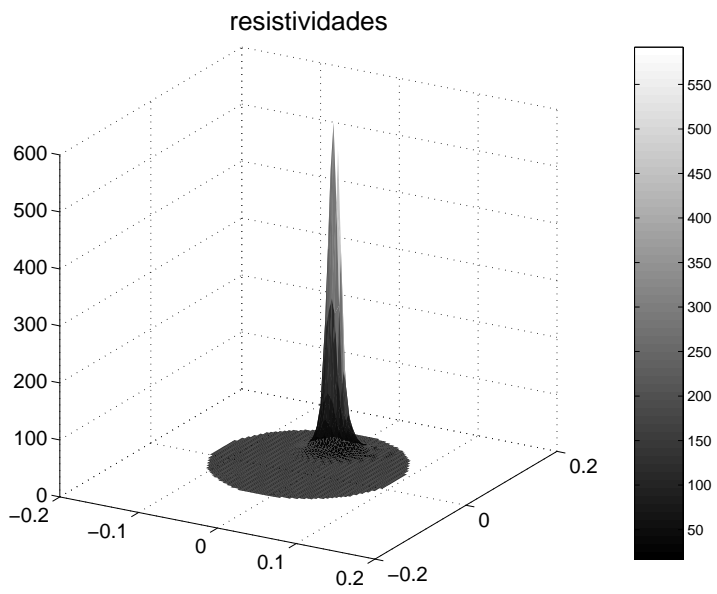

(b) gráfico de resistividades

Figura 7.126: Gráficos de convergência e resistividades da imagem obtida com $p=4$ e $\rho_{k}^{0}=0,50$, mostrada na figura 7.120(b). 


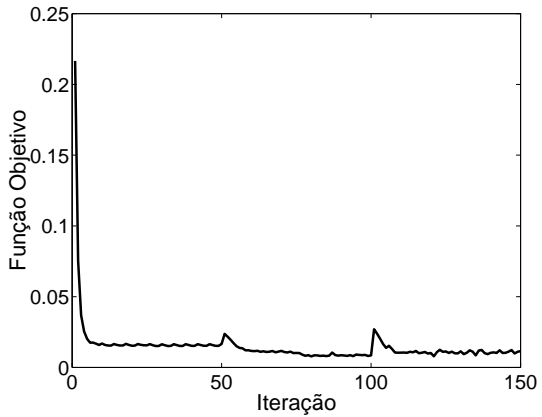

(a) gráfico de convergência

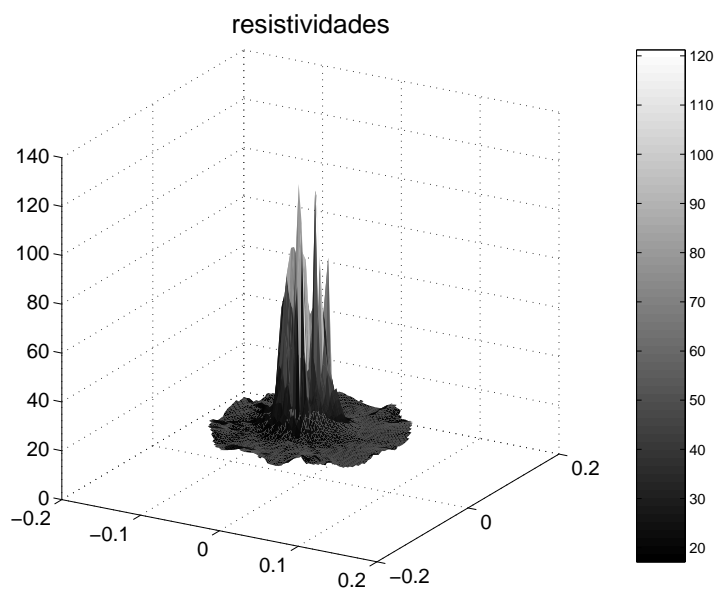

(b) gráfico de resistividades

Figura 7.127: Gráficos de convergência e resistividades da imagem obtida com $p=4$ e $\rho_{k}^{0}=0,50$, mostrada na figura $7.120(\mathrm{c})$.

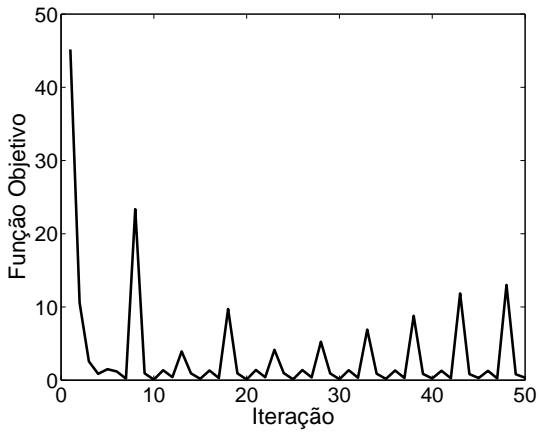

(a) gráfico de convergência

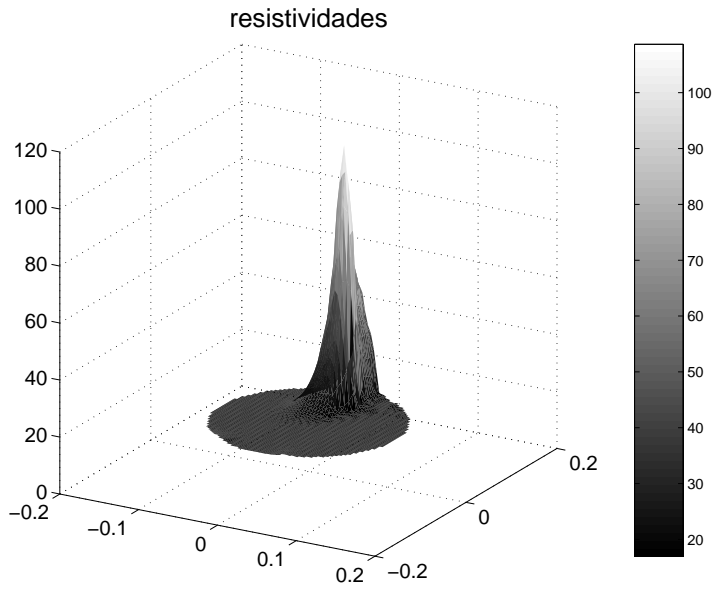

(b) gráfico de resistividades

Figura 7.128: Gráficos de convergência e resistividades da imagem obtida com $p=4$ e $\rho_{k}^{0}=0,85$, mostrada na figura $7.121(\mathrm{a})$.

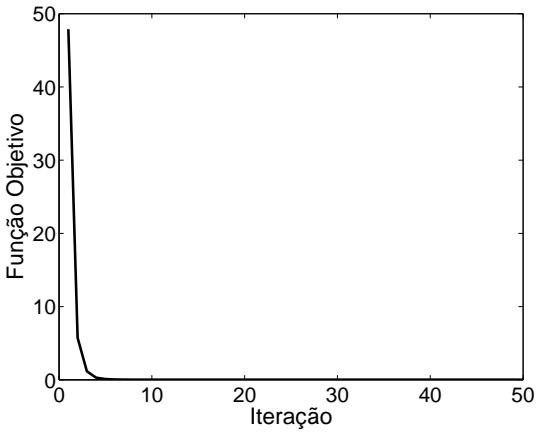

(a) gráfico de convergência

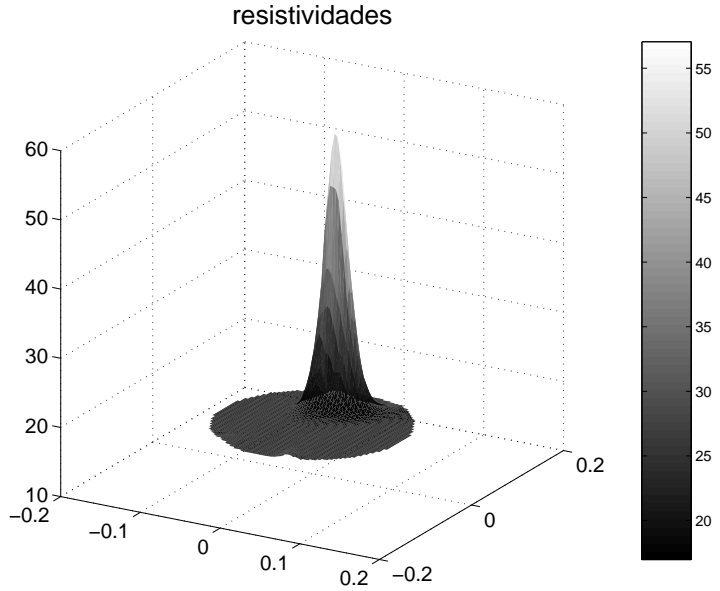

(b) gráfico de resistividades

Figura 7.129: Gráficos de convergência e resistividades da imagem obtida com $p=4$ e $\rho_{k}^{0}=0,85$, mostrada na figura 7.121(b). 


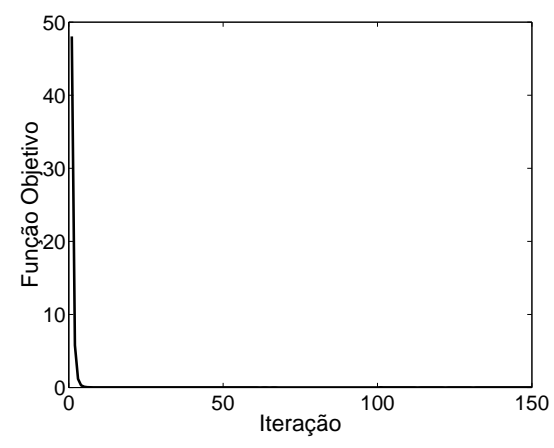

(a) gráfico de convergência

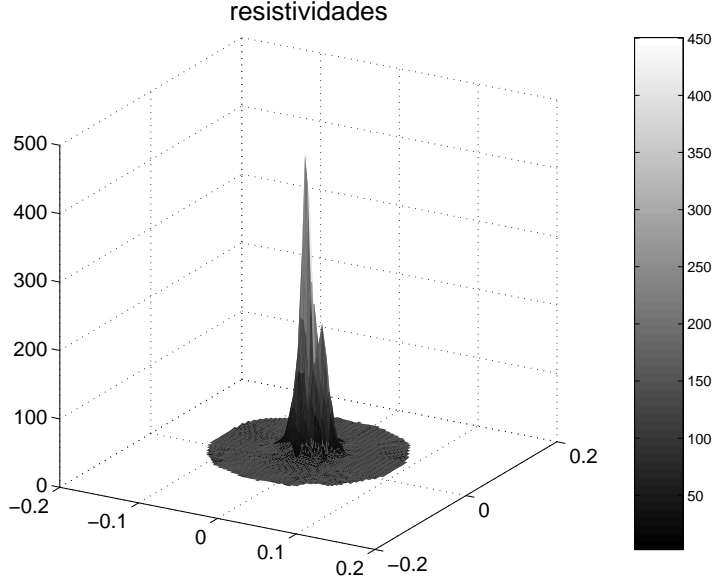

(b) gráfico de resistividades

Figura 7.130: Gráficos de convergência e resistividades da imagem obtida com $p=4$ e $\rho_{k}^{0}=0,85$, mostrada na figura $7.121(\mathrm{c})$.

Tabela 7.10: Erro de $V^{*}$ e da coordenada $(x, y)$ do centróide da imagem do objeto e valor máximo de $\rho_{k}$, com $p=4, \mathrm{RCM}$, filtro e elementos triangulares

\begin{tabular}{|c|c|c|c|c|c|c|}
\hline posição & figura & $\rho_{k}^{0}$ & $e\left(V^{*}\right)[\%]$ & $e(x)[\mathrm{mm}]$ & $e(y)[\%]$ & $\rho_{k}^{\max }$ \\
\hline \multirow{5}{*}{ borda } & $7.119(\mathrm{a})$ & 0,15 & 13,1 & 4,2 & 15,7 & 0,90 \\
& $7.120(\mathrm{a})$ & 0,50 & 76,3 & 0 & 13,9 & 0,95 \\
& $7.121(\mathrm{a})$ & 0,85 & 81,6 & 0 & 15,0 & 0,96 \\
\hline \hline \multirow{5}{*}{ meio } & $7.119(\mathrm{~b})$ & 0,15 & 36,8 & 3,6 & 7,3 & 0,98 \\
& $7.120(\mathrm{~b})$ & 0,50 & 42,1 & 2,1 & 0,9 & 0,99 \\
& $7.121(\mathrm{~b})$ & 0,85 & 0 & 0 & 2,8 & 0,91 \\
\hline \hline \multirow{3}{*}{ centro } & $7.119(\mathrm{c})$ & 0,15 & 0 & 0 & $5,6 \mathrm{~mm}$ & 0,93 \\
& $7.120(\mathrm{c})$ & 0,50 & 26,3 & 10,3 & $5,2 \mathrm{~mm}$ & 0,93 \\
& $7.121(\mathrm{c})$ & 0,85 & 23,7 & 2,6 & $2,6 \mathrm{~mm}$ & 0,98 \\
\hline
\end{tabular}

é muito maior do que a imagem esperada, inclusive em alguns casos o erro no volume $V^{*}$ da imagem obtida ultrapassa $100 \%$ (veja tabela 7.8). Porém, se não estiver na borda do domínio a imagem obtida é mais satisfatória, conforme pode ser confirmada nas imagens das figuras 7.85(b), 7.97(c), 7.109(b) e 7.121(b). Observa-se também pequenas diferenças entre os resultados apresentados nas seções 7.3.7.1 e 7.3.7.2, porém os resultados obtidos a partir do domínio discretizado em elementos quadriláteros (seção 7.3.7.1) produzem imagens com melhor definição para os casos investigados.

Observando as curvas de convergência dos resultados obtidos com $p$ igual a 2, para o caso onde o objeto está posicionado na borda do domínio (figuras 7.86(a), 7.89(a), 7.92(a), 7.110(a), 7.113(a) e 7.116(a)), nota-se que a função objetivo, após cair a um valor mínimo em poucas iterações (geralmente 10 iterações somente), 
permanece com altas oscilações durante o restante das iterações. Porém, com a aplicação do filtro, nota-se que não há mais iterações cujo valor da função objetivo seja maior do que o valor da função no início do processo, conforme observado nos resultados mostrado nas seções 7.3.7.1 e 7.3.7.2. No entanto, os resultados obtidos com $p$ igual a 4 apresentam este problema e, conseqüentemente, mostram imagens com resolução inferior as obtidas com $p$ igual a 2. Além disso, para qualquer um dos casos estudados (veja figura 7.33), os erros observados para o volume $V^{*}$ e para as coordenadas $(x, y)$ do centróide da região da imagem do objeto são maiores nos resultados obtidos com aplicação do fator $p$ igual a 4 , conforme pode ser confirmado nas tabelas 7.8 e 7.10 .

Contudo, os resultados obtidos com aplicação do filtro espacial são satisfatórios. Percebe-se que o filtro atenua e suaviza a mudança da variável de projeto na região da imagem do objeto (região escura), fazendo com que haja uma definição melhor da imagem, sem elementos desconexos. Porém, ele sacrifica os valores de condutividade absoluta dessa região forçando-os para valores menores que o caso sem filtro (apresentado na seção 7.3.6). Na realidade, observando os gráficos 3D de resistividades dos resultados apresentados nas seções 7.3.7.1 e 7.3.7.2 verifica-se que a imagem $3 \mathrm{D}$ da região do objeto tem a forma semelhante a um cone, indicando que os elementos centrais da região da imagem possuem valores de resistividade maiores. Portanto, apesar de obtermos uma imagem melhor definida, os valores de condutividade (ou resistividade) não são uniformes nos elementos da região da imagem do objeto.

Diferentemente dos resultados apresentados nas seções 7.3.7.1 e 7.3.7.2, os gráficos 3D de resistividades mostram que em todos os três casos estudados, com aplicações distintas do valor inicial das variáveis de projeto $\left(\rho_{k}^{0}\right)$ e do fator $p$, os valores de resistividades dos elementos da região da imagem do objeto não atingem o valor máximo de resistividade esperado $\left(10^{6} \Omega \mathrm{m}\right)$, exceto para o caso da imagem mostrada na figura 7.95(b), cujo gráfico de resistividades é mostrado na figura 7.99(b). Isto também pode ser verificado nas tabelas apresentadas nesta seção e nas seções 7.3.7.1 e 7.3.7.2, onde mostram que o valor máximo de pseudo-densidade $\left(\rho_{k}^{\max }\right)$ da região da imagem do objeto foi obtido abaixo do esperado $\left(\rho_{k}=1\right)$. Conclui-se que, neste caso, o filtro restringe bastante o processo de obtenção da imagem de tal forma a não aceitar diferenças elevadas nas variáveis de projeto, indicando que outras soluções devem ser adotadas para se elevar os valores de resistividades para próximo do valor adotado, porém deve ser aproveitada a eficiência do filtro em definir melhor a imagem. 


\subsubsection{Utilizando o Método da Continuação}

Como visto na seção 7.3.7, o filtro espacial auxiliou o TOMOGOT a obter a imagem do objeto de uma forma mais nítida, porém aumentou a quantidade de pseudo-densidades intermediárias obtidas. Isto pode ser confirmado observando-se os valores de $\rho_{k}^{\max }$ (menores que 1) mostrados nas tabelas da seção seção 7.3.7. Por outro lado, quando utilizado o fator $p$ igual a 4 nota-se que, apesar dos resultados piores em relação aos resultados com $p$ igual a 2 , os valores de $\rho_{k}^{\max }$ aumentaram para os resultados mostrados na seção seção 7.3.7.

Assim, nesta seção, são mostrados os resultados obtidos com a aplicação do método da continuação descrito na seção 6.5. Neste caso, primeiro inicia-se o processo com $p$ igual a 1 e ao longo das iterações o valor de $p$ é aumentado consecutivamente até um valor de $p$ igual a 6 . Para efeitos de comparação, o método da continuação implementado é testado para a obtenção da imagem do objeto nos três casos distintos mostrados na figura 7.33. A figura 7.131 mostra as imagens obtidas utilizando-se o domínio de obtenção de imagem mostrado na figura 7.25 (discretizado em elementos quadriláteros), a RCM (veja seção 5.3) e o filtro espacial (descrito na seção 6.4). Além disso, o valor inicial da variáveis de projeto $\left(\rho_{k}^{0}\right)$ adotado neste caso é 0,85 e o expoente $q$ da distância $d_{k}$ na RCM permanece o mesmo adotado nos exemplos anteriores. Os gráficos das figuras 7.132, 7.133 e 7.134 mostram as curvas de convergência da função objetivo e a distribuição de resistividades.

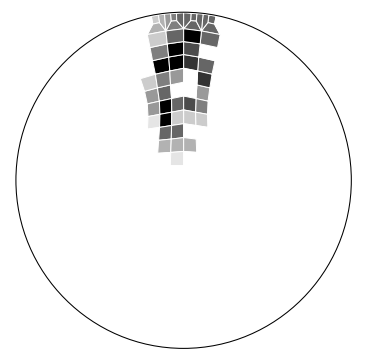

(a) $V^{*}=5,3 \% ; \mathrm{x}=0 ; \mathrm{y}=77,2$

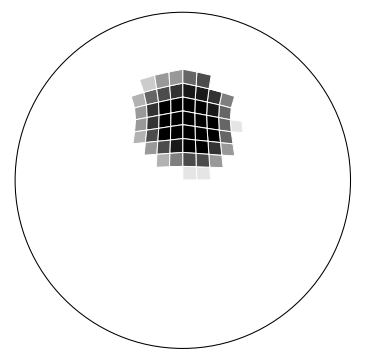

(b) $V^{*}=7,7 \% ; \mathrm{x}=2,7 ; \mathrm{y}=41$

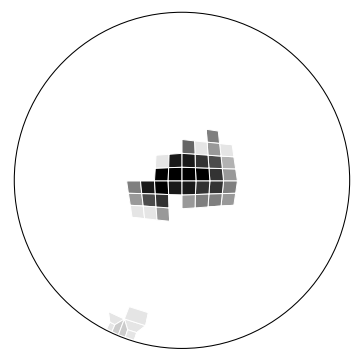

(c) $V^{*}=4,7 \% ; \mathrm{x}=5 ; \mathrm{y}=2,6$

Figura 7.131: Imagens obtidas com o método da continuação $(p=1,2,3,4,5$ e 6), RCM, filtro e $\rho_{k}^{0}=0,85$.

Através dos gráficos de resistividades mostrados nas figuras 7.132(b), 7.133(b) e 7.134(b), pode-se notar que o método da continuação elevou os valores de $\rho_{k}^{\max }$ dos elementos da região da imagem do objeto para valores próximo ou igual ao valor de limite de pseudo-densidade $\left(\rho_{k}=1\right)$, garantindo a alguns elementos dessa região alcançar o valor de condutividade (ou resistividade) esperada. Porém, alguns resultados não foram satisfatórios. Por exemplo, constata-se novamente a 


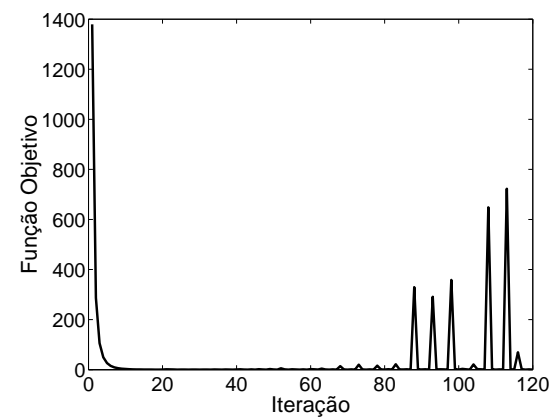

(a) gráfico de convergência

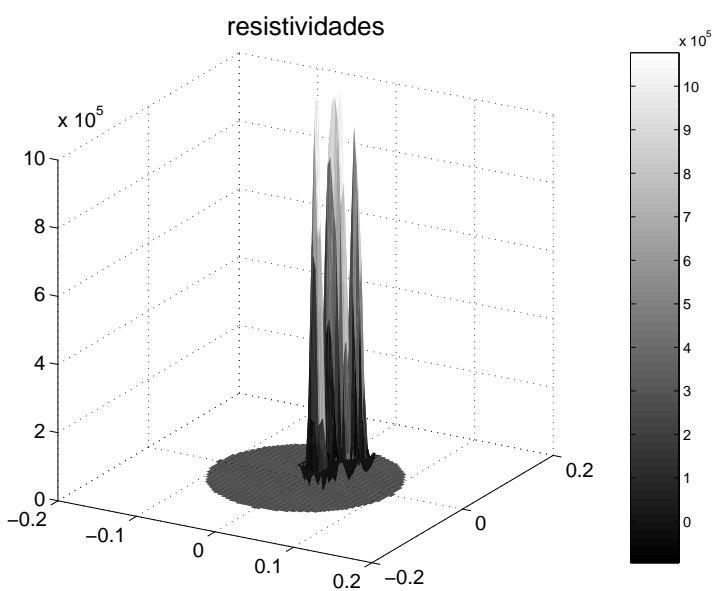

(b) gráfico de resistividades

Figura 7.132: Gráfico de convergência e gráfico de resistividades da imagem mostrada na figura 7.131(a).

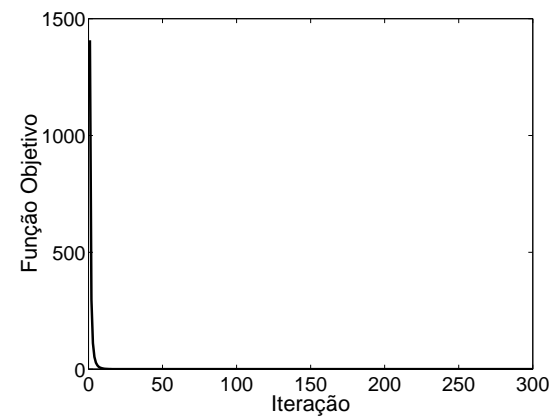

(a) gráfico de convergência

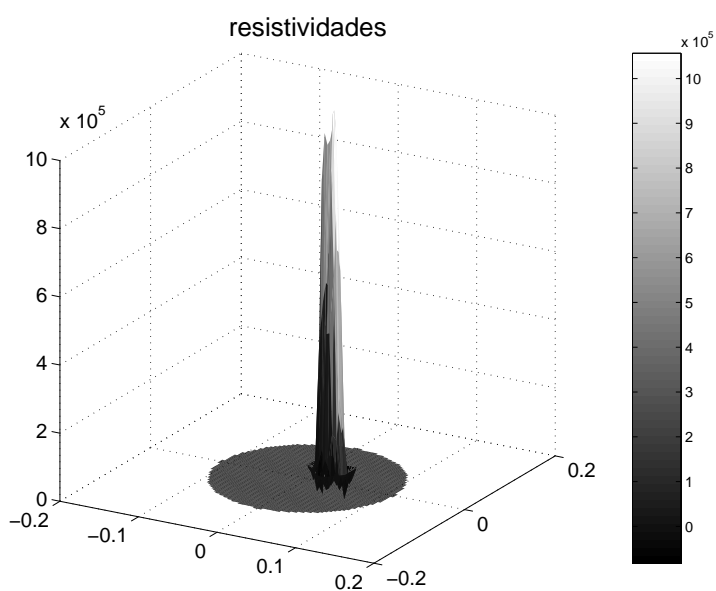

(b) gráfico de resistividades

Figura 7.133: Gráfico de convergência e gráfico de resistividades da imagem mostrada na figura 7.131(b).

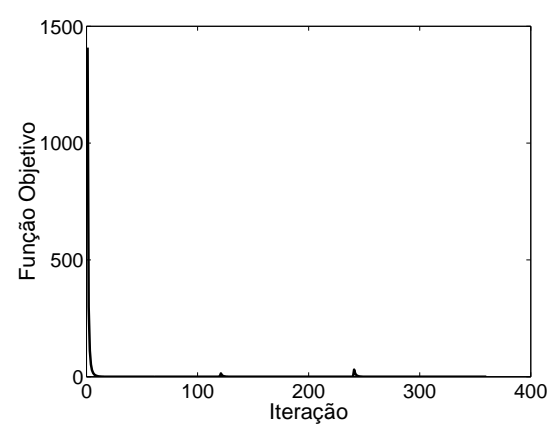

(a) gráfico de convergência

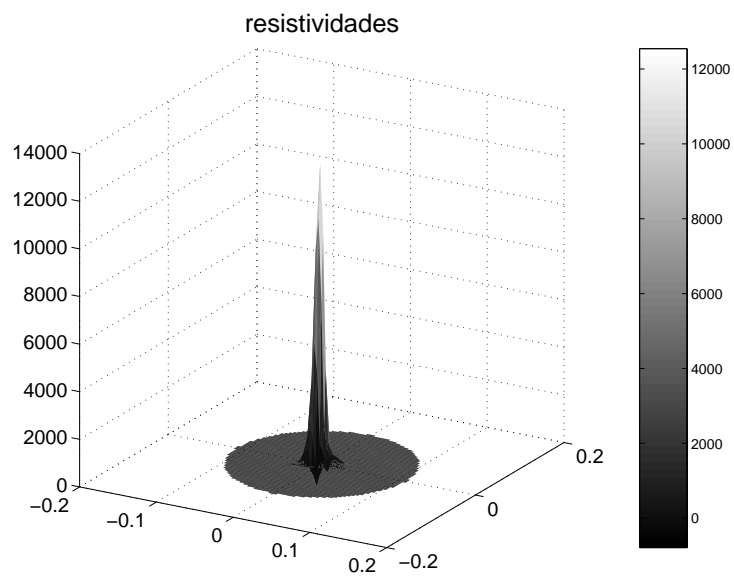

(b) gráfico de resistividades

Figura 7.134: Gráfico de convergência e gráfico de resistividades da imagem mostrada na figura 7.131(c). 
dificuldade do método em definir melhor a geometria do objeto, quando o mesmo está na borda do domínio. Neste caso, apesar dos resultados obtidos com o método da continuação serem melhores que os mostrados na seção 7.3.7, pois foi alcançado o valor esperado de resistividade em todos os casos, podemos notar por exemplo que a região da imagem do objeto (região escura da imagem obtida) não se concentra somente na borda do domínio e os valores de condutividade encontrados para essa região ainda não são uniformes, podendo ser confirmado pela presença de elementos claros e escuros na imagem mostrada na figura 7.131(a).

O tamanho e localização da imagem obtidos (indicados pelos valores de $V^{*}$ e da coordenada $(x, y)$ do centróide da imagem do objeto, respectivamente) para cada caso estudado pode ser visto na figura 7.131. Relembrando que estes valores foram calculados considerando-se valores de pseudo-densidade maior que $80 \%$ do valor máximo de pseudo-densidade obtida, portanto é possível que alguns elementos "cinza" (material intermediário) esteja computado no cálculo do tamanho da imagem. Isso explica os valores elevados encontrados para $V^{*}$ (veja figura 7.131). Comparando o tamanho das imagens obtidas do objeto com o tamanho esperado (3,8\% do volume total do domínio) observa-se que o tamanho da região da imagem do objeto mostrados nas figuras 7.131(a) e 7.131(c) são $39,5 \%$ e $23,7 \%$ maior que o esperado, respectivamente.

Já, o tamanho calculado da região da imagem do objeto mostrada na figura 7.131(b) é aproximadamente duas vezes o tamanho esperado. Isto indica que o método da continuação foi eficaz para o objetivo proposto (elevar os valores de $\rho_{k}$ dos elementos da região da imagem do objeto), pois mantendo o padrão de incluir no cálculo do tamanho da região da imagem do objeto somente valores de pseudo-densidades maiores que $80 \%$ do valor máximo de pseudo-densidade obtida (padrão de corte), que para os resultados mostrados nesta seção é obtido igual a $1\left(\rho_{k}^{\max }=1\right)$, nota-se que há uma grande quantidade de elementos "cinza" (material intermediário) na região da imagem do objeto cuja pseudo-densidades se enquadram nesta faixa, com valores mais próximos ao valor de pseudo-densidade esperada. Há a opção de evitar que esses elementos sejam contabilizados no cálculo do tamanho da região da imagem do objeto aumentado-se o padrão de corte das pseudo-densidades que entram no cálculo. Por exemplo, adotando-se 0,95\% como padrão de corte o tamanho $\left(V^{*}\right)$ da região da imagem do objeto em cada caso mostrado na figura 7.131 seria $1,6 \%, 4,6 \%$ e 2,8\%, respectivamente, e portanto mais próximos do tamanho esperado $\left(V^{*}=3,8 \%\right)$. Porém, para efeitos de comparação entre resultados obtidos neste trabalho, o valor de fator de corte 
adotado até o momento (80\%) será mantido.

Observando as imagens das figuras 7.131(b) e 7.131(c) nota-se que o uso do método da continuação auxiliou a detectar a imagem do objeto para os casos em que o objeto está entre a borda e o centro do domínio, figura 7.33(b), e no centro do domínio, figura 7.33(c). Neste caso, diferentemente dos resultados mostrados na seção 7.3.7, observa-se que nos dois casos o valor máximo de pseudo-densidade $\left(\rho_{k}=1\right)$ da região da imagem do objeto é alcançado e, portanto, obtendo-se os valores de resistividades da região da imagem do objeto próximos ao esperado $\left(10^{6} \Omega m\right)$. Comparando os valores das coordenadas de localização $(x, y)$ do centróide da região da imagem do objeto com o resultado esperado, verifica-se que no caso do resultado mostrado na figura 7.131(b), a região da imagem do objeto apesar de bem definida está localizada a uma distância na direção vertical (eixo y) 22,6\% menor do que a esperada $(y=53 \mathrm{~mm}$ ). Já, para o caso do resultado mostrado na figura 7.131(c), a região está um pouco deslocada na direção horizontal (5 milímetros em relação ao centro do domínio, na direção do eixo $x)$.

Para o caso onde o objeto está posicionado no centro do domínio, a aplicação do método da continuação não apresentou maiores dificuldades em detectar com uma certa precisão a imagem do objeto e, apesar da imagem apresentar uma geometria diferente do objeto cilíndrico, o método conseguiu elevar os valores de resistividades, ora não conseguido nos resultados apresentados na seção 7.3.7. Neste caso, o maior valor de resistividade alcançado é de $1,2 \times 10^{4} \Omega m$, conforme pode ser visto no gráfico da figura 7.134(b). Este valor apesar de ainda distante do valor esperado $\left(10^{6} \Omega m\right)$ é muito maior que o máximo valor de resistividade obtido nos resultados apresentados na seção 7.3.7. Já, os gráficos das figuras 7.132(b) e 7.133(b) mostram que o método da continuação, apesar de deslocar a região da imagem do objeto, melhora os resultados em termos de valores de condutividade (ou resistividade) obtidos, alcançando o valor máximo esperado $\left(10^{6} \Omega m\right)$.

Concluindo, os resultados apresentados nesta seção mostram que é possível aliar as eficiência do filtro espacial em produzir uma imagem melhor definida, porém restringido o problema a valores de condutividade bem abaixo do esperado (conforme visto na seção 7.3.7), e a robustez do método da continuação empregado para elevar gradualmente os valores de condutividades (ou resistividade) na região da imagem do objeto e, assim, garantir uma solução do problema de forma satisfatória. Acredita-se também ser necessário explorar mais a aplicação do máximo fator de penalidade $(p)$ a ser aplicado, para que haja um equilíbrio entre 
a técnica de filtragem empregada e o retorno ao problema discreto (problema de difícil solução) ao aumentar exageradamente o fator $p$.

\subsubsection{Aplicação da Aproximação Contínua de Distribuição de Material ("CAMD")}

Nesta seção são mostrados os resultados obtidos com a aplicação do CAMD ("Continuous Approximation of Material Distribution") que, diferente do modelo de material até então utilizado (veja capítulo 3), permite uma variação contínua da condutividade (ou resistividade) ao longo do domínio do elemento (veja seção 6.6 para maiores detalhes).

Neste caso, a nova versão do TOMOGOT, considerando a rotina que aplica o CAMD, é testado para obter a imagem de TIE dos três casos distintos apresentados na 7.33. As imagens a serem obtidas apresentam a mesma características estudadas até o momento, ou seja, a região escura simula a presença de um objeto cilíndrico de baixa condutividade, $10^{-6}(\Omega m)^{-1}$, e o restante do domínio circular possui condutividade igual a $1 / 17(\Omega m)^{-1}$.

O valor inicial da variáveis de projeto $\left(\rho_{k}^{0}\right)$ adotado neste caso é 0,85 e o expoente $q$ da distância $d_{k}$ na restrição da condutividade média (RCM) é igual 2, exceto para o caso em que a imagem do objeto (região escura) está localizada no centro do domínio, onde é aplicado um expoente $q$ igual a 4. A figura 7.135 mostra as imagens obtidas utilizando-se o domínio de obtenção de imagem discretizado em 576 elementos quadriláteros (veja figura 7.25), a RCM (veja seção 5.3), o método da continuação $(p=1 \quad a \quad 6)$ e o filtro espacial apresentado na seção 6.4. Os gráficos das figuras 7.136, 7.137 e 7.138 mostram as curvas de convergência da função objetivo e a distribuição de resistividades em cada caso estudado.

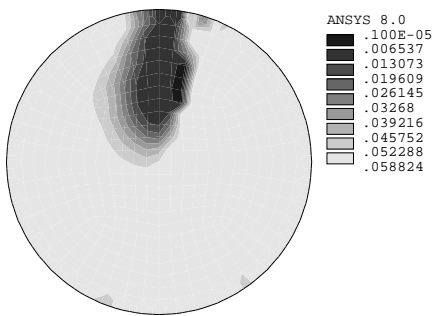

(a) $V^{*}=10,2 \% ; \mathrm{x}=-2,5 ; \mathrm{y}=65,3$

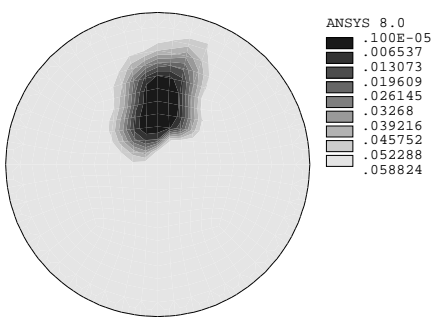

(b) $V^{*}=7,5 \% ; \mathrm{x}=1,6 ; \mathrm{y}=47,3$

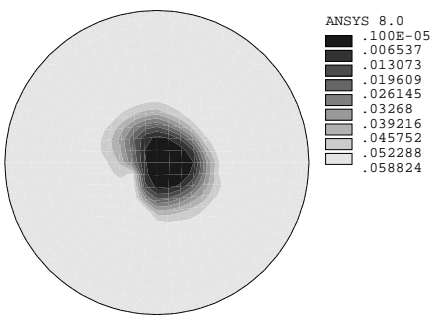

(c) $V^{*}=7,8 \% ; \mathrm{x}=6,8 ; \mathrm{y}=0$

Figura 7.135: Imagens obtidas com a aplicação do CAMD (condutividades em $\left.(\Omega m)^{-1}\right)$.

Observa-se que a visualização da imagem obtida nos resultados com a aplicação do CAMD é realizada interpolando-se o valor das pseudo-densidades 


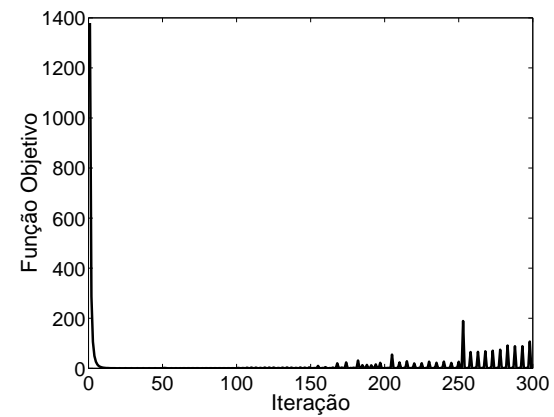

(a) gráfico de convergência

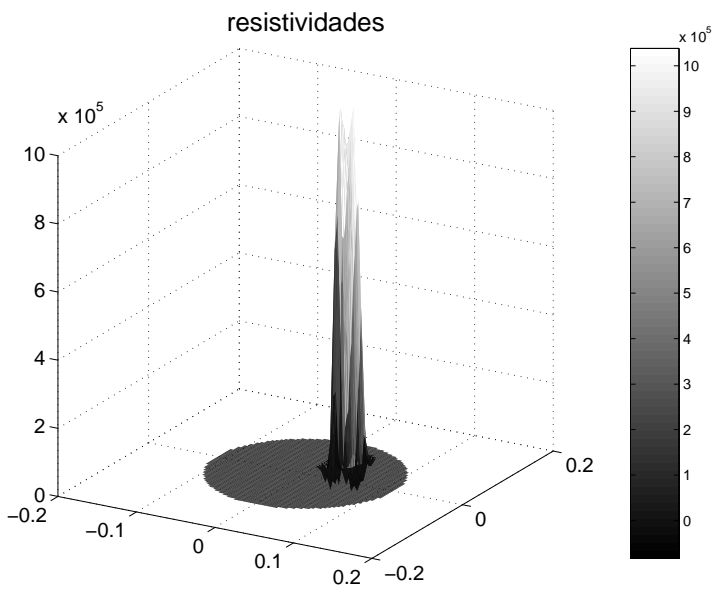

(b) gráfico de resistividades

Figura 7.136: Gráfico de convergência e gráfico de resistividades da imagem mostrada na figura 7.135(a).

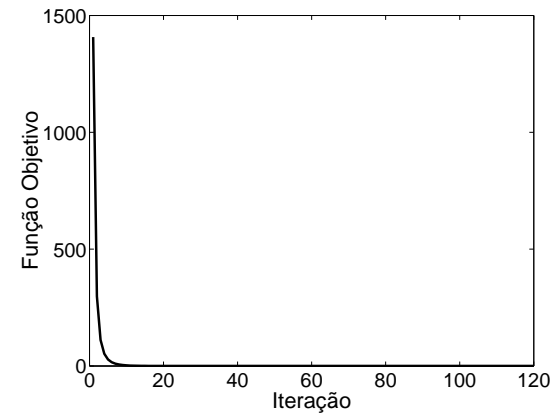

(a) gráfico de convergência

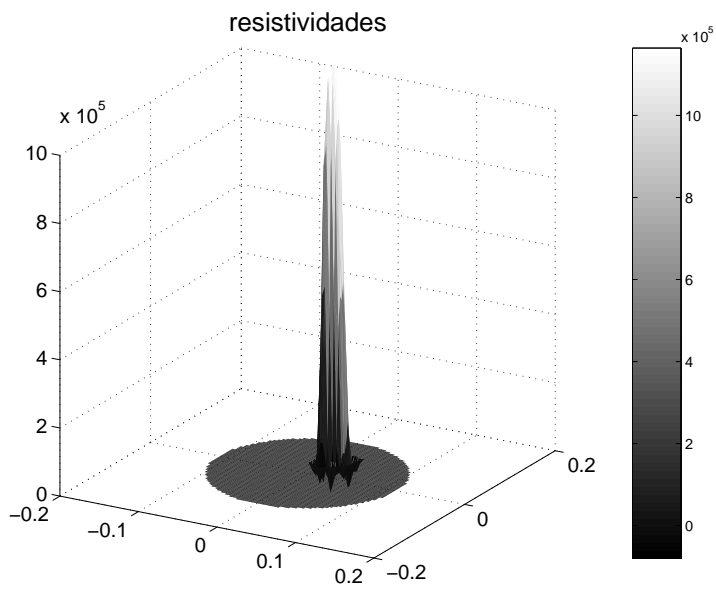

(b) gráfico de resistividades

Figura 7.137: Gráfico de convergência e gráfico de resistividades da imagem mostrada na figura 7.135(b).

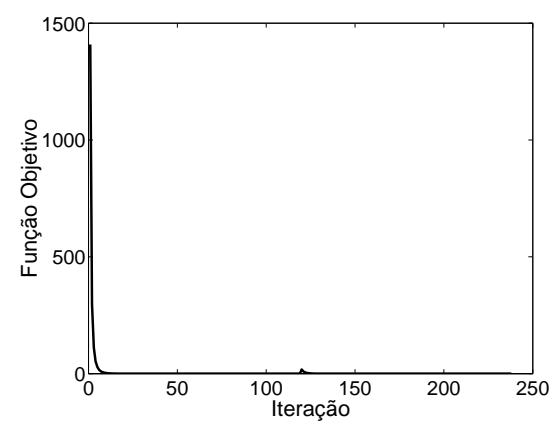

(a) gráfico de convergência

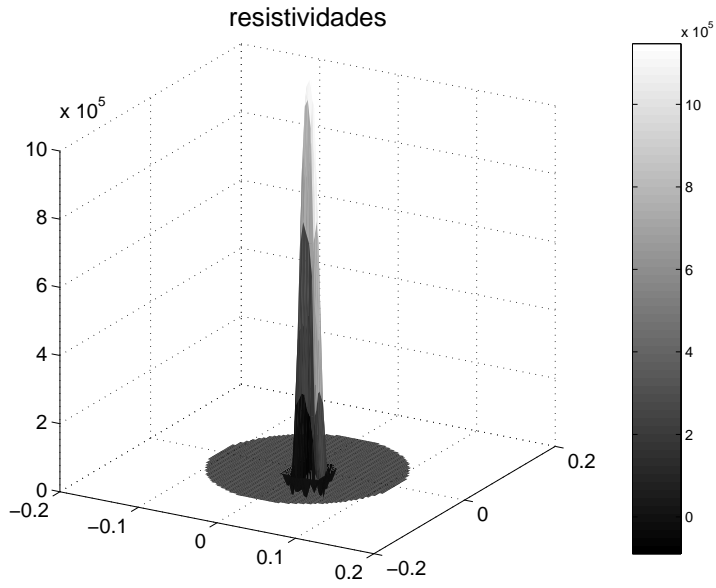

(b) gráfico de resistividades

Figura 7.138: Gráfico de convergência e gráfico de resistividades da imagem mostrada na figura 7.135(c). 
obtidas para os nós do elemento e, portanto, as imagens mostradas nesta seção possuem um aspecto diferente do mostrado nos resultados das seções anteriores. Além disso, cada imagem obtida possui a sua esquerda uma legenda contendo uma escala com valores de condutividades, em $(\Omega m)^{-1}$, alcançados para diferentes regiões do domínio.

Analogamente aos resultados mostrados na seção 7.3.8, constata-se novamente a dificuldade do método em definir melhor a geometria do objeto quando o mesmo está na borda do domínio. Como mostrado nos resultados apresentados na seção 7.3.8, observa-se que o comportamento da função objetivo para este caso, figura 7.136(a), cai a um valor mínimo rapidamente, porém sofre muita oscilações durante as iterações do processo de obtenção da imagem do objeto. Observa-se também, através dos gráficos de resistividades mostrados nas figuras 7.136(b), 7.137(b) e 7.138(b), que o método da continuação elevou os valores de $\rho_{k}^{\max }$ dos elementos da região da imagem do objeto para valores próximo ou igual ao valor limite de pseudo-densidade $\left(\rho_{k}=1\right)$, garantindo a alguns nós dessa região alcançar o valor de condutividade (ou resistividade) esperada.

O tamanho $\left(V^{*}\right)$ da imagem do objeto e a localização $(x, y)$ do centróide, obtidos para cada caso estudado pode ser visto na figura 7.135. Comparando o tamanho das imagens obtidas com o tamanho esperado (3,8\% do volume total do domínio) observa-se que os tamanhos das imagens (região do objeto) mostradas na figura 7.135 estão bem acima do esperado, pelo mesmo motivo apresentado na discussão dos resultados mostrados na seção 7.3.8. Por exemplo, para a imagem mostrada na figura 7.135(a) (objeto na borda do domínio) a medida $V^{*}$ é aproximadamente 2,5 vezes maior que o valor esperado. Isto indica que a aplicação do CAMD alcançou também o objetivo de elevar os valores de $\rho_{k}$ dos elementos da região da imagem do objeto, já que mantido o padrão de corte das pseudo-densidades (80\%), que entra no cálculo de $V^{*}$, mais nós com valores intermediários de pseudo-densidades são encontrados na região da imagem do objeto e portanto contribuindo para o aumento no tamanho da imagem do objeto, conforme descrito na seção 7.3.8.

A imagem da figura 7.135(c) mostra que a aplicação do CAMD auxiliou a detectar sem dificuldades a imagem do objeto para o caso em que o mesmo está no centro do domínio, com um deslocamento mínimo de 6,8 milímetros na direção horizontal (eixo $x$ ) em relação ao centro do domínio. Comparando os valores das coordenadas de localização $(x, y)$ do centróide da região da imagem do objeto mostrada na figura 7.135(b) com o resultado esperado, verifica-se um erro menor na localização da imagem em relação ao obtido somente com a aplicação do 
método da continuação (veja seção 7.3.8). No caso, a região da imagem do objeto está localizada a uma distância em relação ao centro do domínio, na direção do eixo $y, 10,7 \%$ menor do que a esperada.

Para concluir, a tabela 7.11 mostra uma comparação entre resultados obtidos sem a aplicação do CAMD (apresentados na seção 7.3.8) e com aplicação do CAMD (apresentados nesta seção) para os três casos estudados (veja figura 7.33), considerando um padrão de corte de 100\%, ou seja, os valores de $V^{*}$ e da coordenada $(x, y)$ do centróide da imagem do objeto são calculados considerando-se somente valores de $\rho_{k}$ obtidos igual a 1 (máximo esperado).

Tabela 7.11: Comparação entre resultados obtidos para $V^{*}$ e para a coordenada $(x, y)$ (dadas em milímetros), sem e com aplicação do CAMD

\begin{tabular}{|c||c|c|c||c|c|c|}
\hline \multicolumn{1}{|c||}{ posição } & \multicolumn{3}{c||}{ sem CAMD } & \multicolumn{3}{c|}{ com CAMD } \\
\cline { 2 - 7 } & $V^{*}$ & $\mathrm{x}$ & $\mathrm{y}$ & $V^{*}$ & $\mathrm{x}$ & $\mathrm{y}$ \\
\hline borda & $1,4 \%$ & $-6,9$ & 75,7 & $0,8 \%$ & 17,9 & 59,7 \\
meio & $0,7 \%$ & 6,2 & 39,5 & $0,9 \%$ & 3,3 & 49,3 \\
centro & $0,2 \%$ & $-4,7$ & 4,7 & $1,1 \%$ & 3,7 & $-1,8$ \\
\hline
\end{tabular}

OBSERVAÇÃO: A coluna "posição" da tabela 7.11 refere-se as três diferentes posições do objeto no domínio, conforme mostrado nas figuras 7.33(a) ("borda"), 7.33(b) ("meio") e 7.33(c) ("centro").

Através dos dados apresentados na tabela 7.11, conclui-se que houve um pequeno ganho nos resultados com aplicação do CAMD, exceto para o caso onde o objeto está posicionado na borda do domínio. O ganho maior é observado para o caso em que o objeto se encontra no centro do domínio. Neste caso, a aplicação do CAMD propiciou obter a região da imagem do objeto com tamanho $\left(V^{*}\right) 5,5$ vezes maior que a obtida sem aplicação do CAMD, além de obtê-la menos deslocada (veja coordenadas $(x, y)$ na tabela 7.11). Porém, apesar do ganho alcançado com a aplicação do CAMD, observa-se que os valores obtidos em ambos os resultados (sem e com aplicação do CAMD) estão aquém do valores esperados.

\subsection{Resultados Obtidos a Partir de Dados Experimentais}

Explorado vários aspectos do método otimização topológica aplicado a TIE, a partir deste ponto é investigado o comportamento do TOMOGOT em lidar com dados obtidos de fantomas experimentais. 
Os resultados mostrados nesta seção são obtidos a partir de dados (potenciais elétricos) extraídos de uma fantoma experimental, com 32 eletrodos, pertencente ao grupo de pesquisa do Prof. Dr. Raul Gonzalez Lima, do Departamento de Engenharia Mecânica da Escola Politécnica da USP, e de um protótipo de um aparelho de TIE, que utiliza um fantoma com 30 eletrodos, pertencente ao Laboratório de Cardio-Pneumologia (LIM 09), coordenado pelo Prof. Dr. Marcelo Britto Passos Amato, da Escola de Medicina da USP. Ambos os fantomas são recipientes (ou cubas) circulares, com meio salino, análogos aos encontrados na literatura e utilizados nos experimentos de diversos pesquisadores em TIE, com o intuito de simplificar o problema de obtenção de imagem (PAULSON; BRECKON; PIDCOCK, 1992; FUKS, 1991).

Nos resultados apresentados nesta seção, as otimizações dos parâmetros de eletrodos e distribuição de condutividades são executadas de maneira alternada, como descrito na seção 6.3. A estimativa dos parâmetros de eletrodos é feita a partir de potenciais elétricos de um meio homogêneo, ou seja, neste caso aproveita-se o conjunto de potenciais elétricos medidos no fantoma $\left(\phi_{\mathrm{ij} 0}\right)$ considerando que no interior do mesmo haja somente o meio salino. Nesta etapa, o algoritmo do método implementado "congela a imagem" de um meio conhecido (meio homogêneo) e toma como variável de otimização os parâmetros de eletrodos $\left(\rho t_{j}\right)$. Depois de estimado os parâmetros de eletrodos, o software realiza a otimização da distribuição de material $\left(\rho_{k}\right)$ no interior do domínio. O software repete o processo, conforme fluxograma mostrado na figura 6.4 do capítulo 6 , alternando as otimizações até a convergência.

A seguir, são detalhados as características principais de cada um dos fantomas experimentais e os resultados obtidos a partir dos valores de potenciais elétricos extraídos desses fantomas.

\subsubsection{Utilizando o Fantoma com 32 Eletrodos}

Nesta bancada, o fantoma experimental possui uma cuba construída a partir de um tubo de PVC de 230 milímetros de diâmetro, sobre uma base circular de vidro de 8 milímetros de espessura (MOLINA, 2002). O fantoma possui 32 eletrodos (chapas de bronze com $10 \mathrm{~mm}$ de largura, $60 \mathrm{~mm}$ de altura e $1 \mathrm{~mm}$ de espessura) espaçados de maneira equidistance e fixados através de parafusos nas suas paredes verticais, conforme mostrado na figura 7.139.

A cuba do fantoma é preenchida com solução salina, com concentração de 0.3 gramas de sal para 1,3 litros de água destilada, até a altura de 35 milímetros. 


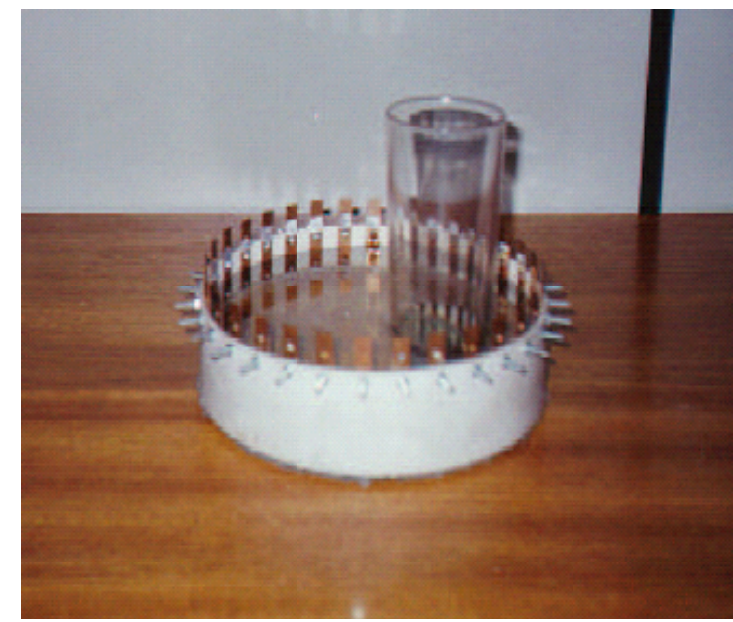

Figura 7.139: Fantoma experimental com solução salina, 32 eletrodos e um copo de vidro inserido (cortesia do Prof. Raul Gonzalez Lima).

A resistividade desse meio salino é considerada igual a $17 \Omega m$. Dentro da cuba do fantoma foi colado um objeto cilíndrico de vidro (copo) de 60 milímetros de diâmetro, que corresponde a $6,8 \%$ do volume da cuba, e posicionado conforme mostrado na figura 7.139. A resistividade do objeto cilíndrico é considerada igual a $10^{6} \Omega m$.

Desta forma, utilizando as malhas de MEF mostradas nas figuras 7.25 e 7.26, que discretiza o domínio de obtenção de imagem em 576 elementos quadriláteros e 1248 elementos triangulares, respectivamente, obtém-se os resultados apresentados nesta seção. Neste caso, são utilizados para obtenção das imagens a restrição da condutividade média (RCM) com expoente $q$ da distância $d_{k}$ igual 2 (veja seção 5.3), o filtro espacial com raio de abrangência que envolve aproximadamente oito elementos vizinhos em torno de um elemento central (veja seção 6.4) e o método da continuação apresentado na seção 6.5, que inicia o processo com $p$ igual a 1 e ao longo das iterações aumenta o valor de $p$ consecutivamente até um valor igual a 6 .

Os valores de potenciais elétricos $\left(\phi_{\mathrm{ij0}}\right)$, utilizados para a obtenção das imagens do objeto cilíndrico no interior da cuba do fantoma, são obtidos através da aplicação do padrão adjacente de excitação elétrica (veja figura 7.2) nos eletrodos do fantoma. A corrente elétrica aplicada é igual a 1 miliampère. Além disso, o valor inicial da variáveis de projeto $\left(\rho_{k}^{0}\right)$ no processo de otimização topológica é adotado igual a 0,85.

A figura 7.140 mostra a imagem obtida utilizando-se o domínio de obtenção de imagem discretizado em 576 elementos quadriláteros (figura 7.25), bem como o gráfico de convergência da função objetivo. A região escura simula a presença 
do objeto cilíndrico de baixa condutividade, $10^{-6}(\Omega m)^{-1}$, e o restante do domínio (região clara) representa o material de maior condutividade, $1 / 17(\Omega m)^{-1}$. O gráfico da figura 7.141 mostram o perfil da distribuição de resistividades encontrada.

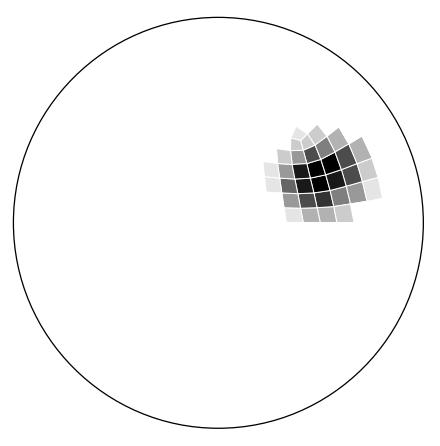

(a) imagem obtida

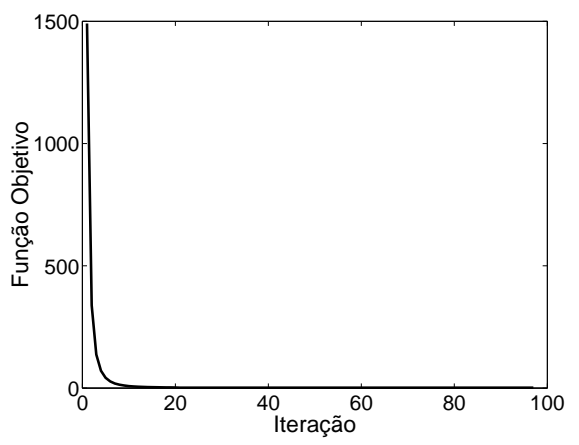

(b) gráfico de convergência

Figura 7.140: Resultado obtido com dados experimentais, elementos quadriláteros e considerando o padrão adjacente.

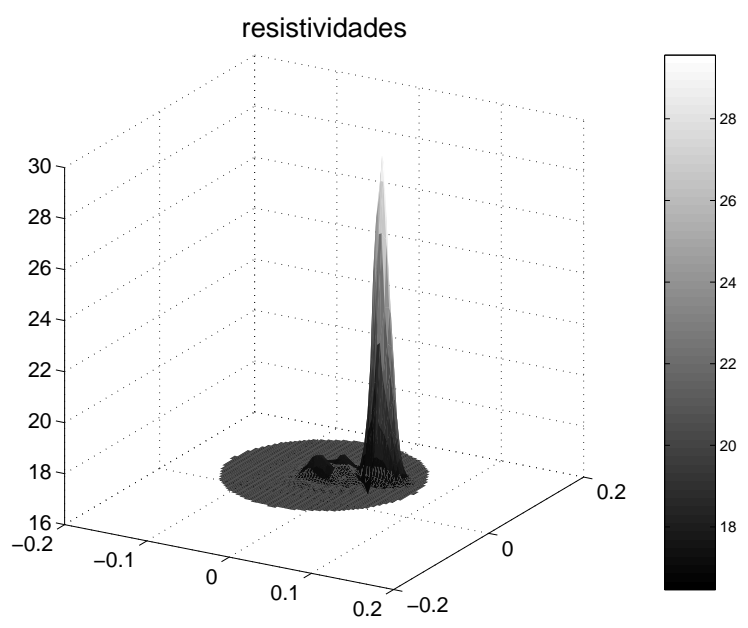

Figura 7.141: Gráfico de resistividades da imagem mostrada na figura 7.140(a).

Através da imagem mostrada na figura 7.140(a) conclui-se que o TOMOGOT é capaz de detectar a presença do objeto cilíndrico (copo de vidro) no interior da cuba experimental. O comportamento da convergência da função objetivo segue o padrão até então observado em todos os resultados apresentados neste trabalho, ou seja, a função objetivo cai a um valor mínimo em poucas iterações ( 20) e permanece o restante do processo iterativo com uma pequena oscilação, conforme pode ser visto no gráfico da figura 7.140(b).

Conforme dissertação de Molina (2002), sabe-se que o copo está posicionado entre os eletrodos 5 e 9 (veja ilustração na figura 7.142), sendo que a informação do valor da coordenada $(x, y)$ da posição do copo na cuba do fantoma não é conhecida. Assim, podemos observar através dos resultados das figura 7.140 que 


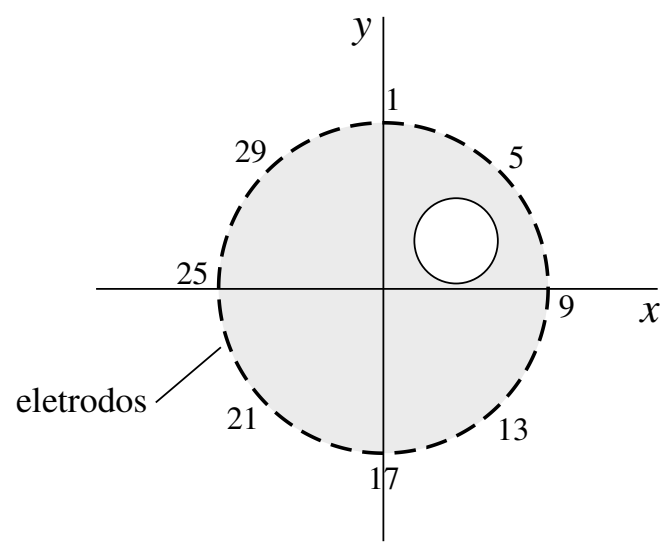

Figura 7.142: Ilustração da posição do copo de vidro na cuba com 32 eletrodos.

a imagem é obtida na posição esperada (entre os eletrodos 5 e 9), sendo que o resultado mostra que as coordenadas do centro do copo em relação a direção horizontal $(x)$ e vertical $(y)$, que passa pelo centro do domínio, são iguais a 58 e 26 milímetros, respectivamente. O tamanho da imagem $\left(V^{*}\right)$ é obtido com $6,3 \%$ do volume da cuba, que corresponde um erro de aproximadamente $7 \%$ em relação ao volume esperado $\left(V^{*}=6,8 \%\right)$. Porém, verifica-se através do gráfico de resistividades da figura 7.141 que os valores absolutos de resistividades (ou condutividades) da região que denota a presença do copo (região escura da imagem) são obtidos muito aquém do valor esperado $\left(10^{6} \Omega m\right)$.

Neste caso, nota-se que o filtro auxilia na definição da imagem, porém restringe bastante o problema de otimização topológica, de maneira a não permitir variações bruscas entre os valores das variáveis de projeto na região de baixa resistividade (meio salino) e alta resistividade (copo de vidro). Assim, com o intuito de melhorar esse aspecto do resultado obtido, adota-se a estratégia de desligar o filtro nas últimas iterações do processo de obtenção de imagem para que o método, a partir da imagem definida, possa acomodar diferenças elevadas nas variáveis de projeto e, conseqüentemente, definir melhor os valores de condutividade ou resistividade da região da imagem do objeto cilíndrico.

Desta forma, a figura 7.143(a) mostra a imagem obtida com o domínio de obtenção de imagem discretizado em 576 elementos quadriláteros e desligando-se o filtro nas cinco últimas iterações do processo de obtenção de imagem realizado pelo TOMOGOT. Os demais parâmetros utilizados para obtenção do resultado anterior (figura 7.140) são mantidos. O gráfico da figura 7.143(b) mostra o novo perfil da distribuição de valores absolutos de resistividades encontrados.

Através do resultado mostrado na figura 7.143 podemos notar que o TOMOGOT detecta a presença do objeto cilíndrico (copo de vidro) no interior 


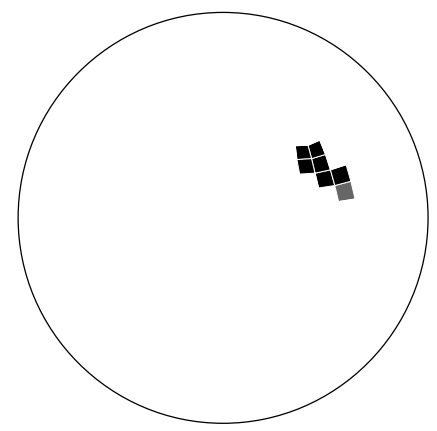

(a) imagem obtida

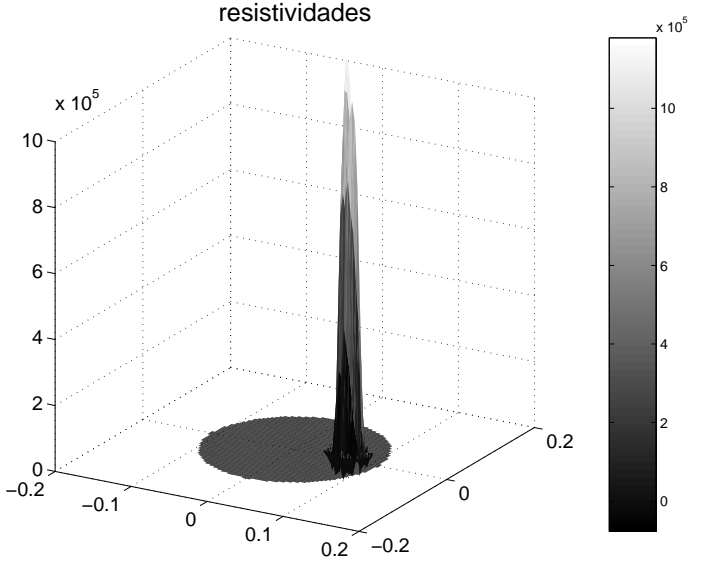

(b) gráfico de resistividades

Figura 7.143: Resultado obtido com dados experimentais, elementos quadriláteros e desligando o filtro nas cinco últimas iterações.

da cuba do fantoma, posicionado entre os eletrodos 5 e 9. Porém, o tamanho da imagem do objeto cilíndrico é obtida com 1,3\% do volume da cuba e portanto muito menor que o tamanho da imagem alcançado no resultado apresentado na figura 7.140, obtido sem a estratégia de desligar o filtro nas últimas iterações. Porém, o gráfico da figura 7.143(b) mostra que os valores de resistividades esperados para o meio salino $(17 \Omega m)$ e para o objeto cilíndrico $\left(10^{6} \Omega m\right)$ foram alcançados.

Para efeitos de comparação, a figura 7.144 mostra a imagem obtida (distribuição de condutividades) e o gráfico da distribuição de resistividades encontrada, utilizando-se o domínio discretizado em 1248 elementos triangulares (figura 7.26). Neste caso, o filtro também é desligado nas cinco últimas iterações e adotado os mesmos parâmetros utilizados nos resultados apresentados anteriormente nesta seção. Através dos resultados apresentados na figura 7.144 podemos observar que a imagem é obtida na posição esperada (entre os eletrodos 5 e 9), bem como os valores de resistividades (ou condutividades) esperados para o meio salino e para o objeto cilíndrico. No entanto, o tamanho da imagem encontrada ( $2 \%$ do volume da cuba) ainda é menor que o valor esperado $(6,8 \%$ do volume da cuba), porém $54 \%$ maior que o tamanho da imagem obtida no resultado apresentado na figura 7.143 .

A seguir, são apresentados os resultados utilizando-se a aproximação contínua de distribuição de material no elemento (CAMD), descrita na seção 6.6 e que é aplicada como tentativa de melhorar o resultado em termos do tamanho e forma da imagem obtida para o objeto cilíndrico. Assim, nas figuras 7.145 e 7.146 são mostrados as imagens obtidas (em termos de condutividade) e o gráfico de 


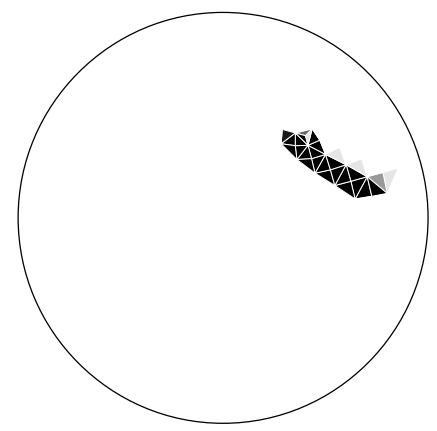

(a) imagem obtida

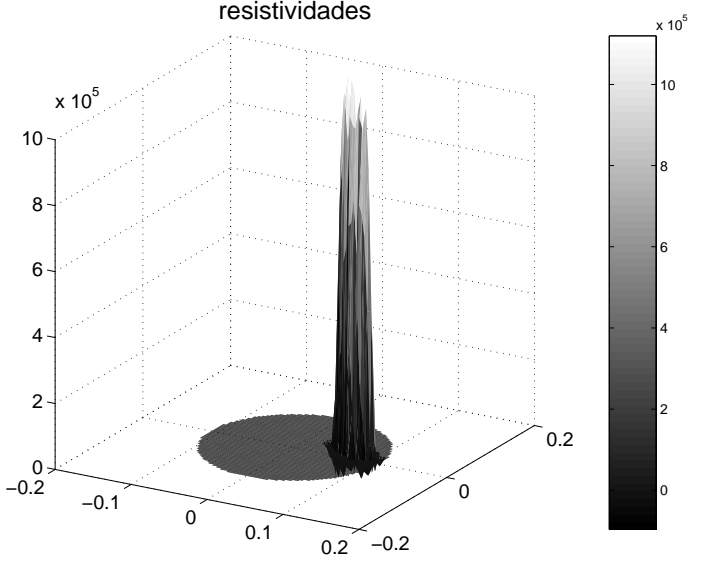

(b) gráfico de resistividades

Figura 7.144: Resultado obtido com dados experimentais, elementos triangulares e desligando o filtro nas últimas iterações.

distribuição de resistividades ao longo do domínio, alcançados com a aplicação do CAMD, a RCM, o método da continuação e desligando o filtro nas cinco últimas iterações. Os demais parâmetros são os mesmos utilizados nos resultados apresentados anteriormente nesta seção. Especificamente, a figura 7.145 mostra os resultados obtidos utilizando-se o domínio de obtenção de imagem discretizado em 576 elementos quadriláteros e a figura 7.146 mostra os resultados obtidos a partir do domínio discretizado em 1248 elementos triangulares.

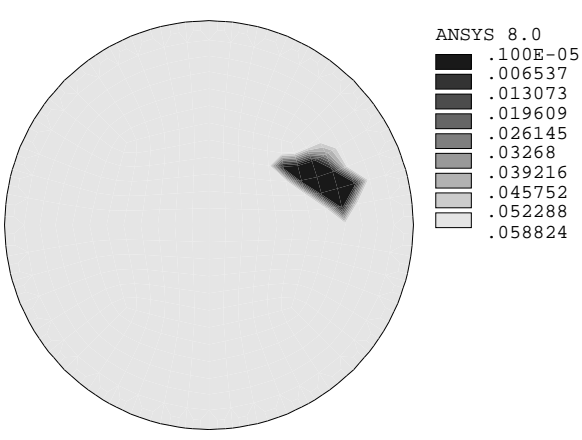

(a) imagem obtida

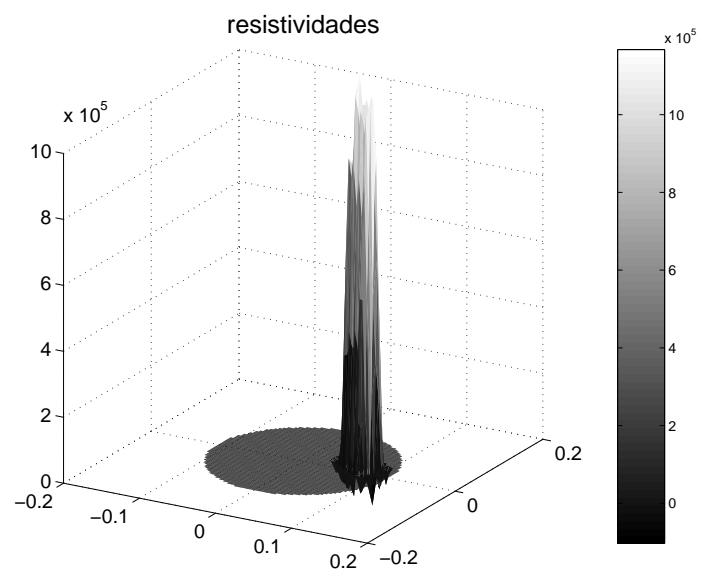

(b) gráfico de resistividades

Figura 7.145: Resultado obtido com dados experimentais, utilizando o CAMD e malha de obtenção de imagem com 576 elementos quadriláteros.

Conforme pode ser visto nos resultados apresentados nas figuras 7.145 e 7.146, a aplicação do CAMD melhorou consideravelmente a qualidade da imagem da região que corresponde a presença do copo de vidro no domínio, obtendo-a na posição correta (entre os eletrodos 5 e 9) e confirmando o valor de 26 milímetros para a distância entre o centro da imagem do copo e o centro do domínio, na direção do eixo vertical $(y)$. Já a distância do centro da imagem do copo na 


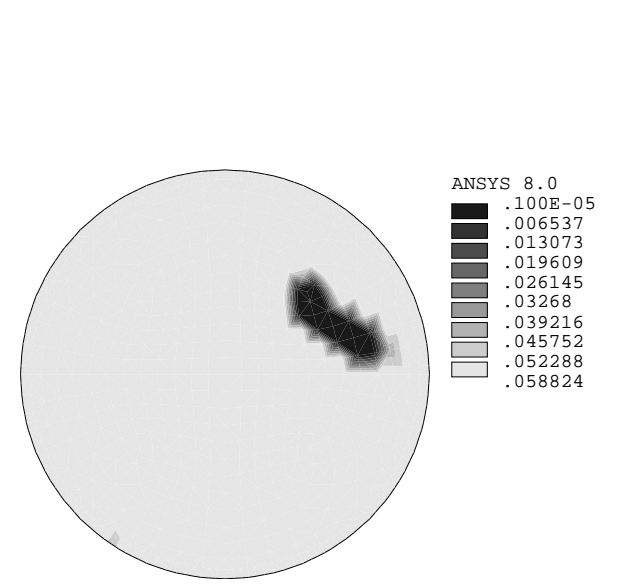

(a) imagem obtida

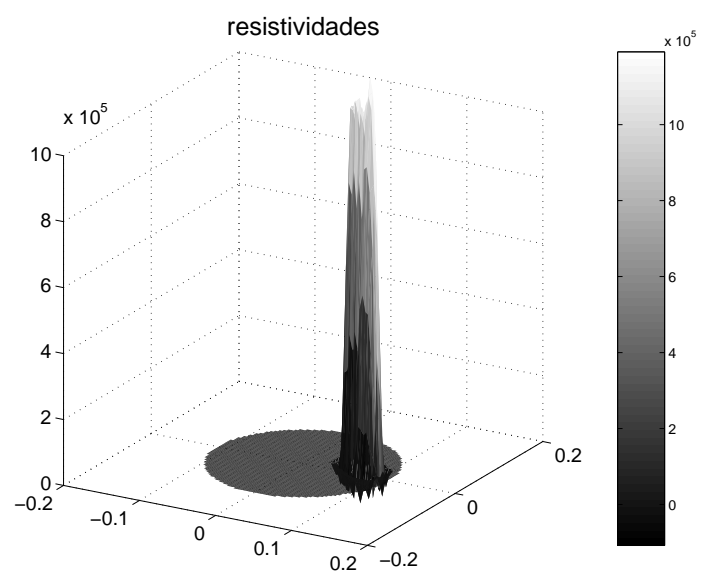

(b) gráfico de resistividades

Figura 7.146: Resultado obtido com dados experimentais, utilizando o CAMD e malha de obtenção de imagem com 1248 elementos triangulares.

direção do eixo horizontal $(x)$ que passa pelo centro do domínio foi atualizada para 62 milímetros. Além disso, o tamanho das imagens mostradas nas figuras 7.145(a) e 7.146(a) são maiores se comparadas as imagens obtidas nos resultados mostrados nas figuras 7.143 e 7.144, que não utilizam o CAMD. Precisamente, o tamanho da imagem do copo obtida a partir do domínio discretizado em elementos quadriláteros, figura 7.145(a), corresponde a $2,2 \%$ do volume da cuba (69\% maior que o tamanho da imagem do copo mostrada na figura 7.143(a)) e o tamanho da imagem do copo obtida a partir do domínio discretizado em elementos triangulares, figura 7.146(a), corresponde a 3.6\% do volume da cuba, ou seja, $80 \%$ maior que o tamanho da imagem do copo mostrada na 7.144(a).

Observa-se também que os valores absolutos de resistividades tanto da região que corresponde ao meio salino como a do copo de vidro (região escura das imagens) são obtidos muito próximos dos valores esperados, inclusive com vários pontos (nós da malha do domínio discretizado) da região de alta resistividade (região do objeto cilíndrico) alcançando o valor respectivo $\left(10^{6} \Omega m\right)$, conforme pode ser visto nos gráficos das figuras 7.145(b) e 7.146(b). Conclui-se então que, particularmente neste caso a aplicação do CAMD é a melhor opção para se trabalhar com o TOMOGOT para obter a imagem de TIE a partir de dados experimentais obtidos através do padrão adjacente de excitação de corrente elétrica.

\subsubsection{Utilizando o Fantoma com 30 Eletrodos}

O fantoma com 30 eletrodos do protótipo de um aparelho de TIE, utilizado no Laboratório de Cardio-Pneumologia (LIM 09) da Escola de Medicina da USP, 


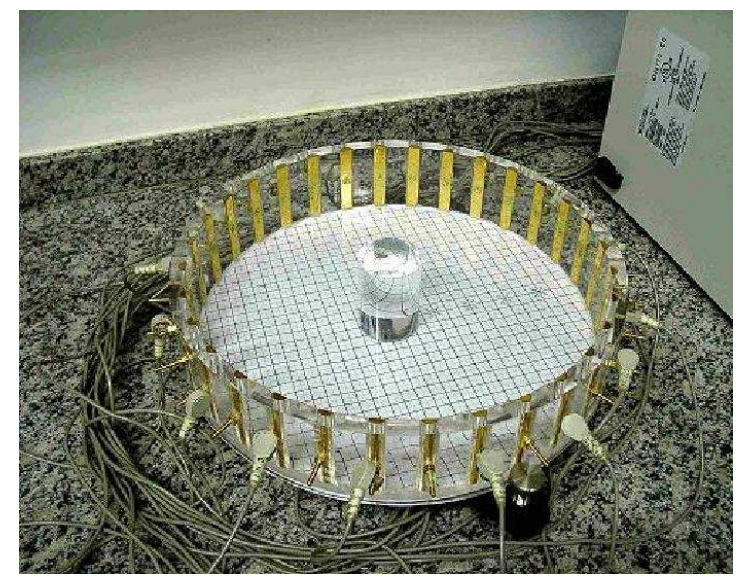

Figura 7.147: Fantoma experimental com solução salina, 30 eletrodos e um objeto cilíndrico de acrílico inserido (cortesia do Prof. Raul Gonzalez Lima).

possui uma cuba circular construída em material acrílico incolor de diâmetro igual a 300 milímetros, conforme mostrado na figura 7.147. Os eletrodos de aço folheados a ouro tem formato de um meio cilindro, embutido na parede da cuba e ficando o lado plano em contato com 50 milímetros de altura de solução salina.

Dentro da cuba do fantoma, um objeto cilíndrico de acrílico de 32 milímetros de diâmetro é colocado em três posições diferentes: no centro da cuba, na borda da cuba e entre o centro e a borda da cuba, similar aos casos mostrados na figura 7.33. A resistividade do objeto cilíndrico é considerada igual a $10^{6} \Omega m$. O recipiente da cuba do fantoma é preenchido com solução salina cuja resistividade é considerada igual a $35 \Omega m$.

Neste caso, os valores de potenciais elétricos $\left(\phi_{\mathrm{ij0}}\right)$, utilizados para a obtenção das imagens das três posições do objeto cilíndrico no interior da cuba do fantoma, são medidos de forma "diferencial" no protótipo do aparelho de TIE do LIM 09, ou seja, o valor de potencial elétrico considerado em cada eletrodo é uma medida referente a diferença $(\Delta \phi)$ entre os valores dos potenciais elétricos de dois eletrodos extremos de um conjunto de três eletrodos (esquema "pula um"). A figura 7.148 ilustra o esquema de excitação elétrica adotado pelo grupo de pesquisa do Laboratório de Cardio-Pneumologia (LIM 09) da Escola de Medicina da USP, onde $I$ é a corrente elétrica e $\Delta \Phi$ é a diferença entre potenciais elétricos dos eletrodos. As medidas de potenciais "diferenciais" vizinhas aos eletrodos em que se injeta e retira a corrente elétrica são desprezadas.

Na medida "diferencial" de potencial elétrico o "aterramento" não é considerado e, desta forma, acredita-se minimizar os erros oriundos do processo de medição dos potenciais elétricos através do aparato eletrônico do tomógrafo de TIE, segundo conclusão do grupo de pesquisa do LIM 09 coordenado pelo Prof. 


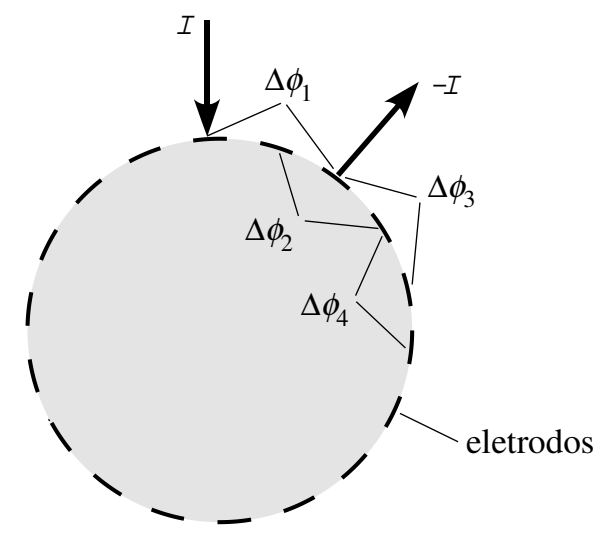

Figura 7.148: Esquema para medição dos potenciais elétricos na forma "diferencial".

Dr. Marcelo Britto Passos Amato.

A rotina que realiza a análise de MEF do software TOMOGOT é baseada na vinculação de pelo menos um dos nós da malha do modelo do domínio, de forma que o sistema de equações resolvido pelo MEF seja determinado, ou seja, possua uma solução viável. Neste caso, a vinculação é feita a partir da atribuição de um valor de potencial elétrico nulo ("aterramento") a um dos nós que corresponde ao elemento de eletrodo. Porém, os dados fornecidos pelo grupo do LIM 09 são medidas de diferenças de potenciais elétricos obtidas não em relação a um ponto de "aterramento" mas sim entre dois valores de potenciais elétricos medidos em eletrodos próximos (conforme esquema da figura 7.148). Assim, para utilizar esses dados no TOMOGOT, primeiro a rotina de MEF do software determina os valores de potenciais elétricos do domínio, considerando o "aterramento", e depois executa a diferença entre os valores de potenciais elétricos obtidos para os 30 nós correspondentes aos elementos de eletrodos no modelo de MEF do domínio, seguindo também o esquema ilustrado na figura 7.148. Esses valores calculados são utilizados para o cálculo da função objetivo do problema de otimização topológica resolvido pelo TOMOGOT e, conseqüentemente, para estimação da distribuição de condutividades do domínio de projeto (imagem desejada). Observa-se que, desta maneira, o cálculo dos gradientes da função objetivo em relação as variáveis de projeto do método proposto é reformulado e, assim, uma nova versão do TOMOGOT é criada para atender essa nova configuração. A reformulação do cálculo dos gradientes da função objetivo é descrita no anexo A.

A corrente elétrica injetada e retirada no par de eletrodos do esquema de excitação elétrica utilizado (veja figura 7.148) é igual a 2 miliampères. Além disso, o valor inicial das variáveis de projeto $\left(\rho_{k}^{0}\right)$ no processo de otimização topológica 
é adotado igual a 0,85. Desta forma, utilizando a malha MEF mostrada na figura 7.149, que discretiza o domínio de obtenção de imagem em 934 elementos triangulares de 3 nós, com 30 elementos de eletrodos igualmente espaçados, obtêm-se os resultados apresentados a seguir.

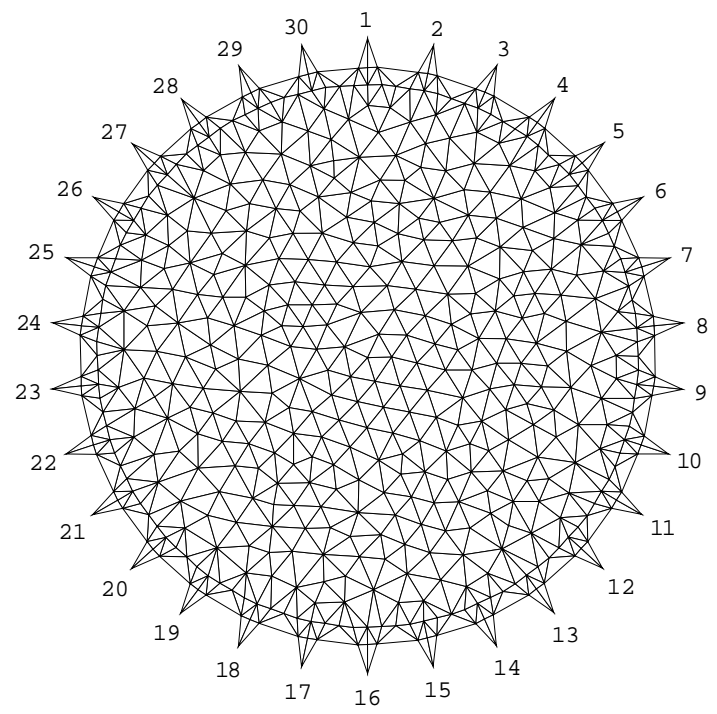

Figura 7.149: Domínio de obtenção da imagem com 934 elementos triangulares e 30 elementos de eletrodos.

Neste caso, são considerados a RCM (seção 5.3), o filtro espacial (seção 6.4) e o método da continuação apresentado na seção 6.5. O expoente $q$ da distância $d_{k}$ da RCM é igual a 2, exceto para o caso onde o objeto cilíndrico está posicionado no centro do domínio, onde utiliza-se um expoente $q$ igual a 4 . O filtro espacial possui raio de abrangência que envolve aproximadamente oito elementos vizinhos em torno de um elemento central. O método da continuação é iniciado com $p$ igual a 1 e ao longo das iterações aumenta o valor de $p$ consecutivamente até um valor igual a 6 .

A figura 7.150 mostra as imagens obtidas (distribuição de condutividades), para os três casos de posicionamento do objeto cilíndrico na cuba do fantoma objeto na borda da cuba (figura 7.150(a)), entre a borda e o centro da cuba (figura 7.150(b)) e no centro e da cuba (figura 7.150(c)). O gráfico da figura 7.151(a) mostra o comportamento da convergência da função objetivo para os três casos estudados e os gráficos das figuras 7.151(b), 7.152(a) e 7.152(b) mostram o perfil das distribuições de resistividades encontradas em cada caso de posicionamento do objeto cilíndrico estudado.

Através do resultado mostrado na figura 7.150 podemos notar que o TOMOGOT é capaz de detectar a presença do objeto cilíndrico de acrílico, nos três casos distintos de posicionamento, no interior da cuba experimental. O gráfico da figura 7.151(a) mostra que a função objetivo converge para um 


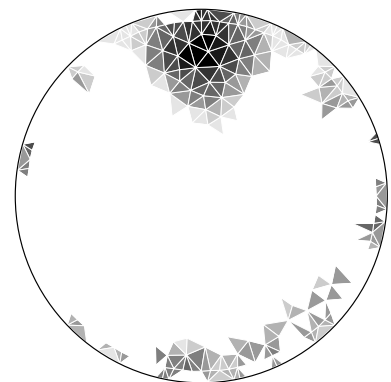

(a)

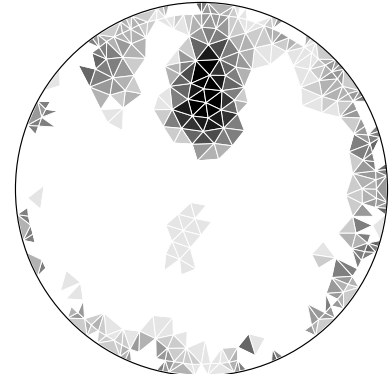

(b)

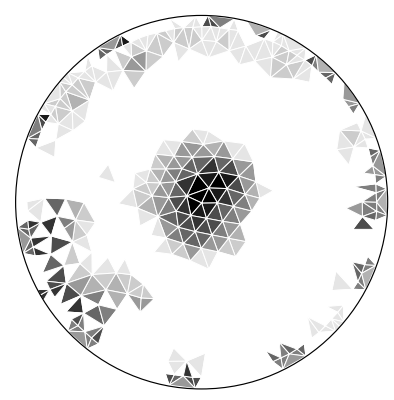

(c)

Figura 7.150: Imagens obtidas (distribuição de condutividades) com medidas de potenciais elétricos "diferenciais".

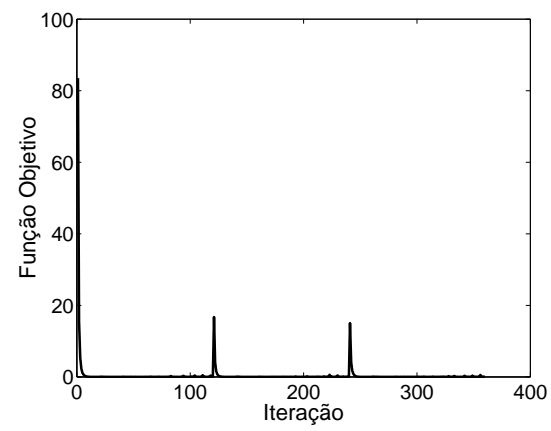

(a) gráfico de convergência

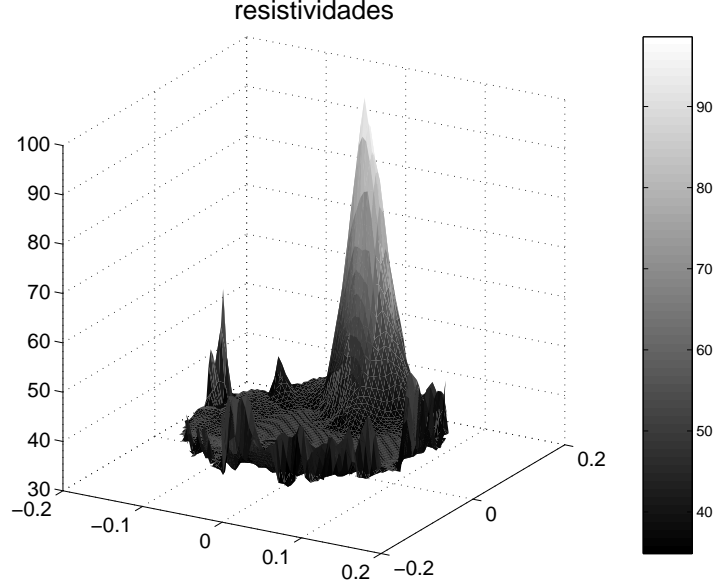

(b) gráfico de resistividades

Figura 7.151: Gráfico de convergência e gráfico de resistividades da imagem mostrada na figura 7.150(a).

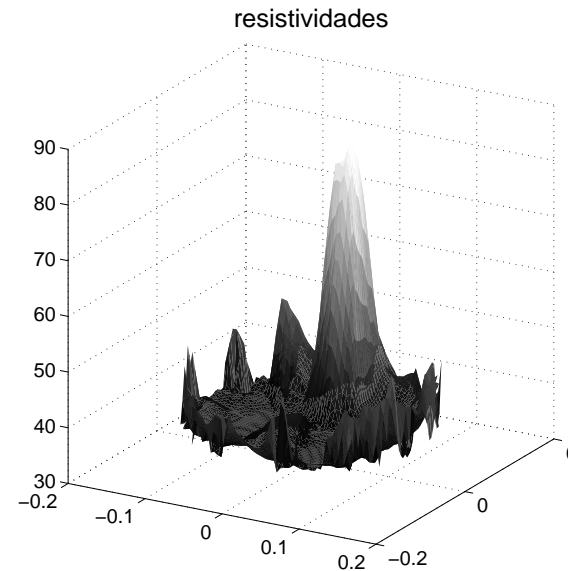

(a)

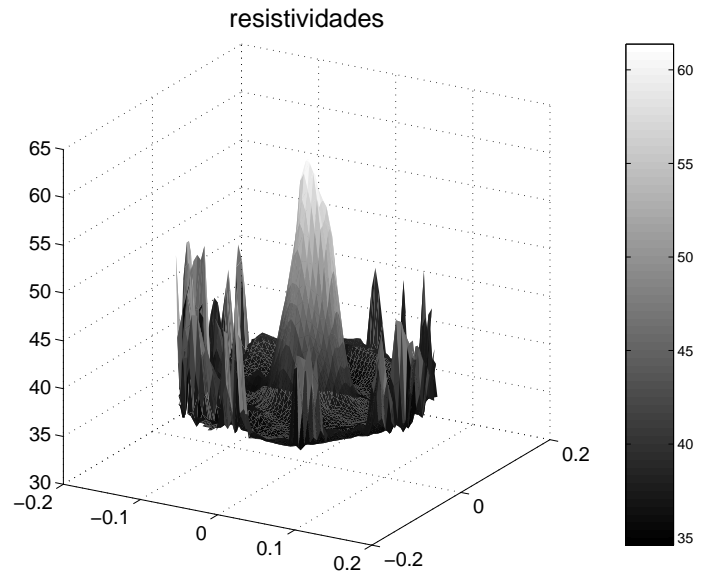

(b)

Figura 7.152: Gráficos da distribuição de resistividades das imagem mostradas nas figuras 7.150(b) e 7.150(c), respectivamente. 
valor mínimo de maneira análoga aos casos apresentados anteriormente. Porém, também podemos notar a prevalência do excesso de ruídos na imagem próximos a borda do domínio em todas as três imagens obtidas (figura 7.150). A região da borda do domínio causa interferência na imagem obtida provavelmente devido a forte influência dos valores de resistividades da camada de contato entre eletrodos e meio salino, simulada no MEF pelos parâmetros dos elementos de eletrodo, (veja seção 4.6). Neste caso, mediante utilização de potenciais medidos de forma "diferencial", percebe-se que a interferência da região dos eletrodos é acentuada e o método adotado opta por uma solução que prioriza a formação de material com condutividade (ou resistividade) diferente do valor esperado (condutividade do meio salino).

Essa pertubação na borda do domínio implicou em imagens cujos valores absolutos de resistividades (ou condutividades) da região do objeto cilíndrico são muito aquém do valor esperado $\left(10^{6} \Omega \mathrm{m}\right)$, conforme pode ser visto nos gráficos das figuras 7.151(b), 7.152(a) e 7.152(b). No entanto, o tamanho da imagem $\left(V^{*}\right)$ do objeto cilíndrico é obtido em média com $2,1 \%$ em relação ao volume total do domínio circular da cuba e portanto muito acima do tamanho esperado (1,14\% do volume total do domínio). Neste caso, mesmo com a aplicação do método da continuação, com $p$ variando de 1 a 6, o TOMOGOT não gerou resultados melhores. Em algumas experiências sem a utilização do filtro espacial observou-se resultados cujos valores de resistividades são obtidos próximos ao valor esperado, porém localizados ao longo da borda do domínio e não na região que representa a imagem do objeto cilíndrico.

Uma experiência que apresenta melhores respostas, utilizando as medidas de potenciais "diferenciais, é a utilização da aproximação CAMD, descrita na seção 6.6, sem utilização do filtro espacial e considerando o fator de penalidade $p$ igual a 1. Desta forma, obtém-se os resultados mostrados nas figuras 7.153, 7.154 e 7.155. Neste caso, as imagens apresentadas nas figuras 7.153(a), 7.154(a) e 7.155(a) mostram que a região da borda do domínio continua crítica, em termos do método estimar os valores de propriedades do material nesta região. No entanto, a região que denota a presença do objeto cilíndrico possui pontos (nós) cujo valor de resistividade (ou condutividade) esperado é alcançado $\left(10^{6} \Omega \mathrm{m}\right.$ ), conforme pode ser verificado nos gráficos das figuras 7.153(b), 7.154(b) e 7.155(b).

Observa-se que, em todos os testes realizados com a utilização das medidas de potenciais elétricos "diferenciais", a obtenção da imagem através do TOMOGOT no caso em que o objeto cilíndrico está posicionado no centro do domínio não apresentam resultados satisfatórios. Isto pode ser verificado através da imagem 


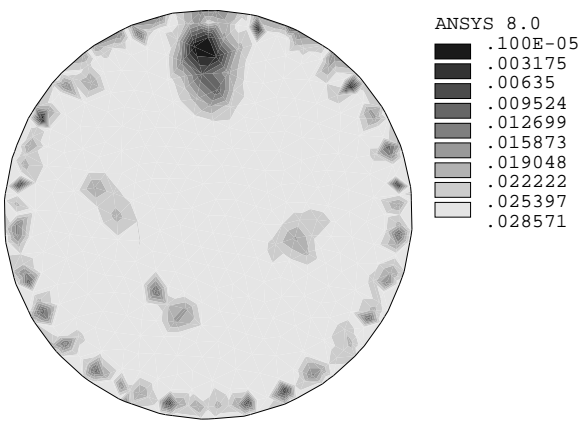

(a) imagem obtida

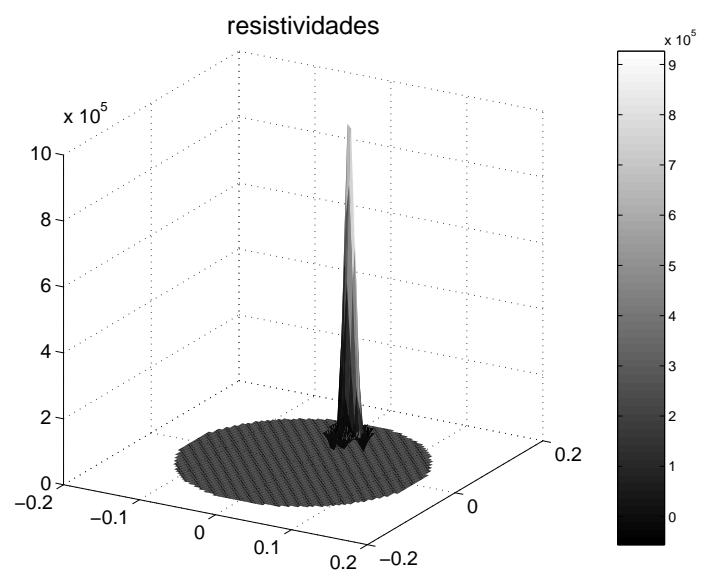

(b) gráfico de resistividades

Figura 7.153: Resultado obtido com medidas de potenciais elétricos "diferenciais", utilizando o CAMD e objeto posicionado na borda da cuba.

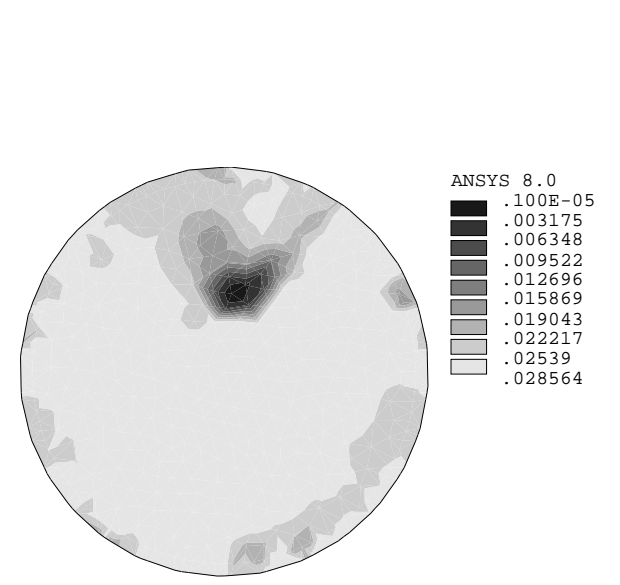

(a) imagem obtida

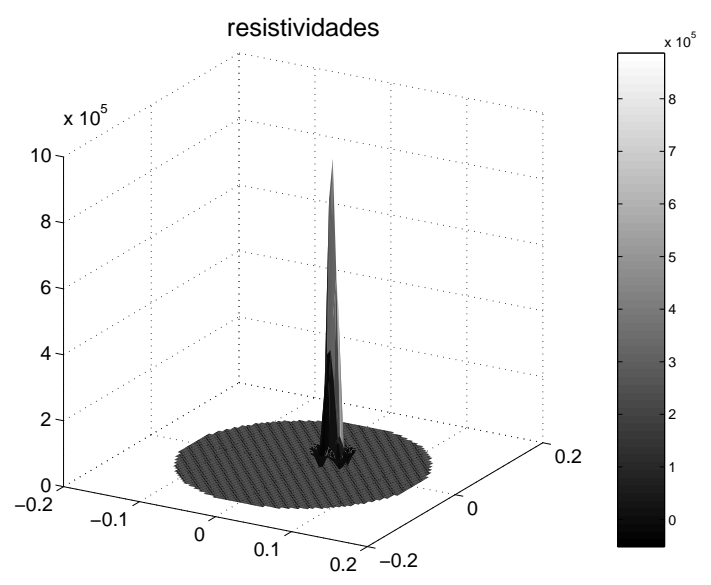

(b) gráfico de resistividades

Figura 7.154: Resultado obtido com medidas de potenciais elétricos "diferenciais", utilizando o CAMD e objeto posicionado entre a borda e o centro da cuba.

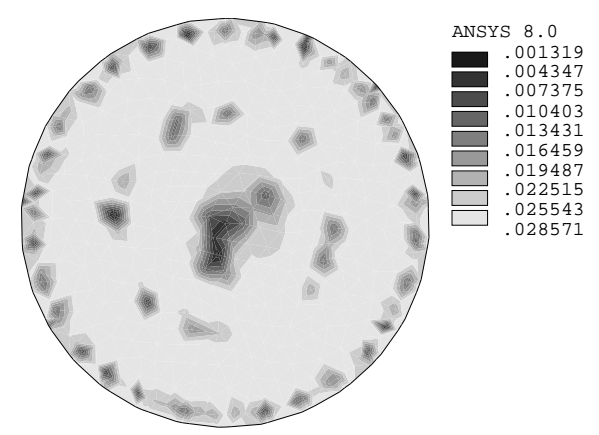

(a) imagem obtida

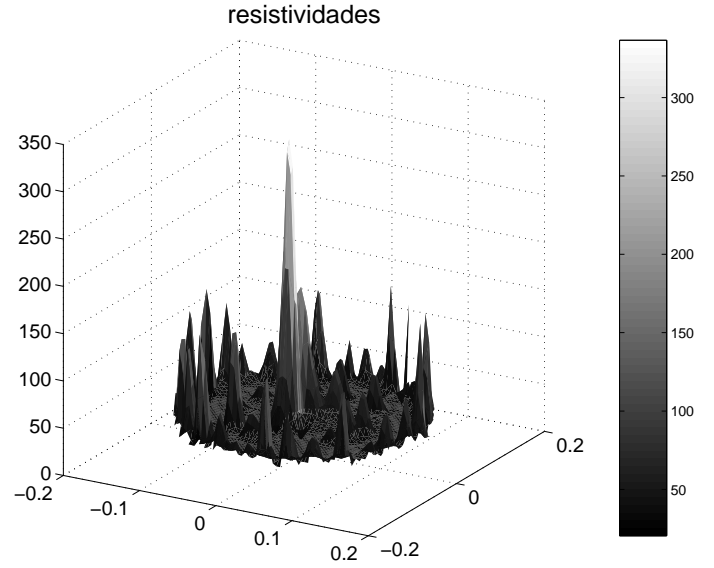

(b) gráfico de resistividades

Figura 7.155: Resultado obtido com medidas de potenciais elétricos "diferenciais", utilizando o CAMD e objeto posicionado no centro da cuba. 
mostrada na figura 7.155(a), onde nota-se que qualitativamente a imagem não é bem definida, e nos gráficos de distribuição de resistividades das figuras 7.152(b) e 7.155(b), que apresentam os menores picos de valores de resistividades alcançados para a região da imagem que denota a presença do objeto cilíndrico. 


\section{Conclusões}

Neste trabalho, um algoritmo de Otimização Topológica aplicado a Tomografia por Impedância Elétrica (TIE) foi proposto para obter imagens da seção transversal de um corpo. Um software, escrito em linguagem $\mathrm{C}$, foi implementado para executar o processo iterativo do Método de Otimização Topológica (MOT). O software utiliza a Programação Linear Seqüencial (PLS), como método de busca da solução ótima do problema de otimização topológica proposto para estimação da imagem na TIE, e o Método dos Elementos Finitos (MEF), para determinação dos potenciais elétricos num domínio discretizado. Assim, foram implementados um modelo de MEF com elementos de eletrodos incorporados que simulam o efeito da resistência de contato na interface entre eletrodos e pele do paciente, uma função objetivo comumente aplicada para solução do problema inverso da TIE, uma metodologia de cálculo de gradientes da função objetivo baseado nos conceitos do método adjunto, um modelo de material baseado no método das densidades para a mistura de dois materiais (modelo de material SIMP) e um método de otimização baseado na PLS.

Nos resultados apresentados neste trabalho, o "crime de inversão" foi evitado utilizando-se discretizações distintas dos modelos de MEF do domínio do fantoma numérico e do domínio de obtenção da imagem. Os parâmetros de eletrodos, necessários para a determinação da matriz de condutividade dos elementos de eletrodos, e a distribuição de material (pseudo-densidades) no domínio de projeto são obtidos por otimizações distintas, utilizando-se o próprio software. A otimização dessas variáveis de projeto é feita através de um processo de alternância, ou seja, o software alterna entre duas otimizações (parâmetros de eletrodos e pseudo-densidades) seqüencialmente, até que uma solução ótima seja encontrada e, conseqüentemente, a imagem obtida. Concluiu-se através dos resultados apresentados que o algoritmo do software implementado tende a compensar erros (ruído), provenientes da utilização de modelos de MEF distintos do fantoma numérico e do domínio de obtenção de imagem (menos discretizado), nos valores dos parâmetros de eletrodos otimizados, preservando assim a imagem 
a ser reproduzida.

Além disso, foram construídos e testados dois modelos de MEF para o domínio de obtenção da imagem (seção do corpo), um que discretiza o domínio em elementos triangulares e outro que discretiza em elementos quadriláteros. Através dos resultados obtidos, nota-se que não houve uma diferença significativa na resposta obtida com o uso de um ou outro modelo, ou seja, não se percebe muita diferença entre os resultados com elementos quadriláteros e triangulares. Observa-se que o modelo com elementos triangulares apresenta a vantagem de ter um elemento que se acomoda melhor geometricamente às curvas do domínio e cuja formulação é analítica, o que evita o uso de algoritmos numéricos para determinação da matriz de condutividade do elemento e, conseqüentemente, o acúmulo de erros numéricos. No entanto, o modelo com elementos quadriláteros, apesar de requerer métodos de solução numérica, também forneceu boas respostas, talvez devido a formulação mais robusta do elemento que representa com maior fidelidade o campo de potenciais no interior do elemento.

O software é testado para domínios elíptico e circular e, conforme os resultados obtidos a partir de dados numéricos, verifica-se que o software é capaz de obter em poucas iterações os parâmetros de eletrodos e os valores absolutos de condutividade ou resistividade elétrica de dois materiais no interior do domínio de projeto (seção do corpo humano) e conseqüentemente a imagem desejada, mesmo com a utilização de valores de potenciais elétricos com ruído, incluído artificialmente através do fantoma numérico ou mesmo provenientes de dados experimentais. São testados dois padrões de excitação elétrica - adjacente e diametral. Observa-se que na comparação entre esses padrões, constata-se que o padrão adjacente foi o que gerou imagens com melhor resolução e definição dos valores absolutos de condutividades ou resistividades. O erro médio na detecção do tamanho e da localização do objeto foi de aproximadamente 10\%, para o caso em que são utilizados dados obtidos através de fantomas numéricos. No entanto, há alguns resultados cujas resolução das imagens devem ser melhoradas, principalmente para o caso onde a imagem está no centro do domínio. Além disso, é verificado que a solução do problema de otimização implementado no TOMOGOT é sensível a mudança do fator de penalidade $(p)$ e ao valor $\rho_{k}^{0}$ das variáveis de projeto no inicio da otimização, concluindo-se que os resultados são obtidos de maneira satisfatória quando $\rho_{k}^{0}$ é igual a 0,85 , porém não é possível generalizar.

O método de otimização utilizado na PLS permite facilmente a inclusão de várias restrições no problema de reconstrução da imagem limitando facilmente 
o espaço de solução àquele esperado, evitando-se assim imagens sem significado clínico. Assim, algumas restrições foram acrescentadas no problema de otimização topológica com o intuito de regularizar o problema inverso da TIE. Uma delas, é o parâmetro de sintonia da imagem ("tuning"), que melhorou consideravelmente os resultados porém sua escolha é muito dependente da experiência do médico. Outra restrição alternativa ao "tuning", é a restrição da condutividade média, cuja aplicação auxiliou o processo de obtenção das imagens dos exemplos apresentados neste trabalho, principalmente para obter a imagem do objeto quando o mesmo se encontra no centro do domínio, embora a resolução ainda precise ser melhorada.

Além disso, também foram implementados o filtro espacial, um método de continuação e a aproximação contínua de distribuição de material ("CAMD"). Essas regularizações mostram-se eficientes, pois melhoraram os resultados obtidos, porém alguns ajustes ainda são necessários. Por exemplo, o filtro atenua as mudanças bruscas das pseudo-densidades (variáveis de projeto) no domínio, fazendo com que haja uma definição melhor da imagem obtida, porém sacrifica os valores absolutos de resistividades (ou condutividades) alcançados, forçando-os para baixo (no caso da resistividade). Uma alternativa testada, para solucionar este problema, é combinar o uso do filtro com um método de continuação e, assim, elevar gradualmente os valores de resistividades na região da imagem do objeto. No entanto, neste caso, ainda é necessário maior investigação sobre o máximo fator de penalidade $(p)$ que deve ser aplicado, sem que o problema de otimização topológica retorne ao caso discreto (problema de difícil solução). Com a aplicação do CAMD, conclui-se que houve um pequeno ganho nos resultados, principalmente para o caso em que o objeto investigado se encontra no centro do domínio. Porém, apesar do ganho alcançado com a aplicação do CAMD, observa-se que os resultados obtidos estão aquém do valores esperados.

Testando o algoritmo com dados obtidos de bancadas experimentais, conclui-se que o software é capaz de obter a imagem de um objeto cilíndrico de baixa condutividade (copo de vidro ou cilindro de acrílico) imerso num meio salino de alta condutividade (cuba com água salina). Para o caso em que foram utilizados dados da cuba com 32 eletrodos, os valores de resistividades (ou condutividades) esperados para o meio salino e para o objeto cilíndrico foram alcançados. Observa-se que a aplicação do CAMD, com o padrão adjacente de excitação elétrica, neste caso, gerou melhores resultados se comparado com os resultados que não utilizam o CAMD, porém em ambos os casos nota-se que o tamanho da imagem obtida, medido em termos de volume, é menor do que o 
esperado.

Já, na aplicação dos dados experimentais medidos de forma "diferencial" (cuba com 30 eletrodos) nota-se que o TOMOGOT detecta a presença do objeto cilíndrico em todos os casos estudados (objeto na borda, entre a borda e o centro e no centro do domínio), sendo o tamanho da imagem obtida maior se comparado com os resultados obtidos com a bancada de 32 eletrodos. Porém, neste caso, nota-se excesso de ruídos na imagem próximos a borda do domínio, implicando em imagens cujos valores absolutos de resistividades (ou condutividades) da região do objeto cilíndrico são muito aquém do valor esperado. Neste caso, observa-se que mesmo com a aplicação do método da continuação, com $p$ variando de 1 a 6 , o TOMOGOT não gerou melhores resultados. Observa-se também que, a obtenção da imagem a partir de dados "diferenciais", através do TOMOGT, principalmente para o caso em que o objeto cilíndrico está posicionado no centro do domínio, não apresenta bons resultados, pois as imagens não são bem definidas e apresentam os menores picos de valores de resistividades alcançados para a região da imagem do objeto cilíndrico. Isto mostra que, a utilização de dados "diferenciais" parece implicar numa perda de informação do processo de reconstrução de imagem, embora seja adequada para a obtenção de dados experimentais com menor nível de ruído.

\subsection{Trabalhos Futuros}

O software implementado é um trabalho pioneiro na aplicação do MOT para obtenção de imagens na TIE, que já pode ser testado em aplicações clínicas. Porém, ainda é possível aprimorar o algoritmo do software em versões futuras. Assim, como extensão deste trabalho, ficam as seguintes sugestões.

Aprimorar o procedimento para determinação do valor da condutividade média do domínio contendo imagem. Desta maneira, acredita-se que seja possível aumentar a resolução da imagem obtida, ou seja, acentuar ainda mais os valores de condutividades ou resistividades encontrados para o objeto no centro do domínio, por exemplo.

Implementar, testar e comparar outras rotinas de otimização. A rotina de otimização que foi implementada no software TOMOGOT é baseada na programação linear e utiliza o método de Kamarkar (ou Simplex) para a otimização das variáveis de projetos. Com o intuito de comparação e verificação do desempenho do MOT na obtenção de imagem na TIE, sugere-se 
a implementação de outras rotinas de otimização, baseadas por exemplo no MMA ("Method of Moving Asymptotes") (SVANBERG, 1987) ou no Método dos Gradientes Conjugados (BYUN et al., 2000) ou na Programação Seqüencial Quadrática (SWAN; ARORA, 1997).

Além disso, outras formulações para a função objetivo e restrições do problema de otimização podem ser elaboradas para melhorar a regularização do problema. Por exemplo, podemos incluir mais uma restrição no problema de otimização para fazer a função objetivo convergir para valores menores que os atuais. Percebe-se que ao final da otimização o método encontra um conjunto de valores de potenciais elétricos que minimiza a função objetivo, porém a diferença entre esses valores de potenciais otimizados $\left(\phi_{\mathrm{ij}}\right)$ e os valores dos potenciais "medidos" $\left(\phi_{\mathrm{ij} 0}\right)$ ainda é significativa. Portanto, a idéia é implementar no software um procedimento para ativar, após algumas iterações, uma restrição para essa diferença $\left(\phi_{\mathrm{ij}}-\phi_{\mathrm{ij} 0}\right)$, que deverá assumir valores muito baixo. Assim, acredita-se também que esse procedimento talvez evite a oscilação da função objetivo no final do processo.

Estudar a aplicação do MOT aliado a métodos probabilísticos, para obtenção de imagens através da TIE, levando-se em conta o caráter incerto de algumas variáveis. O presente trabalho desenvolvido nesta tese não leva em consideração incertezas presentes no modelo adotado, tais como incertezas no valor das correntes elétricas aplicadas, variações nas propriedades do material adotado, bem como incertezas de medição dos valores de potenciais elétricos, impedindo que haja um grau maior de certeza sobre as imagens obtidas. Desta forma, a metodologia adotada neste trabalho (MOT aplicado a TIE) pode ser aprimorada, aplicando os conceitos do MOT baseado em Confiabilidade ("Reliability-Based Topology Optimization") proposto por Kharmanda et al. (2004), para obter uma formulação capaz de alcançar os valores absolutos de condutividades dos materiais presentes no domínio com certo nível de confiabilidade.

Por último, estudar uma metodologia para eliminar do processo de otimização regiões do domínio conhecidas. No MOT, o domínio pode assumir qualquer geometria, que pode ser modelada por uma malha de elementos finitos na qual é realizado o processo iterativo de distribuição de material. Por exemplo, o domínio pode ter a geometria de uma seção do corpo humano. Sendo assim, podemos identificar regiões do domínio que já possuem algum tipo de material previamente definido, tais como osso ou um órgão do corpo humano, cujo tamanho e posição são conhecidos. Essas regiões podem ser eliminadas do processo de otimização, porém devem ser mantidas na análise por elementos finitos. Assim, por exemplo, 
podemos limitar no domínio a região em que a presença de ar no pulmão pode ocorrer, além de permitir lidar com a presença de regiões conhecidas no interior do domínio, como por exemplo, osso, coração, etc.

\subsection{Considerações Finais}

Como considerações finais, observa-se que ao final da conclusão do trabalho de Doutorado, espera-se ter contribuído com um software genérico e sistemático que aplique o MOT para a obtenção de imagens na TIE e, conseqüentemente, também com o desenvolvimento de uma técnica de tomografia útil para aplicações médicas de pneumologia.

Por final, o presente trabalho foi direcionado para habilitar um software de MOT utilizado na TIE para aplicações médicas, em específico a ventilação forçada de pulmões, onde a detecção da variação de resistividade do meio é mais comum. No entanto, o software desenvolvido neste trabalho, pode ser aproveitado também para outras aplicações, como por exemplo o diagnóstico da mistura de água e óleo em tubulações industriais e marítimas (DICKIN et al., 1992; BENNETT; WILLIAMS, 2004). 


\section{Anexo A - Reformulação dos gradientes da função objetivo para dados com $\Delta \phi$}

Conforme descrito no capítulo 7, através do fantoma com 30 eletrodos são extraídos dados com potenciais elétricos medidos na forma "diferencial" (veja figura 7.148). Assim, para utilizar esses dados no TOMOGOT, a seguir é reformulado o cálculo da derivada da função objetivo em relação as variáveis do problema de otimização.

Sabemos que a função objetivo $(F)$ do problema de otimização topológica para obtenção de imagem na TIE é escrita como sendo a diferença quadrática entre os valores de potencial elétrico medidos em eletrodos $\left(\phi_{\mathrm{ij} 0}\right)$ e os calculados num modelo computacional da seção usando elementos finitos $\left(\phi_{\mathrm{ij}}\right)$. Então, se adotarmos como potencial medido ou calculado a diferença entre dois valores de potenciais elétricos medidos em eletrodos vizinhos, com esquema "pula um" mostrado na figura 7.148, a função objetivo torna-se:

$$
F_{2}=\frac{1}{2} \sum_{\mathrm{j}=1}^{n e} \sum_{\mathrm{i}=1}^{n p}\left(\Delta \phi_{\mathrm{ij}}-\Delta \phi_{\mathrm{ij} 0}\right)^{2}
$$

$\operatorname{com} \Delta \phi_{\mathrm{ij}}=\phi_{\mathrm{ij}}-\phi_{\mathrm{ij}}^{k+2}$ e $\Delta \phi_{\mathrm{ij} 0}=\phi_{\mathrm{ij} 0}-\phi_{\mathrm{ij} 0}^{k+2}$, onde $k$ o eletrodo por onde se injeta e retira a corrente elétrica.

Aplicando a regra da cadeia, a derivada da função objetivo em relação as variáveis do problema de otimização, é escrita da seguinte forma:

$$
\frac{d F_{2}}{d \rho}=\sum_{\mathrm{j}=1}^{n e} \sum_{\mathrm{i}=1}^{n p}\left(\Delta \phi_{\mathrm{ij}}-\Delta \phi_{\mathrm{ij} 0}\right) \frac{\partial \Delta \phi_{\mathrm{ij}}}{\partial \rho}
$$

Porém:

$$
\frac{\partial \Delta \phi_{\mathrm{ij}}}{\partial \rho}=\frac{\partial\left(\phi_{\mathrm{ij}}-\phi_{\mathrm{ij}}^{k+2}\right)}{\partial \rho}=\frac{\partial \phi_{\mathrm{ij}}}{\partial \rho}-\frac{\partial \phi_{\mathrm{ij}}^{k+2}}{\partial \rho}
$$

Assim, a derivada da equação (A.2) pode ser reescrita da seguinte forma:

$$
\frac{d F_{2}}{d \rho}=\sum_{\mathrm{j}=1}^{n e} \sum_{\mathrm{i}=1}^{n p}\left(\Delta \phi_{\mathrm{ij}}-\Delta \phi_{\mathrm{ij} 0}\right)\left(\frac{\partial \phi_{\mathrm{ij}}}{\partial \rho}-\frac{\partial \phi_{\mathrm{ij}}^{k+2}}{\partial \rho}\right)
$$



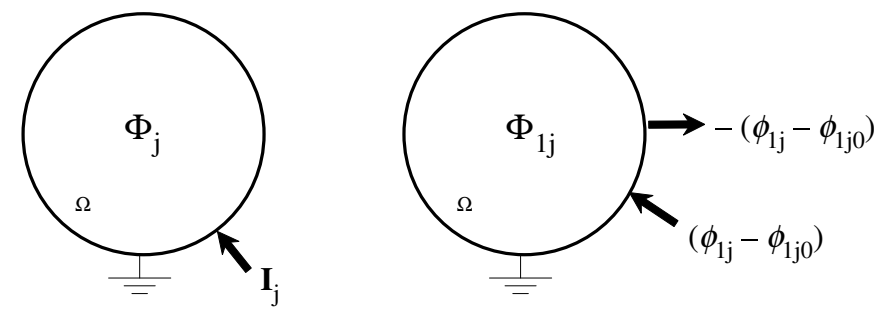

Figura A.1: Aplicação da primeira medição de potenciais (i=1).

De maneira análoga ao desenvolvimento realizado na seção 5.4 do capítulo 6, utiliza-se a derivada da energia mútua, dada pela equação (5.21), para deduzir a equação (5.22) e, assim, calcular os gradientes da equação (A.4).

Conforme visto, na TIE são feitas várias medições ( $\mathrm{i}=1$ a $n p$ ) ao redor da seção do corpo, em diferentes eletrodos, para cada caso de carregamento. Assim, considerando a configuração do domínio para a primeira medição $(i=1)$, conforme mostrado na figura A.1, e a excitação fictícia da equação (5.12) (veja seção 5.4) como um vetor cujas componentes valem:

$$
\mathbf{I}_{1 \mathrm{j}}=\left\{\begin{array}{c}
\left(\Delta \phi_{1 \mathrm{j}}-\Delta \phi_{1 \mathrm{j} 0}\right) \\
0 \\
-\left(\Delta \phi_{1 \mathrm{j}}-\Delta \phi_{1 \mathrm{j} 0}\right) \\
0 \\
0 \\
\cdots \\
0
\end{array}\right\}
$$

Desta forma, a excitação elétrica da equação (A.5) produz no domínio $(\Omega)$ uma distribuição de potenciais elétrico $\left(\boldsymbol{\Phi}_{1 \mathrm{j}}\right)$. Assim, sabendo-se que o vetor $\mathbf{I}_{1 \mathrm{j}}$ é constante durante o caso de carga, aplicando a equação (5.22) (veja seção 5.4), obtemos:

$$
-\boldsymbol{\Phi}_{\mathrm{j}}^{T} \frac{\partial \mathbf{K}}{\partial \rho} \boldsymbol{\Phi}_{1 \mathrm{j}}+\left(-\boldsymbol{\Phi}_{\mathrm{j}}^{T} \frac{\partial \mathbf{K}}{\partial \rho} \boldsymbol{\Phi}_{1 \mathrm{j}}^{k+2}\right)=\left(\Delta \phi_{1 \mathrm{j}}-\Delta \phi_{1 \mathrm{j} 0}\right) \frac{\partial \phi_{1 \mathrm{j}}}{\partial \rho}-\left(\Delta \phi_{1 \mathrm{j}}-\Delta \phi_{1 \mathrm{j} 0}\right) \frac{\partial \phi_{1 \mathrm{j}}^{k+2}}{\partial \rho}
$$

Simplificando a equação (A.6), temos:

$$
-\boldsymbol{\Phi}_{\mathrm{j}}^{T} \frac{\partial \mathbf{K}}{\partial \rho}\left(\boldsymbol{\Phi}_{1 \mathrm{j}}+\boldsymbol{\Phi}_{1 \mathrm{j}}^{k+2}\right)=\left(\Delta \phi_{1 \mathrm{j}}-\Delta \phi_{1 \mathrm{j} 0}\right)\left(\frac{\partial \phi_{1 \mathrm{j}}}{\partial \rho}-\frac{\partial \phi_{1 \mathrm{j}}^{k+2}}{\partial \rho}\right)
$$


Desta forma, considerando $n p$ casos de medição, obtemos:

$$
-\boldsymbol{\Phi}_{\mathrm{j}}^{T} \frac{\partial \mathbf{K}}{\partial \rho}\left(\boldsymbol{\Phi}_{(n p) \mathrm{j}}+\boldsymbol{\Phi}_{(n p) \mathrm{j}}^{k+2}\right)=\left(\Delta \phi_{(n p) \mathrm{j}}-\Delta \phi_{(n p) \mathrm{j} 0}\right)\left(\frac{\partial \phi_{(n p) \mathrm{j}}}{\partial \rho}-\frac{\partial \phi_{(n p) \mathrm{j}}^{k+2}}{\partial \rho}\right)
$$

Então, utilizando todos os casos de medição (de 1 a $n p$ ), considerando o desenvolvimento da primeira somatória da equação (A.4) e comparando com as equações A.7 e A.8, de forma análoga ao realizado na seção 5.4, conclui-se que a derivada da função objetivo em relação às variáveis de projeto, neste caso, é dada por:

$$
\frac{\partial F_{2}}{\partial \rho}=-\sum_{\mathrm{j}=1}^{n e} \boldsymbol{\Phi}_{\mathrm{j}}^{T} \frac{\partial \mathbf{K}}{\partial \rho}\left[\left(\boldsymbol{\Phi}_{1 \mathrm{j}}+\boldsymbol{\Phi}_{1 \mathrm{j}}^{k+2}\right)+\left(\boldsymbol{\Phi}_{2 \mathrm{j}}+\boldsymbol{\Phi}_{2 \mathrm{j}}^{k+2}\right)+\ldots+\left(\boldsymbol{\Phi}_{(n p) \mathrm{j}}+\boldsymbol{\Phi}_{(n p) \mathrm{j}}^{k+2}\right)\right]
$$

ou

$$
\frac{d F_{2}}{d \rho}=-\sum_{\mathrm{j}=1}^{n e} \sum_{\mathrm{i}=1}^{n p} \boldsymbol{\Phi}_{\mathrm{j}}^{T} \frac{\partial \mathbf{K}}{\partial \rho}\left[\left(\boldsymbol{\Phi}_{\mathrm{ij}}+\boldsymbol{\Phi}_{\mathrm{ij}}^{k+2}\right)\right]
$$




\section{Anexo B - Estrutura do software de MOT aplicado à TIE}

O objetivo deste anexo é apresentar uma descrição geral sobre o procedimento de funcionamento da estrutura do software implementado neste trabalho (TOMOGOT), que aplica o MOT para obtenção de imagem na TIE . A primeira etapa da estrutura do software se refere ao pré-processamento, para geração dos dados iniciais, que serão utilizados na segunda etapa da estrutura - o processamento e verificação dos resultados obtidos. A figura B.1 mostra o fluxograma da etapa de pré-processamento e as figuras B.2 e B.3 mostram o fluxograma básico da estrutura do TOMOGOT na etapa de processamento.

O pré-processamento inicia-se a partir da obtenção dos nc (30 ou 32) casos de carregamento (elétrico) que contém os potenciais elétricos medidos $\left(\phi_{\mathrm{ij0}}\right)$. Neste ponto, podem ser utilizados valores de potenciais obtidos experimentalmente, ou seja, medidos no próprio corpo do paciente através de protótipos de aparelhos de TIE ou fantomas experimentais. No entanto, também podem ser utilizados dados obtidos numericamente, através de um modelo de MEF da seção cuja imagem é desejada, para fins de calibração do software. Neste caso, é necessário a construção de um fantoma numérico através de um software de MEF. Neste trabalho, o software ANSYS foi utilizado para realização de tarefa. Basicamente, o usuário utiliza no ANSYS somente os recursos de CAD e gerador de malhas para criar um arquivo texto (<nome do arquivo $>$.txt), no formato padrão do ANSYS (ASCII).

Obtidos os potenciais elétricos medidos $\left(\phi_{\mathrm{ij0}}\right)$, o próximo passo é a geração da malha de elementos finitos do domínio de obtenção de imagem. Neste trabalho, a geração dessa malha é feita através do gerador de malhas do software ANSYS, porém o código fonte do TOMOGOT pode ser facilmente adaptado para trabalhar com outros geradores de malhas. Desta forma, para gerar a malha do modelo de MEF no ANSYS, basta criar a geometria desejada para o domínio no CAD do ANSYS, escolher o tipo de elemento e o tipo de material. Para 


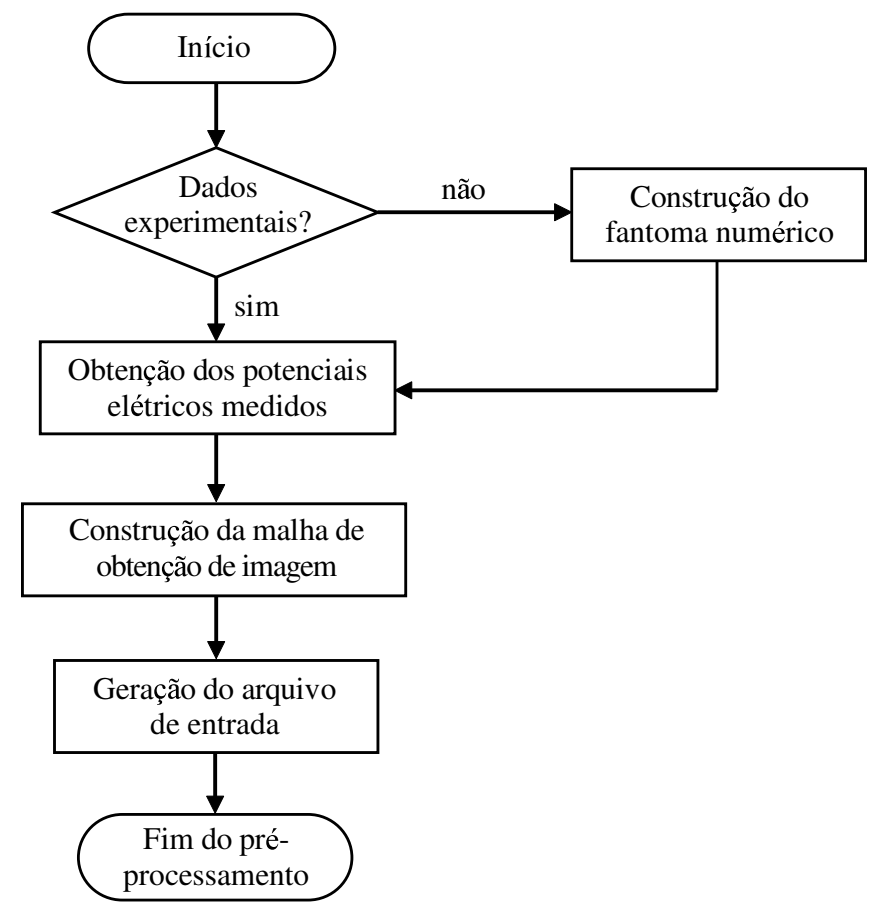

Figura B.1: Fluxograma básico do pré-processamento.

geração de malhas irregulares, aplica-se o comando do ANSYS que gera a malha livremente ("Main Menu> Preprocessor $>$ Meshing $>$ Mesh $>$ Areas $>$ Free"), ou seja, o software decide como distribuir os elementos no interior do domínio. Esta forma automática de geração de malha tem a vantagem de ser fácil e rápida, porém geralmente se obtém malhas com elementos distorcidos que podem causar problemas, como limitações no cálculo do Jacobiano dos elementos distorcidos. Para geração de malhas regulares, pode-se aplicar o comando que gera malhas mapeadas ("Main Menu $>$ Preprocessor $>$ Meshing $>$ Mesh $>$ Areas $>$ Mapped") ou criar a malha manualmente através do CAD do ANSYS. Depois de gerado a malha do modelo de MEF do domínio, gera-se manualmente os elementos de eletrodos (30 ou 32) em torno do domínio discretizado, tomando-se o cuidado de manter a largura de todos os elementos de eletrodos iguais, inclusive mantendo igual também o espaçamento entre eles.

O ANSYS gera um arquivo texto em formato ASCII, Com isso, cria-se um arquivo texto do tipo "GEOM" através da função CDWRITE do ANSYS, contento a informação sobre os dados geométricos da malha de elementos finitos, ou seja, a quantidade e as coordenadas dos nós, a quantidade de elementos e a conectividade de cada elemento. Este arquivo texto é complementado com a informação sobre o restante dos dados necessários para a análise de MEF no TOMOGOT, ou seja, o valor da corrente elétrica aplicada, o ponto de "aterramento" (nó com potencial nulo), os valores de condutividades específicas dos materiais que compõem o interior do domínio e a listagem dos $n c$ casos de 


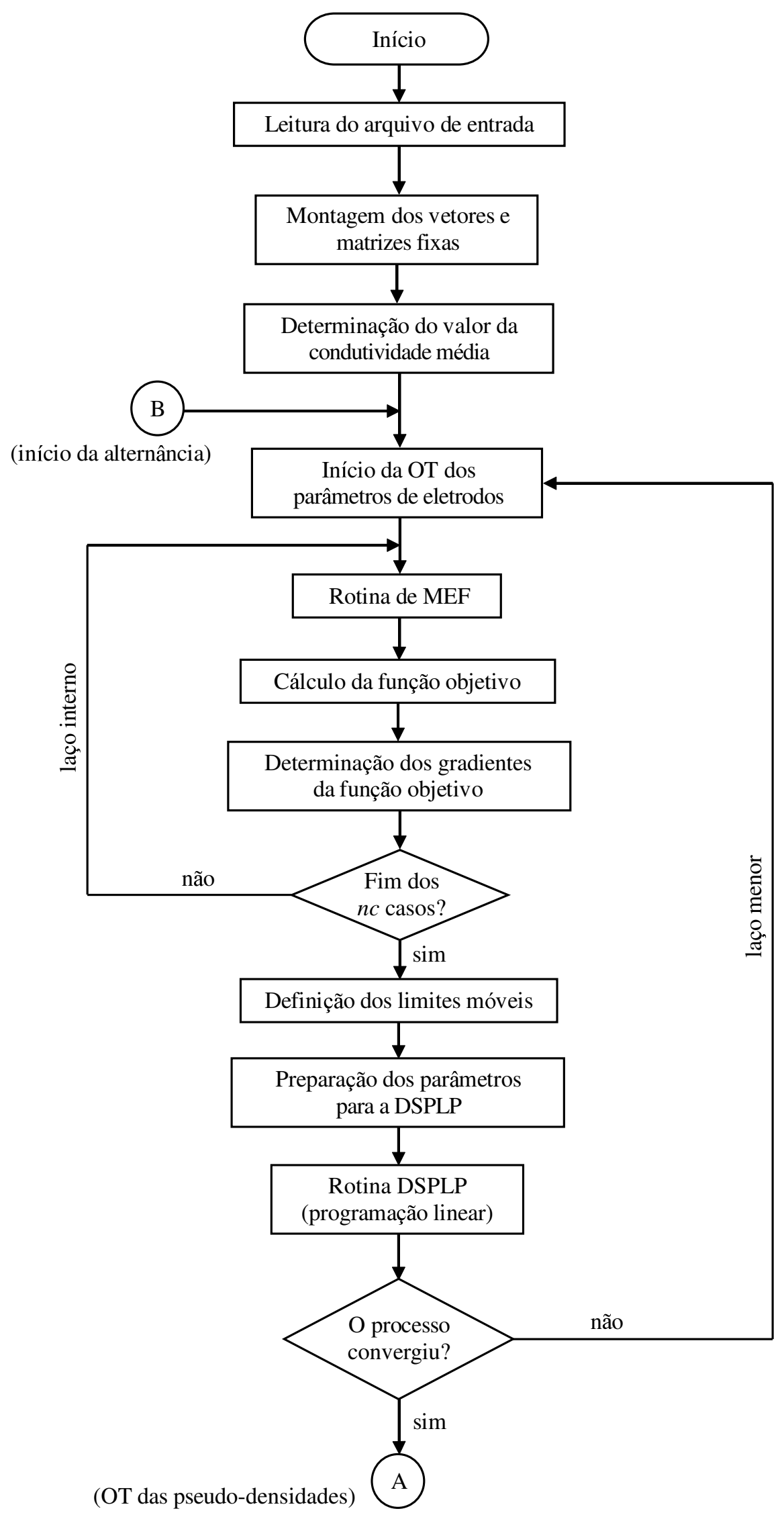

Figura B.2: Fluxograma da estrutura do TOMOGOT - Parte I. 


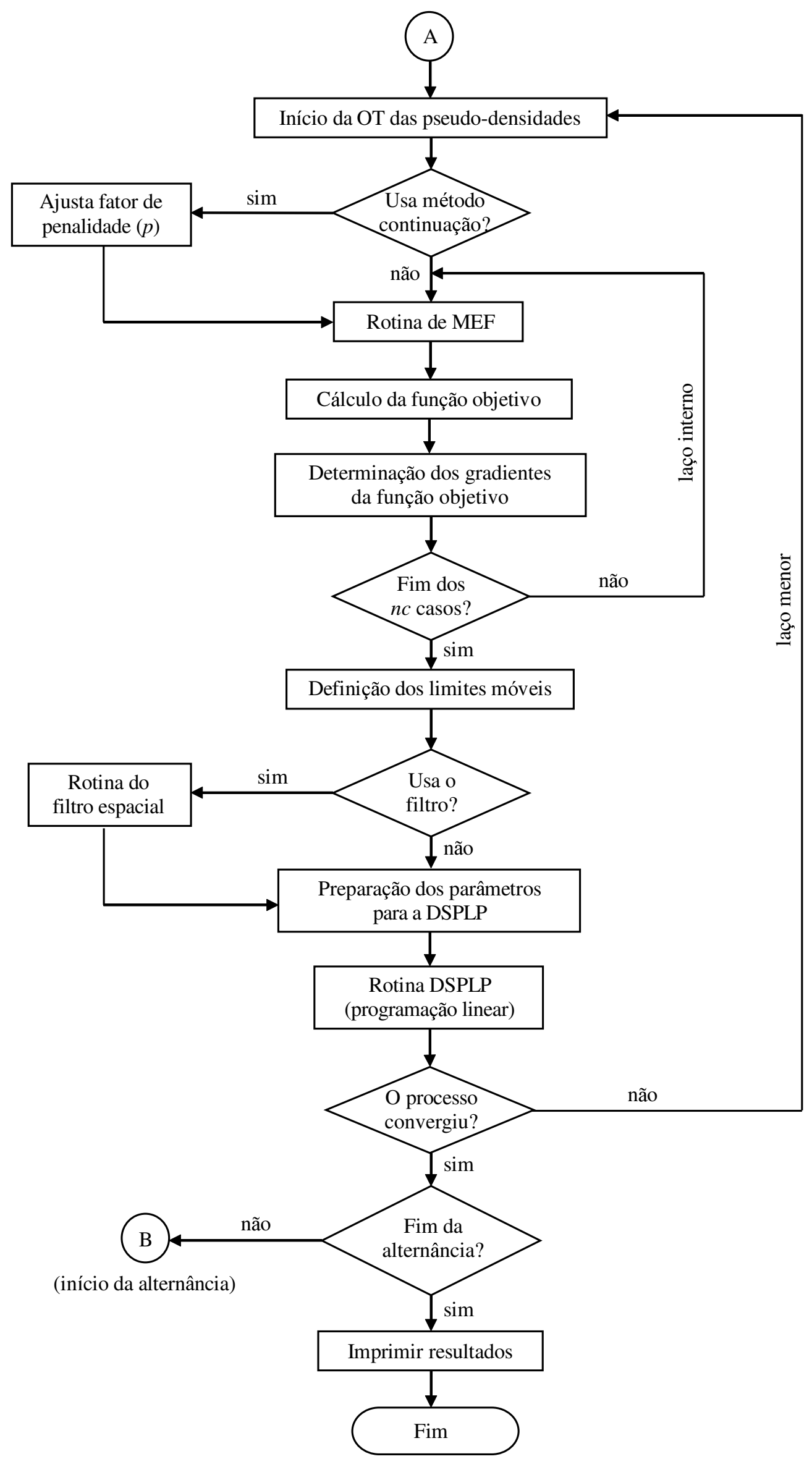

Figura B.3: Fluxograma da estrutura do TOMOGOT - Parte II. 
carregamento elétrico (potenciais $\phi_{\mathrm{ij} 0}$ ). Gera-se, assim, o arquivos de entrada de dados para o TOMOGOT.

Finalizada a etapa de pré-processamento, inicia-se a etapa de processamento com o TOMOGOT executando a leitura do arquivo de entrada de dados, cujo conteúdo é utilizado pelas várias rotinas programadas no software. Como visto na seção 6.3, durante o processo de obtenção da imagem o algoritmo do TOMOGOT executa as otimizações dos parâmetros de eletrodos e da distribuição de material (pseudo-densidades) de forma alternada, conforme ilustrado na figura 6.4. Assim, a etapa do processamento é constituído de um laço ("loop") maior que determina quantas "rodadas" são executadas (número de vezes que o TOMOGOT alterna as otimização até a convergência do processo). Inicialmente, o TOMOGOT realiza a otimização dos parâmetros de eletrodos e em seguida a otimização das pseudo-densidades (veja fluxograma nas figuras B.2 e B.3).

Para otimização do parâmetros de eletrodos, após a leitura do arquivo de entrada, o TOMOGOT determina os vetores e matrizes fixas que serão utilizados ao longo do processo de otimização, ou seja, são montados: a matriz de coordenadas nodais, a matriz de conectividades dos nós da malha de MEF, o vetor de restrições nodais, o vetor de carregamento elétrico, os vetores dos limites laterais das variáveis de projeto (pseudo-densidade de cada elemento) e o vetor dos valores iniciais das variáveis de projeto $\left(\rho_{k}^{0}\right)$. Após a montagem das matrizes fixas, o TOMOGOT inicia um laço menor de otimização, cujo número de voltas depende do número de iterações necessárias para a convergência da função objetivo do problema. Neste caso, considera-se que a convergência ocorre quando o valor da função objetivo torna-se constante, dentro de uma margem de erro de $0,001 \%$, durante as iterações.

Basicamente, o laço de otimização dos parâmetros de eletrodos compreende as rotinas de MEF, de cálculo do valor da função objetivo e seus gradientes, de determinação dos limites móveis e de programação linear, conforme mostrado na figura B.2. O laço de otimização é iniciado com um laço interno que contabiliza todos os $n c$ casos de carregamento elétrico para determinação da função objetivo e gradientes. No interior deste laço, a rotina de MEF executa outro laço interno de $M$ voltas (sendo $M$ o número total de elementos) que, em cada volta, constrói a matriz de rigidez local do elemento e posiciona os valores dessa matriz local na matriz de rigidez global, de acordo com a conectividade de cada elemento da malha. A figura B.4 mostra o fluxograma específico da rotina de MEF.

A matriz de rigidez do elemento é construída através de uma rotina de 


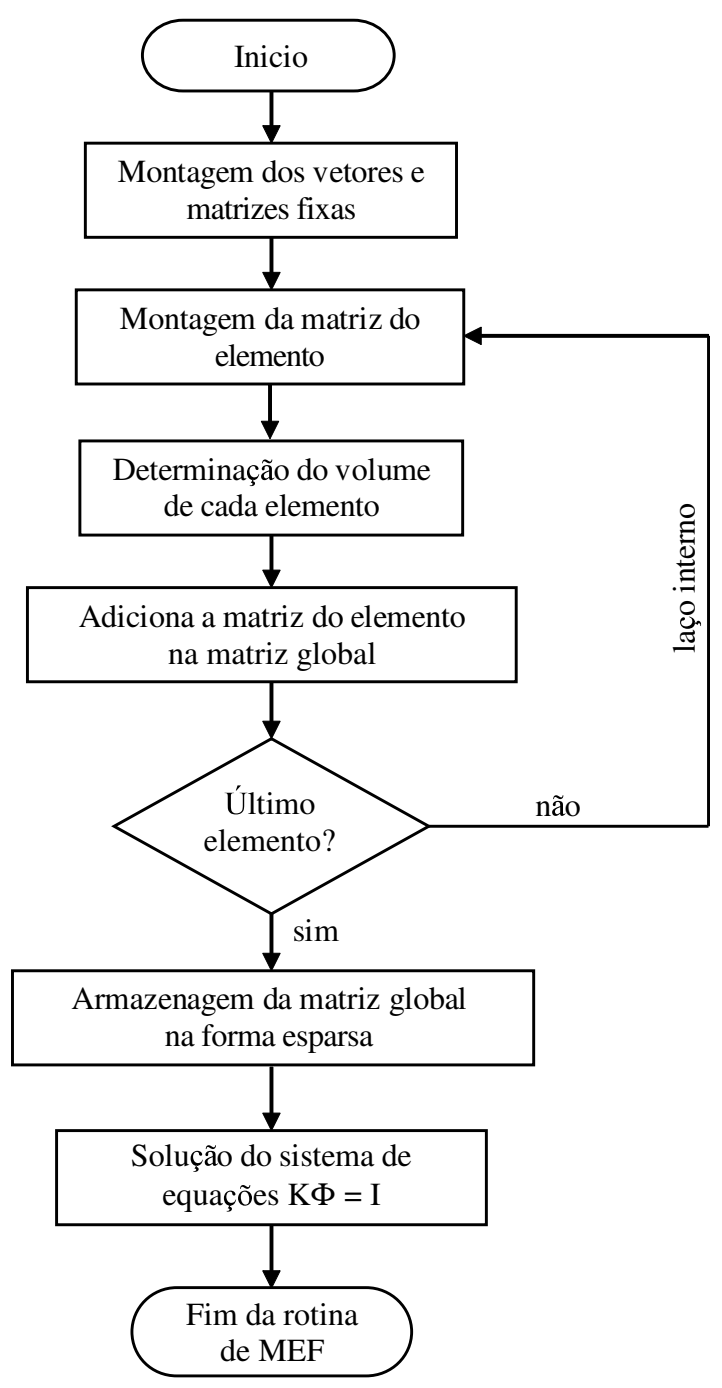

Figura B.4: Fluxograma da rotina de MEF.

integração numérica de Gauss-Legendre ( $2 \times 2$ pontos), se estiver sendo utilizado elementos quadriláteros, ou outra que calcula analiticamente os elementos da matriz, se estiver sendo utilizado elementos triangulares. A matriz de rigidez global é montada de maneira que não sejam consideradas as linhas e colunas referentes aos potenciais elétricos nulos ("aterramento), isto reduz o tamanho da matriz e, conseqüentemente, o tempo de processamento. Neste caso, a rotina de MEF armazena a matriz de rigidez global "cheia" no formato esparso, de acordo com Press et al. (1999), e para cada caso de carregamento elétrico (de 1 até $n c$ ) a rotina obtém os vetores de potenciais elétricos nodais correspondentes, resolvendo o sistema de equações de equilíbrio de cada caso $(\mathbf{K} \mathbf{\Phi}=\mathbf{I})$, através de uma rotina de Gradientes Biconjugados (PRESS et al., 1999). Uma vez obtidos esses vetores, o TOMOGOT calcula o valor da função objetivo e seus gradientes, através de rotinas específicas.

Antes de entrar na rotina de otimização das variáveis de projeto (parâmetros de eletrodos ou pseudo-densidades), o TOMOGOT determina os limites móveis da 
Programação Linear Seqüencial (PLS), armazenando-os em dois vetores distintos, um para o limite superior e outro para o limite inferior. Numa etapa seguinte, o TOMOGOT executa a otimização das variáveis de projeto através da rotina de programação linear DSPLP, adaptada ao TOMOGOT. Numa rotina anterior, o TOMOGOT monta os vetores com parâmetros de entrada da DSPLP (HANSON; HIEBERT, 1981). Na primeira iteração, a DSPLP utiliza o vetor de variáveis de projeto iniciais $\left(\rho_{k}^{0}\right)$, contendo valores iguais para todos os elementos do domínio (respeitando os limites máximo e mínimo), o qual servem de ponto de partida para o processo de busca dos valores ótimos das variáveis de projeto. O TOMOGOT utiliza automaticamente o último conjunto ótimo de variáveis de projeto como valor inicial para as iterações seguintes. A DSPLP recebe todos os parâmetros iniciais e devolve um vetor com a nova configuração de variáveis de projeto, o qual é utilizado para um novo cálculo na rotina de MEF, dando início a mais uma iteração da PLS do software, até a convergência.

Após o processo de obtenção dos parâmetros de eletrodos, o TOMOGOT desenvolve a otimização das pseudo-densidades, conforme mostrado na figura B.3. Podemos notar que o fluxo desenvolvido é o mesmo desenvolvido na otimização dos parâmetros de eletrodos, porém são incluídas como opcionais as rotinas que aplica o filtro espacial e o método da continuação. A rotina de filtro recebe os vetores dos limites móveis e devolve outros dois (limites superior e inferior filtrados), que são utilizados pela rotina de programação linear. A rotina de filtro do TOMOGOT é um laço de $M$ voltas que utiliza as informações da matriz de coordenadas do centro de cada elemento (matriz fixa) para calcular as distâncias entre um elemento central e seus adjacentes e, por meio da comparação com o raio de abrangência (definido pelo usuário), determinar quais são efetivamente os elementos vizinhos que serão utilizados no processo de filtragem (veja seção 6.4). Se a distância de um elemento adjacente for menor que o raio de abrangência do filtro, esse elemento será considerado um vizinho do elemento central. Depois de finalizado o laço da rotina do filtro, os novos valores limites filtrados são verificados, para evitar que valores de densidades acima do limite máximo e abaixo do limite mínimo sejam obtidos.

Depois de finalizado o laço de alternância dos dois processos de otimização, o TOMOGOT gera um arquivos texto (otANSYScond.txt), em formato padrão lido pelo ANSYS, que contém a distribuição ótima de pseudo-densidades no domínio e a dados necessários (coordenadas, conectividades, etc) para visualizar a imagem obtida (topologia das pseudo-densidades). Além disso, o TOMOGOT também gera outro arquivo texto que contém uma listagem dos valores de condutividades 
e resistividades de cada elemento (ou nó) do domínio para visualização de gráficos (3D) dessas propriedades em software manipuladores de gráficos, tais como MATLAB, SCILAB e GNUPLOT.

Observa-se que os arquivos fontes das rotinas do TOMOGOT, mencionadas neste anexo, são compiladas conjuntamente em um compilador de linguagem C, sendo que a escolha do compilador fica a critério do usuário. Neste trabalho foi utilizado o compilador do sistema operacional Linux que, neste caso, demonstrou-se um sistema mais rápido e com melhor gerenciamento de memória, para rodar a rotina DSPLP com uma quantidade grande (na ordem de milhares) de variáveis de projeto. 


\section{Referências}

ADLER, A.; AMYOT, R.; GUARDO, R.; BATES, J. H. T.; BERTHIAUME, Y. Monitoring changes in lung air and liquid volumes with electrical impedance tomography. Journal of Applied Physiology, v. 83, n. 5, p. 1762-1767, 1997.

ADLER, A.; GUARDO, R. Electrical impedance tomography: Regularized imaging and contrast detection. IEEE Transactions on Medical Imaging, v. 15, n. 2, p. 170-179, 1996.

ADLER, A.; GUARDO, R.; BERTHIAUME, Y. Impedance imaging of lung ventilation: Do we need to account for chest expansion? IEEE Transactions on Biomedical Engineering, v. 43, n. 4, p. 414-420, 1996.

ALLAIRE, G. Shape optimization by the homogenization method. New York: Springer-Verlag, 2002. (Applied Mathematical Sciences, v. 146).

AMATO, M. B. P. Novas estratégias em ventilação artificial: Diagnóstico e prevenção do barotrauma/ biotrauma através da tomografia de impedância elétrica. Sumário do Projeto Temático FAPESP (proc. 01/05303-4), 2001.

AMATO, M. B. P.; BARBAS, C. S.; MEDEIROS, D. M.; ET al. Effect of a protective-ventilation strategy on mortality in the acute respiratory distress syndrome. Journal of Medicine, v. 338, n. 6, p. 347-354, 1998.

ANATHASURESH, G. K.; KOTA, S.; GIANCHANDANI, Y. A methodical approach to the design of compliant micromechanisms. Solid-state Sensor and Actuator Workshop, p. 189-192, 1994.

ARAKAKI, R.; ARAKAKI, J.; ANGERAMI, P. M.; AOKI, O. L.; SALLES, D. S. Fundamentos de Programação em C: Técnicas e Aplicações. Segunda edição. [S.l.]: LITEC, 1990.

AVIS, N.; BARBER, D. Incorporating a-priori information into the sheffield filtered backprojection algorithm. Physiol. Meas., v. 16, p. 111-122, 1995. Suppl. $3 \mathrm{~A}$.

AVIS, N. J.; BARBER, R. H. D. C. Image reconstruction using non-adjacent drive configuration. Physiological Measurements, v. 16, p. 153-160, 1994. Suppl. A.

BACRIE, C. C.; GOUSSARD, Y.; GUARDO, R. Regularized reconstruction in electrical impedance tomography using a variance uniformization constraint. IEEE Transactions on Medical Imaging, v. 16, p. 562-571, 1997.

BARBER, D. C. A review of image reconstruction techniques for electrical impedance tomography. Medical Physics, v. 16, n. 2, p. 162-169, 1989. 
BARBER, D. C. Quantification in impedance imaging. Clinical Physics and Physiological Measurement, v. 11, p. 45-56, 1990. Suppl. A.

BARBER, D. C.; BROWN, B. H. Applied potencial tomography. J. Phys. E: Sci. Instrum., v. 17, p. 723-733, 1984.

BARBER, D. C.; BROWN, B. H.; FREESTON, I. L. Imaging spatial distributions of resistivity using applied potential tomography. Electronic Letters, v. 19, n. 22, p. 933-935, 1983.

BATES, R.; GARDEN, K. L.; PETERS, T. M. Overview of computerized tomography with emphasis on future developments. Proceedings of the IEEE, v. 71 , n. 3, p. 356-372, 1983.

BATHE, K. J. Finite Element Procedures. New Jersey: Prentice Hall, 1996.

BAYFORD, R.; HANQUAN, Y.; BOONE, K.; HOLDER, D. S. Experimental validation of a novel reconstruction algorithm for electrical-impedance tomography based on backprojection of lagrange multipliers. Physiological Measurement, v. 16, p. 237-247, 1995. Suppl. A.

BECKERS, M. Topology optimization using a dual method with discrete variables. Structural Optimization, v. 17, n. 1, p. 14-24, 1999.

BELEGUNDU, A. D.; ARORA, J. S. A study of mathematical programming methods for structural optimization. part i: Theory. International Journal of Numerical Methods in Engineering, vol. 21, p. 1583-1599, 1985.

BENDSØE, M. P. Optimal shape design as a material distribution problem. Structural Optimization, v. 1, p. 193-202, 1989.

BENDSØE, M. P. Optimization of Structural Topology, Shape and Material. New York: Springer - Verlag, 1995.

BENDSØE, M. P.; KIKUCHI, N. Generating optimal topologies in structural design using a homogenization method. Computer Methods in Applied Mechanics and Engineering, v. 71, n. 2, p. 197-224, 1988.

BENDSØE, M. P.; SIGMUND, O. Material interpolation schemes in topology optimization. Archive of Applied Mechanics, v. 69, n. 9-10, p. 635-654, 1999.

BENDSØE, M. P.; SIGMUND, O. Topology Optimization: Theory Methods and Applications. Berlin: Springer-Verlag, 2003. ISBN 3-540-42992-1.

BENNETT, M.; WILLIAMS, R. Monitoring the operation of an oil/water separator using impedance tomography. Minerals Engineering, v. 17, p. 605-614, 2004 .

BERTEMES-FILHO, P. Tissue Characterisation using an Impedance Spectroscopy Probe. Tese (Doutorado) — University of Sheffield, 2002.

BOONE, K.; BARBER, D.; ; BROWN, B. Review: Imaging with electricity: Report of the european concerted action on impedance tomography. Journal of Med. Eng. Tech., v. 21, n. 6, p. 201-232, 1997. 
BORCEA, L. Electrical impedance tomography. Inverse Problems, v. 18, n. 6, p. 99-136, 2002.

BROWN, B. H. Tissue impedance methods. Imaging with non-ionising radiation. [S.l.]: Surrey Univ. Press, 1983.

BROWN, B. H. Medical impedance tomography and process impedance tomography: a brief review. Measurement Science and Technology, v. 12, n. 8, p. 991-996, 2001.

BYUN, J. K.; LEE, J. H.; PARK, I. H. Node-based distribution of material properties for topology optimization of electromagnetic devices. IEEE Transactions on Magnetics, v. 40, n. 2, p. 1212-1215, 2004.

BYUN, J. K.; LEE, J. H.; PARK, I. H.; LEE, H. B.; CHOI, K.; HAHN, S. Y. Inverse problem application of topology optimization method with mutual energy concept and design sensitivity. IEEE Transactions on Magnetics, v. 36, n. 4, p. 1144-1147, 2000.

BYUN, J. K.; PARK, I. H.; HAHN, S. Y. Topology optimization of electrostatic actuator using design sensitivity. IEEE Transactions on Magnetics, v. 38, n. 2, p. $1053-1056,2002$.

CARDOSO, E. L. Controle de Complexidade na Otimização Topológica de Estruturas Contínuas. Dissertação (Mestrado) — Universidade Federal do Rio Grande do Sul (UFRGS), 2000.

CENSOR, Y. Finite series-expansion reconstruction methods. Proceedings of the IEEE, v. 71, n. 3, p. 409-419, 1983.

CHENEY, M.; ISAACSON, D. An Overview of Inversion Algorithms for Impedance Imaging. [S.1.]: Inverse Scattering and Applications, O.H.Sattinger, C.A.Tracy, and S. Venakides, eds., AMS, Providence, RI., 1991.

CHENEY, M.; ISAACSON, D. Distinguishability in impedance imaging. IEEE Transactions on Biomedical Engineering, v. 39, p. 852-860, 1992.

CHENEY, M.; ISAACSON, D.; NEWELL, J. C. Electrical impedance tomography. SIAM Review, v. 41, n. 1, p. 85-101, 1999.

CHENEY, M.; ISAACSON, D.; NEWELL, J. C.; GOBLE, J.; SIMSKE, S. Noser: An algorithm for solving the inverse conductivity problem. International Journal of Imaging Systems and Technology, v. 2, p. 66-75, 1990.

CHENG, T. K.; OLHOFF, N. An investigation concerning optimal design of solid elastic plates. International Journal of Solids Structures, v. 17, p. 305-323, 1981.

CHENG, T. K.; OLHOFF, N. Regularized formulation for optimal design of axisymmetric plates. International Journal of Solids Structures, v. 18, n. 2, p. 153-169, 1982.

CHO, K. H.; KIM, S.; LEE, Y. J. A fast eit image reconstruction method for the two-phase flow visualization. International Communications in Heat And Mass Transfer, v. 26, n. 5, p. 637-646, 1999. 
CHOI, K. K.; SEONG, K. K. A domain method for shape design sensitivity analysis of built-up structures. Computer Methods in Applied Mechanics and Engineering, v. 57, p. 1-16, 1986.

CHUNG, Y. S.; CHEON, C.; HAHN, S. Y. Reconstruction of dielectric cylinders using fdtd and topology optimization technique. IEEE Transactions on Magnetics, v. 36, n. 4, p. 956-959, 2000.

CONWAY, J. Electrical impedance tomography for thermal monitoring of hyperthermia treatment: an assessment using in vitro and in vivo measurements. Clin. Phys, Physiol. Meas, v. 8, p. 141-146, 1987. Suppl. A.

COOK, R. D.; SALUNIER, G. J.; GISSER, D. G.; GOBLE, J. C.; NEWELL, J. C.; ISAACSON, D. Act3: High speed, high precision electrical impedance tomograph. IEEE Transactions on Biomed. Imag., v. 41, p. 713-722, 1994.

COOK, R. D.; YOUNG, W. C. Advanced Mechanics of Materials. New York: Macmillan, 1985.

D'ANTONA, G.; FERRERO, A.; LAZZARONI, M.; OTTOBONI, R.; SAMARANI, E. Active monitoring apparatus for underground pollutant detection based on electrical impedance tomography. IEEE Instrumentation and Measurement, Technology Conferece, p. 577-579, 2002.

D'ANTONA, G.; ROCCA, L. Electrical impedance tomography for underground pollutant detection and polluted lands reclaiming monitoring. IEEE Instrumentation and Measurement, Technology Conferece, p. 1035-1038, 2002.

DANTZIG, G. B. Linear Programming and Extensions. New Jersey: Princeton, 1963.

DíAZ, A. R.; BENDSØE, M. P. Shape optimization of structures for multiple loading conditions using homogenization method. Structural Optimization, v. 4, p. 17-22, 1992.

DíAZ, A. R.; KIKUCHI, N. Solution to shape and topology eigenvalue optimization problems using a homogenization method. International Journal for Numerical Methods in Engineering, v. 35, p. 1487-1502, 1992.

DIAZ, A.; SIGMUND, O. Checkerboard patterns in layout optimization. Structural Optimization, v. 10, n. 1, p. 40-45, 1995.

DICKIN, F. J.; HOYLE, B.; HUNT, A.; HUANG, S. M.; ILIAS, O.; LENN, C.; WATERFALL, R. C.; WILliAnS, R. A.; XIE, C. G.; BECK, M. S. Tomografic imaging of industrial process equipment: techniques and applications. IEE Proceedings G, v. 139, n. 1, p. 72-82, 1992.

DINES, K.; LYTLE, R. Analysis of electrical conductivity imaging. Geophysics, v. 46, p. 1025-1036, 1981.

DUCK, F. Physical Properties of Tissue - A Comprehensive Reference Book. London: Academic Press, 1990.

EDIC, P. M.; ISAACSON, D.; SAULNIER, G. J.; JAIN, H.; NEWELL, J. C. An iterative newton-raphson method to solve the inverse admittivity problem. IEEE Transactions on Biomedical Engineering, v. 45, n. 7, p. 899-908, 1998. 
EDIC, P. M.; SAULNIER, G. J.; NEWELL, J. C.; ISAACSON, D. A real-time electrical impedance tomograph. IEEE Transactions on Biomedical Engineering, v. 42, n. 9, p. 849-859, 1995.

EGGLESTON, M.; SCHWABE, R.; ISAACSON, D.; COFFIN, L. The application of electric current computed tomography to defect imaging in metals. [S.l.]: in Review of Progress in Quantitative NDE, D.O. Thompson and D.E. Chimenti, eds. Plenum, New York, 1989.

EYüBOGLU, B. M. Development and Application of Electrical Impedance Tomography for Thoracic Imaging. Tese (Doutorado) - University of Sheffield, 1988.

EYüBOGlU, B. M.; BROWN, B. H.; BARBER, D. C.; SEAGAR, A. D. Localisation of cardiac related impedance changes in the thorax. Clin Phys. Physiol. Meas., v. 8, p. 167-173, 1987. Suppl. A.

FRERICHS, I. Electrical impedance tomography (eit) in applications related to lung and ventilation: a review of experimental and clinical activities. Physiological Measurement, v. 21, n. 2, p. R1-R21, 2000.

FRERICHS, I.; HAHN, G.; HELLIGE, G. Gravity dependent phenomena in lung ventilation determined by functional eit. Physiolical Measurements, v. 17, p. 149-157, 1996.

FRERICHS, I.; HAHN, G.; SCHRODER, T.; HELLIGE, G. Electrical impedance tomography in monitoing experimental lung injury. Intensive Care Medicine, Springer Verlag, v. 24, p. 829-836, 1998.

FUJII, D.; KIKUCHI, N. Improvement of numerical instabilities in topology optimization using the slp method. Structural and Multidisciplinary Optimization, v. 19, n. 2, p. 113-121, 2000.

FUKS, L. P. Detection and imaging of electrical conductivity and permittivity at low frequency. IEEE Transactions on Biomedical Engineering, v. 38, n. 11, p. 1106-1110, 1991.

GADD, R.; RECORD, P.; ROLFE, P. Electrical impedance tomography: A sensitivity region reconstruction algorithm using adjacent drive current injection strategy. Clin. Phys. Physiol. Meas., v. 13, n. 1, p. 101-105, 1992. Suppl A.

GENDERINGEN, H. R.; VUGHT, A. J.; JANSEN, J. R. C. Estimation of regional lung volume changes by electrical impedance tomography during a pressure-volume maneuver. Intensive Care Medicine, v. 29, n. 2, p. 233-240, 2003.

GEORGE, D. L.; TORCZYNSKI, J. R.; SHOLLENBERGER, K. A.; O'HERN, T. J.; CECCIO, S. L. Validation of electrical-impedance tomography for measurements of material distribution in two-phase flows. International Journal of Multiphase Flow, v. 26, n. 4, p. 549-581, 2000.

GISSER, D. G.; ISAACSON, D.; ; NEWELL, J. C. Theory and performance of an adaptive tomography system. Clin. Phys. Physiol. Meas., v. 9, p. A35-A41, 1988. 
GISSER, D. G.; ISAACSON, D.; NEWELL, J. C. Electric current tomography and eigenvalues. SIAM,. Journal Appl. Math., v. 50, p. 1623-1634, 1990.

GRIFFITHS, H. The importance of phase measurement in electrical-impedance tomography. Physics in Medicine and Biology, v. 32, n. 11, p. 1435-1444, 1987.

GUARDO, R.; BOUlAY, C.; MURRAY, B.; BERTRAND, M. An experimental-study in electrical-impedance tomography using backprojection reconstruction. IEEE Transactions on Biomedical Engineering, v. 38, n. 7, p. 617-627, 1991.

GUTIERREZ, J. A.; DYAKOWSKI, T.; BECK, M. S.; WILLIAMS, R. A. Using electrical impedance tomography for controlling hydrocyclone underflow discharge. Powder Technology, v. 108, n. 2-3, p. 180-184, 2000.

HABER, R. B.; JOG, C. S.; BENDSOE, M. P. A new approach to variable-topology shape design using a constraint on perimeter. Structural Optimization, v. 11, n. 1, p. 1-12, 1996.

HAFTKA, R. T.; GANDHI, R. V. Structural shape optimization - a survey. Computer Methods in Applied Mechanics and Engineering, v. 57, p. 91-106, 1986.

HAFTKA, R. T.; GüRDAL, Z.; KAMAT, M. P. Element of Structural Optimization. Boston: Kluwer Academic Publishers, 1996.

HANSON, R.; HIEBERT, K. A Sparse Linear Programming Subprogram. Sandia National Laboratories, Technical Report SAND81-0297, 1981.

HARRIS, N.; SUGGETT, A.; BARBER, D.; BROWN, B. Applications of applied potential tomography (apt) in respiratory medicine. Clin. Phys. Physiol. Meas, v. 8, p. 155-165, 1987. Suppl. A.

HARRIS, N.; SUGGETT, A.; BARBER, D.; BROWN, B. Applied potential tomography: A new technique for monitoring pulmonary function. Clin. Phys. Physiol. Meas., v. 9, p. 79-85, 1988. Suppl. A.

HASSANI, B.; HILTON, E. A review of homogenization and topology optimization, i- homogenization theory for media with periodic structure. Computer and Structures, v. 69, p. 707-717, 1998.

HAYT, J. W. H. Eletromagnetism. New York: McGraw-Hill, Inc., 1986.

HENDERSON, R. P.; WEBSTER, J. G. An impedance camera for spatially specific measurements of the thorax. IEEE Transactions on Biomedical Engineering, v. 25, n. 3, p. 250-254, 1978.

HERMAN, G. T. Image Reconstruction from Projections - The fundamentals of Computerized Tomography. San Francisco: Academic Press, 1980.

HINSHAW, W.; LENT, A. Nuclear magnetic resonance. Proceedings of the IEEE, v. 71, n. 3, p. 338-350, 1983.

HINZ, J.; HAHN, G.; NEUMANN, P.; SYDOW, M.; MOHRENWEISER, P.; HELLIGE, G.; BURCHARDI, H. End-expiratory lung impedance change enables bedside monitoring of end-expiratory lung volume change. Intensive Care Medicine, v. 29, p. 37-43, 2003. 
HOLDER, D. Clinical and Physiological Applications of Electrical Impedance Tomography. London: UCL Press, 1993.

HOLDER, D. Electrical impedance tomography in epilepsy. Electronic Engineering, v. 70, n. 859, p. 69-70, 1998.

HUA, P.; WOO, E. J.; WEBSTER, J. G.; TOMPKINS, W. J. Finite element modeling of electrode skin contact impedance in electrical impedance tomography. IEEE Transactions on Biomedical Engineering, v. 40, n. 4, p. 335-343, 1993.

HYARIC A.L., P. M. A one step image reconstruction algorithm for electrical impedance tomography in three dimensions. Physiological Measurement, v. 21, p. 95-98, 2000.

ISAACSON, D.; CHENEY, M.; NEWELL, J. C. Comments on reconstruction algorithms. Clin. Phys. Physiol. Meas., v. 13, p. 83-89, 1992. Suppl. A.

JAUNCEY, G. E. M. The birth and early infancy of x-rays. American Journal of Physics, v. 13, n. 6, p. 362-379, 1945.

JEON, H. J.; CHOI, B. Y.; KIM, M. C.; KIM, K. Y.; KIM, S. Phase boundary estimation in two-phase flows with electrical impedance imaging technique. International Communications in Heat and Mass Transfer, v. 31, n. 8, p. 1105-1114, 2004.

JONSMANN, J.; SIGMUND, O.; BOUWSTRA, S. Compliant thermal microactuators. Sensors and Actuators, v. 76, p. 463-469, 1999.

KANG, N. W.; CHUNG, Y. S.; CHEON, C.; JUNG, H. K. A new 2-d image reconstruction algorithm based on fdtd and design sensitivity analysis. IEEE Transactions on Microwave Theory and Techniques, v. 50, n. 12, p. 2734-2740, 2002.

KERNER, T. E.; WILLIAMS, D. B.; OSTERMAN, K. S.; REISS, F. R.; HARTOV, A.; PAULSEN, K. D. Electrical impedance imaging at multiple frequencies in phantoms. Physiological Measurement, v. 21, n. 1, p. 67-77, 2000.

KHARMANDA, G.; OLHOFF, N.; MOHAMED, A.; LEMAIRE, M. Reliability-based topology optimization. Structural and Multidisciplinary Optimization, v. 26, p. 295-307, 2004.

KIBER, M. A. Determination of Object Boundary Shape for Electrical Impedance Tomography. Tese (Doutorado) — University of Sheffield, 1991.

KIM, M. C.; KIM, S.; KIM, K. Y.; LEE, Y. J. Regularization methods in electrical impedance tomography technique for the two-phase flow visualization. International Communications in Heat and Mass Transfer, v. 28, n. 6, p. 773-782, 2001.

KIM, Y.; WEBSTER, J.; TOMPKINS, W. Electrical impedance imaging of the thorax. Journal of Microwave Power, v. 18, p. 245-257, 1983.

KOHN, R.; VOGELIUS, M. Determining conductivity by boundary measurements. Comm. Pure. App. Math., v. 37, p. 289-298, 1984. 
KOHN, R.; VOGELIUS, M. Determining conductivity by boundary measurements ii. interior results. Comm. Pure. Appl. Math., v. 38, p. 643-667, 1985 .

KOHN, R. V.; STRANG, G. Optimal design and relaxation of variational problems. Communications On Pure And Applied Mathematics, v. 39, n. 1, p. 113-137 (Part I), 139-182 (Part II), 353-377 (Part III), 1986.

KOTRE, C. J. Eit image-reconstruction using sensitivity weighted filtered backprojection. Physiological Measurement, v. 15, p. 125-136, 1994. Suppl. A.

LAWRENCE, C. W. Electronics for real-time and three-dimensional electrical impedance tomography. Tese (Doutorado) — University of Denver, Denver, 1996.

LAZAROVITCH, R.; RITTEL, D.; BUCHER, I. Experimental crack identification using electrical impedance tomography. NDT $\&$ E International, v. 35, n. 5, p. 301-316, 2002.

LEATHARD, A.; BROWN, B.; CAMPBELL, J.; ZHANG, F. A comparison of ventilatory and cardiac related changes in eit images of normal human lungs and of lungs with pulmonary emboli. Physiolical Measurements, v. 15, p. 137-146, 1994. Suppl. 2A.

LEWITT, R. M. Reconstruction algorithms: Transform methods. Proceedings of the IEEE, v. 71, n. 3, p. 390-408, 1983.

LIMA, C. R. Projeto de mecanismos flexíveis usando o método de otimização topológica. Dissertação (Mestrado) - Escola Politécnica da USP, São Paulo, Brasil, 2002.

MANGNALL, Y.; BAXTER, A. J.; AVILL, R.; BIRD, N. C.; BROWN, B. H.; BARBER, D. C.; SEAGAR, A. D.; JOHNSON, A. G.; READ, N. Applied potential tomography: a new non-invasive technique for measuring gastric function. Clin. Phys. Physiol. Meas., v. 8, p. 119-129, 1987. Suppl. A.

MANSFIELD, P.; MORRIS, P. G. NMR imaging in biomedicine. New York: Academic Press, 1982. Suppl. 2.

MATSUI, K.; TERADA, K. Continuous approximation of material distribution for topology optimization. International Journal for Numerical Methods In Engineering, v. 59, n. 14, p. 1925-1944, 2004.

MCARDLE, F. J. Investigation of cardiosynchronous images of the heart and head using applied potential tomography. Tese (Doutorado) - University of Sheffield, 1992.

METHERALL, P. Three dimensional electrical impedance tomography of the human thorax. Tese (Doutorado) - University of Sheffield, 1998.

MIRANDA, D. Tomografia por impedância elétrica utilizando o método de Newton-Raphson. Dissertação (Mestrado) — Escola Politécnica da USP, Brasil, 2003.

MLEJNEK, H. P. Some aspects of the genesis of structures. Structural Optimization, v. 5, p. 64-69, 1992. 
MOLINA, N. A. V. Redução de erro numérico no filtro estendido de Kalman aplicado à tomografia por impedância elétrica. Dissertação (Mestrado) - Escola Politécnica da USP, São Paulo, Brasil, 2002.

MORUCCI, J. P.; MARSILI, P. M.; GRANIE, M.; SHI, Y.; LEI, M.; DAI, W. W. A direct sensitivity matrix approach for fast reconstruction in electrical impedance tomography. Physiological Measurements, v. 15, n. 6, p. 107-114, 1994. Suppl. 2A.

MURAY, T.; KAGAWA, Y. Electrical impedance computed tomography based on a finite elements model. IEEE Transaction on Biomedical Engineering, v. 32, n. 3 , p. $177-184,1985$.

MURPHY, D.; BURTON, P.; COOMBS, R.; TARASSENKO, L.; ROLFE, P. Impedance imaging in the newborn. Clin. Phys. Physiol. Meas., v. 8, p. 131-140, 1987. Suppl. A.

MURUGAN, R. M. An improved electrical impedance tomography (EIT) algorithm for the detection and diagnosis of early stages of breast cancer. Tese (Doutorado) - Dept. of Electrical and Computer Engineering, University of Manitoba, Winnipeg, Manitoba, 1999.

NEVES, M.; RODRIGUES, H.; GUEDES, J. M. Generalized topology design of structures with a buckling load criterion. Structural Optimization, v. 10, p. 71-18, 1995.

NEWELL, J. C.; EDIC, P. M.; REN, X.; WISEMAN, J. L. L.; DANYLEYKO, M. D. Assessment of acute pulmonary edema in dogs by electrical impedance imaging. IEEE Transactions on Biomedical Engineering, v. 43, n. 2, p. 133-138, 1996.

NEWELL, J. C.; GISSER, D. G.; ISAACSON, D. An electric current tomograph. IEEE Transactions on Medical Engineering, v. 10, p. 828-32, 1988. BME-35.

NISHIWAKI, S.; FRECKER, M. I.; MIN, S.; KIKUCHI, N. Topology optimization of compliant mechanisms using the homogenization method. International Journal of Numerical Methods in Engineering, v. 42, p. 535-559, 1998.

NOBLE, T. J.; MORICE, A. H.; CHANNER, K. S.; MILNES, P.; HARRIS, N. D.; BROWN, B. H. Monitoring patients with left ventricular failure by electrical impedance tomography. European Journal of Heart Failure, v. 1, n. 4, p. 379-384, 1999.

NOPP, P.; RAPP, E.; PFUTZNER, H.; NAKESCH, H.; RUSHAM, C. Dielectric properties of lung tissue as a function of air content. Physics in Medicine and Biology, v. 38, n. 6, p. 699-716, 1993.

OLMI, R.; BINI, M.; PRIORI, S. A genetic algorithm approach to image reconstruction in electrical impedance tomography. IEEE Transactions on Evolutionary Computation, v. 4, n. 1, p. 83-88, 2000.

OOSTEROM, A. V. History and evolution of methods for solving the inverse problem. Journal Clin. Neurophys, v. 8, p. 371-380, 1991. 
PARK, Y. K. Extensions of optimal layout design using the homogenization method. Tese (Doutorado) — University of Michigan, Ann Arbor, 1995.

PARKER, R. L. The inverse problem of resistivity sounding. Geophysics, v. 142, p. 2143-2158, 1984.

PAULSON, K.; BRECKON, W.; PIDCOCK, M. A hybrid phantom for electrical impedance tomography. Clinical Physics And Physiological Measurement, v. 13, p. $155-159,1992$.

PRESS, W. H.; TEUKOLSKY, S. A.; VETTERLING, W. T.; FLANNERY, B. P. Numerical Recipes in C-The Art of Scientific Computing. [S.l.]: Cambridge University Press, 1999.

PRICE, L. R. Electrical impedance computed tomography: A new ct imaging technique. IEEE Transactions Nuclear Sci., vol. NS-26, n. 2, p. 2736-2739, 1979.

RAMIREZ, A.; DAILY, W.; LABREQUE, D.; OWEN, E.; D., C. Monitoring an underground steam injection process using electrical resistance tomography. Water Resources Res, v. 29, p. 73-87., 1993.

RIETZ, A. Sufficiency of a finite exponent in simp (power law) methods. Structural and Multidisciplinary Optimization, v. 21, n. 2, p. 159-163, 2001.

RIGAUD, B.; MORUCCI, J. P. Bioelectrical impedance techniques in medicine .3. impedance imaging - first section: General concepts and hardware. Critical Reviews in Biomedical Engineering, v. 24, n. 4-6, p. 467-597, 1996.

RIGAUD, B.; SHI, Y.; CHAUVEAU, N.; MORUCCI, J. P. Experimental acquisition system for impedance tomography with active electrodes approach. Med. Biol. Eng. Comput., v. 31, p. 593-599, 1993.

RODRIGUES, H.; FERNANDES, P. Material based model for topology optimization of thermoelastic structures. International Journal for Numerical Methods in Engineering, v. 38, n. 12, p. 1951-1965, 1995.

ROZVANY, G. I. N.; BENDSØE, M. P.; KIRSCH, U. Layout optimization of structures. Applied Mechanics Reviews, v. 48, n. 2, p. 41-119, 1995.

SANTOSA, F.; KAUP, P.; VOGELIUS, M. A method for imaging corrosion damage in thin plates from electrostatic data. Inverse Problems, v. 12, p. 279-93, 1996.

SANTOSA, F.; VOGELIUS, M. A backprojection algorithm for electrical impedance. Imaging. SIAM J. Appl. Math., v. 50, p. 216-243, 1990.

SANTOSA, F.; VOGELIUS, M. A computational algorithm for determining cracks from electrostatic boundary measurements. International J. Eng. Sci., v. 29, p. 917-938, 1991.

SCHMITT, U.; LOUIS, A. K.; WOLTERS, C.; VAUHKONEN, M. Efficient algorithms for the regularization of dynamic inverse problems: Ii. applications. Inverse Problems, v. 18, n. 3, p. 659-676, 2002. 
SEAGAR, A.; BABER, D.; BROWN, B. Theoretical limits to sensitivity and resolution in impedance imaging. Clin. Phys. Physiol. Meas., v. 8, p. 13-31, 1987. Suppl. A.

SIGMUND, O. On the design of compliant mechanisms using topology optimization. Mechanics of Structures and Machines, v. 25, n. 4, p. 493-524, 1997.

SIGMUND, O.; PETERSSON, J. Numerical instabilities in topology optimization: A survey on procedures dealing with checkerboards, mesh-dependencies and local minima. Structural Optimization, v. 16, n. 1, p. 68-75, 1998.

SILVA, E. C. N.; FONSECA, J. S. O.; KIKUCHI, N. Optimal design of piezoelectric microstructures. Computational Mechanics, v. 19, n. 5, p. 397-410, 1997.

SILVA, E. C. N.; NISHIWAKI, S.; KIKUCHI, N. Topology optimization design of flextensional actuators. IEEE Transactions on Ultrasonics Ferroelectrics and Frequency Control, v. 47, n. 3, p. 657-671, 2000.

SMULDERS, L. A. W.; OOSTEROM, A. V. Application of electrical impedance tomography to the determination of lung volume. Clinical Physics and Physiological Measurement, v. 13, p. 167-170, 1992.

SOMERSALO, E.; CHENEY, M. Existence and uniqueness for electrode models for electric current computed tomography. SIAM Journal Appl. Math., v. 52, p. 1023-1040, 1992.

SORENSON, H. Introduction in kalman filtering: theory and application. New York: IEEE Press, 1985.

SUZUKI, K.; KIKUCHI, N. A homogenization method for shape and topology optimization. Computer Methods in Applied Mechanics and Engineering, v. 93, n. 3, p. 291-318, 1991.

SVANBERG, K. The method of moving asymptotes - a new method for structural optimization. International Journal for Numerical Methods in Engineering, v. 24, p. 359-373, 1987.

SVANBERG, K.; WERME, M. A hierarchical neighbourhood search method for topology optimization. Structural and Multidisciplinary Optimization, v. 29, n. 5, p. 325-340, 2005.

SWAN, C. C.; ARORA, J. S. Topology design of material layout in structured composites of high stiffness and strength. Structural Optimization, v. 13, n. 1, p. 45-59, 1997.

SWAN, C. C.; KOSAKA, I. Voigt-reuss topology optimization for structures with linear elastic material behaviours. International Journal for Numerical Methods in Engineering, v. 40, n. 16, p. 3033-3057, 1997.

SYLVESTER, J.; UHLMANN, G. A. A uniqueness theory for an inverse boundary value problem in electrical prospection. Comm. Pure. Appl. Math., v. 39, p. 91-112, 1986. 
SYLVESTER, J.; UHLMANN, G. A. Global uniqueness theorem for an inverse boundary value problem. Annals of Mathematics, v. 125, p. 153-169, 1987.

TANG, M. X.; WANG, W.; WHEELER, J.; MCCORMICK, M.; DONG, X. Z. The number of electrodes and basis functions in eit image reconstruction. Physiological Measurement, v. 23, n. 1, p. 129-140, 2002.

THOMAS, H.; VANDERPLAATS, G.; SHYY, Y. A study of move limit adjustment strategies in the approximation concepts approach to structural synthesis. AIAA-VMA Engineering, p. 507-512, 1992.

THOMSEN, J. Topology optimization of structures composed of one or 2 materials. Structural Optimization, v. 5, n. 1-2, p. 108-115, 1992.

TIKHONOV, A. N. Ill-posed problems in natural sciences. Proceedings of the International Conference Held in Moscow, p. 19-25, August 1991.

TIKHONOV, A. N.; ARSENIN, V. Y. Solutions of ill- posed problems. Washington D.C., Winston V.H. and Sons N.W., 1977.

TRIGO, F. C. Estimação não linear de parâmetros através dos filtros de Kalman na tomografia por impedância elétrica. Tese (Doutorado) - Escola Politécnica da USP, 2005.

TRIGO, F. C.; GONZALEZ-LIMA, R.; AMATO, M. B. P. Electrical impedance tomography using the extended kalman filter. IEEE Transactions on Biomedical Engineering, v. 51, n. 1, p. 72-81, 2004.

VANDERPLAATZ, G. Numerical Optimization Techniques for Engineering Design: with Applications. [S.l.]: McGraw-Hill, 1984.

VAUHKONEN, M.; KARJALAINEN, P. A.; KAIPIO, J. P. A kalman filter approach to track fast impedance changes in electrical impedance tomography. IEEE Transactions on Biomedical Engineering, v. 45, n. 4, p. 486-493, 1998.

WATERFALL, R. C.; HE, R. H.; BECK, C. M. Visualizing combustion using electrical impedance tomography. Chemical Engineering Science, v. 52, n. 13, p. 2129-2138, 1997.

WEST, R. M.; TAPP, H. S.; SPINK, D. M.; BENNETT, M. A.; WILLIAMS, R. A. Application specific optimization of regularization for electrical impedance tomography. Measurement Science and Technology, v. 12, n. 8, p. 1050-1054, 2001.

WILLIAMS, R. A.; JIA, X.; WEST, R. M.; WANG, M.; CULLIVAN, J. C.; BOND, J.; FAULKS, I.; DYAKOWSKI, T.; ; WANG, S. J.; CLIMPSON, N.; KOSTUCH, J. A.; PAYTON, D. Industrial monitoring of hydrocyclone operation using electrical resistance tomography. Minerals Engineering, v. 12, n. 10, p. 1245-1252, 1999.

WITSOE, D. A.; KINNEN, E. Electrical resistivity of lung at 100khz. Med. Biol. Eng., v. 5, p. 239-248, 1967.

WOO, E. J.; HUA, P.; WEBSTER, J. G.; TOMPKINS, W. J. Measuring lung resistivity using electrical impedance tomography. IEEE Transactions on Biomedical Engineering, v. 39, n. 7, p. 756-760, 1992. 
WOO, E. J.; HUA, P.; WEBSTER, J. G.; TOMPKINS, W. A robust image reconstruction algorithm nd its paralell implementation in electrical impedance tomography. IEEE Transactions on Biomedical Engineering, v. 12, n. 2, p. 137-146, 1993.

XIE, C. G.; HUANG, S. M.; HOYLE, B. S.; THORN, R.; LENN, C.; SNOWDEN, D.; BECK, M. S. Electrical capacitance tomography for flow imaging: system model for development of image reconstruction algorithms \& design of primary sensors. IEE Proceedings G, v. 139, n. 1, p. 89-98, 1992.

YOO, J.; KIKUCHI, N. Topology optimization in magnetic fields using homogenization design method. International Journal for Numerical Methods in Engineering, v. 48, p. 1463-1479, 2000.

YORK, T. Status of electrical tomography in industrial applications. Journal of Electronic Imaging, v. 10, n. 3, p. 608-619, 2001.

YORKEY, T. J.; WEBSTER, J. G.; TOMPKINS, W. J. Comparing reconstruction algorithms for electrical-impedance tomography. IEEE Transactions on Biomedical Engineering, v. 34, n. 11, p. 843-852, 1987.

ZHOU, M.; ROZVANY, G. I. N. The coc algorithm, part ii: Topological, geometrical, and generalized shape optimization. Computer Methods in Applied Mechanics and Engineering, v. 89, p. 309-336, 1991.

ZOU, Y.; GUO, Z. A review of electrical impedance techniques for breast cancer detection. Medical Engineering and Physics, v. 25, n. 2, p. 79-90, 2003. 


\section{Apêndice A - Princípio dos Potenciais Virtuais}

A seguir é feita a dedução da equação do Princípio dos Potenciais Virtuais, apresentada no capítulo 4 e aplicada para definir a matriz de condutividade elétrica dos elementos finitos utilizados neste trabalho.

Expandindo-se a equação de Poisson, mostrada na equação (4.7) do capítulo 4, obtemos a seguinte equação:

$$
\frac{\partial}{\partial x}\left(\sigma_{x} \frac{\partial \phi}{\partial x}\right)+\frac{\partial}{\partial y}\left(\sigma_{y} \frac{\partial \phi}{\partial y}\right)=0
$$

Multiplicando a equação (A.1) pela distribuição virtual $\bar{\phi}$ (arbitrária e nula no local da fronteira do domínio onde se aplica a condição de contorno de potenciais elétricos) e integrando o resultado no volume do domínio $(V)$, obtém-se:

$$
\int_{V}\left[\frac{\partial}{\partial x}\left(\sigma_{x} \frac{\partial \phi}{\partial x}\right)+\frac{\partial}{\partial y}\left(\sigma_{y} \frac{\partial \phi}{\partial y}\right)\right] \bar{\phi} d V=0
$$

Aplicando a integração por partes, a equação (A.2) torna-se:

$$
\begin{array}{r}
\int_{V}\left\{\frac{\partial}{\partial x}\left[\bar{\phi}\left(\sigma_{x} \frac{\partial \phi}{\partial x}\right)\right]+\frac{\partial}{\partial y}\left[\bar{\phi}\left(\sigma_{y} \frac{\partial \phi}{\partial y}\right)\right]-\right. \\
\left.\left[\frac{\partial \bar{\phi}}{\partial x}\left(\sigma_{x} \frac{\partial \phi}{\partial x}\right)+\frac{\partial \bar{\phi}}{\partial y}\left(\sigma_{y} \frac{\partial \phi}{\partial y}\right)\right]\right\} d V=0
\end{array}
$$

Com o auxílio do teorema do divergente (ou teorema de Gauss), podemos modificar a primeira parcela da equação (A.3) da seguinte forma:

$$
\begin{array}{r}
\int_{V}\left\{\frac{\partial}{\partial x}\left[\bar{\phi}\left(\sigma_{x} \frac{\partial \phi}{\partial x}\right)\right]+\frac{\partial}{\partial y}\left[\bar{\phi}\left(\sigma_{y} \frac{\partial \phi}{\partial y}\right)\right]\right\} d V= \\
\int_{\partial \Omega}\left\{\left[\bar{\phi}\left(\sigma_{x} \frac{\partial \phi}{\partial x}\right)\right] n_{x}+\left[\bar{\phi}\left(\sigma_{y} \frac{\partial \phi}{\partial y}\right)\right] n_{y}\right\} d S
\end{array}
$$

onde $n_{x}$ e $n_{y}$ são as componentes do vetor unitário $\mathbf{n}$, normal ao domínio $(\Omega)$ e apontado para fora. Além disso, temos:

$$
\int_{\partial \Omega}\left\{\left[\bar{\phi}\left(\sigma_{x} \frac{\partial \phi}{\partial x}\right)\right] n_{x}+\left[\bar{\phi}\left(\sigma_{y} \frac{\partial \phi}{\partial y}\right)\right] n_{y}\right\} d S=\int_{\partial \Omega}\left[\bar{\phi}\left(\sigma_{n} \frac{\partial \phi}{\partial n}\right)\right] d S
$$


Agora, impondo-se as condições de contorno da equação (4.8) do capítulo 4, temos:

$$
\int_{\partial \Omega}\left[\bar{\phi}\left(\sigma_{n} \frac{\partial \phi}{\partial n}\right)\right] d S=\int_{\Gamma_{q}} \bar{\phi}_{q} I_{q} d \Gamma
$$

onde $\Gamma_{q}$ é o local da fronteira do domínio onde se aplica a condição de contorno de fluxo de corrente, $\bar{\phi}_{q}$ é a distribuição de potenciais elétricos virtuais em $\Gamma_{q}$. Desta maneira, a equação (A.3) torna-se:

$$
\int_{V}\left[\frac{\partial \bar{\phi}}{\partial x}\left(\sigma_{x} \frac{\partial \phi}{\partial x}\right)+\frac{\partial \bar{\phi}}{\partial y}\left(\sigma_{y} \frac{\partial \phi}{\partial y}\right)\right] d V=\int_{\Gamma_{q}} \bar{\phi}_{q} I_{q} d \Gamma
$$

A equação (A.7) é conhecida como Princípio dos Potenciais Virtuais, que também pode ser escrita na forma apresentada na equação (4.16) do capítulo 4. 